\title{
Partial Oxidation of Hydrocarbons in a Segmented Bed Using Oxide-based Catalysts and Oxygen-conducting Supports
}

\author{
Mark W. Smith
}

Follow this and additional works at: https://researchrepository.wvu.edu/etd

\section{Recommended Citation}

Smith, Mark W., "Partial Oxidation of Hydrocarbons in a Segmented Bed Using Oxide-based Catalysts and Oxygen-conducting Supports" (2015). Graduate Theses, Dissertations, and Problem Reports. 6669. https://researchrepository.wvu.edu/etd/6669

This Dissertation is protected by copyright and/or related rights. It has been brought to you by the The Research Repository @ WVU with permission from the rights-holder(s). You are free to use this Dissertation in any way that is permitted by the copyright and related rights legislation that applies to your use. For other uses you must obtain permission from the rights-holder(s) directly, unless additional rights are indicated by a Creative Commons license in the record and/ or on the work itself. This Dissertation has been accepted for inclusion in WVU Graduate Theses, Dissertations, and Problem Reports collection by an authorized administrator of The Research Repository @ WVU.

For more information, please contact researchrepository@mail.wvu.edu. 
Partial Oxidation of Hydrocarbons in a Segmented Bed Using Oxide-based Catalysts and Oxygen-conducting Supports

by

Mark W. Smith

Dissertation submitted to the College of Engineering and Mineral Resources at West Virginia University in partial fulfillment of the requirements for the degree of

Doctor of Philosophy

in

Chemical Engineering

Approved by

John W. Zondlo, Ph.D., Chair

Charter Stinespring, Ph.D.

Edwin Kugler, Ph.D.

Edward Sabolsky, Ph.D.

David A. Berry, M.S.ChE.

Department of Chemical Engineering

Morgantown, West Virginia

2015

Keywords: Partial oxidation; Oxide catalyst; Oxygen-conducting support

Copyright 2015 Mark W. Smith 


\title{
ABSTRACT \\ Partial Oxidation of Hydrocarbons in a Segmented Bed Using Oxide-based Catalysts and Oxygen-conducting Supports
}

\author{
by Mark W. Smith
}

Two objectives for the catalytic reforming of hydrocarbons to produce synthesis gas are investigated herein: (1) the effect of oxygen-conducting supports with partially substituted mixed-metal oxide catalysts, and (2) a segmented bed approach using different catalyst configurations. Excess carbon deposition was the primary cause of catalyst deactivation, and was the focus of the experiments for both objectives. The formation and characterization of deposited carbon was examined after reaction for one of the selected catalysts to determine the quantity and location of the carbon on the catalyst surface leading to deactivation.

A nickel-substituted barium hexaaluminate (BNHA), with the formula $\mathrm{BaAl}_{11.6} \mathrm{Ni}_{0.4} \mathrm{O}_{18.8}$, and a Rh-substituted lanthanum zirconate pyrochlore (LCZR) with the formula $\mathrm{La}_{1.89} \mathrm{Ca}_{0.11} \mathrm{Zr}_{1.89} \mathrm{Rh}_{0.11}$, were combined with two different doped ceria supports. These supports were gadolinium-doped ceria (GDC) and zirconium-doped ceria (ZDC). The active catalyst phases were combined with the supports in different ratios using different synthesis techniques. The catalysts were characterized using several different techniques and were tested under partial oxidation (POX) of $n$-tetradecane (TD), a diesel fuel surrogate. It was found that the presence of GDC and ZDC reduced the formation of carbon for both catalysts; the optimal ratio of catalyst to support was different for the hexaaluminate and the pyrochlore; a loading of $20 \mathrm{wt} \%$ of the pyrochlore with ZDC produced the most stable performance in the presence of common fuel contaminants $(>50$ h); and, the incipient wetness impregnation synthesis method of applying the active catalyst to the support produced more stable product yields than the catalyst prepared by a solid-state mixing technique.

Different hexaaluminate and pyrochlore catalysts were used in different configurations in a segmented bed approach. The first strategy was to promote the indirect reforming mechanism by placing a combustion catalyst in the reactor inlet, followed by a reforming catalyst. This approach demonstrated that BNHA can be used in the reactor inlet to promote combustion with 1 wt\% Rh-substituted pyrochlore in the reactor outlet, but the combustion catalyst should fill less than $50 \%$ of the reactor. The second approach placed specific catalysts in regions of the reactor that have conditions in which they are less likely to deactivate. This showed the most benefit in the use of a sulfur-tolerant noble metal catalyst in the reactor outlet.

The carbon formation study was conducted on a 2 wt\% Rh-substituted pyrochlore. POX of TD for various run times, followed by temperature programmed oxidation, revealed two different types of carbon deposits in the catalyst bed: carbon that burned off at relatively low temperature (LTC), and carbon that burned off at higher temperatures (HTC). The LTC reached a steady state level within two hours of reaction, and was determined not to lead to catalyst deactivation. The HTC continued to accumulate with time on stream. A mathematical expression was developed to predict the rate of formation of the HTC for a given set of reaction conditions $(\mathrm{O} / \mathrm{C}=1.25)$. This expression was modified from data from a test under different reaction conditions $(\mathrm{O} / \mathrm{C}=1.1)$ for one length of time, and was found to predict the carbon formation for a different run time within $3 \%$. 


\section{ACKNOWLEDGEMENTS}

I would first like to give thanks and dedicate this work to my Creator from whom all I am and all I have comes. Next, I dedicate this to my beautiful wife, Kristin, and thank her for her tremendous love and support. I also dedicate this to my three amazing children: Aidan, Ava, and Andrew. I love you all more than I can express. You are my reason.

Special thanks to my family (Mom, Dad, and Tim) for their support in all my efforts throughout my life. And other personal thanks to my family at St. Francis de Sales Catholic Church for their prayers and frequent words of encouragement.

Next, I thank Dr. John Zondlo, Dr. Charter Stinespring, Dr. Ed Kugler, Dr. Ed Sabolsky, and Mr. Dave Berry, my committee, for their time and guidance throughout my work on this dissertation. Also, thanks to all the professors I had the privilege of studying under in the Chemical Engineering Department at WVU, from which I also received my B.S. I would especially like to thank Dr. Zondlo, who has been my advisor in various capacities for almost 20 years. Without his support, professionally and personally, I would not be where I am.

Finally, I have many to thank from NETL. First, sincere thanks to Dave Berry, for encouraging me to pursue this degree in the first place, and for his support and direction throughout my research. Next, significant thanks to Dushyant Shekhawat for his patience and support these many years, and for the large lunch bill I had to pay at the Kenyan Café, which led to me finally bringing this thing to a close. Thanks also to the rest of the team I have had the immense pleasure and privilege of working with for several years now: Dan Haynes, Don Floyd, Jerry Spivey, Devendra Pakhare, and Victor Abdelsayed. You have all contributed in many different ways to this work, and it is truly far better than it would have been without your input, encouragement, and occasional harassment. Thanks to Mike Bergen, my supervisor at URS/AECOM; Essi Monazam, for my first job; Jim Poston, for the SEM images and assistance with the XRD; Clark Robinson, for his support and friendship; and John VanOsdol for his help with algebra. Finally, I acknowledge and thank the U.S. Department of Energy and Pyrochem Catalyst Corporation for their financial support to conduct my research. 


\section{Table of Contents}

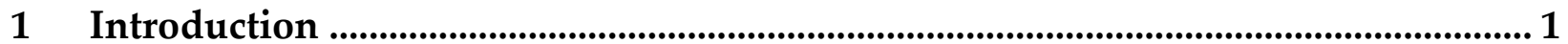

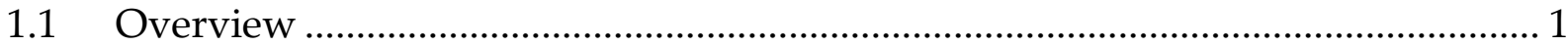

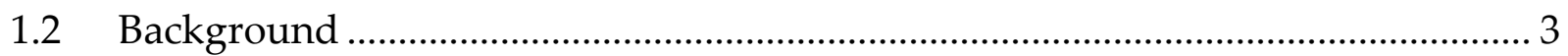

1.2.1 Thermodynamics ……........................................................................ 5

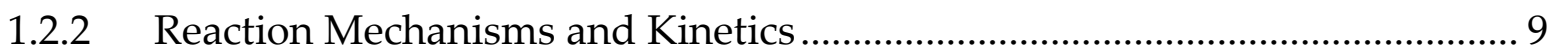

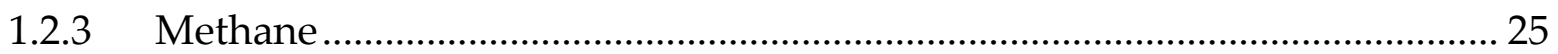

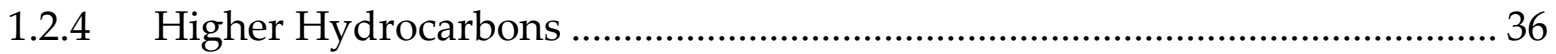

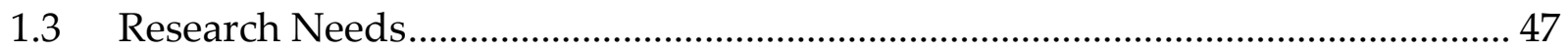

1.3.1 Substituted oxides on oxygen-conducting supports ................................... 47

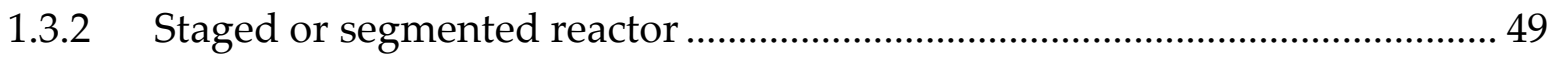

2 Substituted Oxides on Oxygen-conducting Supports ................................................. 51

$2.1 \quad$ Effect of Weight Loading and Support Type ......................................................... 51

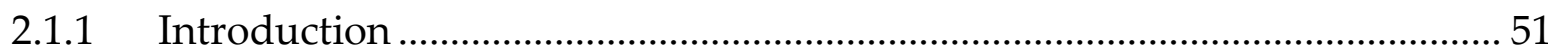

2.1.2 Experimental Methods ……………………….............................................. 51

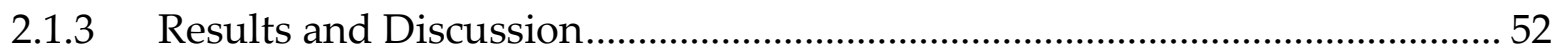

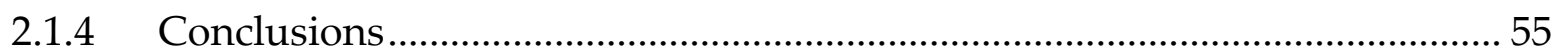

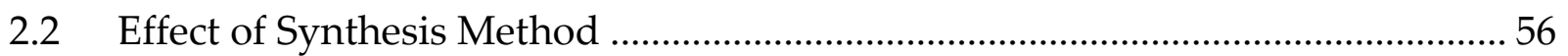

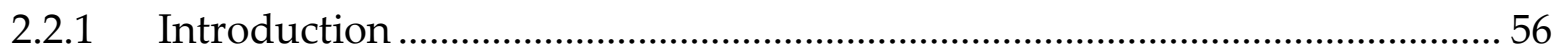

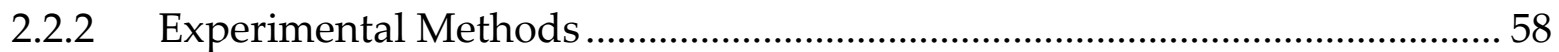

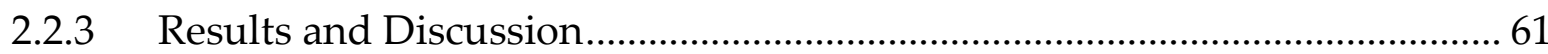

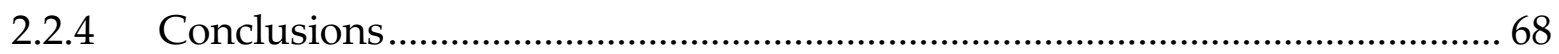

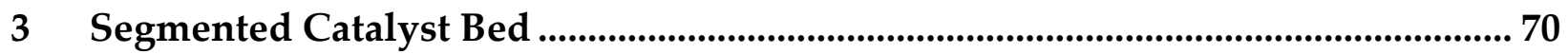

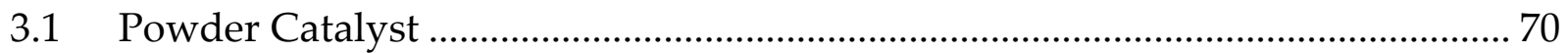

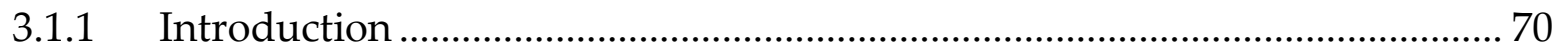

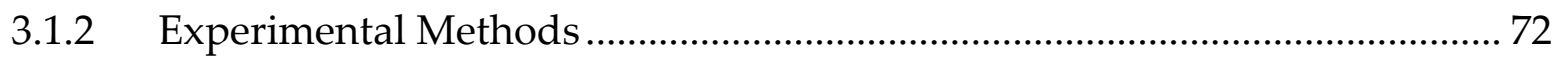

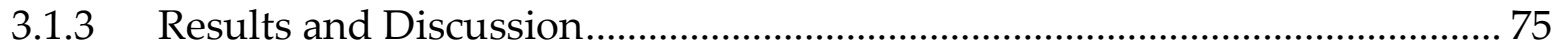

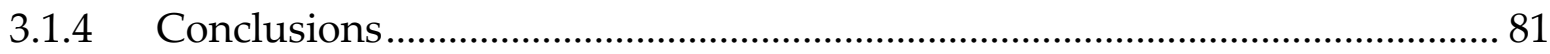

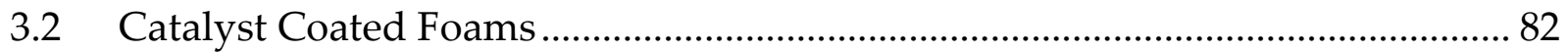

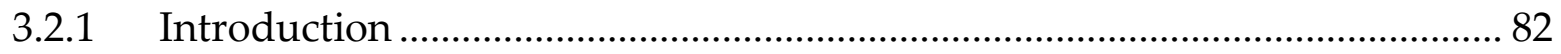

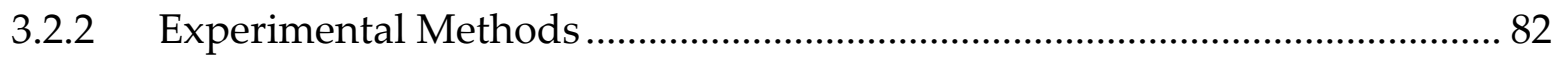

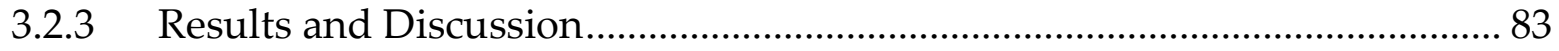

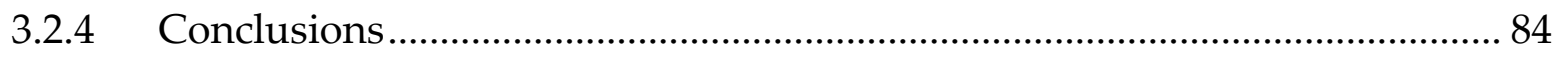

$4 \quad$ Carbon Formation Study ……..................................................................................... 87

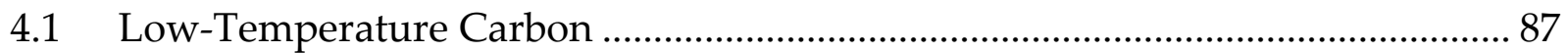

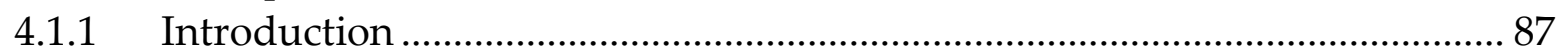

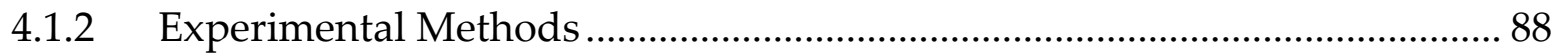

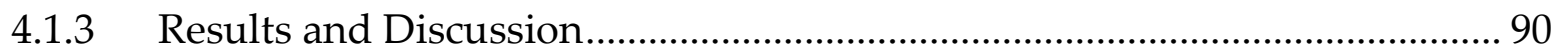




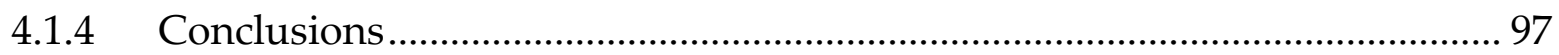

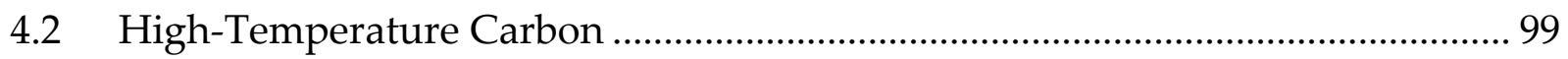

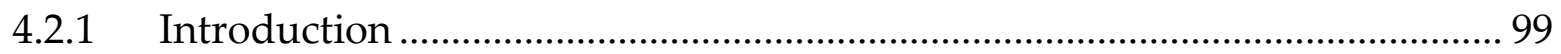

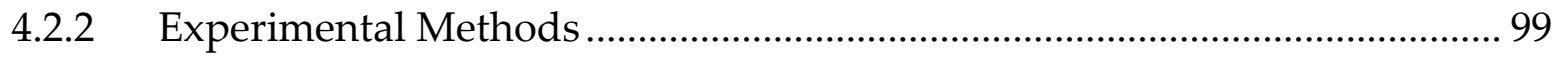

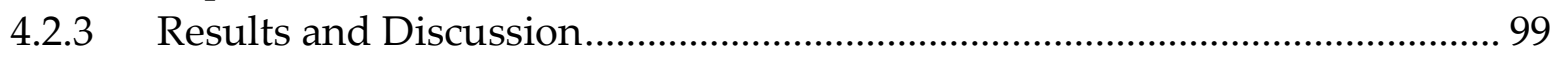

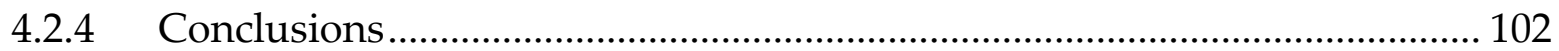

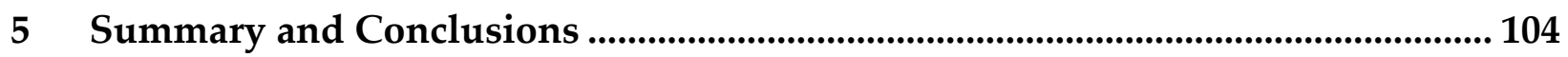

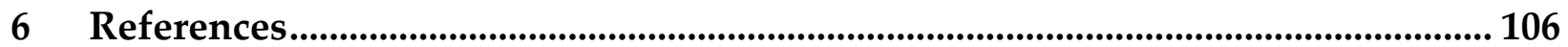




\section{List of Figures}

Figure 1-1. Development of hydrocarbon reforming catalyst. 2

Figure 1-2. Enthalpy of reaction for POX of methane, $i$-octane, and $n$-TD at different temperatures: $\mathrm{O} / \mathrm{C}=1.2,0.10 \mathrm{MPa}$ (Calculations using HSC Chemistry 5.0 [9])................. 6 Figure 1-3. Equilibrium product distribution for the POX of methane for different temperatures: $\mathrm{O} / \mathrm{C}=1.2, \mathrm{P}=0.10 \mathrm{MPa}$ (Calculations using HSC Chemistry 5.0 [9]) ............ 7 Figure 1-4. Equilibrium product distribution for the POX of TD for different temperatures: $\mathrm{O} / \mathrm{C}=1.2, \mathrm{P}=0.10 \mathrm{MPa}$ (Calculations using HSC Chemistry 5.0 [9])............ 7 Figure 1-5. Equilibrium product distribution for the POX of methane for different $\mathrm{O} / \mathrm{C}$ ratios: $\mathrm{T}=900^{\circ} \mathrm{C}, \mathrm{P}=0.10 \mathrm{MPa}$ (Calculations using HSC Chemistry 5.0 [9]) ........................ 8 Figure 1-6. Equilibrium product distribution for the POX of TD for different $\mathrm{O} / \mathrm{C}$ ratios: $\mathrm{T}=900^{\circ} \mathrm{C}, \mathrm{P}=0.10 \mathrm{MPa}$ (Calculations using HSC Chemistry 5.0 [9]). 8

Figure 1-7. Diagram comparing the direct and indirect mechanism for the CPOX of methane. 10

Figure 1-8. Diagram of CPOX reactor with indirect mechanism. 14 Figure 1-9. Species and temperature profiles for CPOX of methane at different $\mathrm{C} / \mathrm{O}$ ratios [33].....

Figure 1-10. Schematic representation of the temperature profile in a CPOX reactor $[3$, $15,40]$. 16

Figure 1-11. Position of temperature spike in reactor bed for CPOX of $\mathrm{CH} 4$ on $\mathrm{Ni} / \alpha$ $\mathrm{Al}_{2} \mathrm{O}_{3}[41]$

Figure 1-12. Effect of flow-rate on catalyst-bed temperature using $\mathrm{Ni} / \mathrm{MgO}(\mathrm{Ni} / \mathrm{Mg}=3)$ catalysts. Furnace temperature $=723 \mathrm{~K}, \mathrm{CH}_{4} / \mathrm{O}_{2}=2[3]$ 17 Figure 1-13. Plot of the effect of gas hourly space velocity (GHSV) on CO selectivity and $\mathrm{CH}_{4}$ conversion. Figure generated by Bharadwaj and Schmidt [2] with data from (a) Aschroft et al. [42], (b) Dissanayake et al. [15], (c) Hickman et al. [10]............................... 18 Figure 1-14. Effect of metal oxidation state on reaction mechanism [44, 45] ................... 19 Figure 1-15. Effect of support on Ni reforming catalysts [51] . ......................................... 27 Figure 1-16. $\mathrm{H}_{2}$-TPR spectra of catalyst samples [52]........................................................ 28 Figure 1-17. Proposed mechanism for the transport of gas phase oxygen with a supported catalyst 29

Figure 1-18. Ionic conductivity of several doped ceria support materials [53]................. 30 Figure 1-19. Methane conversion and $\mathrm{CO}$ selectivity at different temperatures for CPOX with $\mathrm{Ni}$ catalysts on alumina and oxygen-conducting supports [54]. 31 Figure 1-20. Methane conversion over time for CPOX with catalysts on alumina and

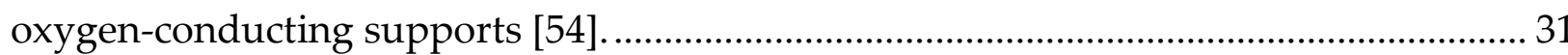

Figure 1-21. TPR profiles for Ni catalysts on several doped-ceria supports [55]............. 32 
Figure 1-22. Diagram comparing surface reactions on Pt and Rh catalysts $[4,10,11,13$, 56]. 33

Figure 1-23. Diagram comparing surface reactions on $\mathrm{Pt}$ and Rh catalysts [26]. 34 Figure 1-24. CO selectivity (a) and $\mathrm{H}_{2}$ selectivity (b) for CPOX with Ru catalysts on alumina and titania supports as a function methane conversion [43]..... 35 Figure 1-25. Step function response to the introduction of $50 \mathrm{ppmw}$ sulfur as DBT during the partial oxidation of $n$-tetradecane over $\mathrm{LaNi}_{0.4} \mathrm{Al}_{11.6} \mathrm{O}_{19-\delta}$. Test conditions were GHSV $=50,000 \mathrm{~cm}^{3} / \mathrm{g} / \mathrm{h}, \mathrm{O} / \mathrm{C}=1.2, \mathrm{~T}=850^{\circ} \mathrm{C}$ and $\mathrm{P}=197.8 \mathrm{kPa}[69]$. 38

Figure 1-26. Step function response to the introduction of $50 \mathrm{ppmw}$ sulfur as DBT during the partial oxidation of $n$-tetradecane over $\mathrm{SrNi}_{0.4} \mathrm{Al}_{11.6} \mathrm{O}_{19-\delta}$. Test conditions were $\mathrm{GHSV}=50,000 \mathrm{~cm}^{3} / \mathrm{g} / \mathrm{h}, \mathrm{O} / \mathrm{C}=1.2, \mathrm{~T}=850^{\circ} \mathrm{C}$ and $\mathrm{P}=197.8 \mathrm{kPa}[69]$. 38 Figure 1-27. Effect of oxygen-conducting supports and metal substitution into an oxide structure on CPOX of $n$-tetradecane: GHSV $=50,000 \mathrm{~cm}^{3} /$ gcat $/ \mathrm{h}, \mathrm{O} / \mathrm{C}=1.2, \mathrm{~T}=900^{\circ} \mathrm{C}, \mathrm{P}$ $=0.23 \mathrm{MPa}[70]$. 39 Figure 1-28. Dry gas yields for (b) BNHA, and (c) LSZN catalyst during $4 \mathrm{~h}$ CPOX of $n$ tetradecane with $5 \mathrm{wt} \% \mathrm{MN}$ and 50 ppmw DBT: GHSV $=50,000 \mathrm{~cm}^{3} / \mathrm{g}_{\mathrm{cat}} / \mathrm{h}, \mathrm{O} / \mathrm{C}=1.2, \mathrm{~T}$ $=900^{\circ} \mathrm{C} \mathrm{P}=0.23 \mathrm{MPa}[72]$ 41

Figure 1-29. Effect of oxygen-conducting support on Ni-substituted hexaaluminate catalysts for the CPOX of $n$-tetradecane in the presence of MN and DBT [73] ................ 42 Figure 1-30. Gibbs free energy for sulfides of common metals used in CPOX [9].......... 43 Figure 1-31. CPOX step response plot for $\mathrm{H}_{2}$ production (concentration, dry gas vol\%) from TD with 1000 ppmw sulfur [75]. 45 Figure 1-32. CPOX step response plot for $\mathrm{H}_{2}$ production (concentration, dry gas vol\%) from TD with $5 \mathrm{wt} \%$ 1-methylnaphthalene [75].

Figure 1-33. Yields for LSRuZ during $5 \mathrm{~h} \mathrm{CPOX} \mathrm{experiment:} \mathrm{GHSV}=50,000 \mathrm{~cm}^{3} / \mathrm{g}_{\text {cat }} / \mathrm{h}$, $\mathrm{O} / \mathrm{C}=1.2, \mathrm{~T}=900^{\circ} \mathrm{C}, \mathrm{P}=0.23 \mathrm{MPa}[83]$. 46

Figure 1-34. Yields for LSRhZ during $5 \mathrm{~h} \mathrm{CPOX} \mathrm{experiment:} \mathrm{GHSV}=50,000 \mathrm{~cm}^{3} / \mathrm{g}_{\text {cat }} / \mathrm{h}$, $\mathrm{O} / \mathrm{C}=1.2, \mathrm{~T}=900^{\circ} \mathrm{C}, \mathrm{P}=0.23 \mathrm{MPa}[71]$. 47

Figure 1-35. Development of POX catalyst for reforming hydrocarbons........................... 48

Figure 1-36. Segmented catalyst bed design. ........................................................................ 50 Figure 2-1: Diagram of substituted mixed-metal oxide catalyst over oxygen-conducting support. 51

Figure 2-2 Performance of BNHA catalysts over GDC at different surface coverages for the CPOX of TD: WHSV = 50,000 scc $\mathrm{gcat}^{-1} \mathrm{~h}^{-1}, \mathrm{O} / \mathrm{C}=1.2,900^{\circ} \mathrm{C}$, and $0.23 \mathrm{MPa}$. 53 Figure 2-3 Performance of BNHA catalysts over ZDC at different surface coverages for the CPOX of TD: WHSV = 50,000 scc $\mathrm{gcat}^{-1} \mathrm{~h}^{-1}, \mathrm{O} / \mathrm{C}=1.2,900^{\circ} \mathrm{C}$, and $0.23 \mathrm{MPa}$. 54 Figure 2-4 Performance of LCZR catalyst over ZDC at different surface coverages for the CPOX of TD: WHSV = 50,000 $\mathrm{scc} \mathrm{cat}^{-1} \mathrm{~h}^{-1}, \mathrm{O} / \mathrm{C}=1.2,900^{\circ} \mathrm{C}$, and $0.23 \mathrm{MPa}$................ 55 Figure 2-5 Crystal structure of hexaaluminate [62]; Ni particles are substituted into the Al sites. 
Figure 2-6 Diagram of catalyst deposition methods.

Figure 2-7: XRD spectra for GDC supported BNHA system.

Figure 2-8: SEM images and EDS spectra for catalysts prepared by different methods: (a,b) 10wt\%BNHA/GDC-IWI, (c,d) 10wt\%BNHA/GDC-SSM. The EDS peaks for Au are present since the samples were non-conducting and had to be coated for SEM images.63 Figure 2-9: Performance of $3 w t \% N i / \alpha$-alumina, $3 w t \% N i / G D C, \&$ bulk BNHA in the POX of $n$-tetradecane: WHSV $=50,000 \mathrm{scc} / \mathrm{g}_{\text {cat }} \bullet \mathrm{h}, \mathrm{T}=900^{\circ} \mathrm{C}, \mathrm{P}=0.23 \mathrm{MPa}, \mathrm{O} / \mathrm{C}=1.2$ : (a) Hydrogen yield, (b) Carbon monoxide yield, (c) Carbon dioxide yield, (d) Methane

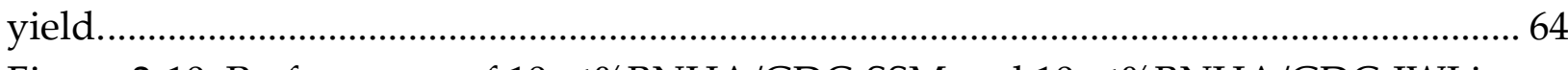
Figure 2-10: Performance of 10wt\%BNHA/GDC-SSM and 10wt\%BNHA/GDC-IWI in the POX of $n$-tetradecane: WHSV $=50,000 \mathrm{scc} / \mathrm{g}_{\mathrm{cat}} \bullet \mathrm{h}, \mathrm{T}=900^{\circ} \mathrm{C}, \mathrm{P}=0.23 \mathrm{MPa}, \mathrm{O} / \mathrm{C}=1.2$ : (a) Hydrogen yield, (b) Carbon monoxide yield, (c) Carbon dioxide yield, (d) Methane yield.

Figure 2-11: Olefin concentrations in product stream determined by GC for $10 \mathrm{wt} \% \mathrm{BNHA} / \mathrm{GDC}-\mathrm{SSM}$ and 10wt $\%$ BNHA/GDC-IWI in the partial oxidation of $n$ tetradecane: $\mathrm{WHSV}=50,000 \mathrm{scc} / \mathrm{g}_{\text {cat }} \bullet \mathrm{h}, \mathrm{T}=900^{\circ} \mathrm{C}, \mathrm{P}=0.23 \mathrm{MPa}, \mathrm{O} / \mathrm{C}=1.2 \ldots \ldots \ldots \ldots \ldots \ldots . .67$

Figure 2-12: TPO plots for reactor beds after partial oxidation tests. 68

Figure 2-13: Performance of 10wt\%BNHA/GDC-SSM and 10wt\%BNHA/GDC-IWI in the extended POX test with $n$-tetradecane plus DBT and MN: WHSV $=50,000 \mathrm{scc} / \mathrm{g}_{\text {cat }} \bullet$ $\mathrm{h}, \mathrm{T}=900^{\circ} \mathrm{C}, \mathrm{P}=0.23 \mathrm{MPa}, \mathrm{O} / \mathrm{C}=1.2$ : (a) Hydrogen yield, (b) Carbon monoxide yield.. 69 Figure 3-1 Reactor diagram for CPOX of a hydrocarbon via the indirect mechanism.... 71 Figure 3-2 XRD spectra of the Rh1-PC, Ru1-PC, and Ni3-PC catalysts; (•) pyrochlore, $\left(^{*}\right)$ perovskite. 75

Figure 3-3 Performances of two single-composition bed runs for catalysts used in series 1 under CPOX: WHSV $=25,000 \mathrm{scc} \mathrm{g}_{\mathrm{cat}^{-1}} \mathrm{~h}^{-1}, \mathrm{O} / \mathrm{C}=1.2,900^{\circ} \mathrm{C}$, and $0.23 \mathrm{MPa}$. 77 Figure 3-4 Comparison of the performances of different segmented bed configurations using BNHA and Rh1-PC catalysts under CPOX: WHSV $=25,000 \mathrm{scc} \mathrm{g}_{\text {cat }}{ }^{-1} h^{-1}, \mathrm{O} / \mathrm{C}=1.2$, $900^{\circ} \mathrm{C}$, and $0.23 \mathrm{MPa}$.

Figure 3-5 Performances of two single-composition bed runs for catalysts used in series 2 under CPOX: WHSV $=25,000 \mathrm{scc}_{\mathrm{cat}}{ }^{-1} \mathrm{~h}^{-1}, \mathrm{O} / \mathrm{C}=1.1,900^{\circ} \mathrm{C}$, and $0.23 \mathrm{MPa}$. 79 Figure 3-6 Comparison of the performances of different segmented bed configurations

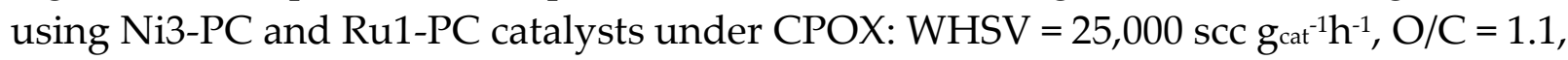
$900^{\circ} \mathrm{C}$, and $0.23 \mathrm{MPa}$.

Figure 3-7 Alumina foam materials coated with reforming catalysts. 82 Figure 3-8 Performance of Ni3-PC coated foams in the top and bottom of the reactor under CPOX: WHSV $=75,000 \mathrm{scc}_{\mathrm{cat}}-1 \mathrm{~h}^{-1}, \mathrm{O} / \mathrm{C}=1.1,900^{\circ} \mathrm{C}$, and $0.23 \mathrm{MPa}$. 83 Figure 3-9 Performance of Rh1-PC coated foams in the top and bottom of the reactor

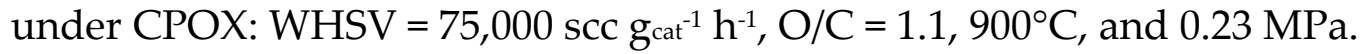


Figure 3-10 Performance of Rh1-PC coated foam in the top and Ni3-PC coated foam in the bottom of the reactor under CPOX: WHSV $=75,000 \mathrm{scc} \mathrm{gat}^{-1} \mathrm{~h}^{-1}, \mathrm{O} / \mathrm{C}=1.1,900^{\circ} \mathrm{C}$, and $0.23 \mathrm{MPa}$.

Figure 3-11 Performance of Ni3-PC coated foam in the top and Rh1-PC coated foam in the bottom of the reactor under CPOX: WHSV: $75,000 \mathrm{scc} \mathrm{gat}^{-1} \mathrm{~h}^{-1}, \mathrm{O} / \mathrm{C}=1.1,900^{\circ} \mathrm{C}$, and $0.23 \mathrm{MPa}$. 86

Figure 4-1 TPR of substituted pyrochlore catalysts: LCZY, LCZR1Y, LCZR2Y, and LCZR3Y. 91

Figure 4-2 XRD of pyrochlore reforming catalysts having different Rh loadings: LCZY, LCZR1Y, LCZR2Y, LCZR3Y; (•) pyrochlore, $\left({ }^{*}\right)$ perovskite. 92

Figure 4-3 XRD spectra of LCZR2Y pyrochlore catalyst after reduction at different temperatures. 93

Figure 4-4 POX of TD over LCZR2Y pyrochlore for $18 \mathrm{~h}$ : WHSV $=50,000 \mathrm{scc}_{\mathrm{cat}}{ }^{-1} \mathrm{~h}^{-1}$, $\mathrm{O} / \mathrm{C}=1.1,900^{\circ} \mathrm{C}$, and $0.23 \mathrm{MPa}$. 94 Figure 4-5 TPO of pyrochlore catalysts with different Rh loadings after $4 \mathrm{~h}$ POX of TD: (a) LCZY, LCZR1Y, LCZR3Y, (b) LTC only, LCZY removed. 95 Figure 4-6 TPO of LCZR2Y after POX testing at varying TOS.......................................... 98 Figure 4-7 Raman spectra of LCZR2Y after POX of TD and partial carbon burn-off...... 98 Figure 4-8 TPO profiles of LCZR2Y after POX of TD $(\mathrm{O} / \mathrm{C}=1.25)$ at various TOS........ 100 Figure 4-9 Fitting of HTC formation data to produce predictive mathematical expression. 101

Figure 4-10 TPO profiles for LCZR2Y catalyst after POX of TD $(\mathrm{O} / \mathrm{C}=1.1)$ at various TOS. 103 


\section{List of Tables}

Table 1-1. Side reactions ${ }^{\mathrm{a}}$ in the hydrocarbon partial oxidation system (adapted from [1])

Table 1-2. Enthalpy of POX reaction for various hydrocarbon fuels: $\mathrm{O} / \mathrm{C}=1.2, \mathrm{~T}=900^{\circ} \mathrm{C}$ ) (Calculations using HSC Chemistry 5.0 [9]).

Table 1-3. Summary of methane CPOX mechanisms provided by York et al. [6]............ 11

Table 1-4. CPOX reaction mechanism by Wang et al. [34].

Table 1-5. Comparison of methane dissociation with and without oxygen participation [17]

Table 1-6. Reaction mechanism steps for kinetic study [46].

Table 1-7. POM reaction scheme over supported Pt adapted from the proposition of de Smet et al. to account for the reversible oxygen adsorption, carbon species oxidation and $\mathrm{CO} 2$ formation $[47,48]$.

Table 1-8. POM reaction scheme over supported Pt proposed in this study accounting for $\mathrm{H}_{2}$ production $[47,48]$

Table 1-9. Indirect reaction mechanism steps for kinetic study by de Groote et al. [49].. 24 Table 1-10. Kinetic equations for study by de Groote et al. [49].

Table 1-11. 12 Results of TPR studies and CO selectivity data for Ni, Co, and Fe catalysts over La-promoted alumina supports [50].

Table 1-12. $\mathrm{H}_{2} / \mathrm{CO}$ ratios for $\mathrm{Ni}, \mathrm{Co}$, and $\mathrm{Fe}$ catalysts over La-promoted alumina supports [50]. 26

Table 1-13. Effect of basic promoters on CPOX of methane with $\mathrm{Ni} / \gamma-\mathrm{Al}_{2} \mathrm{O}_{3}$ catalysts [52]. 28

Table 1-14. Characterization data of Ni catalysts with alumina and zirconia-doped ceria supports [54]. 30

Table 2-1Summary of Characterization Data..................................................................... 52

Table 2-2 Summary of Carbon Formation on GDC Supported Catalysts. ......................... 53

Table 2-3 Summary of Carbon Formation on ZDC Supported Catalysts............................ 54

Table 2-4 Reaction Conditions for Partial Oxidation Step-response Experiments............ 60

Table 2-5: Comparison of surface area and Ni content of reforming catalysts.................. 61

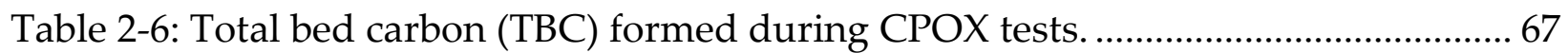

Table 2-7: Total bed carbon (TBC) formed during extended CPOX tests.............................. 68

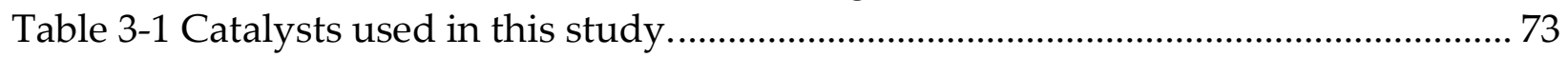

Table 3-2 Summary of CPOX conditions for reaction studies............................................. 74

Table 3-3 Surface Area of Reforming Catalysts Used in This Study................................ 75

Table 3-4 Carbon formation for Series 1 single-composition bed runs............................... 76

Table 3-5 Carbon Formation for Series 1 Segmented Bed Runs......................................... 78

Table 3-6 Carbon Formation for Series 2 Single-composition Bed Runs. ............................ 80 
Table 3-7 Carbon Formation for Series 2 Segmented Bed Runs............................................ 81

Table 3-8 Carbon Formation in Sections of Segmented Catalyst Bed. .................................. 86

Table 4-1 Catalysts Prepared for This Study ..................................................................... 88

Table 4-2 Summary of POX Experimental Conditions......................................................... 89

Table 4-3 Metal Dispersion from $\mathrm{H}_{2} \mathrm{PC}$ Experiments. ........................................................... 91

Table 4-4 Carbon Formation Determined from TPO of Pyrochlore Catalysts with

Different Rh Loadings After $4 \mathrm{~h}$ POX of TD......................................................................... 96

Table 4-5 Carbon Calculated from TPO for LCZR2Y After POX of TD at Different TOS:

$\mathrm{O} / \mathrm{C}=1.25$. 100

Table 4-6 Results of data fitting parameters....................................................................... 102

Table 4-7 Carbon calculated from TPO for LCZR2Y After POX of TD at Different TOS:

$\mathrm{O} / \mathrm{C}=1.25$ 103 


\section{$1 \quad$ Introduction}

\subsection{Overview}

Research on catalytic reforming has progressed through several stages in recent years. The focus of many studies has been on reforming current infrastructure fuels to produce a $\mathrm{H}_{2}$ and CO-rich product stream for use in solid oxide fuel cells. This application requires a catalyst that can perform for long periods of time at temperatures $>850^{\circ} \mathrm{C}$, and remain thermally stable at temperatures as high as $1200^{\circ} \mathrm{C}$. Simple supported metal catalysts deactivate quickly under these conditions, especially in the presence of sulfur and aromatic species, both of which are found in the fuels considered for transportation, distributed, and remote applications. The deactivation occurs in several ways: loss of active metal from vaporization, sulfur poisoning from agglomeration into large metal particles, covering of active sites with coke, and the loss of active metal from support collapse.

The design of a better catalyst has focused on improvements to address the different modes of deactivation. Efforts have included the examination of both transition and precious metals. Several efforts examined the substitution of the active metal into thermally stable oxides like perovskites $\left(\mathrm{ABO}_{3}\right)$, pyrochlores $\left(\mathrm{A}_{2} \mathrm{~B}_{2} \mathrm{O}_{7}\right)$, and hexaaluminates $\left(\mathrm{ABAl}_{12} \mathrm{O}_{19}\right)$. This approach results in the formation of small metal particles that are more resistant to poisoning, and less likely to move around the surface and form agglomerates.

Other studies demonstrated improved performance by supporting the active metal onto materials with oxygen-conducting (OC) properties to reduce carbon formation. This led to the approach of depositing the substituted oxide onto an oxygen-conducting support. These materials demonstrated even greater resistance to deactivation than substituted oxides and metals supported on OC materials alone.

The next major development consisted of substituting active metals into a thermally stable oxide structure that possesses OC properties. The pyrochlore structure was identified as a good candidate and was studied with various levels of doping the A and B sites. The pyrochlore was also selected since larger, and more active metals like Rhodium, could be successfully substituted into its crystal lattice, unlike the hexaaluminate structure. It was determined that the active metal could be substituted into the B site, while other metals could be substituted into both the A and B sites to promote oxygen conductivity and other desired properties.

The final form of the catalyst may be a combination of the substituted pyrochlores supported by a separate OC material, to provide additional oxygen mobility to active metal sites. Figure 1-1 is a diagram of the catalyst development in the stages described. 


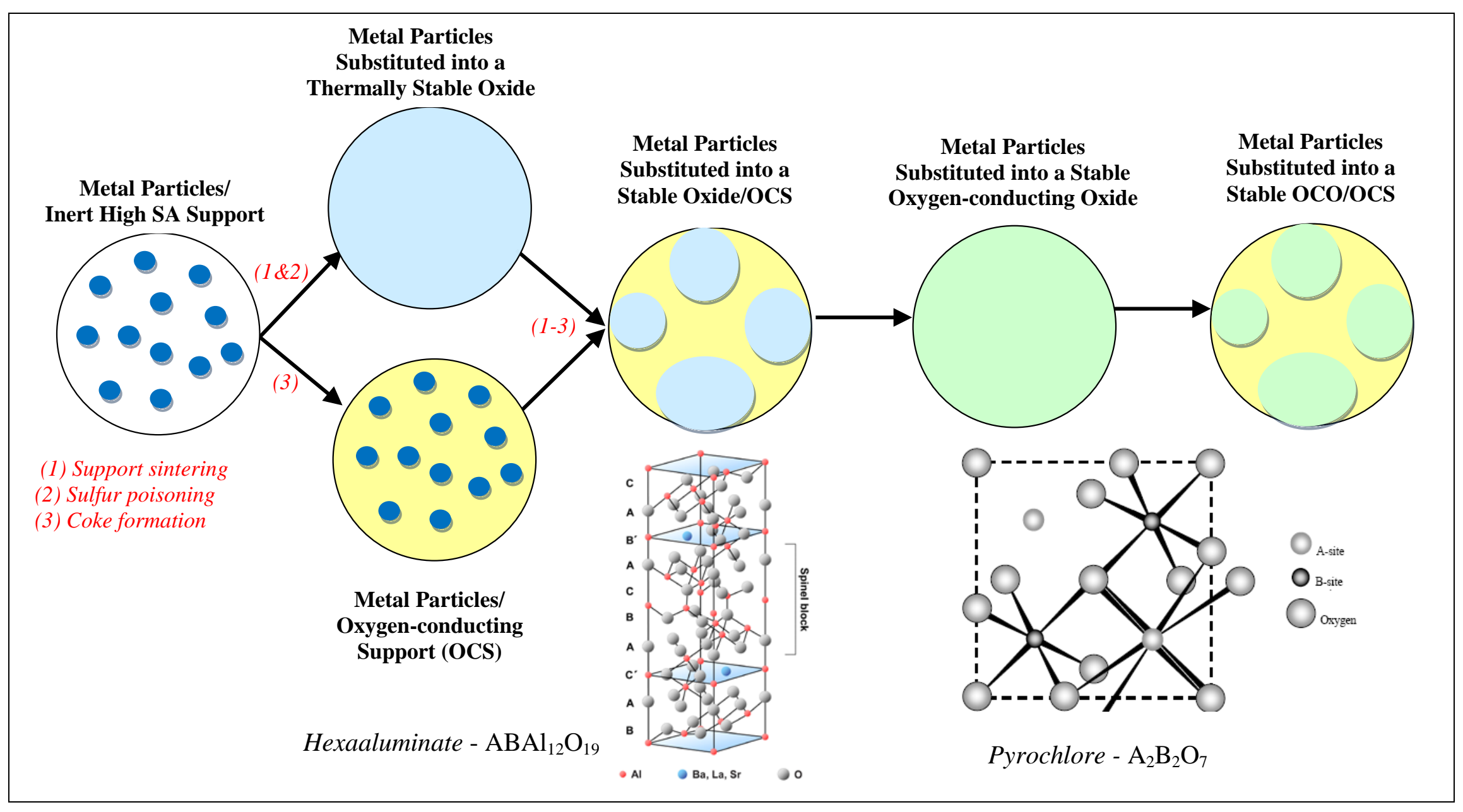

Figure 1-1. Development of hydrocarbon reforming catalyst. 
The objectives of this research were to investigate different approaches for 1) the catalyst design and 2) reactor design for catalytic partial oxidation (CPOX) of hydrocarbons.

1) Catalyst design approaches included substitution of active metals into two different mixed-metal oxide structures (hexaaluminate (HA) and pyrochlore (PC)), and the combination of these materials with ceria based oxygen-conducting supports (OCS).

a. Deposition of HA onto zirconium-doped ceria (ZDC) and gadolinium-doped ceria (GDC) at different weight loadings (10, 15, 20, and $50 \mathrm{wt} \%)$.

b. Deposition of HA onto GDC using two different deposition techniques: incipient wetness impregnation and solid-state mixing.

c. Deposition of PC onto ZDC at different weight loadings (10 and $20 \mathrm{wt} \%$ ).

2) Reactor design consisted of a segmented catalyst bed, with placement of catalyst compositions in different locations of the reactor bed.

a. Ni-substituted HA and Rh-substituted PC alternated in the top and bottom sections of the catalyst bed.

b. Ni-substituted PC and Ru-substituted PC alternated in the top and bottom sections of the catalyst bed.

Ni-substituted PC and Rh-substituted PC were deposited onto structured alumina foams and alternated in the top and bottom section of the catalyst bed.

Additionally, the formation of deactivating carbon on a Rh-substituted pyrochlore catalyst was examined and modelled for CPOX of a hydrocarbon fuel followed by temperature programmed reduction. The carbon formed on the catalytic sites and the non-catalytic surface sites was measured separately to determine the cause of catalyst deactivation.

The significance of this work is the introduction of a new catalyst design and reactor bed configuration to reform a hydrocarbon fuel under waterless or near-waterless conditions with a reduced amount of costly noble metal. This is desirable for generating gaseous fuel for solid oxide fuel cell applications in transportation and remote and distributed power generation. Further, the novel aspects of this research are the combination of a substituted oxide catalyst with an oxygen-conducting support, rather than the traditional deposited metal catalyst, for reforming. Additionally, the approach of studying the carbon formation in different regions of the reactor by CPOX of a hydrocarbon followed by temperature programmed oxidation to produce a carbon deposition profile in a segmented bed has not been found previously in the literature.

\section{$1.2 \quad$ Background}

Catalytic partial oxidation (CPOX) is an attractive option to produce $\mathrm{H}_{2}$ and $\mathrm{CO}$ from hydrocarbon fuels for fuel cell applications. In particular, CPOX is suitable for compact or mobile fuel processing systems integrated with solid oxide fuel cells due to similarity of operating conditions and the utilization of currently available infrastructure fuels. CPOX can also be followed by the water-gas shift (WGS) reaction to produce a pure $\mathrm{H}_{2}$ stream for use in polymer electrolyte membrane (PEM) fuel cells.

CPOX has the advantage of inherently rapid reforming kinetics with rapid light-off characteristics and response to transients. Since there is no need to feed water, as in steam 
reforming (SR) and oxidative-steam reforming (OSR), CPOX reactors are smaller and more easily integrated into transportation-based, onboard fuel reforming systems, as well as remote and distributed power applications. Additionally, the exothermic nature of this process reduces the heat needed to be supplied to the system, making it ideal for integration with hightemperature fuel cells. Challenges for the CPOX of hydrocarbons include catalyst deactivation from high-temperature sintering, metal vaporization, support degradation, coke formation, and poisoning from sulfur and other contaminants.

The reactions occurring in the CPOX of hydrocarbons are complex. The overall CPOX reaction can be described by Equation 1-1. However, several side reactions can occur and are presented in Table 1-1 using methane as the hydrocarbon species. The most significant side reactions are the WGS (1-4), steam reforming (1-5), and $\mathrm{CO}_{2}$ reforming (1-6), which help produce the final synthesis gas composition. This composition will vary based on the hydrocarbon fuel and the reaction conditions.

$$
\mathrm{C}_{n} \mathrm{H}_{m}+p\left(\mathrm{O}_{2}+3.76 \mathrm{~N}_{2}\right) \rightarrow w C O+x \mathrm{CO}_{2}+y \mathrm{H}_{2}+z \mathrm{H}_{2} \mathrm{O}+(3.76 p) \mathrm{N}_{2}
$$

Table 1-1. Side reactions ${ }^{\mathrm{a}}$ in the hydrocarbon partial oxidation system (adapted from [1]).

\begin{tabular}{lc}
\hline $\mathrm{CH}_{4}+2 \mathrm{O}_{2} \rightarrow \mathrm{CO}_{2}+2 \mathrm{H}_{2} \mathrm{O}$ & Combustion \\
$\mathrm{CH}_{4}+\mathrm{O}_{2} \rightarrow \mathrm{CO}_{2}+2 \mathrm{H}_{2}$ & \\
$\mathrm{CO}+\mathrm{H}_{2} \mathrm{O} \leftrightarrow \mathrm{CO}_{2}+\mathrm{H}_{2}$ & Water Gas Shift \\
$\mathrm{CH}_{4}+\mathrm{H}_{2} \mathrm{O} \leftrightarrow \mathrm{CO}+3 \mathrm{H}_{2}$ & Steam Reforming \\
$\mathrm{CH}_{4}+\mathrm{CO}_{2} \leftrightarrow 2 \mathrm{CO}+2 \mathrm{H}_{2}$ & $\mathrm{CO}_{2}$ Reforming \\
$\mathrm{CO}+\mathrm{H}_{2} \leftrightarrow \mathrm{C}+\mathrm{H}_{2} \mathrm{O}$ &
\end{tabular}

${ }^{a}$ All reactions involving $\mathrm{O}_{2}$ are thermodynamically irreversible

Typical operating conditions provided by Enger et al. are the temperature range of $400-1000^{\circ} \mathrm{C}$, atmospheric pressure, and flow rates of 0.1-10 Nl/min (at STP). They also provide a very useful set of tables that summarize all the different methane CPOX catalysts found in the authors' review of literature, their promoters, supports, and references [1]. Another important reaction condition is the weight hourly space velocity (WHSV) defined in Equation 1-12. This value is sometimes referred to as gas hourly space velocity (GHSV), although the value for this is typically calculated as the volumetric gas flow rate divided by the volume of the catalyst, resulting in units of $1 / \mathrm{h}$. This value of WHSV can range from several hundred to several hundred thousand scc/g $g_{\text {cat }} \bullet$.

$$
\text { WHSV }=\frac{\text { Volumetric Gas Flow Rate }}{\text { Mass of Catalyst }}
$$

Here the CPOX of various hydrocarbon fuels will be discussed for a variety of catalysts and operating conditions. The fuels include light (gaseous) and heavy (liquid) hydrocarbons. The 
catalysts in the CPOX process are typically noble metals (Pt, $\mathrm{Ru}, \mathrm{Pd}$, or $\mathrm{Rh}$ ) and transition metals such as Ni and Co dispersed onto an appropriate support. However, substituting these metals into thermally stable oxide structures is believed to provide additional thermal stability and some resistance to deactivation.

The discussion will begin with an examination of the thermodynamic equilibrium compositions at atmospheric pressure for the hydrocarbon fuels at different oxygen-to-carbon (O/C) ratios and temperatures in Section 1.2.1. Section 1.2.2 is an analysis of the kinetics and reaction mechanisms that have been proposed in the literature for CPOX.

Sections 1.2.3 and 1.2.4 cover the CPOX of gaseous and liquid hydrocarbons, respectively. Specifically, these sections will look at a variety of factors that affect the CPOX of these fuels, including reaction conditions, catalyst, and the specific fuel being reformed. The catalyst properties that will be examined include activity of transition and noble metals, metal loading or substitution, surface properties, and resistance to deactivation. Further, the effect of the catalyst support properties, such as morphology, composition, and ionic conductivity, will be discussed. Finally, the factors related to the fuel type include the presence of unsaturated and/or aromatic hydrocarbon species, sulfur-containing species, and oxygenated compounds.

Several reviews on the CPOX of hydrocarbons have been published in recent years. The largest amount of research reported and reviewed has been related to the CPOX of methane [1-6], while fewer studies have been reviewed related to the CPOX of higher hydrocarbons $[7,8]$. Major points of discussion provided in these reviews will be summarized in the appropriate sections to follow. The most important issues and factors with regard to the current state of research on the CPOX of hydrocarbons are identified and discussed.

\subsubsection{Thermodynamics}

Thermodynamic calculations for the POX (Equation 1-1) of the various fuel types were performed using HSC Chemistry 5.0 [9], and the results are presented in the following sections. The effects of temperature and $\mathrm{O} / \mathrm{C}$ ratios are examined in this section. $\mathrm{O} / \mathrm{C}$ ratio is defined as the atomic ratio of oxygen fed by air to the carbon number of the fuel species. Equilibrium product distributions and carbon formation characteristics for several representative fuels are examined over the temperature range of $300-1000^{\circ} \mathrm{C}$ and over an $\mathrm{O} / \mathrm{C}$ ratio of $0.9-1.5$. All calculations were conducted at atmospheric pressure; therefore, the effect of pressure is not addressed.

\subsubsection{Heat of reaction}

Table 1-2 shows enthalpy values for selected $C_{1}-C_{18}$ hydrocarbons. The enthalpies of reaction for all alkanes decrease with increasing carbon number; however, the enthalpy for each hydrocarbon per carbon atom approaches a near-constant value for a given set of conditions. These values are the enthalpy for each hydrocarbon divided by the number of carbon atoms per mole.

The enthalpy values for the POX of methane, $i$-octane, and $n$-tetradecane (TD), according to Equation $1-1$, at an $\mathrm{O} / \mathrm{C}=1.2$ from $300-1000^{\circ} \mathrm{C}$ are presented in Figure $1-2$. Isooctane was selected as a model compound for gasoline; TD was selected as a model compound for diesel fuel. At temperatures above $700^{\circ} \mathrm{C}$, the enthalpy becomes slightly positive for methane, indicating that the endothermic reactions ( $\mathrm{SR}$ and $\mathrm{CO}_{2}$ reforming) dominate. At these higher 
temperatures, the steam and $\mathrm{CO}_{2}$ produced from an increase in combustion reaction increases the extent of these reactions.

Table 1-2. Enthalpy of POX reaction for various hydrocarbon fuels: $O / C=1.2, T=900^{\circ} \mathrm{C}$ ) (Calculations using HSC Chemistry 5.0 [9]).

\begin{tabular}{|c|c|c|}
\hline Hydrocarbon & $\Delta \mathbf{H}(\mathbf{k J} / \mathbf{k m o l})$ & $\boldsymbol{\Delta} \mathbf{H}(\mathbf{k J} / \mathbf{k m o l} \mathbf{C})$ \\
\hline $\mathrm{CH}_{4}$ & 55.90 & 55.90 \\
\hline $\mathrm{C}_{2} \mathrm{H}_{6}$ & 20.70 & 10.35 \\
\hline $\mathrm{C}_{3} \mathrm{H}_{8}$ & -5.59 & -1.86 \\
\hline $\mathrm{C}_{4} \mathrm{H}_{10}$ & -28.70 & -7.18 \\
\hline $\mathrm{C}_{6} \mathrm{H}_{14}$ & -78.70 & -13.12 \\
\hline $\mathrm{C}_{8} \mathrm{H}_{18}$ & -129.00 & -16.13 \\
\hline $\mathrm{C}_{10} \mathrm{H}_{22}$ & -178.00 & -17.80 \\
\hline $\mathrm{C}_{12} \mathrm{H}_{26}$ & -228.00 & -19.00 \\
\hline $\mathrm{C}_{14} \mathrm{H}_{30}$ & -278.00 & -19.86 \\
\hline $\mathrm{C}_{16} \mathrm{H}_{34}$ & -328.00 & -20.50 \\
\hline $\mathrm{C}_{18} \mathrm{H}_{38}$ & -378.00 & -21.00 \\
\hline
\end{tabular}

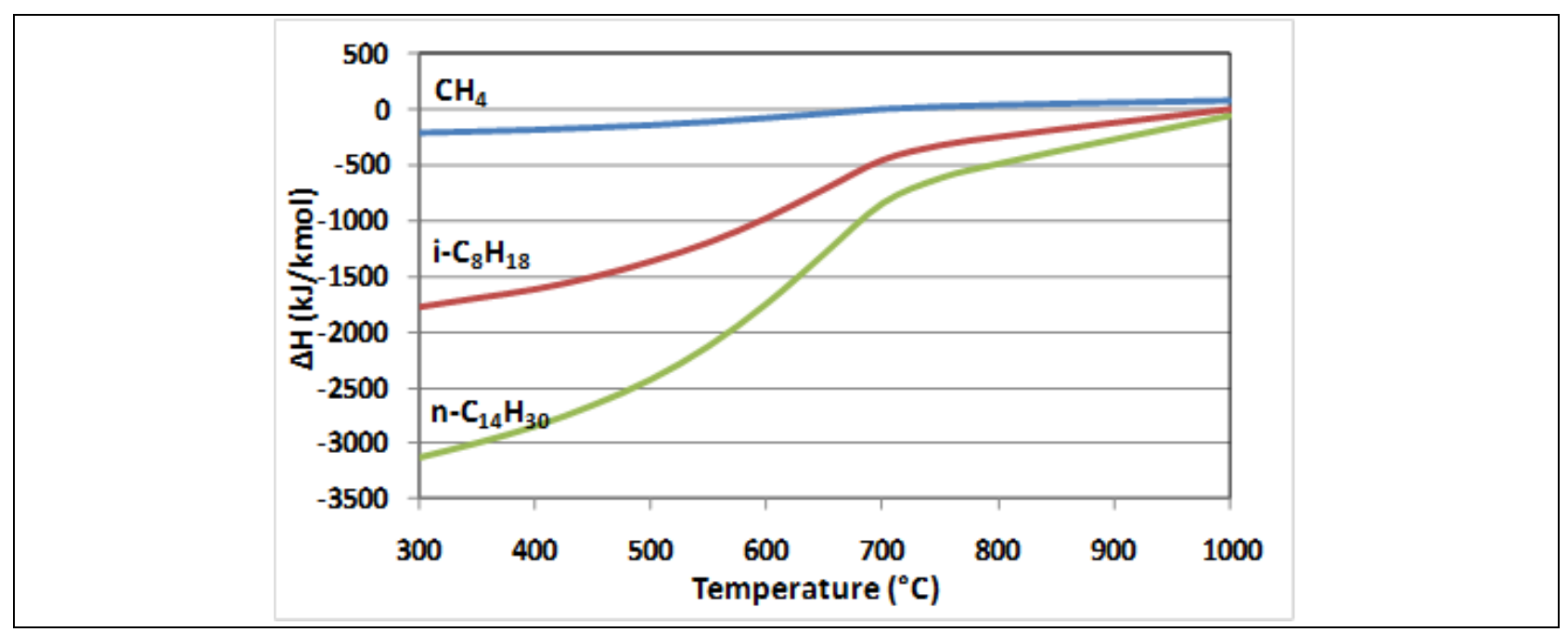

Figure 1-2. Enthalpy of reaction for POX of methane, i-octane, and $n$-TD at different temperatures: $\mathrm{O} / \mathrm{C}=1.2,0.10 \mathrm{MPa}$ (Calculations using HSC Chemistry 5.0 [9]).

\subsubsection{Effect of temperature}

Figure 1-3 shows the effect of temperature on methane POX over a temperature range of 300$1000^{\circ} \mathrm{C}$ at an $\mathrm{O} / \mathrm{C}$ ratio of 1.2 and atmospheric pressure. $\mathrm{H}_{2}$ and $\mathrm{CO}$ levels increase up to $\sim 750^{\circ} \mathrm{C}$, after which they remain essentially constant. The $\mathrm{CO}_{2}$ level increases slightly up to $\sim 550^{\circ} \mathrm{C}$, at which point it begins to be consumed by reforming of the remaining methane (Equation 1-6). $\mathrm{H}_{2} \mathrm{O}$ and $\mathrm{C}$ decrease up to $\sim 700^{\circ} \mathrm{C}$, beyond which carbon is thermodynamically unfavorable. Complete conversion of methane is accomplished at $\sim 800^{\circ} \mathrm{C}$. Above $800^{\circ} \mathrm{C}$, there is a slight and gradual increase in $\mathrm{CO}$ and $\mathrm{H}_{2} \mathrm{O}$, along with a decrease in $\mathrm{CO}_{2}$, indicating that the reverse WGS reaction is occurring. 


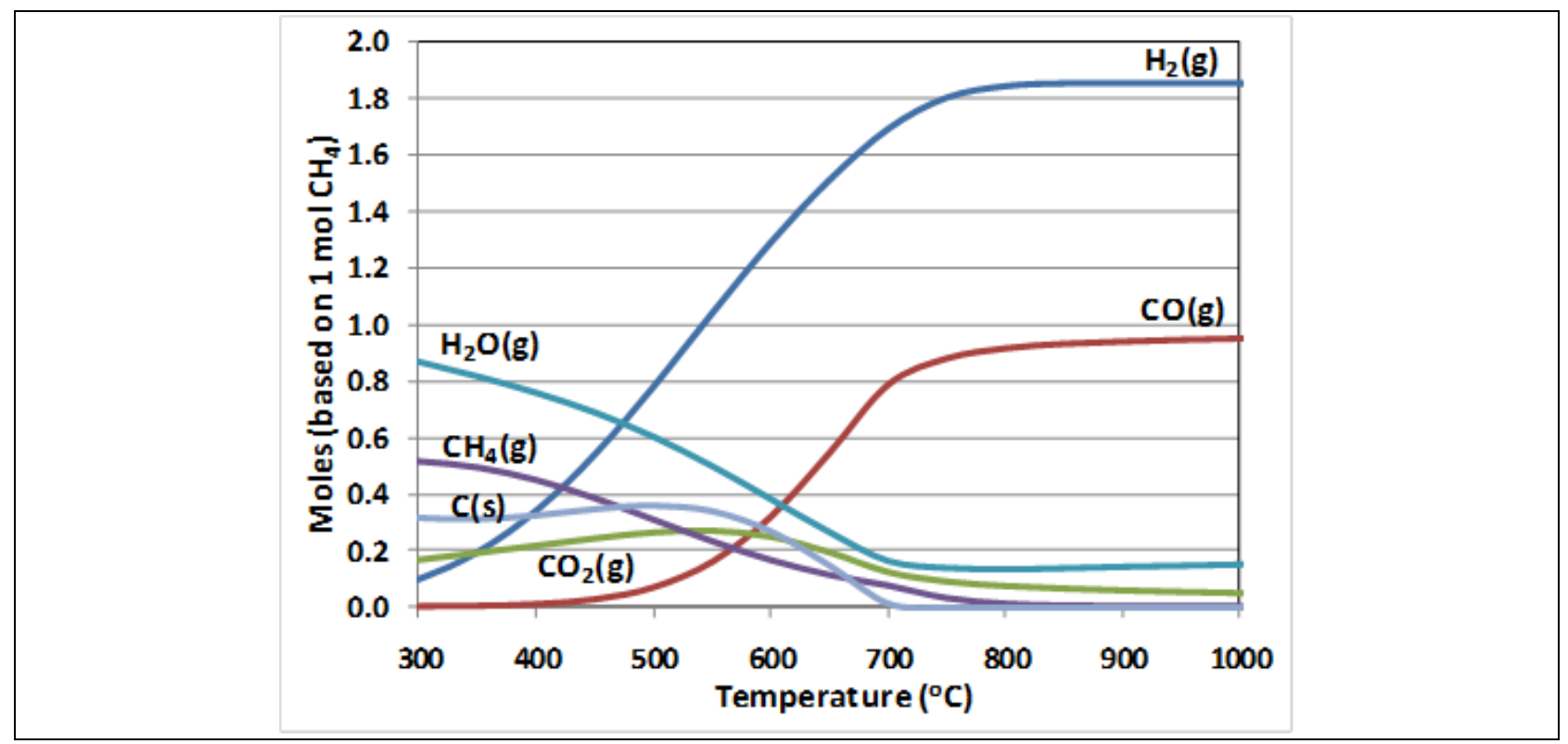

Figure 1-3. Equilibrium product distribution for the POX of methane for different temperatures:

$\mathrm{O} / \mathrm{C}=1.2, \mathrm{P}=0.10 \mathrm{MPa}$ (Calculations using HSC Chemistry 5.0 [9]).

Figure 1-4 shows the effect of temperature on TD POX over a temperature range of $300-1000^{\circ} \mathrm{C}$ at an $\mathrm{O} / \mathrm{C}$ ratio of 1.2 and atmospheric pressure. Unlike methane, the $\mathrm{H}_{2}$ produced does not level off, but reaches a maximum at $\sim 750^{\circ} \mathrm{C}$ before gradually declining due to formation of water. The $\mathrm{CO}$ continues to increase through this temperature range from the reverse WGS. Complete hydrocarbon conversion is achieved at $\sim 800^{\circ} \mathrm{C}$; carbon formation goes to zero at $\sim 710^{\circ} \mathrm{C}$.

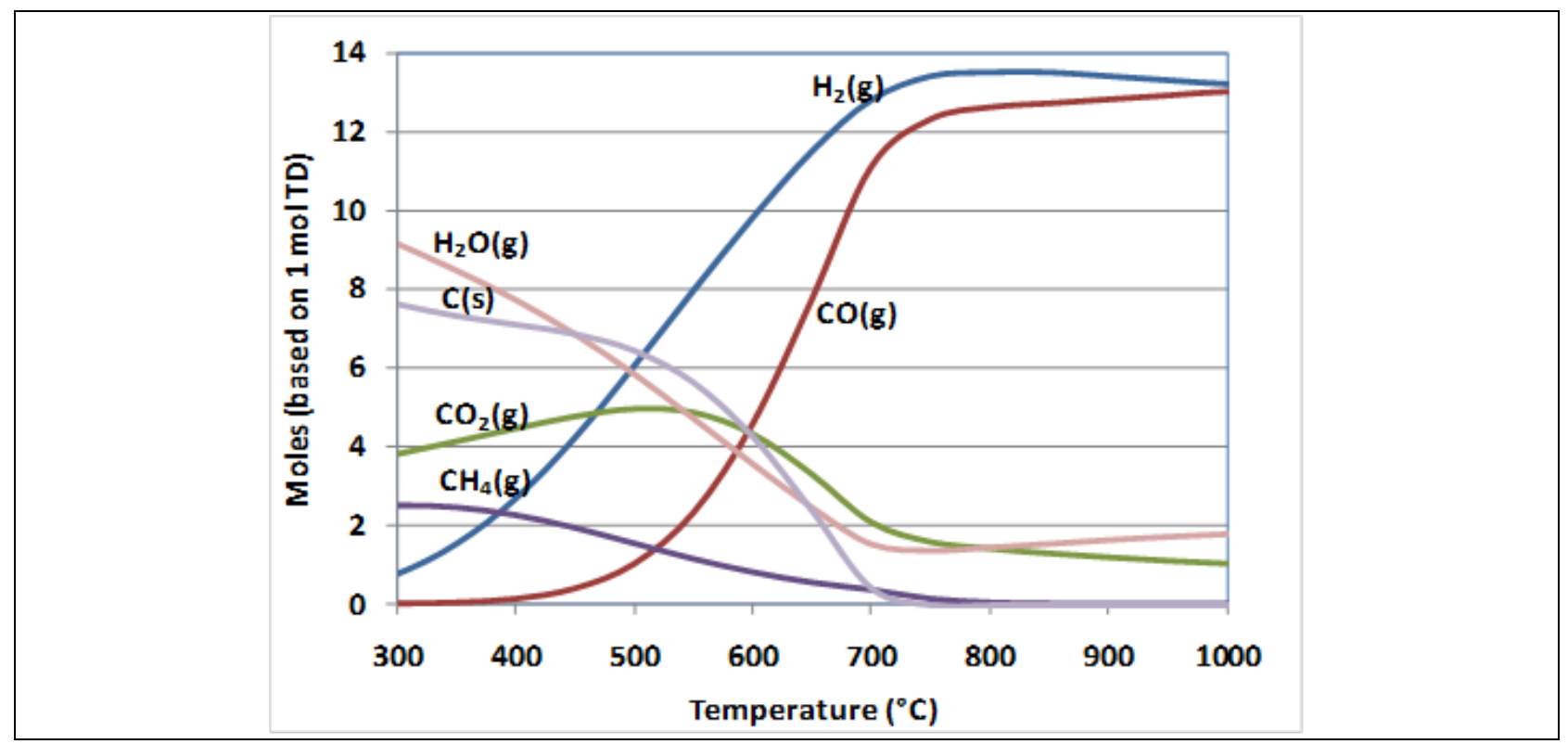

Figure 1-4. Equilibrium product distribution for the POX of TD for different temperatures: $O / C=1.2$, $\mathrm{P}=0.10 \mathrm{MPa}$ (Calculations using HSC Chemistry 5.0 [9]). 


\subsubsection{Effect of $\mathrm{O} / \mathrm{C}$ ratio}

The effect of the $\mathrm{O} / \mathrm{C}$ ratio on the product distributions for methane $\mathrm{POX}$ at $900^{\circ} \mathrm{C}$ is shown in Figure 1-5. Conversion of methane is complete over the range of $\mathrm{O} / \mathrm{C}$ ratios studied.

Thermodynamically, carbon formation goes to zero at $\mathrm{O} / \mathrm{C}$ ratios greater than 1.0, with the highest $\mathrm{H}_{2}$ and $\mathrm{CO}$ yields near this ratio. The levels of combustion products, $\mathrm{CO}_{2}$ and $\mathrm{H}_{2} \mathrm{O}$, increase with a corresponding decline in $\mathrm{H}_{2}$ and $\mathrm{CO}$ levels above an $\mathrm{O} / \mathrm{C}$ of 1.0.

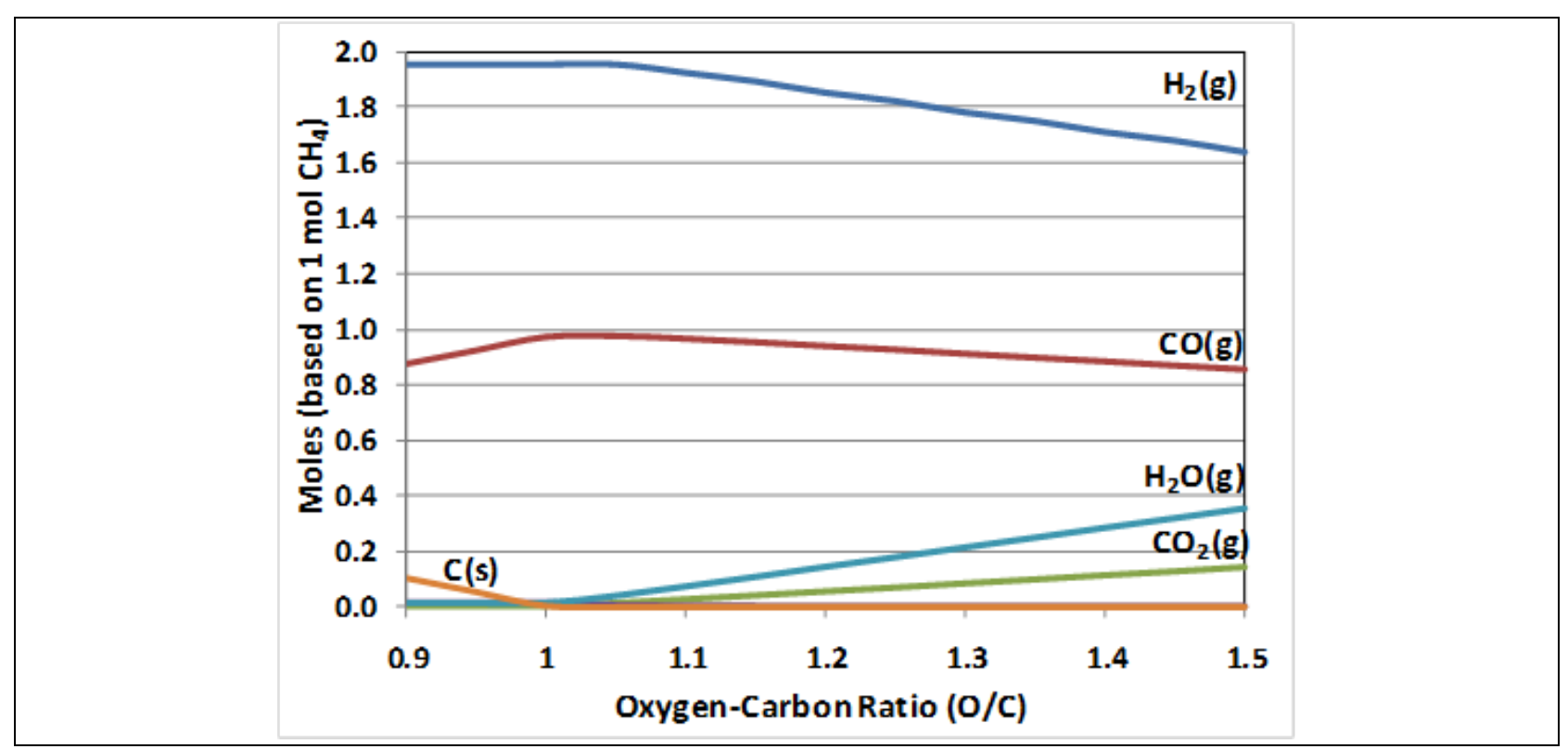

Figure 1-5. Equilibrium product distribution for the POX of methane for different $\mathrm{O} / \mathrm{C}$ ratios: $\mathrm{T}=900^{\circ} \mathrm{C}, \mathrm{P}=0.10 \mathrm{MPa}$ (Calculations using HSC Chemistry 5.0 [9]).

The effect of the $\mathrm{O} / \mathrm{C}$ ratio on the product distributions for TD POX at $900^{\circ} \mathrm{C}$ is shown in Figure 1-6. The trends for this hydrocarbon are qualitatively identical to those for methane.

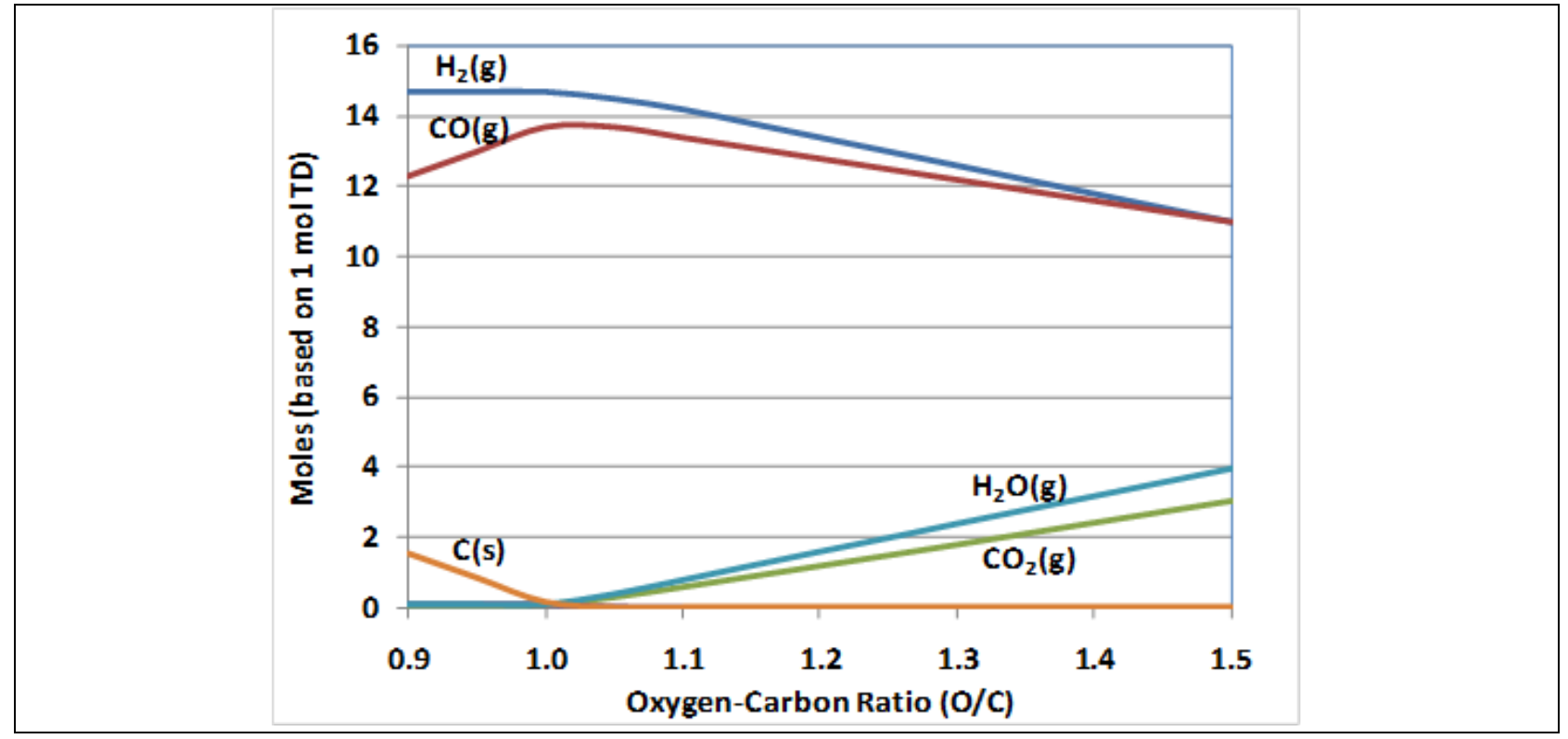

Figure 1-6. Equilibrium product distribution for the POX of TD for different $\mathrm{O} / \mathrm{C}$ ratios: $\mathrm{T}=900^{\circ} \mathrm{C}$, $\mathrm{P}=0.10 \mathrm{MPa}$ (Calculations using HSC Chemistry 5.0 [9]). 


\subsubsection{Reaction Mechanisms and Kinetics}

\subsubsection{Reaction mechanisms}

The reaction mechanisms for the CPOX of hydrocarbons are extremely complex. This discussion will focus on the CPOX of methane for simplicity and will be generalized for any catalyst. Additional discussion of mechanisms related to specific catalytic metals will be given in Section 1.2.3. The mechanisms for higher hydrocarbons are much more complex with a significantly greater number of possible side reactions and intermediate steps. Additionally, cracking reactions become significant for higher hydrocarbons, making the mechanism even more difficult to predict.

There are several challenges to determining a reaction mechanism for the CPOX of methane. First, it is likely that more than one mechanism is occurring for a given reaction system. Second, the nature of the catalyst, which may change over time, can affect which mechanism dominates. Further, the interaction of the active metal with the support may play a role. Third, the reaction mechanism can change under different operating conditions ( $\mathrm{O} / \mathrm{C}$ ratio, temperature, space velocity). These factors and their potential effects on the reaction mechanisms for the CPOX of methane will be discussed in depth in the following sections.

Two main mechanisms for the CPOX of methane have been proposed and reviewed in literature: direct and indirect [6]. In the direct mechanism, methane is decomposed to elemental carbon and hydrogen. Next, the elemental carbon on the surface of the catalyst reacts with oxygen on the surface to form CO. Finally, $\mathrm{H}_{2}$ and $\mathrm{CO}$ gas desorb from the surface to yield synthesis gas.

In the indirect mechanism, sometimes referred to as combustion and reforming reactions (CRR), the formation of the products takes place in two separate regions, or zones, of the reactor. First, a portion of the methane reacts with oxygen to form combustion products (water and carbon dioxide). This is followed by steam and $\mathrm{CO}_{2}$ reforming reactions with the remaining methane in the second region of the bed. Additionally, a mixture of the direct and indirect mechanisms has been proposed.

Figure 1-7 is a diagram showing a simplified comparison of the direct and indirect mechanism for the CPOX of methane on a catalyst surface. The first three steps are the adsorption and decomposition of methane to carbon and hydrogen species on the surface, present in both mechanisms, represented in Figure 1-7 (a-c). The dissociation of methane to each $\mathrm{CH}_{\mathrm{x}}$ species is not presented. For the direct mechanism, the dissociative adsorption of oxygen follows, which oxidizes the surface carbon to CO (Figure 1-7 [d-e]). This is then desorbed into the bulk gas.

For the indirect mechanism, the combustion products $\mathrm{CO}_{2}$ and $\mathrm{H}_{2} \mathrm{O}$ are formed from the adsorbed oxygen (Figure 1-7 [f]). This can occur if the rate of oxidation of the $\mathrm{CO}$ species is faster than the rate of $\mathrm{CO}$ desorption and if the $\mathrm{OH}$ species (not shown) formed from the reaction of oxygen with surface hydrogen are very stable, also leading to deep oxidation. The indirect mechanism then can take two parallel pathways to convert the remaining methane via steam reforming (Figure 1-7 [g-h]) and $\mathrm{CO}_{2}$ reforming (Figure 1-7 [i-j]). These reactions are both highly endothermic and dominate once all the oxygen fed with the methane is consumed in the first part of the bed. Other possible side reactions not shown are the WGS and methanation reactions. 


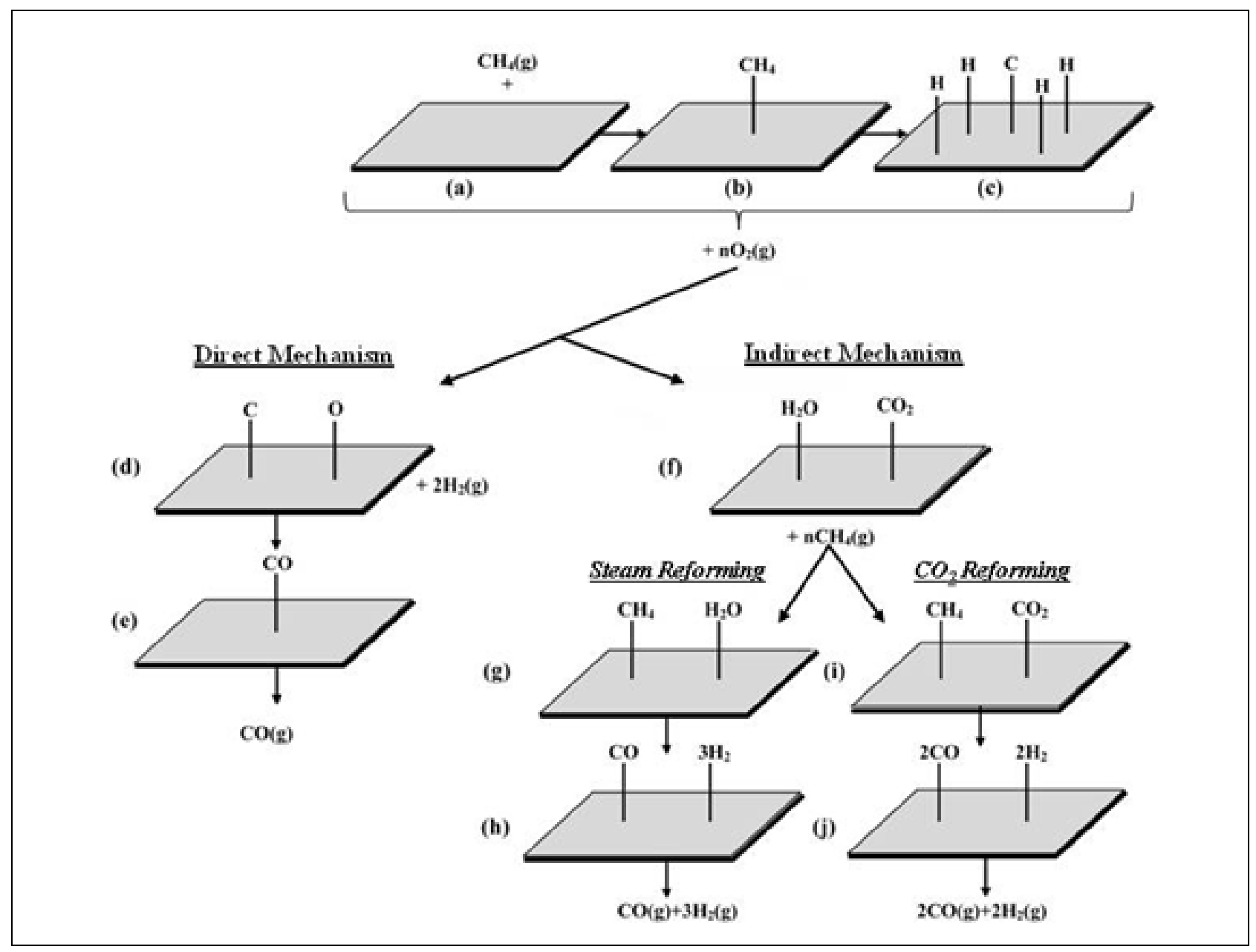

Figure 1-7. Diagram comparing the direct and indirect mechanism for the CPOX of methane.

Table 1-3 provides a summary of the studies reviewed by York et al. [6] for the direct and indirect mechanisms for methane CPOX. They correlate the mechanism to reduced vs. oxidized catalyst surfaces, where reduced sites promote the direct mechanism and oxidized sites promote the indirect mechanism. In some studies, both oxidized and reduced species are present. It is assumed that the indirect mechanism is expected for the catalyst exotherm studies reported. Further, it is concluded that the direct mechanism proposed by Hickmann and Schmidt [10-13] is reasonable at low surface coverage; however, the indirect mechanism is more strongly supported for "working catalysts." 
Table 1-3. Summary of methane CPOX mechanisms provided by York et al. [6].

\begin{tabular}{|c|c|c|c|c|c|}
\hline \multicolumn{3}{|c|}{ Direct Mechanism } & \multicolumn{3}{|c|}{ Indirect Mechanism } \\
\hline Author(s) & Metal(s) & Support(s) & Author(s) & Metal(s) & Support(s) \\
\hline Peters et al. [14] & N/A & $\mathrm{N} / \mathrm{A}$ & Dissanayake et al. [15] & $\mathrm{Ni}$ & Alumina \\
\hline Au et al.[16, 17] & $\mathrm{Ni}$ & $\begin{array}{l}\text { Silica, } \\
\text { Alumina }\end{array}$ & Vermeiren et al. [18] & $\mathrm{Ni}$ & $\begin{array}{l}\text { Alumina, Silica, } \\
\text { Zirconia, Zeolites }\end{array}$ \\
\hline Hu and Ruckenstein $[19,20]$ & $\mathrm{Ni}$ & $\mathrm{La}_{2} \mathrm{O}_{3}$ & Heitnes et al. [21, 22] & Ni, Pt, Pd & $\begin{array}{l}\text { Alumina, } \\
\text { Cordierite }\end{array}$ \\
\hline Mallens et al. [23] & Pt & N/A & Passos et al. [24] & $\mathrm{Pt}$ & $\begin{array}{c}\text { Alumina, Zirconia, } \\
\text { Ceria }\end{array}$ \\
\hline Passos et al. [24] & $\mathrm{Pt}$ & Yttria & Hochmuth [25] & $\mathrm{Pt} / \mathrm{Pd}$ & Ceria/Alumina \\
\hline $\begin{array}{l}\text { Hickmann and Schmidt [10-13, } \\
\text { 26] }\end{array}$ & $\begin{array}{l}\text { Pt, Pt- } \\
\text { Rh }\end{array}$ & Alumina & Oh et al. [27] & $\begin{array}{c}\text { Pt, Pd, Rh } \\
\text { w/ \& w/o Ce }\end{array}$ & Alumina \\
\hline Baerns et al. [28-30] & $\mathrm{Rh}$ & Alumina & Heitnes et al. [31] & Pt-wire gauze & $\mathrm{N} / \mathrm{A}$ \\
\hline Qin et al. [32] & $\mathrm{Ru}$ & $\mathrm{MgO}$ & Horn et al. [33] & $\mathrm{Rh}$ & Alumina \\
\hline Wang et al. [34] & $\mathrm{Rh}$ & Alumina & Boucouvalas et al. [35] & $\mathrm{Rh}$ & Alumina \\
\hline & & & Wang et al. [34] & $\mathrm{Rh}$ & Alumina \\
\hline
\end{tabular}




\subsection{Direct mechanism for partial oxidation}

A complete set of steps for the direct mechanism for the CPOX of methane is much more complex than shown Figure 1-7. One such set of reaction steps is provided by Wang et al. [34]. Their mechanism studies were conducted with $\mathrm{Rh} / \mathrm{Al}_{2} \mathrm{O}_{3}$ through the use of temporal analysis of products (TAP). This method used a pulse reactor under vacuum with residence times for each pulse that are less than the reaction, adsorption, and/or desorption times. The results of this study yielded a mechanism consisting of 24 steps divided into five categories: (1) adsorption and dissociation of methane, (2) surface reactions, (3) desorption, (4) events on $\mathrm{Al}_{2} \mathrm{O}_{3}$-sites, and (5) inverse spillover from the support to the metal surface. These steps are listed in Table 1-4.

Step 1 in Table 1-4 shows the dissociative adsorption of oxygen, which was not shown in Figure 1-7. Steps 2-6 provide a more detailed step-by-step look at the adsorption and dissociation of methane represented previously in Figure 1-7 (a-c). Step 8 is the formation of CO from the reaction of surface oxygen and carbon, while Steps 7, 9, 10, and 13 show the formation of hydroxyls and their role in oxidizing surface carbon species to CO through the formation of $\mathrm{COH}$. Weak Me-O bonds helps produce $\mathrm{CO}$ as primary product.

Steps $11,12,16$, and 17 show the formation of combustion products $\mathrm{CO}_{2}$ and $\mathrm{H}_{2} \mathrm{O}$. As mentioned earlier, the stability of the adsorbed $\mathrm{CO}$ and $\mathrm{OH}$ surface species will control the extent of the formation of these products. Although this is discussed as a direct mechanism, it does not exclude the formation of these over-oxidized species. However, this is not considered an indirect mechanism since it does not include steps for the reaction of methane with adsorbed water or $\mathrm{CO}_{2}$.

Steps 22-24 show how the nature of the support can play a role in the formation of hydroxyls and the combination of these hydroxyls to form water on the support surface. This demonstrates how the nature of the support can affect the steps in the CPOX of methane.

In the direct mechanism, reaction conditions require reduced, highly active metals and low methane conversion, which suggest low temperatures and/or high space velocities. The increased space velocity can cause reduction in methane conversion from either shorter residence time or decreased catalyst surface temperatures. Longer residence time of adsorbed species on the catalyst surface increases the formation of combustion products, leading to the indirect mechanism. Differences between the bulk gas and surface temperatures have been shown to be as high as $300^{\circ} \mathrm{C}$ [15]; therefore, lower temperatures can suppress the combustion reactions, again leading to the direct mechanism.

The dissociation of methane has been reported as the rate-limiting step for CPOX. The oxidation state of the active metal and the role of oxygen in methane dissociation is a subject of debate. Au and Wang [36] studied Rh and RhO catalysts for the CPOX of methane. They reported that reduced $\mathrm{Rh}$ metal was the active site for the reaction and that $\mathrm{RhO}$ reduces quickly to a metallic site. At high Rh surface coverages, the dispersion was low, and it was determined that the larger metal sites could completely dissociate methane. At low coverages and high dispersion, it was determined that lattice oxygen could play a role in the dissociation of methane.

Oxygen adsorbed on the metal has been reported to promote dehydrogenation, while oxygen adsorbed on bridge or hollow sites does not. Some studies report that methane is activated by lattice oxygen of the support, while others suggest its dissociation takes place on the active metal site with no interaction with oxygen. Au and Wang [36] used the bond-order conservation 
Morse-potential approach [37] to evaluate the activation of methane with and without the interaction of chemisorbed oxygen. A comparison of the activation energies for these two scenarios is given in Table 1-5. It was determined that oxygen can play a role in the dissociation of methane, but that it occurs with oxygen species at the on-top sites and not with the bridge or hollow sites.

Table 1-4. CPOX reaction mechanism by Wang et al. [34].

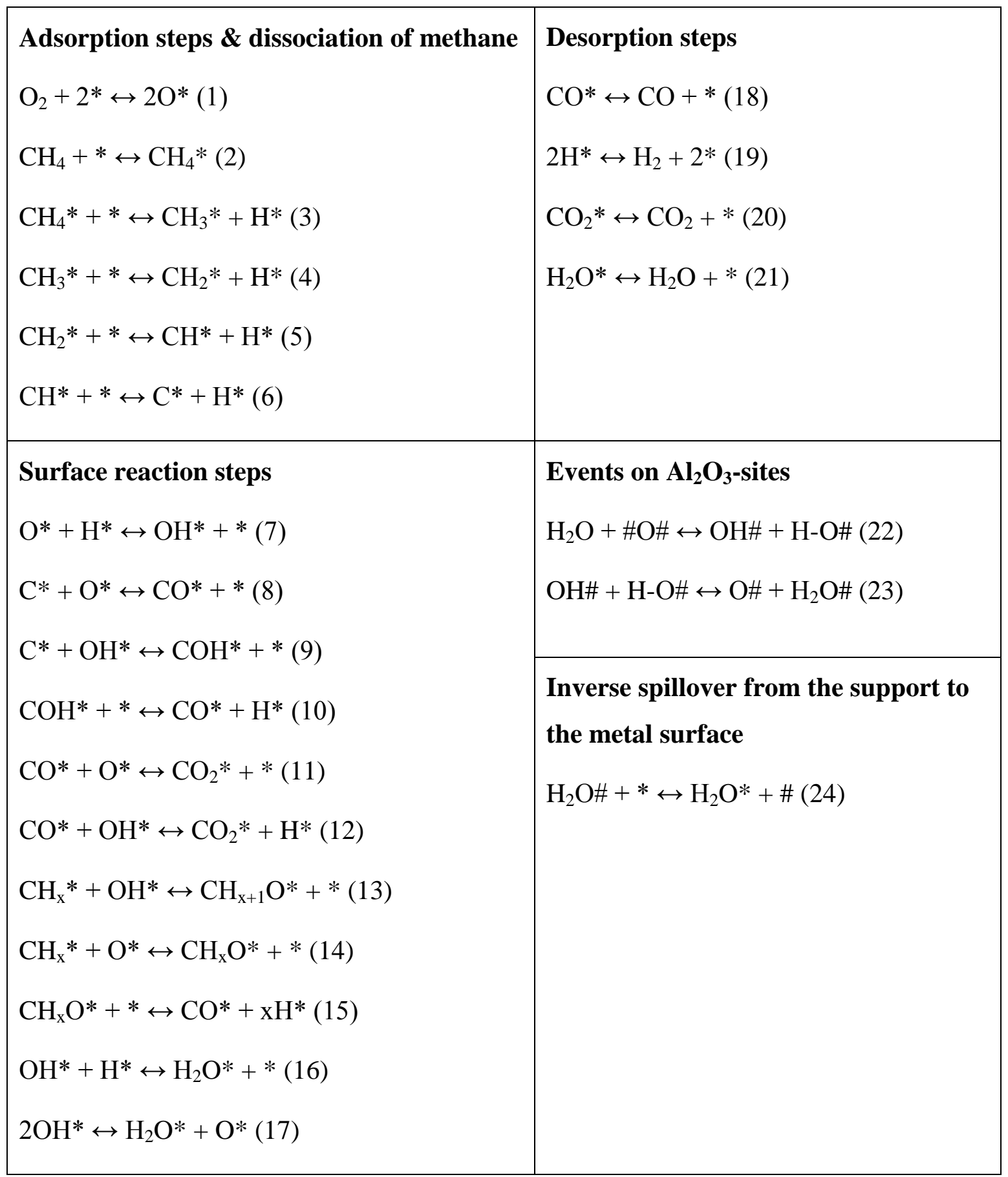

* Metal sites and \# $\mathrm{Al}_{2} \mathrm{O}_{3}$ sites 
Table 1-5. Comparison of methane dissociation with and without oxygen participation [17].

\begin{tabular}{|l|c|c|c|c|c|}
\hline \multirow{2}{*}{$\begin{array}{c}\text { Elementary } \\
\text { reaction }\end{array}$} & \multirow{2}{*}{$\begin{array}{c}\mathbf{E}_{\mathbf{a}} \\
\mathbf{( k J / m o l e )}\end{array}$} & \multirow{2}{*}{$\begin{array}{c}\text { Surface oxygen } \\
\text { adsorbed }\end{array}$} & \multicolumn{3}{|c|}{$\mathbf{E}_{\mathbf{a}}(\mathbf{k J} / \mathbf{m o l e})$} \\
\cline { 4 - 6 } & & & On-top & Bridge & Hollow \\
\hline $\mathrm{CH}_{4} \rightarrow \mathrm{CH}_{3}+\mathrm{H}$ & 61 & $\mathrm{CH}_{4}+\mathrm{O} \rightarrow \mathrm{CH}_{3}+\mathrm{OH}$ & 0 & 56 & 77 \\
\hline $\mathrm{CH}_{3} \rightarrow \mathrm{CH}_{2}+\mathrm{H}$ & 103 & $\mathrm{CH}_{3}+\mathrm{O} \rightarrow \mathrm{CH}_{2}+\mathrm{OH}$ & 31 & 95 & 116 \\
\hline $\mathrm{CH}_{2} \rightarrow \mathrm{CH}+\mathrm{H}$ & 100 & $\mathrm{CH}_{2}+\mathrm{O} \rightarrow \mathrm{CH}+\mathrm{OH}$ & 25 & 89 & 111 \\
\hline $\mathrm{CH} \rightarrow \mathrm{CH}+\mathrm{H}$ & 21 & $\mathrm{CH}+\mathrm{O} \rightarrow \mathrm{CH}+\mathrm{OH}$ & 0 & 33 & 61 \\
\hline
\end{tabular}

\subsection{Indirect mechanism for partial oxidation}

The indirect mechanism along a typical catalyst bed is represented by Figure 1-8. At the top of the bed, all oxygen is consumed by the exothermic reaction with a portion of the methane in the feed. This region can be on the order of $10 \%$ of the total bed and is controlled by the $\mathrm{O} / \mathrm{C}$ ratio and temperature. A temperature spike, as well as localized hot spots, promote the formation of combustion products. The remaining methane is converted in the bottom portion of the catalyst bed through endothermic secondary reforming reaction with the methane and water produced in the first region.

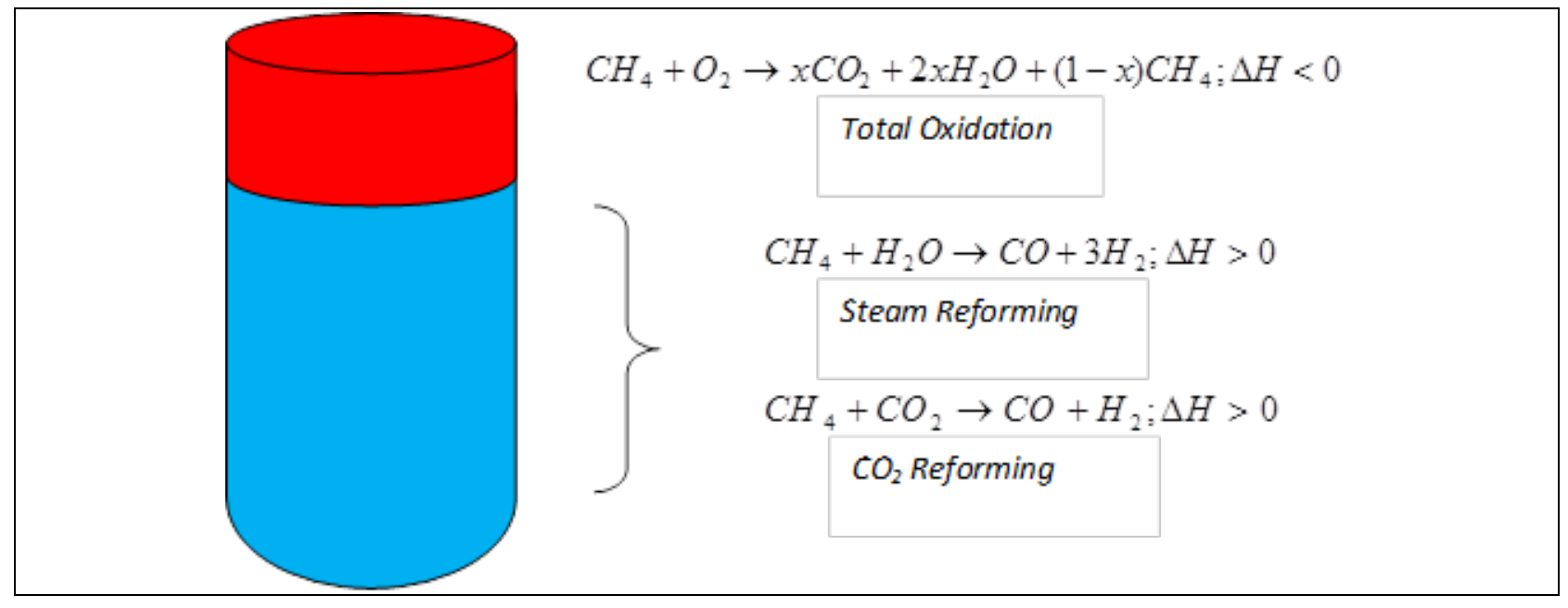

Figure 1-8. Diagram of CPOX reactor with indirect mechanism.

Horn et al. present results supporting the indirect mechanism for the CPOX of methane over Rh catalysts [33, 38, 39]. Although their studies included autothermal conditions, the mechanism proposed is analogous. In their investigations, spatially resolved measurements of temperature and gas compositions down the length of the catalyst bed were made through the use of a quartz capillary tube. These experiments, accompanied by numerical simulations, studied CPOX of methane over a range of $\mathrm{O} / \mathrm{C}$ ratios and flow rates. Some of their results are presented in Figure $1-9$.

Their results support the indirect mechanism and found that oxygen conversion is complete within the first $2 \mathrm{~mm}$ of the catalyst bed, where some $\mathrm{H}_{2}$ and $\mathrm{CO}$ are formed. Carbon dioxide 
was also formed in the oxidation zone, but additional amounts were formed in some cases downstream from the WGS reaction. Additionally, the results suggested that $\mathrm{CO}_{2}$ reforming did not occur and was therefore not considered part of their mechanism. Instead, unconverted methane reacts with steam in the feed and steam formed in the oxidation region at the inlet. The following figure from one of these investigations [33] provides the composition and temperature profiles for one of the conditions reported.

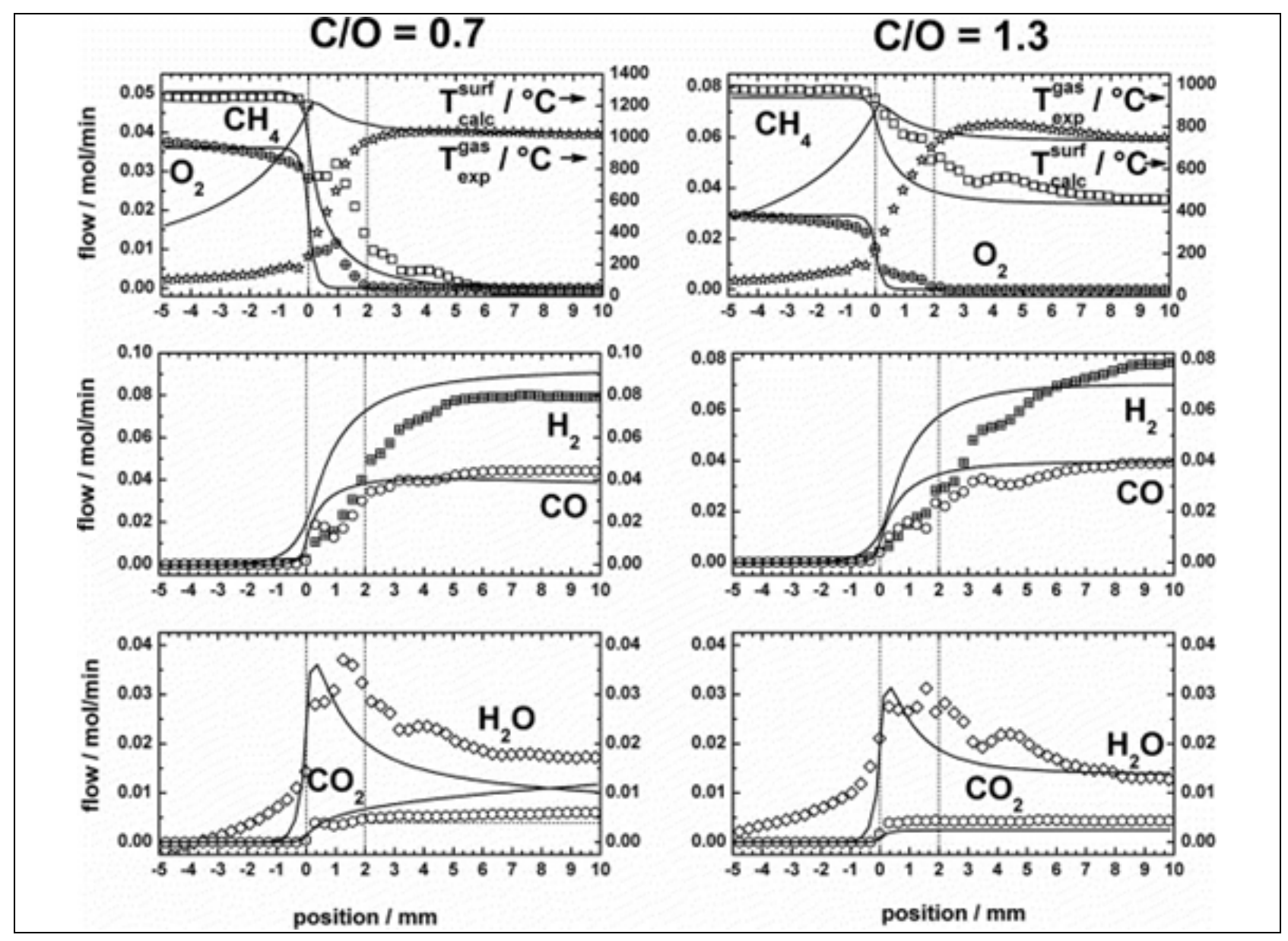

Figure 1-9. Species and temperature profiles for CPOX of methane at different $\mathrm{C} / \mathrm{O}$ ratios [33].

\subsection{Effect of space velocity}

Typically, increasing space velocity reduces conversion since the residence time decreases. In an exothermic reaction, like the oxidation of methane, increasing the space velocity should therefore decrease the amount of heat generated and consequently reduce the temperature spike at the front of the catalyst bed (Figure 1-10). Further, an increase in the flow of a lower temperature feed should decrease the temperature spike, especially in cases with heavy dilution. As stated earlier, the difference in gas feed temperature could have a significant effect on the catalyst surface temperature. However, there appears to be some inconsistencies surrounding these trends in the literature. 


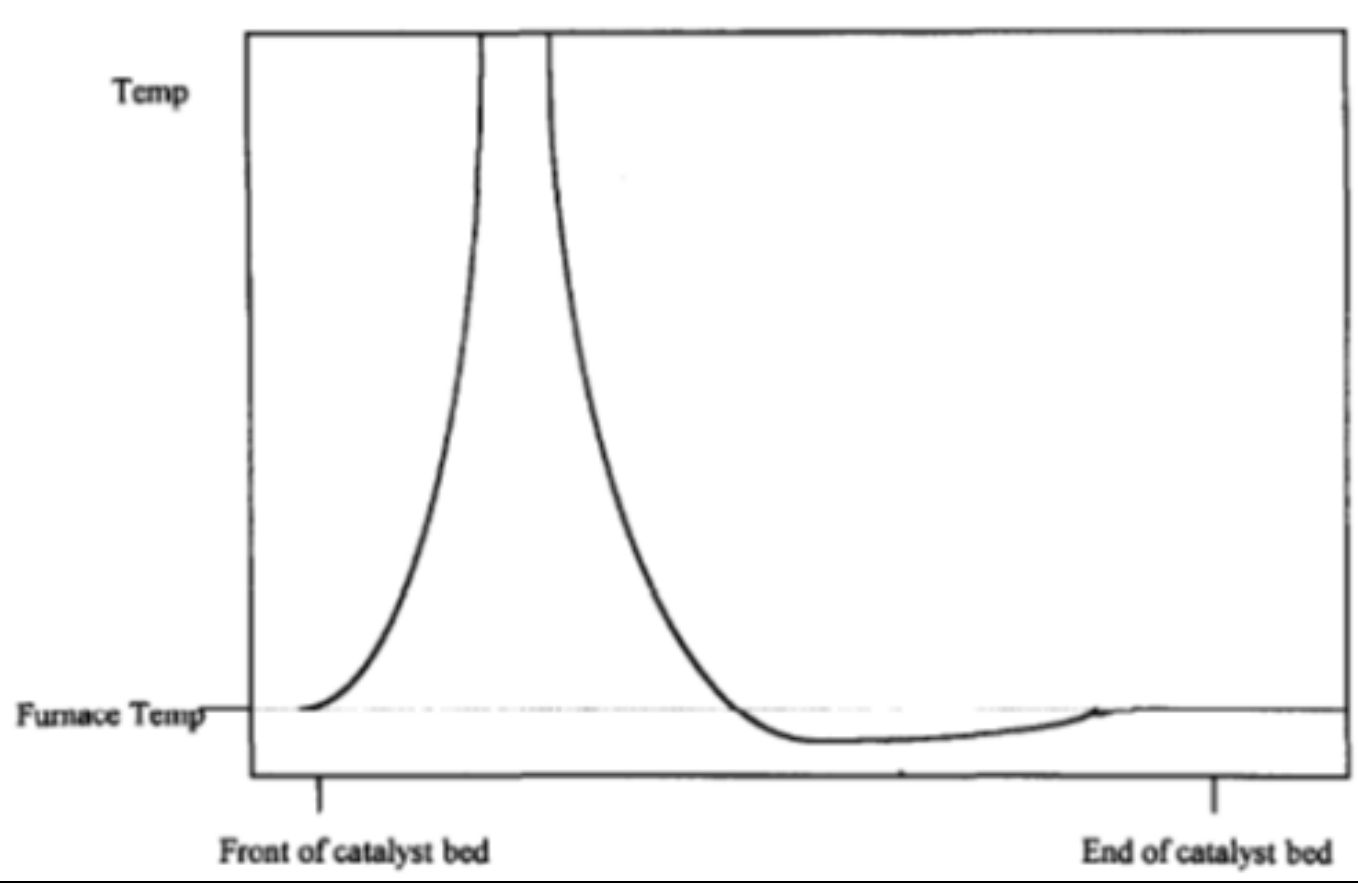

Figure 1-10. Schematic representation of the temperature profile in a CPOX reactor $[3,15,40]$.

It has been reported that increasing the space velocity increases the conversion of methane under partial oxidation conditions and also increases the temperature spike at the front of the catalyst bed. For example, Figure 1-11 shows the measured gas phase temperature of a study conducted by Enger et al. using a Ni-based catalyst [41]. It is clear that the increased space velocity resulted in a higher temperature spike at the front of the reactor bed. The temperature spike occurring before the beginning of the bed was explained by the potential presence of catalyst fine particles in the "inert" portion of the bed, which likely occurred during loading of the reactor.

This phenomenon is also reported by Tsang et al. [3]. Here the catalyst was $\mathrm{Ni} / \mathrm{MgO}$, and the space velocity is reported from $0-900,000 \mathrm{ml} / \mathrm{g} / \mathrm{h}$. The furnace around the reactor was set at 973 $\mathrm{K}$, and the highest measured temperature in the catalyst bed approached $1300 \mathrm{~K}$ at the highest space velocity tested.

It should be considered that the expectation of a decreased conversion with higher space velocity may be assuming a specific mechanism, which if not representative of what is actually taking place, may alter the response of the system to different conditions. It must also be assumed that the starting gas velocities are already beyond the flow regime where mass and heat transfer limitations are significant. It is possible, therefore, that reports of increasing conversion with increasing space velocity indicates that the initial flows were not high enough to overcome diffusion and heat transfer resistance. It may also indicate the presence of two zones in the catalyst bed where different reactions dominate, as in the indirect mechanism. In this case, an increase in flow may result in a decrease in the initial conversion of methane at the front of the bed but increased heat transfer at the end of the bed where secondary reforming reactions occur, leading to an overall increase in methane conversion from steam and $\mathrm{CO}_{2}$ reforming. 


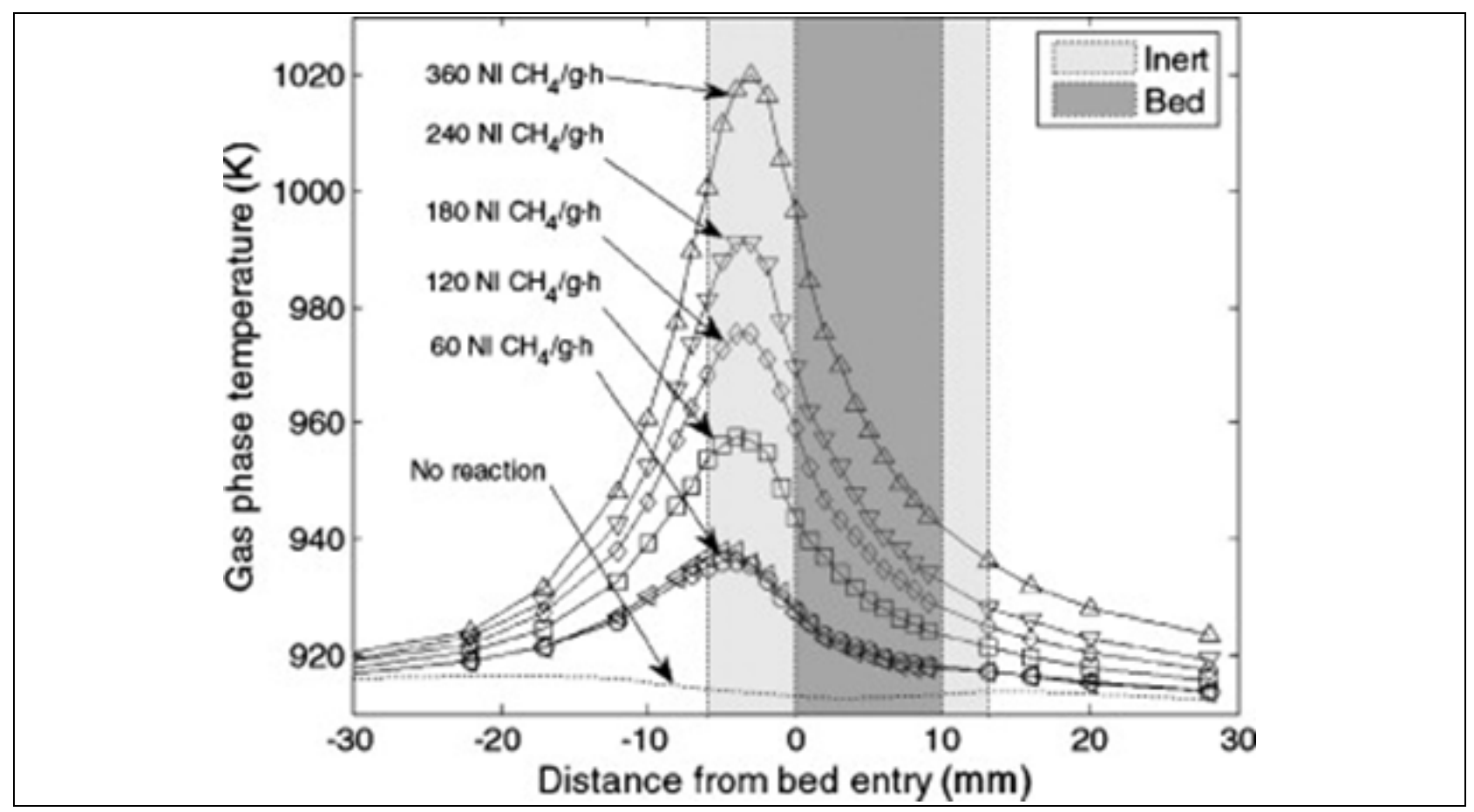

Figure 1-11. Position of temperature spike in reactor bed for $\mathrm{CPOX}$ of $\mathrm{CH} 4$ on $\mathrm{Ni} / \alpha-\mathrm{Al}_{2} \mathrm{O}_{3}[41]$.

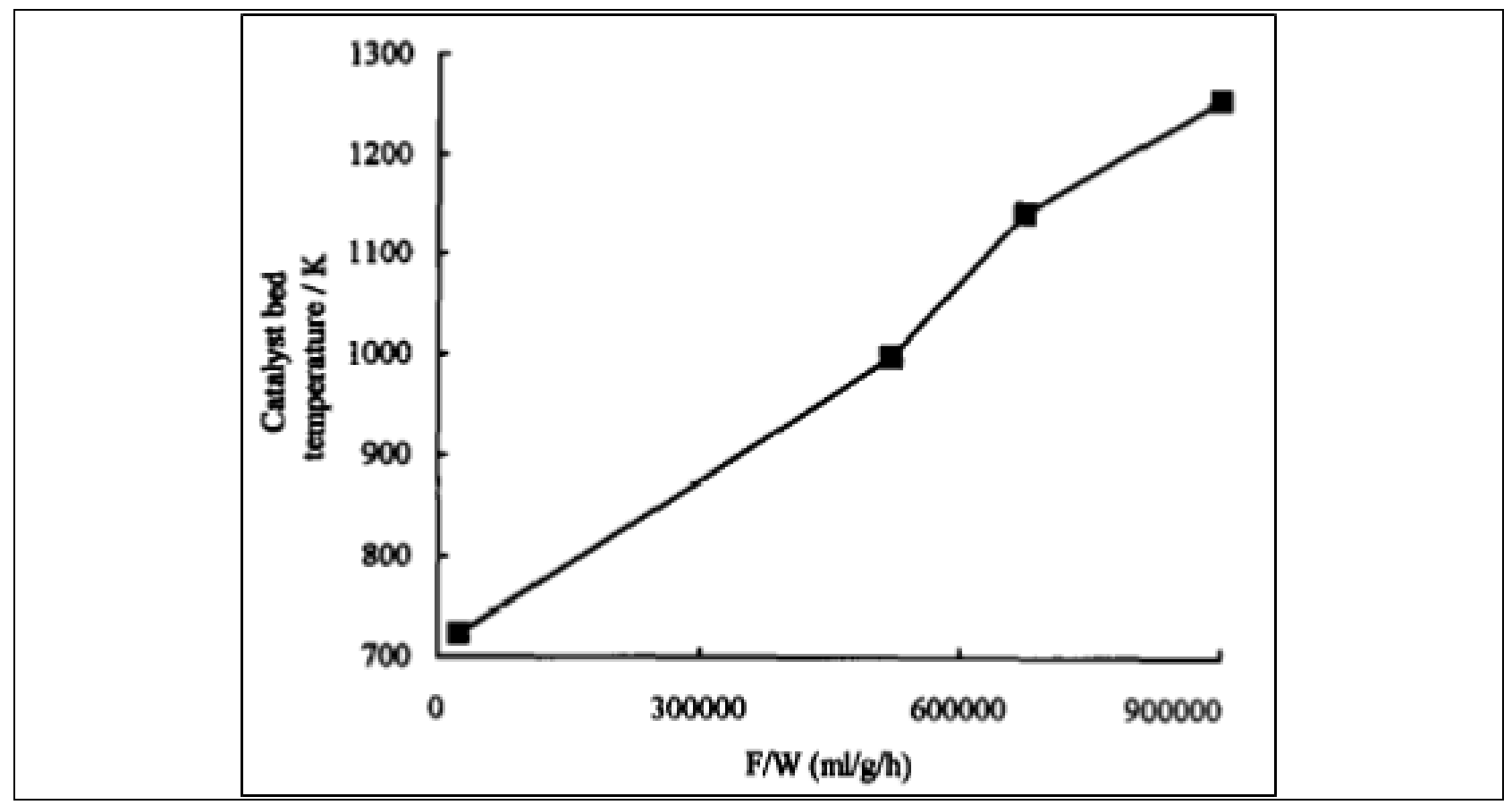

Figure 1-12. Effect of flow-rate on catalyst-bed temperature using $\mathrm{Ni} / \mathrm{MgO}(\mathrm{Ni} / \mathrm{Mg}=3)$ catalysts. Furnace temperature $=723 \mathrm{~K}, \mathrm{CH}_{4} / \mathrm{O}_{2}=2[3]$.

As discussed in Section 1.2.2, the catalyst will determine which mechanism dominates and, as a result, can potentially yield apparently contradictory results under similar conditions. Figure 1-13 provides an example of how this can occur. In their review of CPOX literature, Bharadwaj and Schmidt [2] generated this figure from three different studies for comparison. Three different catalysts are represented: $\mathrm{Ni}, \mathrm{Ru}$, and $\mathrm{Pt}$. For the $\mathrm{Ni}$ and $\mathrm{Ru}$ catalysts, the trend expected for 
increasing space velocity is observed-methane conversion decreases. This figure also shows that $\mathrm{CO}$ selectivity decreases with increasing space velocity for these catalysts. However, for the Pt catalyst reported by Hickman et al. [10], there is a steady increase in methane conversion and an increase followed by a leveling off of CO selectivity as space velocity increases. It should be noted that the range of space velocity studied for the Pt catalyst is relatively narrow. It may be expected that, if the Pt catalyst were to be tested at higher space velocities, it too would begin to yield a decrease in methane conversion and a concomitant drop in CO selectivity.

It would be impossible to draw any conclusions from the data in Figure 1-13 without closely examining the operating conditions associated with each study. For example, the studies conducted on the Ru and Ni catalyst had an $\mathrm{O} / \mathrm{C}$ ratio in the feed of 1.0 and 1.12, respectively, while the study conducted with the Pt catalyst had an O/C ratio of 2.22. This alone may explain the observed difference. Further, the Ni and Ru catalyst studies were conducted at similar temperatures, 800 and $777^{\circ} \mathrm{C}$, respectively. The Pt catalyst was tested at $1227^{\circ} \mathrm{C}$. Therefore, even at lower temperatures, the excess oxygen present for the $\mathrm{Ni}$ and $\mathrm{Ru}$ catalysts will result in a higher yield of combustion products $\left(\mathrm{CO}_{2}\right.$ and $\left.\mathrm{H}_{2} \mathrm{O}\right)$ corresponding to lower $\mathrm{CO}$ selectivity. For the Pt catalyst, the inlet oxygen concentration is sub-stoichiometric, which produces less combustion products even as the methane conversion increases. Also, at the higher temperatures, the exothermic WGS reaction will be suppressed.

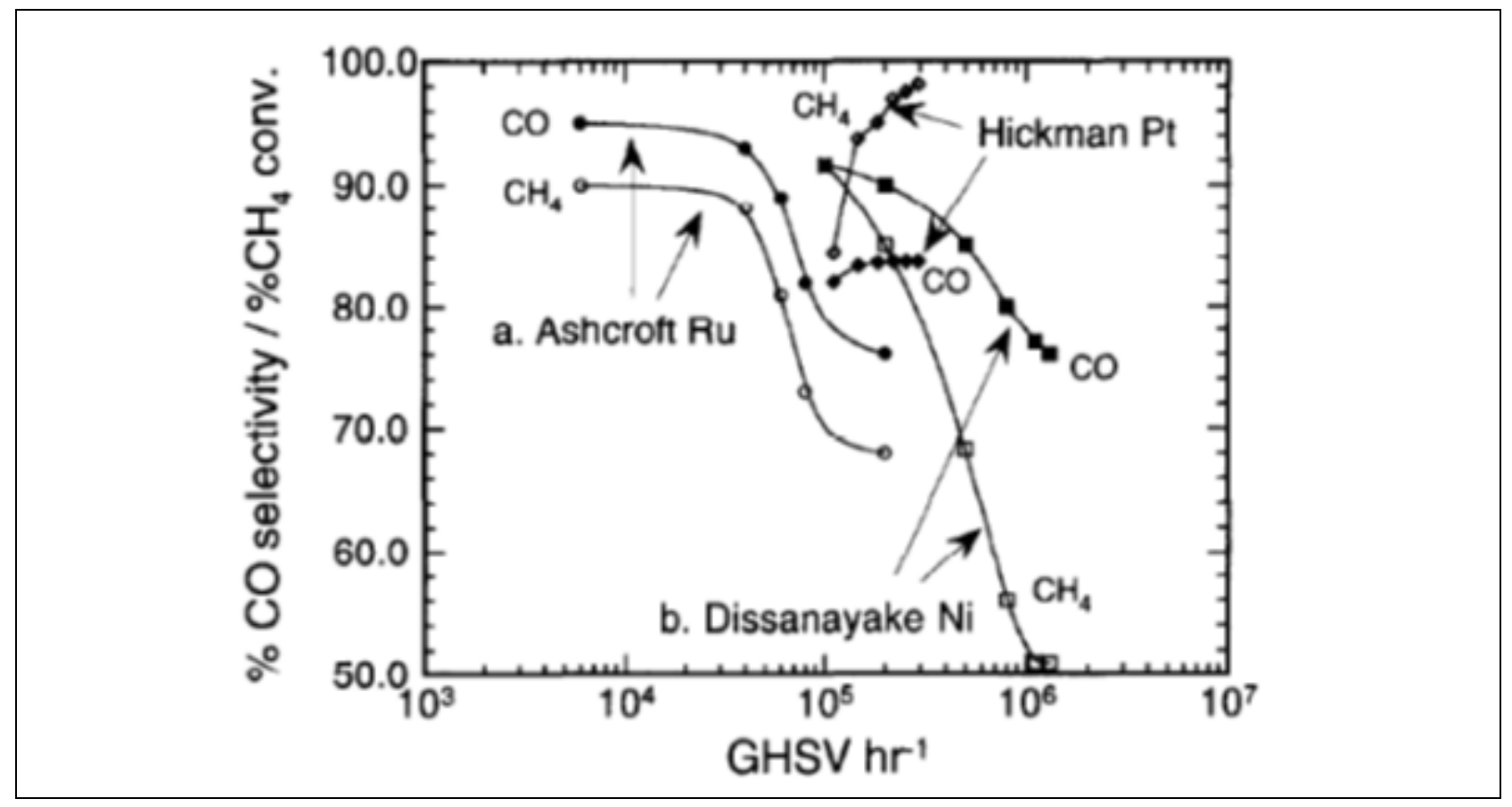

Figure 1-13. Plot of the effect of gas hourly space velocity (GHSV) on $\mathrm{CO}$ selectivity and $\mathrm{CH}_{4}$ conversion. Figure generated by Bharadwaj and Schmidt [2] with data from (a) Aschroft et al. [42], (b) Dissanayake et al. [15], (c) Hickman et al. [10].

\subsection{Effect of catalyst oxidation state}

When conducting mechanistic studies for the CPOX of methane, many factors can produce apparently contradicting results. However, the feed conditions, the metal type, and the nature of the catalyst surface, as well as the catalyst-surface interactions, should be carefully considered. It is likely under typical operating conditions both mechanisms may be present, at least for some 
period of time. While the catalyst may initially produce syngas via the direct mechanism, as the catalyst changes over time, the indirect mechanism may emerge. Indeed, it is not a question of which mechanism is at work, but which mechanism dominates, and for how long.

Boucouvalas et al. reported a direct mechanism for a Ru catalyst supported on titanium oxide, $\mathrm{Ru} / \mathrm{TiO}_{2}$ [43]. This catalyst was compared to Ni, Rh, Pd, Ir, and Ru catalysts supported on alumina. Low methane conversions (oxygen conversion $<100 \%$ ) produced a minimal rate of reforming reactions due to oxidized or partially oxidized metal surfaces and produced synthesis gas primarily by the direct mechanism. It was found that, as methane conversion increased, the formation of $\mathrm{H}_{2} \mathrm{O}$ and $\mathrm{CO}_{2}$ increased, leading to an increase in reforming reactions. The aluminasupported catalysts produced syngas via the indirect mechanism due to the oxidation of the metal surfaces. However, the $\mathrm{Ru} / \mathrm{TiO}_{2}$ catalyst maintained high $\mathrm{CO}$ selectivity even at lower methane conversions, suggesting that the direct mechanism could still dominate. The ability of $\mathrm{Ru} / \mathrm{TiO}$ to maintain a reduced surface under oxidizing conditions was determined to promote the direct mechanism. Isotopic labeling experiments estimated that the total CO produced by steam and $\mathrm{CO}_{2}$ reforming (indirect mechanism) was less than $8 \%$ of the total CO produced. The interaction of the $\mathrm{Ru}$ with the $\mathrm{TiO}_{2}$ support was believed to produce a different type of surface state, which was not able to be fully characterized.

Another example of the effect of metal oxidation state can be found in a study by Rabe et al. [44]. This work also examined Ru catalyst and used pulses of $\mathrm{CH}_{4} / \mathrm{O}_{2}$ and measured the products. The results of this study are presented in Figure 1-14 and indicate that, for the partially oxidized surface, $\mathrm{CO}_{2}$ was the primary product and that, as the Ru became more reduced with the higher number of pulses, CO became the primary product. This supports again that an oxidized catalyst promotes the indirect mechanism.

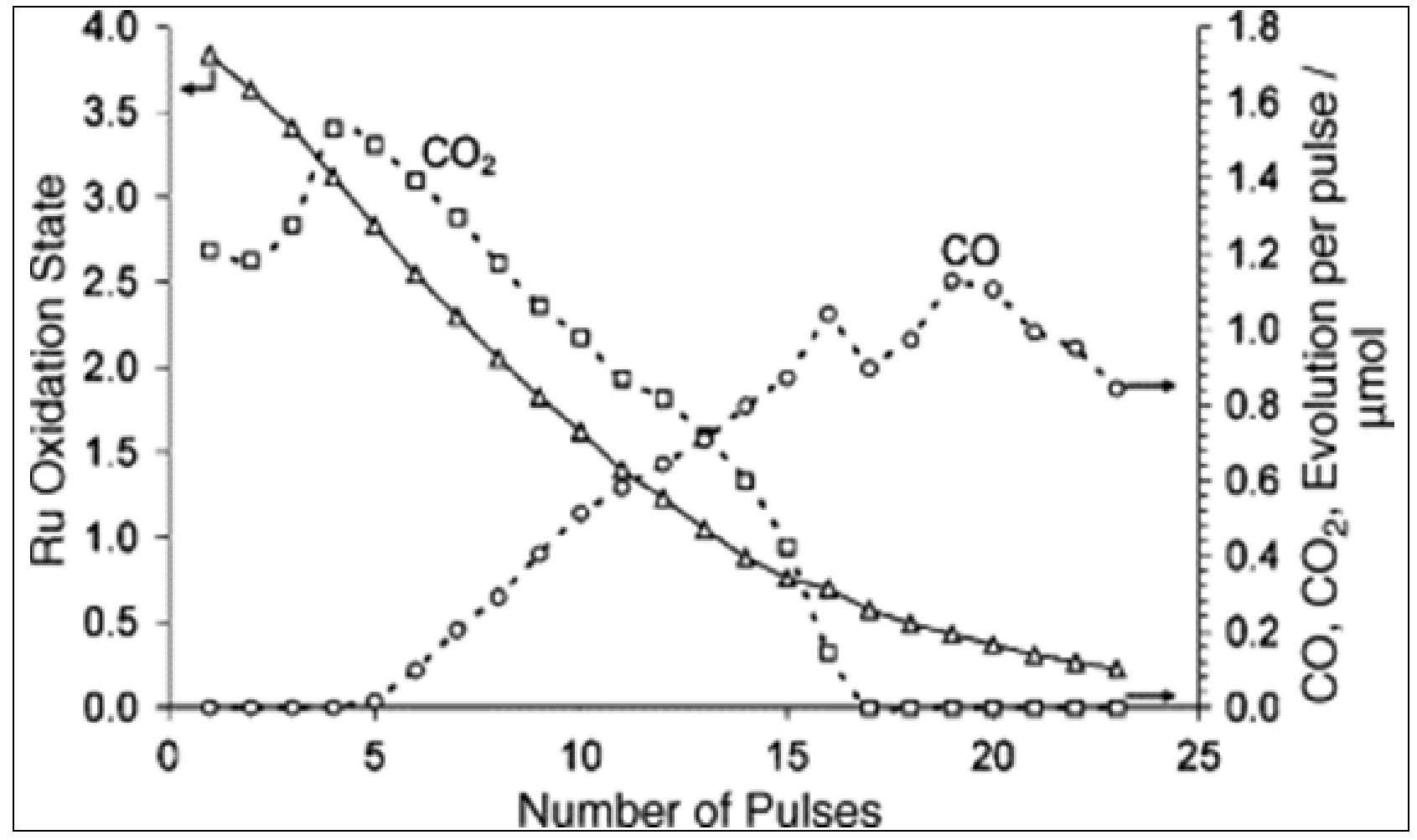

Figure 1-14. Effect of metal oxidation state on reaction mechanism $[44,45]$. 


\subsubsection{Kinetic studies}

Kinetic studies for the CPOX of methane are very difficult for many of the same reasons as mechanistic studies. First, an appropriate mechanism must be selected. Because the reactions occur very rapidly, mass transfer limitations may dominate. These limitations can make kinetic measurements inaccurate. Further, erroneous results can be obtained from the presence of hot spots, heat transfer limitations, surface coverage, and oxidation state of the active surface. Factors that contribute most to hot spots include contact time, solid dilution, gas dilution, and metal loading. Different approaches to overcome these challenges include the use of high space velocities, dilute feed streams, and dilute or low-coverage catalysts, all of which have undesired consequences for industrial applications.

Kinetic studies have been conducted with the goal of analyzing both direct and indirect reaction mechanisms. Boucouvalas et al. examined the direct reaction mechanism with $\mathrm{Ru} / \mathrm{TiO}_{2}$ catalyst [43]. The effects of heat and mass transfer limitations were first studied over Rh catalysts since $\mathrm{Rh}$ is most active for methane CPOX. An additional concern identified in this study was the difference in temperature between the catalyst surface and the temperature measured in the gas stream. This difference was reported to be as high as $300^{\circ} \mathrm{C}$ [15].

Boucouvalas et al. also discussed the challenges encountered by increasing the space velocity in the reactor. While high space velocities can be used to overcome mass transfer limitations, they can contribute to an increase in the temperature spike at the front of the catalyst bed. To avoid this, both the reactant mixture and catalyst bed were diluted to operate in the kinetic regime.

$\mathrm{Hu}$ and Ruckenstein conducted transient kinetic studies for methane CPOX over $\mathrm{Ni} / \mathrm{La}_{2} \mathrm{O}_{3}$ catalyst [20]. As shown in Table 1-3 their results supported the direct mechanism. The kinetic studies were conducted at low temperatures $\left(450-700^{\circ} \mathrm{C}\right)$ and atmospheric pressure, using pulsetransient analysis. The rate-controlling step was found to be the reaction between surface carbon species and surface oxygen species. This was supported by the fact that the formation of these species and the desorption of $\mathrm{CO}$ were much faster than the formation of $\mathrm{CO}$. Theoretical values for the activation energy for methane decomposition and oxidation of carbon on a $\mathrm{Ni}$ (111) surface also confirmed this as the limiting step. Further, it was shown that as the number of pulses increased, the CO selectivity decreased due to the oxidation of the catalyst. Overall, the methane conversion is dependent on its rate of dissociation, and CO selectivity was dependent on the binding strength of the oxygen species to the metal surface (i.e., strong binding produced higher CO selectivities).

A kinetic study over $\mathrm{Ni} / \mathrm{La}_{2} \mathrm{O}_{3}$ catalyst was conducted by Tsipouriari and Verykios [46]. Their findings suggested the indirect mechanism, although they did concede that $\mathrm{CO}$ could be formed by the direct mechanism at low oxygen concentration, depending on the oxidation state of the $\mathrm{Ni}$ crystallites. Both the decomposition of methane and reaction of adsorbed $\mathrm{C}$ and $\mathrm{O}$ to form $\mathrm{CO}$ were identified as the rate determining steps. A mechanism is provided for the formation of $\mathrm{CO}_{2}$ from adsorbed CO, which is assumed to precede later reforming reactions. Table 1-6 presents the mechanism proposed in their study.

In their experiments, methane and oxygen conversions were less than $10 \%$. The main conclusions of this study were that the oxygen partial pressure strongly affected the rate of reaction, while the partial pressure of methane did not. Also, it was determined that direct oxidation occurs at low oxygen partial pressures under specific conditions. However, under 
typical oxygen partial pressure, the Ni catalyst will be oxidized, which is active for combustion of methane to $\mathrm{CO}_{2}$. Based on this mechanism, the following rate expression was developed:

$$
R=\frac{k_{1} K_{2} k_{3} P_{C H 4} P_{O 2}}{\left(k_{1} K_{2} P_{C H 4} P_{O 2}+k_{1} P_{C H 4}+K_{2} k_{3} P_{O 2}\right)}
$$

This kinetic model predicted well the kinetics for the indirect mechanism and was in good agreement with the experimental data.

Table 1-6. Reaction mechanism steps for kinetic study [46].

\begin{tabular}{|l|c|c|}
\hline Reaction & Reaction Rate & Step \\
\hline $\mathrm{CH}_{4}+*_{1} \rightarrow$ intermediate $1 \rightarrow \mathrm{C}-*_{1}+4 \mathrm{H}-*_{1}$ & RDS & 1 \\
\hline $\mathrm{O}_{2}+*_{2} \rightleftarrows \mathrm{O}_{2}-*_{2}$ & Equilibrium & 2 \\
\hline $\mathrm{O}_{2}-*_{2}+*_{2} \rightarrow 2 \mathrm{O}-*_{2}$ & Fast & 3 \\
\hline $\mathrm{C}-*_{1}+\mathrm{O}-*_{2} \rightarrow \mathrm{CO}-*_{1}+*_{2}$ & RDS & 4 \\
\hline $\mathrm{CO}-*_{1}+\mathrm{O}-*_{2} \rightarrow \mathrm{CO}_{2}+*_{1}+*_{2}$ & Fast & 5 \\
\hline $\mathrm{H}-*_{1}+\mathrm{O}-*_{2} \rightarrow \mathrm{OH}_{2} *_{1}+*_{2}$ & Very Fast & 6 \\
\hline $\mathrm{OH}-*_{1}+\mathrm{H}-*_{1} \rightarrow \mathrm{H}_{2} \mathrm{O}+2 *_{1}$ & Very Fast & 7 \\
\hline & & \\
\hline
\end{tabular}

Another kinetic study was conducted using a $1.4 \mathrm{wt} \% \mathrm{Pt} / \mathrm{Pr}_{0.3} \mathrm{Ce}_{0.35} \mathrm{Zr}_{0.35} \mathrm{O}_{\mathrm{x}} / \alpha-\mathrm{Al}_{2} \mathrm{O}_{3}$ catalyst by Gubanova et al. [47]. The mechanism was a sequence initially used in similar studies by de Smet et al. [48] and includes steps for reversible oxygen adsorption, carbon species oxidation, and $\mathrm{CO}_{2}$ formation. Table 1-7 provides the modified reaction sequence used to compare to experimental data. The kinetic model developed matched the experimental results for $\mathrm{H}_{2}$ formation well; however, the mechanism for $\mathrm{H}_{2}$ formation was not clear. Instead of being produced by methane decomposition, reforming reactions, or WGS, it appeared to be formed by the dissociation of water. This mechanism for $\mathrm{H}_{2}$ formation is not typically associated with CPOX.

Table 1-8 presents a reaction scheme and rate expressions for the same study [47]. It incorporates the formation of $\mathrm{H}_{2}$ by the coupling of surface hydrogen species (Step 6a) from the dissociation of methane (Step 2). This scheme also presents the step for $\mathrm{H}_{2}$ formation from the dissociation of water (Step 7b). The model demonstrated good agreement with experimental data. The most significant conclusion of this paper had to do with the role of the ceria support in the kinetic rates. The kinetic model considers $\mathrm{CO}_{2}$ reforming, since ceria catalyzes $\mathrm{CO}_{2}$ dissociation, and suggests this as a parallel reaction pathway not present in other data presented in literature for a Pt gauze catalyst.

One final example of kinetic model development is by de Groote et al. [49]. This study examined methane CPOX over a Ni catalyst. It compared a varying degree of reduction (VDR) model to a 
bivalent (BV) catalyst model and included the effects of co-feeding $\mathrm{CO}_{2}$ and steam. The indirect mechanism was assumed, and the reaction steps are provided in Table 1-9. The methane steam reforming and $\mathrm{CO}_{2}$ reforming reactions are shown in Steps 2 and 5, respectively. The kinetic equations for these steps are provided in Table 1-10. The model was used to compare two states of the Ni catalyst. The first was the VDR-model, and the second was the BV-model catalyst. The results of these simulations were compared to typical values in an industrial autothermal reformer, and both models were found to be in good agreement with observed data. It was concluded, therefore, that the calculated equilibrium values were accurate. The significant difference between the two models was identified as their predicted temperatures, which were higher for the VDR-model. The significance of this finding is the effect of temperature on the $\mathrm{Ni}$ catalyst sites.

Table 1-7. POM reaction scheme over supported Pt adapted from de Smet et al. to account for the reversible oxygen adsorption, carbon species oxidation and $\mathrm{CO}_{2}$ formation $[47,48]$.

\begin{tabular}{|c|c|c|c|c|}
\hline Reaction & $\begin{array}{c}A \text { or } S^{0} \\
\left(\operatorname{Pa}^{-1} S^{-1} \text { or } S^{-1}\right)\end{array}$ & $\begin{array}{c}E_{\text {act }} \\
\left(\mathrm{kJ} \mathrm{mol}^{-1}\right)\end{array}$ & Rate Equation & Step \\
\hline $\mathrm{O}_{2(\mathrm{~g})}+2 * \rightarrow 2 \mathrm{O}^{*}$ & 0.11 & 0 & $\mathrm{k}_{1 \mathrm{a}} \mathrm{P}_{\mathrm{O} 2} \theta_{\mathrm{k}}$ & $1 \mathrm{a}$ \\
\hline $2 \mathrm{O}^{*} \rightarrow \mathrm{O}_{2(\mathrm{~g})}+2^{*}$ & $1.7 \times 10^{13}$ & 200 & $\mathrm{k}_{1 \mathrm{~b}} \theta_{\mathrm{O}}^{2}$ & $1 b$ \\
\hline $\mathrm{CH}_{4(\mathrm{~g})}+2 \mathrm{O}^{*} \rightarrow \mathrm{C}^{*}+2 \mathrm{H}_{2} \mathrm{O}_{(\mathrm{g})}+*$ & $2.4 \times 10^{5}$ & 48.2 & $\mathrm{k}_{2} \mathrm{P}_{\mathrm{CH} 4} \theta_{\mathrm{O}}^{2}$ & 2 \\
\hline $\mathrm{C}^{*}+\mathrm{O}^{*} \rightarrow \mathrm{CO}^{*}+*$ & $1.0 \times 10^{13}$ & 62.8 & $\mathrm{k}_{3 \mathrm{a}} \theta_{\mathrm{C}} \theta_{\mathrm{O}}$ & 3a \\
\hline $\mathrm{CO}^{*}+* \rightarrow \mathrm{C}^{*}+\mathrm{O}^{*}$ & $1.0 \times 10^{11}$ & 184 & $\mathrm{k}_{3 \mathrm{~b}} \theta_{\mathrm{CO}} \theta^{*}$ & $3 b$ \\
\hline $\mathrm{CO}^{*}+\mathrm{O}^{*} \rightarrow \mathrm{CO}_{2(\mathrm{~g})}+2^{*}$ & $1.9 \times 10^{9}$ & 30 & $\mathrm{k}_{4 \mathrm{a}} \theta_{\mathrm{CO}} \theta_{\mathrm{O}}$ & $4 a$ \\
\hline $\mathrm{CO}_{2(\mathrm{~g})}+2^{*} \rightarrow \mathrm{CO}^{*}+\mathrm{O}^{*}$ & $6.3 \times 10^{2}$ & 28 & $\mathrm{k}_{4 \mathrm{~b}} \mathrm{P}_{\mathrm{CO} 2} \theta^{2} *$ & $4 \mathrm{~b}$ \\
\hline $\mathrm{CO}^{*} \rightarrow \mathrm{CO}_{(\mathrm{g})}+*$ & $1.0 \times 10^{13}$ & 126 & $\mathrm{k}_{5 \mathrm{a}} \theta_{\mathrm{CO}}$ & $5 a$ \\
\hline $\mathrm{CO}_{(\mathrm{g})}+* \rightarrow \mathrm{CO}^{*}$ & 0.84 & 0 & $\mathrm{k}_{5 \mathrm{~b}} \mathrm{P}_{\mathrm{CO}} \theta^{*}$ & $5 b$ \\
\hline
\end{tabular}

* Denotes a Pt active site or a site located on the ceria, $\mathrm{k}_{\mathrm{x}}$ denotes the term $\mathrm{A}_{\mathrm{x}} \exp \left(-\mathrm{E}_{\mathrm{act}, \mathrm{x}} / \mathrm{RT}\right)$ or $\mathrm{S}_{\mathrm{x}}^{0} \exp \left(-\mathrm{E}_{\mathrm{act}, \mathrm{x}} / \mathrm{RT}\right)$, respectively. 
Table 1-8. POM reaction scheme over supported Pt proposed in this study accounting for $\mathrm{H}_{2}$ production $[47,48]$.

\begin{tabular}{|c|c|c|c|c|}
\hline Reaction & $\begin{array}{c}A \text { or } S^{0} \\
\left(P^{-1} S^{-1} \text { or } S^{-1}\right)\end{array}$ & $\begin{array}{c}E_{\text {act }} \\
\left(\mathrm{kJ} \mathrm{mol}^{-1}\right)\end{array}$ & Rate Equation & Step \\
\hline $\mathrm{O}_{2(\mathrm{~g})}+2 * \rightarrow 2 \mathrm{O}^{*}$ & 0.68 & 0 & $\mathrm{k}_{1 \mathrm{a}} \mathrm{P}_{\mathrm{O} 2} \theta_{\mathrm{k}}^{2}$ & $1 \mathrm{a}$ \\
\hline $2 \mathrm{O}^{*} \rightarrow \mathrm{O}_{2(\mathrm{~g})}+2^{*}$ & $1.0 \times 10^{14}$ & 200 & $\mathrm{k}_{1 \mathrm{~b}} \theta_{\mathrm{O}}^{2}$ & $1 \mathrm{~b}$ \\
\hline $\mathrm{CH}_{4(\mathrm{~g})}+5^{*} \rightarrow \mathrm{C}^{*}+4 \mathrm{H}^{*}$ & $9.35 \times 10^{3}$ & 125.2 & $\mathrm{k}_{2} \mathrm{P}_{\mathrm{CH} 4} \theta_{\mathrm{O}}^{5}$ & 2 \\
\hline $\mathrm{C}^{*}+\mathrm{O}^{*} \rightarrow \mathrm{CO}^{*}+*$ & $1.0 \times 10^{13}$ & 62.8 & $\mathrm{k}_{3 \mathrm{a}} \theta_{\mathrm{C}} \theta_{\mathrm{O}}$ & За \\
\hline $\mathrm{CO}^{*}+* \rightarrow \mathrm{C}^{*}+\mathrm{O}^{*}$ & $1.0 \times 10^{11}$ & 184 & $\mathrm{k}_{3 \mathrm{~b}} \theta_{\mathrm{CO}} \theta^{*}$ & $3 b$ \\
\hline $\mathrm{CO}^{*}+\mathrm{O}^{*} \rightarrow \mathrm{CO}_{2(\mathrm{~g})}+2^{*}$ & $3.2 \times 10^{13}$ & 37.4 & $\mathrm{k}_{4 \mathrm{a}} \theta_{\mathrm{CO}} \theta_{\mathrm{O}}$ & $4 a$ \\
\hline $\mathrm{CO}_{2(\mathrm{~g})}+2^{*} \rightarrow \mathrm{CO}^{*}+\mathrm{O}^{*}$ & $9.9 \times 10^{3}$ & 10 & $\mathrm{k}_{4 \mathrm{~b}} \mathrm{P}_{\mathrm{CO} 2} \theta^{2 *}$ & $4 \mathrm{~b}$ \\
\hline $\mathrm{CO}^{*} \rightarrow \mathrm{CO}_{(\mathrm{g})}+*$ & $1.0 \times 10^{13}$ & 126 & $\mathrm{k}_{5 \mathrm{a}} \theta_{\mathrm{CO}}$ & $5 a$ \\
\hline $\mathrm{CO}_{(\mathrm{g})}+* \rightarrow \mathrm{CO}^{*}$ & 0.71 & 0 & $\mathrm{k}_{5 \mathrm{~b}} \mathrm{P}_{\mathrm{CO}} \theta^{*}$ & $5 b$ \\
\hline $2 \mathrm{H}^{*} \rightarrow \mathrm{H}_{2(\mathrm{~g})}+2^{*}$ & $1.0 \times 10^{14}$ & 159.7 & $\mathrm{k}_{6 \mathrm{a}} \theta_{\mathrm{H}}^{2}$ & $6 a$ \\
\hline $\mathrm{H}_{2(\mathrm{~g})}+2^{*} \rightarrow 2 \mathrm{H}^{*}$ & 0.02 & 0 & $\mathrm{k}_{6 \mathrm{~b}} \mathrm{P}_{\mathrm{H} 2} \theta^{2} *$ & $6 b$ \\
\hline $2 \mathrm{H}^{*}+\mathrm{O}^{*} \rightarrow \mathrm{H}_{2} \mathrm{O}_{2(\mathrm{~g})}+3^{*}$ & $1.0 \times 10^{13}$ & 20 & $\mathrm{k}_{7 \mathrm{a}} \theta_{\mathrm{H}}^{2} \theta_{\mathrm{O}}$ & $7 a$ \\
\hline $\mathrm{H}_{2} \mathrm{O}_{2(\mathrm{~g})}+3^{*} \rightarrow 2 \mathrm{H}^{*}+\mathrm{O}^{*}$ & $1.0 \times 10^{6}$ & 69 & $\mathrm{k}_{7 \mathrm{~b}} \mathrm{P}_{\mathrm{H} 2 \mathrm{O}} \theta^{3 *}$ & $7 b$ \\
\hline
\end{tabular}

* Denotes a Pt active site or a site located on the ceria, see section 5, kx denotes the term $\mathrm{A}_{\mathrm{x}}$ exp $\left(-\mathrm{E}_{\mathrm{act}, \mathrm{x}} / \mathrm{RT}\right)$ or $\mathrm{S}_{\mathrm{x}}^{0} \exp \left(-\mathrm{E}_{\mathrm{act}, \mathrm{x}} / \mathrm{RT}\right)$, respectively. 
Table 1-9. Indirect reaction mechanism steps for kinetic study by de Groote et al. [49].

\begin{tabular}{|l|c|}
\hline \multicolumn{1}{|c|}{ Reaction } & Step \\
\hline $\mathrm{CH}_{4}+2 \mathrm{O}_{2} \rightleftharpoons \mathrm{CO}_{2}+2 \mathrm{H}_{2} \mathrm{O}$ & 1 \\
\hline $\mathrm{CH}_{4}+\mathrm{H}_{2} \mathrm{O} \rightleftharpoons \mathrm{CO}+3 \mathrm{H}_{2}$ & 2 \\
\hline $\mathrm{CH}_{4}+2 \mathrm{H}_{2} \mathrm{O} \rightleftharpoons \mathrm{CO}_{2}+4 \mathrm{H}_{2}$ & 3 \\
\hline $\mathrm{CO}+\mathrm{H}_{2} \mathrm{O} \rightleftharpoons \mathrm{CO}_{2}+\mathrm{H}_{2}$ & 4 \\
\hline $\mathrm{CH}_{4}+\mathrm{CO}_{2} \rightleftharpoons 2 \mathrm{CO}+2 \mathrm{H}_{2}$ & 5 \\
\hline $2 \mathrm{CO} \rightleftharpoons \mathrm{C}+\mathrm{CO}_{2}$ & 6 \\
\hline $\mathrm{CH} \rightleftharpoons \mathrm{C}+2 \mathrm{H}_{2}$ & 7 \\
\hline $\mathrm{C}+\mathrm{H}_{2} \mathrm{O} \rightleftharpoons \mathrm{CO}+\mathrm{H}_{2}$ & 8 \\
\hline
\end{tabular}

Table 1-10. Kinetic equations for study by de Groote et al. [49].

\begin{tabular}{|c|c|}
\hline Kinetic Equation & Step \\
\hline $\mathrm{r}_{1}=\frac{\mathrm{k}_{1}\left[\mathrm{CH}_{4}\right]\left[\mathrm{O}_{2}\right]}{\left(1+\mathrm{K}_{1}\left[\mathrm{CH}_{4}\right]+\mathrm{K}_{2}\left[\mathrm{O}_{2}\right]\right)^{2}}+\frac{\mathrm{k}_{2}\left[\mathrm{CH}_{4}\right]\left[\mathrm{O}_{2}\right]^{5}}{1+\mathrm{K}_{1}\left[\mathrm{CH}_{4}\right]+\mathrm{K}_{2}\left[\mathrm{O}_{2}\right]}$ & 1 \\
\hline $\mathrm{r}_{2}=\frac{\mathrm{k}_{3} / p_{\mathrm{H}_{2}}^{2.5}\left(\mathrm{p}_{\mathrm{CH}_{4}} \mathrm{p}_{\mathrm{H}_{2} \mathrm{O}}-\mathrm{p}_{\mathrm{H}_{2}}^{3} \mathrm{p}_{\mathrm{CO}} / \mathrm{K}_{3}\right)}{\left(1+\mathrm{K}_{\mathrm{CO}} \mathrm{p}_{\mathrm{CO}}+\mathrm{K}_{\mathrm{H}_{2}} \mathrm{p}_{\mathrm{H}_{2}}+\mathrm{K}_{\mathrm{CH}_{4}} \mathrm{p}_{\mathrm{CH}_{4}}+\mathrm{K}_{\mathrm{H}_{2} \mathrm{O}} \mathrm{p}_{\mathrm{H}_{2} \mathrm{O}} / \mathrm{p}_{\mathrm{H}_{2}}\right)^{2}}$ & 2 \\
\hline $\mathrm{r}_{3}=\frac{\mathrm{k}_{5} / p_{\mathrm{H}_{2}}^{3.5}\left(\mathrm{p}_{\mathrm{CH}_{4}} p_{\mathrm{H}_{2} \mathrm{O}}^{2}-\mathrm{p}_{\mathrm{H}_{2}}^{4} \mathrm{p}_{\mathrm{CO}_{2}} / \mathrm{K}_{5}\right)}{\left(1+\mathrm{K}_{\mathrm{CO}} \mathrm{p}_{\mathrm{CO}}+\mathrm{K}_{\mathrm{H}_{2}} \mathrm{p}_{\mathrm{H}_{2}}+\mathrm{K}_{\mathrm{CH}_{4}} \mathrm{p}_{\mathrm{CH}_{4}}+\mathrm{K}_{\mathrm{H}_{2} \mathrm{O}} \mathrm{p}_{\mathrm{H}_{2} \mathrm{O}} / \mathrm{p}_{\mathrm{H}_{2}}\right)^{2}}$ & 3 \\
\hline $\mathrm{r}_{4}=\frac{\mathrm{k}_{4} / \mathrm{p}_{\mathrm{H}_{2}}\left(\mathrm{p}_{\mathrm{CO}} \mathrm{p}_{\mathrm{H}_{2} \mathrm{O}}-\mathrm{p}_{\mathrm{H}_{2}} \mathrm{p}_{\left.\mathrm{CO}_{2} / \mathrm{K}_{4}\right)}\right.}{\left(1+\mathrm{K}_{\mathrm{CO}} \mathrm{p}_{\mathrm{CO}}+\mathrm{K}_{\mathrm{H}_{2}} \mathrm{p}_{\mathrm{H}_{2}}+\mathrm{K}_{\mathrm{CH}_{4}} \mathrm{p}_{\mathrm{CH}_{4}}+\mathrm{K}_{\mathrm{H}_{2} \mathrm{O}} \mathrm{p}_{\mathrm{H}_{2} \mathrm{O}} / \mathrm{p}_{\mathrm{H}_{2}}\right)^{2}}$ & 4 \\
\hline $\mathrm{r}_{5}=\frac{\mathrm{k}_{6} \mathrm{p}_{\mathrm{CO}}-\mathrm{k}_{7} \mathrm{p}_{\mathrm{CO}_{2}} / \mathrm{p}_{\mathrm{CO}}}{\left(1+\mathrm{K}_{\mathrm{O}} \mathrm{p}_{\mathrm{CO}_{2}} / \mathrm{p}_{\mathrm{CO}}\right)}$ & 5 \\
\hline $\mathrm{r}_{6}=\frac{\mathrm{k}_{8} \mathrm{p}_{\mathrm{CH}_{4}} / p_{\mathrm{H}_{2}}^{1.5}-\mathrm{k}_{9} p_{\mathrm{H}_{2}}^{5}}{\left(1+\mathrm{K}_{\mathrm{H}_{2}} \mathrm{p}_{\mathrm{H}_{2}}\right)^{2}}$ & 6 \\
\hline $\mathrm{r}_{7}=\frac{\mathrm{k}_{10} \mathrm{p}_{\mathrm{H}_{2} \mathrm{O}} / \mathrm{p}_{\mathrm{H}_{2}}}{\left(1+\mathrm{K}_{\mathrm{H}_{2}} \mathrm{p}_{\mathrm{H}_{2}}+\mathrm{K}_{\mathrm{w}} \mathrm{p}_{\mathrm{H}_{2} \mathrm{O}} / \mathrm{p}_{\mathrm{H}_{2}}\right)^{2}}$ & 7 \\
\hline $\mathrm{r}_{8}=f\left(\mathrm{p}_{\mathrm{O}_{2}}\right)$ & 8 \\
\hline
\end{tabular}




\subsubsection{Methane}

\subsubsection{Base Metal Catalysts}

The base metals that have been examined most for the CPOX of methane are $\mathrm{Ni}$, Co, and $\mathrm{Fe}$, and to a much lesser degree $\mathrm{Cu}$. Supported $\mathrm{Ni}$ has been used for decades in industrial methane steam reforming. These metal catalysts are attractive since they are significantly cheaper than noble metals; however, they have much lower activity and are more quickly deactivated by carbon formation, sulfur poisoning, and oxidation.

\subsection{Effect of modified alumina supports}

These metal catalysts are often supported on high surface area alumina supports to provide high levels of dispersion. Under the high temperature and highly oxidizing conditions of methane CPOX, catalytic activity can be lost by the vaporization of the active metal, agglomeration of metal sites into larger cluster, which reduces dispersion, and encapsulation of the metals in collapsed pores from support sintering. Additionally, the formation of inactive spinel crystal structures may occur $\left(\mathrm{NiAl}_{2} \mathrm{O}_{4}, \mathrm{CoAl}_{2} \mathrm{O}_{4}\right.$, and $\left.\mathrm{FeAl}_{2} \mathrm{O}_{4}\right)$. One approach to mitigate this issue is the addition of other metals to the surface of the alumina support to reduce sintering. For example, Ba and La have been added to alumina supports to retard the conversion of higher surface area $\gamma$-alumina to low surface area $\alpha$-alumina. La has also been shown to slow down the incorporation of the $\mathrm{Ni}, \mathrm{Co}$, and $\mathrm{Fe}$ metals into the alumina support to form the spinel structure.

Table 1-11 provides the results of the temperature programmed reduction (TPR) study conducted by Slagtern et al. [50] for $\mathrm{Ni}, \mathrm{Co}$, and $\mathrm{Fe}$ catalysts on alumina with La. The reduction peak for $\mathrm{Ni}$ decreases from $770^{\circ} \mathrm{C}$ to $400^{\circ} \mathrm{C}$ when $\mathrm{La}$ is added; the peak at $995^{\circ} \mathrm{C}$ corresponds to reduction of the support. This result indicates that the Ni metal is more easily reduced when $\mathrm{La}$ is present, which would result in higher activity. The $\mathrm{Fe} / \mathrm{La} / \mathrm{Al}_{2} \mathrm{O}_{3}$ yielded four reduction peaks at 320, 505, 790 , and $930^{\circ} \mathrm{C}$, but was only $53 \%$ reducible. $\mathrm{Co} / \mathrm{La} / \mathrm{Al}_{2} \mathrm{O}_{3}$ yielded a single peak at $950^{\circ} \mathrm{C}$, and only $10 \%$ was reducible.

Table 1-11 also shows that $\mathrm{Ni} / \mathrm{La} / \mathrm{Al}_{2} \mathrm{O}_{3}$ had the highest $\mathrm{CO}$ selectivity at $45 \%$; however, this does not necessarily suggest overall better performance, since the overall conversion is not presented.

Table 1-11. 12 Results of TPR studies and $\mathrm{CO}$ selectivity data for $\mathrm{Ni}$, Co, and Fe catalysts over Lapromoted alumina supports [50].

\begin{tabular}{|l|c|c|c|c|}
\hline \multicolumn{1}{|c|}{ Catalyst } & $\begin{array}{c}\text { Temperature of } \\
\text { peak maxima }\left({ }^{\circ} \mathrm{C}\right)\end{array}$ & $\begin{array}{c}\text { Extent of } \\
\text { reduction from } \mathrm{H}_{2} \\
\text { consumption }(\%)\end{array}$ & $\begin{array}{c}\text { Temperature for } \\
\text { total oxidation } \\
\left({ }^{\circ} \mathrm{C}\right)\end{array}$ & $\begin{array}{c}\mathrm{CO} \\
\text { selectivity } \\
(\%)\end{array}$ \\
\hline $\mathrm{Ni} / \mathrm{Al}_{2} \mathrm{O}_{3}$ & 770 & $117^{\mathrm{a}}$ & 600 & 2 \\
\hline $\mathrm{Ni} / \mathrm{La} / \mathrm{Al}_{2} \mathrm{O}_{3}$ & 400,995 & $100^{\mathrm{a}}$ & 750 & 45 \\
\hline $\mathrm{Fe} / \mathrm{La} / \mathrm{Al}_{2} \mathrm{O}_{3}$ & $320,505,790,930$ & $53^{\mathrm{b}}$ & $750-850$ & $35-45$ \\
\hline $\mathrm{Co} / \mathrm{La} / \mathrm{Al}_{2} \mathrm{O}_{3}$ & 950 & $10^{\mathrm{c}}$ & 750 & 25 \\
\hline
\end{tabular}

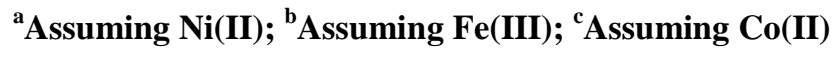


Slagtern et al. [50] also compared the $\mathrm{H}_{2} / \mathrm{CO}$ ratios obtained by these catalysts presented in Table 1-12. These results demonstrate that the $\mathrm{Co} / \mathrm{La} / \mathrm{Al}_{2} \mathrm{O}_{3}$ catalyst produced near equilibrium values as low as $700^{\circ} \mathrm{C}$, while the $\mathrm{Ni} / \mathrm{La} / \mathrm{Al}_{2} \mathrm{O}_{3}$ and $\mathrm{Fe} / \mathrm{La} / \mathrm{Al}_{2} \mathrm{O}_{3}$ catalyst produced no $\mathrm{H}_{2}$ until $900^{\circ} \mathrm{C}$. The $\mathrm{Ni} / \mathrm{Al}_{2} \mathrm{O}_{3}$ catalyst showed some activity at $700^{\circ} \mathrm{C}$ and yielded near equilibrium values at $900^{\circ} \mathrm{C}$. These results seem to be in conflict with the results from the TPR data, suggesting that reducibility is not a main indicator of performance for this catalyst system.

Table 1-12. $\mathrm{H}_{2} / \mathrm{CO}$ ratios for $\mathrm{Ni}$, Co, and Fe catalysts over La-promoted alumina supports [50].

\begin{tabular}{|c|c|c|c|c|c|}
\hline $\begin{array}{c}\text { Temperature } \\
\left({ }^{\circ} \mathrm{C}\right)\end{array}$ & Equilibrium & $\mathrm{Ni} / \mathrm{Al}_{2} \mathrm{O}_{3}$ & $\mathrm{Ni} / \mathrm{La} \mathrm{Al}_{2} \mathrm{O}_{3}$ & $\mathrm{Co} / \mathrm{La} / \mathrm{Al}_{2} \mathrm{O}_{3}$ & $\mathrm{Fe} / \mathrm{La} / \mathrm{Al}_{2} \mathrm{O}_{3}$ \\
\hline 600 & 2.7 & 0 & 0 & a & 0 \\
\hline 700 & 2.1 & 0.2 & 0 & 1.8 & 0 \\
\hline 800 & 2.0 & 1.0 & 0 & 2.0 & 0 \\
\hline 900 & 2.0 & 1.9 & 1.0 & 2.0 & 1.9 \\
\hline
\end{tabular}

\subsection{Effect of basic supports}

The effect of the catalyst support has been studied extensively for the CPOX of methane for all types of metal catalysts. For this discussion, Ni-based catalysts will be used as an illustration, although support effects are seen with all catalysts. Indeed, the proper selection of a catalyst support is as significant as the active metal. The support can provide the desired metal dispersion. It can also be susceptible to degradation under extreme reaction conditions. Further, as discussed in Section 1.2.2, the support can even play a role in the reaction mechanism by lowering the activation energy of adsorbed species (i.e., methane) and can enhance the participation of adsorbed surface or lattice oxygen in the overall mechanism.

To demonstrate this point, the effect of several oxide supports on Ni catalysts for the CPOX of methane was examined. A study presented by Tang et al. [51] compares Ni metal supported on $\mathrm{MgO}, \mathrm{CeO}_{2}$, and $\mathrm{CaO}$. Figure 1-15 presents the results of a temperature programmed oxidation (TPO) experiment on the Ni catalysts supported by the three different supports after methane decomposition. The Ni/MgO catalyst produced the least amount of $\mathrm{CO}_{2}$ during the TPO, indicating that it had the smallest amount of surface carbon species. The $\mathrm{Ni} / \mathrm{CeO}_{2}$ catalyst demonstrated the highest level of methane decomposition indicated by the highest amount of $\mathrm{CO}_{2}$ evolution. This catalyst also produced two different $\mathrm{CO}_{2}$ peaks, suggesting that carbon was present on two different types of surface sites. The first peak at $\sim 773 \mathrm{~K}$ is attributed to carbon adsorbed to the $\mathrm{Ni}$ sites. It is likely that methane decomposition also occurred on the $\mathrm{CeO}_{2}$ support, which produced the higher temperature peak. The $\mathrm{Ni} / \mathrm{CaO}$ produced a very small peak at $\sim 773 \mathrm{~K}$, but a larger peak above $900 \mathrm{~K}$ also from carbon adsorbed on the support.

\subsection{Effect of basic promoters}

The addition of promoter metals can directly alter the nature of the active metal site. This approach includes the addition of alkali earth metals to increase the basic nature of the catalyst surface. This approach can affect the bonding strength of carbon to the active site to mitigate 
coke formation by making them less acidic. This may extend the life of the catalyst; however, it is usually at the sacrifice of initial activity due to the covering of active sites.

An excellent example of the use of basic promoters is found in a study by Ma et al. [52]. Ni catalysts supported onto $\gamma$-alumina supports were promoted with rare earths and other basic metals. The nature of the Ni sites was altered as evidenced by the $\mathrm{H}_{2}$-TPR data presented in Figure $1-16$. The Ni metal without a promoter had a reduction peak around $650^{\circ} \mathrm{C}$. Promotion with $\mathrm{Na}, \mathrm{Cr}$, La, and Ce shifted the reduction peak to a lower temperature in all cases, with Ce giving the lowest temperature peak near $500^{\circ} \mathrm{C}$. The lower reduction temperature also indicates a reduction in the interaction of the Ni sites to the support.

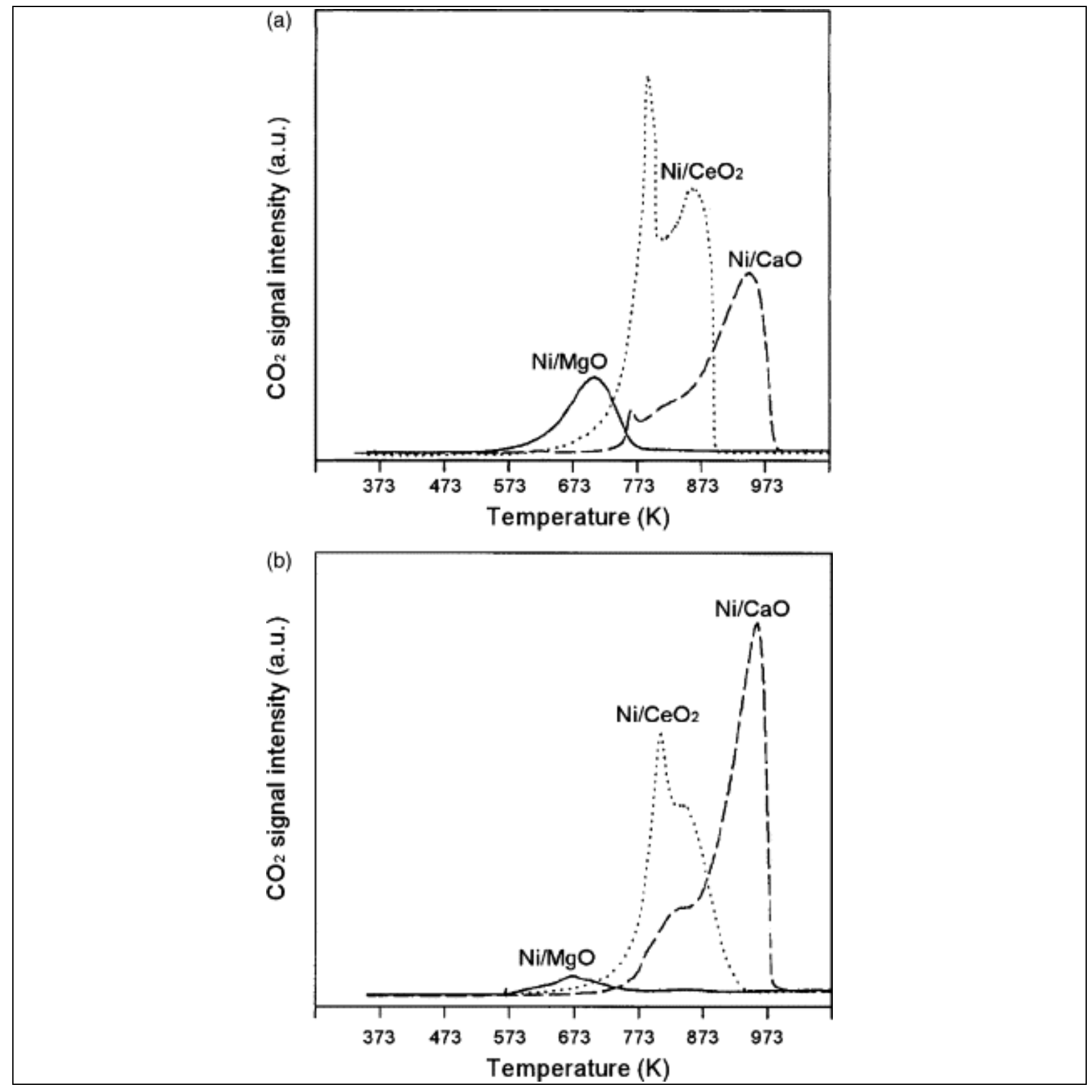

Figure 1-15. Effect of support on Ni reforming catalysts [51]. 


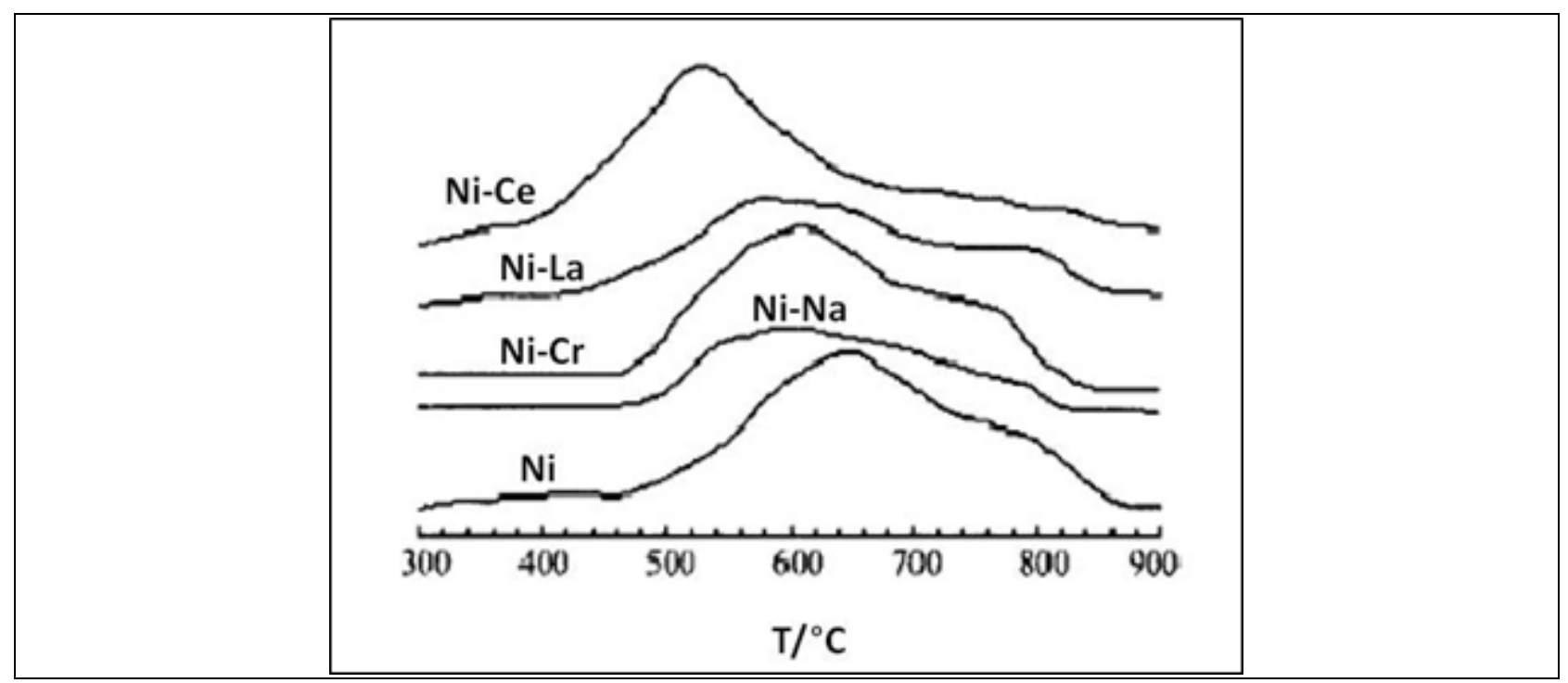

Figure 1-16. $\mathrm{H}_{2}$-TPR spectra of catalyst samples [52].

The performance data of the promoted Ni catalysts presented by Ma et al. [52] are summarized in Table 1-13. It is clear that the presence of the promoter improved conversion and $\mathrm{H}_{2}$ selectivity in all cases with only moderate improvement in CO selectivity. Also, the rate of the combustion reaction decreases significantly and is zero for the La and Ce promoted Ni catalysts. The increase in $\mathrm{H}_{2}$ selectivity can be attributed to the increase in the third reaction. The effect of the promoters can be attributed to a reduction in the interaction of the Ni sites to the alumina support, evidenced by the TPR results. This may be explained further by a reduction in the role of lattice oxygen from the support, which reduces the chance for over-oxidation, leading to combustion products. It must also be considered that the promoters reduced the bond strength of the adsorbed $\mathrm{H}_{2}$ and $\mathrm{CO}$ species, allowing them to desorb more rapidly, thus preventing oxidation to combustion products.

Table 1-13. Effect of basic promoters on CPOX of methane with $\mathrm{Ni} / \mathrm{Y}-\mathrm{Al}_{2} \mathrm{O}_{3}$ catalysts [52].

\begin{tabular}{|c|c|c|c|c|c|c|}
\hline Promoter & $\begin{array}{c}\mathbf{X}_{\mathbf{C H} 4} \\
\mathbf{( \% )}\end{array}$ & $\begin{array}{c}\mathrm{S}_{\mathbf{H} 2} \\
\mathbf{( \% )}\end{array}$ & $\begin{array}{c}\mathbf{S}_{\mathrm{CO}} \\
\mathbf{( \% )}\end{array}$ & $\begin{array}{c}\mathbf{P O X} \\
\mathbf{( \% )}\end{array}$ & $\begin{array}{c}\mathbf{C o m b} \\
\mathbf{( \% )}\end{array}$ & $\begin{array}{c}\mathbf{C H}_{\mathbf{4}}+\mathbf{O}_{2}= \\
\mathbf{C O}_{\mathbf{2}}+\mathbf{2 H}_{\mathbf{2}} \mathbf{( \% )}\end{array}$ \\
\hline-- & 80.2 & 92.6 & 89.2 & 89.2 & 7.4 & 3.4 \\
\hline $\mathrm{Na}$ & 89.2 & 97.4 & 90.3 & 90.3 & 2.6 & 7.1 \\
\hline $\mathrm{Sr}$ & 91.8 & 98.1 & 91.9 & 91.9 & 1.9 & 6.2 \\
\hline $\mathrm{La}$ & 93.9 & 100 & 93.7 & 93.7 & 0 & 6.3 \\
\hline $\mathrm{Ce}$ & 92.1 & 100 & 92.8 & 92.8 & 0 & 7.2 \\
\hline
\end{tabular}

It is worth mentioning that, while in the case of alumina, a reduction in the metal-support interaction can produce a benefit for CPOX of methane, there are catalysts and reaction conditions that see a benefit in the interaction that could be lost by the presence of certain 
promoters. It would, therefore, be undesirable to combine these approaches. One specific example is oxygen-conducting supports, which is discussed in the next section.

\subsection{Effect of oxygen-conducting supports}

Another type of support that has been studied a great deal for the CPOX of methane is an oxygen-conducting support. The use of a support with enhanced oxygen transport can improve the rate of oxidation of adsorbed carbon species to $\mathrm{CO}$ and $\mathrm{CO}_{2}$ by providing more rapid delivery of oxygen to the active metal site. It is also beneficial when lattice oxygen plays a role in the activation of the methane. Here, Ni catalysts supported on ceria-based materials will be examined in detail as an example of how oxygen-conducting supports can help minimize carbon deposition. Figure 1-17 provides a potential mechanism for the transport of oxygen to adsorbed carbon species.

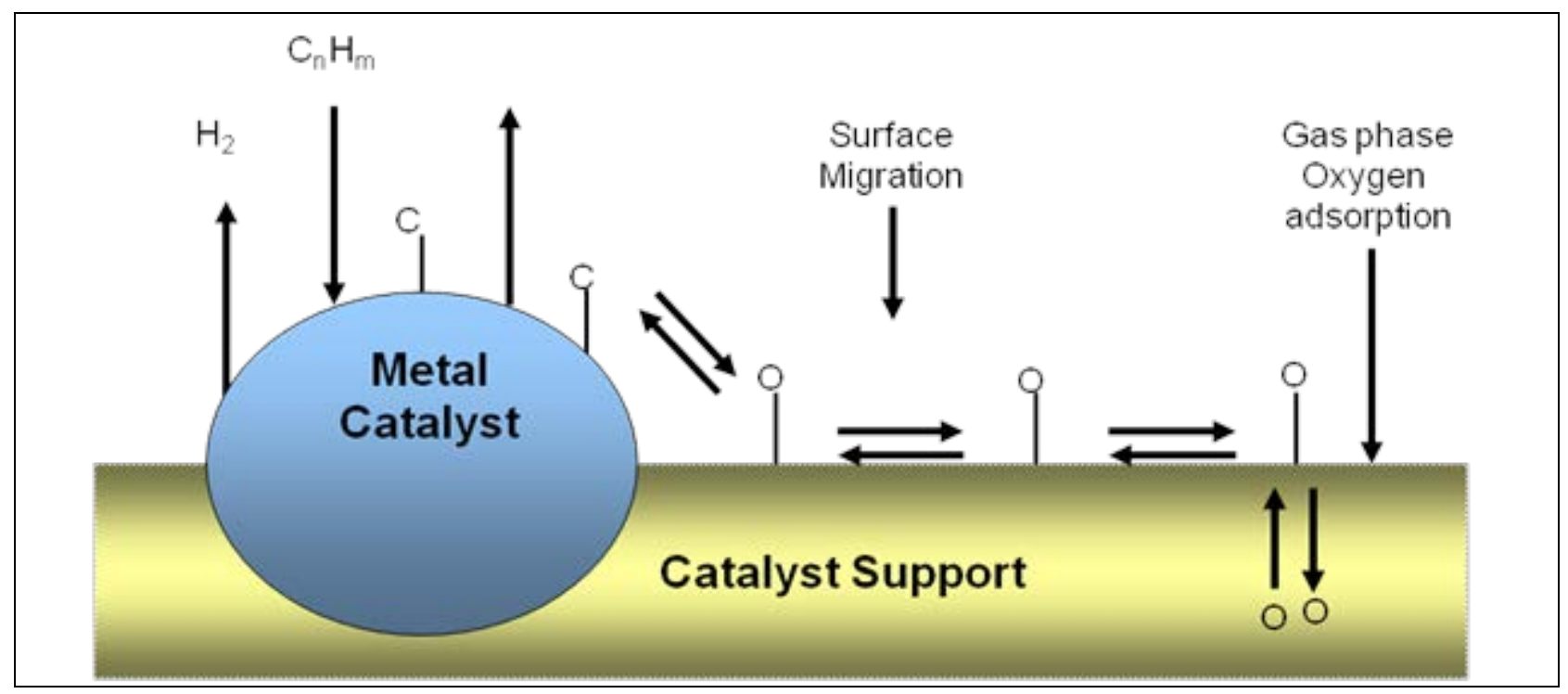

Figure 1-17. Proposed mechanism for the transport of gas phase oxygen with a supported catalyst.

A series of doped ceria materials were examined for total ionic conductivity by Salazar et al. [53], and the results are presented in Figure 1-18. High ionic conductivity has been shown to correlate to high levels of oxygen vacancies, which produce oxygen ion conductivity. Gadolinium-doped ceria (GDC), lanthanum-doped ceria (LDC), and zirconia-doped ceria (ZDC) all yielded much higher ionic conductivity over pure ceria at $800^{\circ} \mathrm{C}$.

The presence of additional oxygen mobility in the catalyst support produced a significant reduction in deactivating carbon formation. One example of this was presented by Dajiang et al. [54]. Ni was supported onto $\mathrm{Al}_{2} \mathrm{O}_{3}, \mathrm{ZDC}$, and $\mathrm{ZDC}+\mathrm{Al}_{2} \mathrm{O}_{3}$. The composition and average carbon formation of these materials under $\mathrm{CPOX}$ of methane are presented in

Table 1-14. Clearly, the presence of ZDC decreased the amount of carbon formed on the Ni catalysts over the pure $\mathrm{Al}_{2} \mathrm{O}_{3}$. Temperature programmed reaction results for these catalysts are presented in Figure 1-19. Methane conversion and CO selectivity indicate that the Ni catalyst supported by $\mathrm{ZDC}+\mathrm{Al}_{2} \mathrm{O}_{3}$ gave the highest $\mathrm{CH}_{4}$ conversion and $\mathrm{CO}$ selectivity. Somewhat surprising is the result that $\mathrm{Ni} / \mathrm{Al}_{2} \mathrm{O}_{3}$ yielded better conversion and selectivity than the $\mathrm{Ni} / \mathrm{ZDC}$. However, the CPOX studies conducted for $24 \mathrm{~h}$ in Figure 1-20 show that conversion drops off 
sharply after $20 \mathrm{~h}$ on stream for the $\mathrm{Ni} / \mathrm{Al}_{2} \mathrm{O}_{3}$, while the $\mathrm{Ni} / \mathrm{ZDC}$ conversion, initially lower, remains stable.

Surface area measurement of the materials presented in these figures are also given in Table 1-14 and show that the ZDC supported catalyst possessed a much lower BET surface area than the other materials. This is significant since a lower surface area will produce a lower dispersion. It is likely that the Ni deposits on the ZDC catalyst were much larger clusters since the metal loading was the same for all three catalysts at $8 \mathrm{wt} \%$. Even though the GHSV was the same, what could be called the "effective space velocity" based on the total number of available metal sites would be much higher for the Ni/ZDC catalyst, which could account for the lower methane conversion. Although different preparation methods may be able to produce a ZDC support of higher surface area, it is not likely that it would retain the same level of ionic conductivity.

Another series of doped ceria supported Ni catalysts was studied by Salazar et al. [55] for the CPOX of methane. These were prepared using the supports presented in Figure 1-18. The TPR profiles for these materials are presented in Figure 1-21. The reducibility of ceria is significantly increased by the presence of the dopants. This increase in reducibility can improve the performance of the catalyst under reaction conditions.

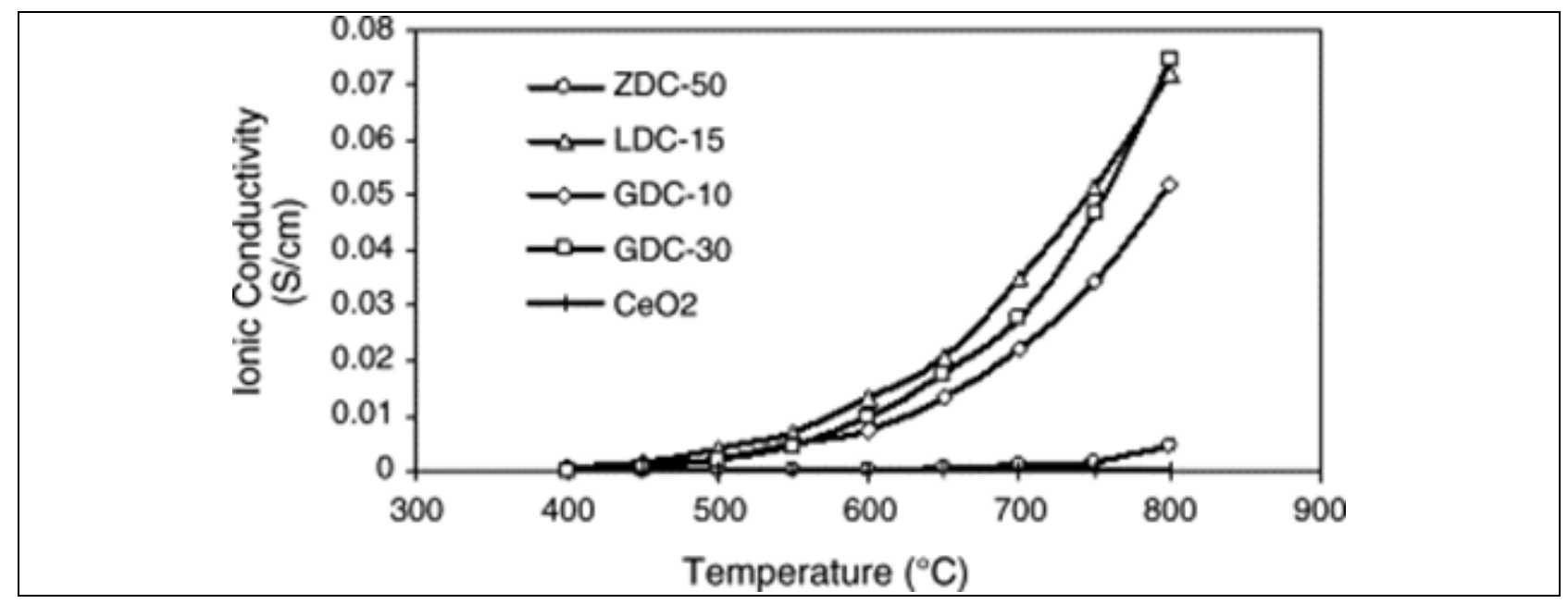

Figure 1-18. Ionic conductivity of several doped ceria support materials [53].

Table 1-14. Characterization data of Ni catalysts with alumina and zirconia-doped ceria supports [54].

\begin{tabular}{|l|c|c|c|c|}
\hline Catalyst & $\begin{array}{c}\text { Ni loading } \\
(\mathrm{wt} \%)\end{array}$ & $\begin{array}{c}\text { Surface } \\
\text { area }\left(\mathrm{m}^{2} / \mathrm{g}\right)\end{array}$ & $\begin{array}{c}\text { Ratio } \\
\left(\mathrm{Ce}_{0.6} \mathrm{Zr}_{0.4} \mathrm{O}_{2}: \mathrm{Al}_{2} \mathrm{O}_{3}\right)\end{array}$ & $\begin{array}{c}\text { Average coking } \\
\text { rate }(\mathrm{g} / \mathrm{g} \text { cat } / \mathrm{h})\end{array}$ \\
\hline $\mathrm{Ni} / \mathrm{CeO}_{2}-\mathrm{ZrO}_{2}$ & 8 & 25.8 & $3: 0$ & 0.008 \\
\hline $\mathrm{Ni} / \mathrm{CeO}_{2}-\mathrm{ZrO}_{2}-\mathrm{Al}_{2} \mathrm{O}_{3}$ & 8 & 165.3 & $1: 2$ & 0.004 \\
\hline $\mathrm{Ni} / \mathrm{Al}_{2} \mathrm{O}_{3}$ & 8 & 156.3 & $0: 3$ & 0.027 \\
\hline
\end{tabular}



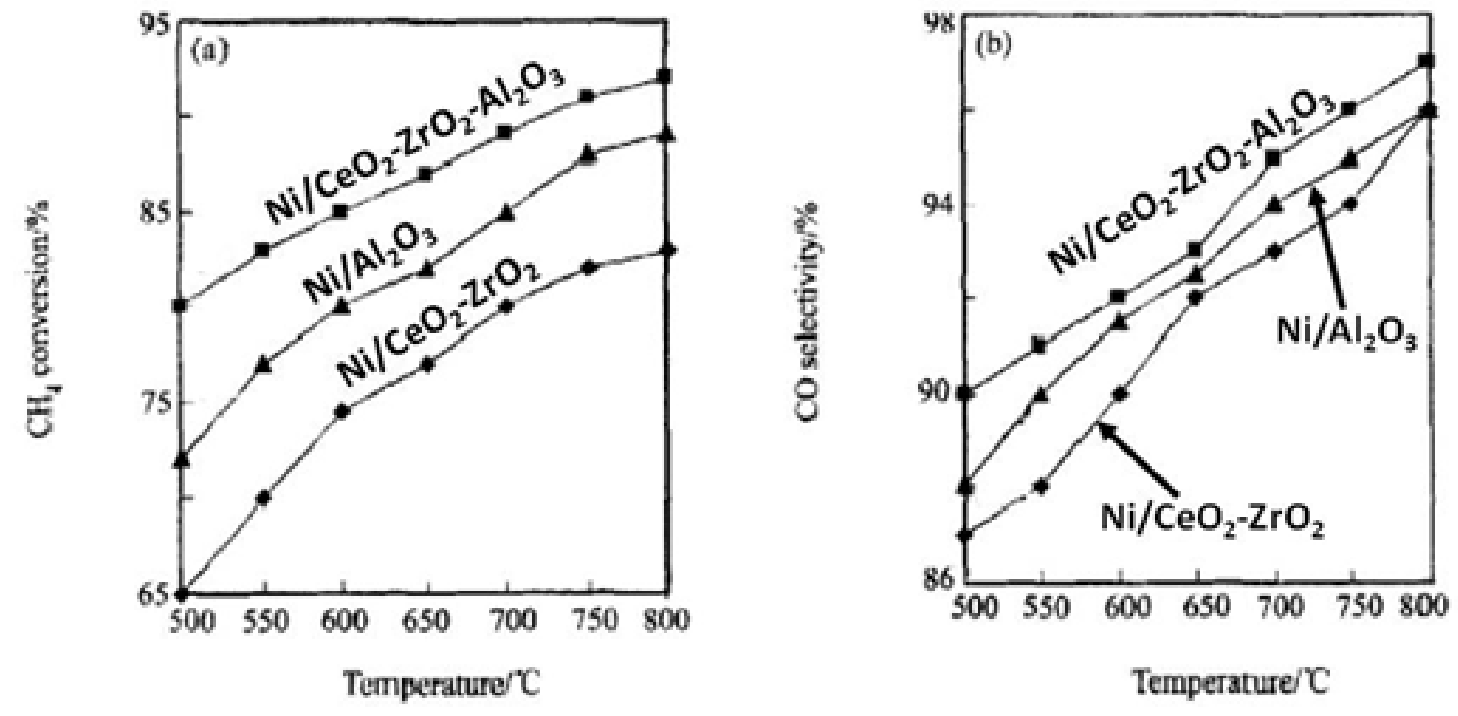

Figure 1-19. Methane conversion and CO selectivity at different temperatures for CPOX with Ni catalysts on alumina and oxygen-conducting supports [54].

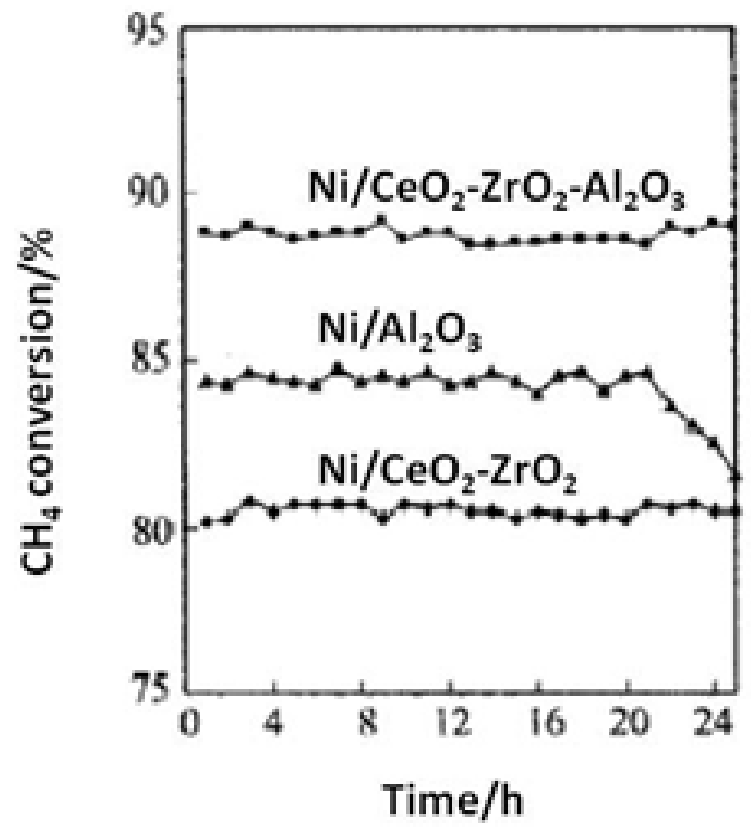

Figure 1-20. Methane conversion over time for CPOX with catalysts on alumina and oxygenconducting supports [54]. 

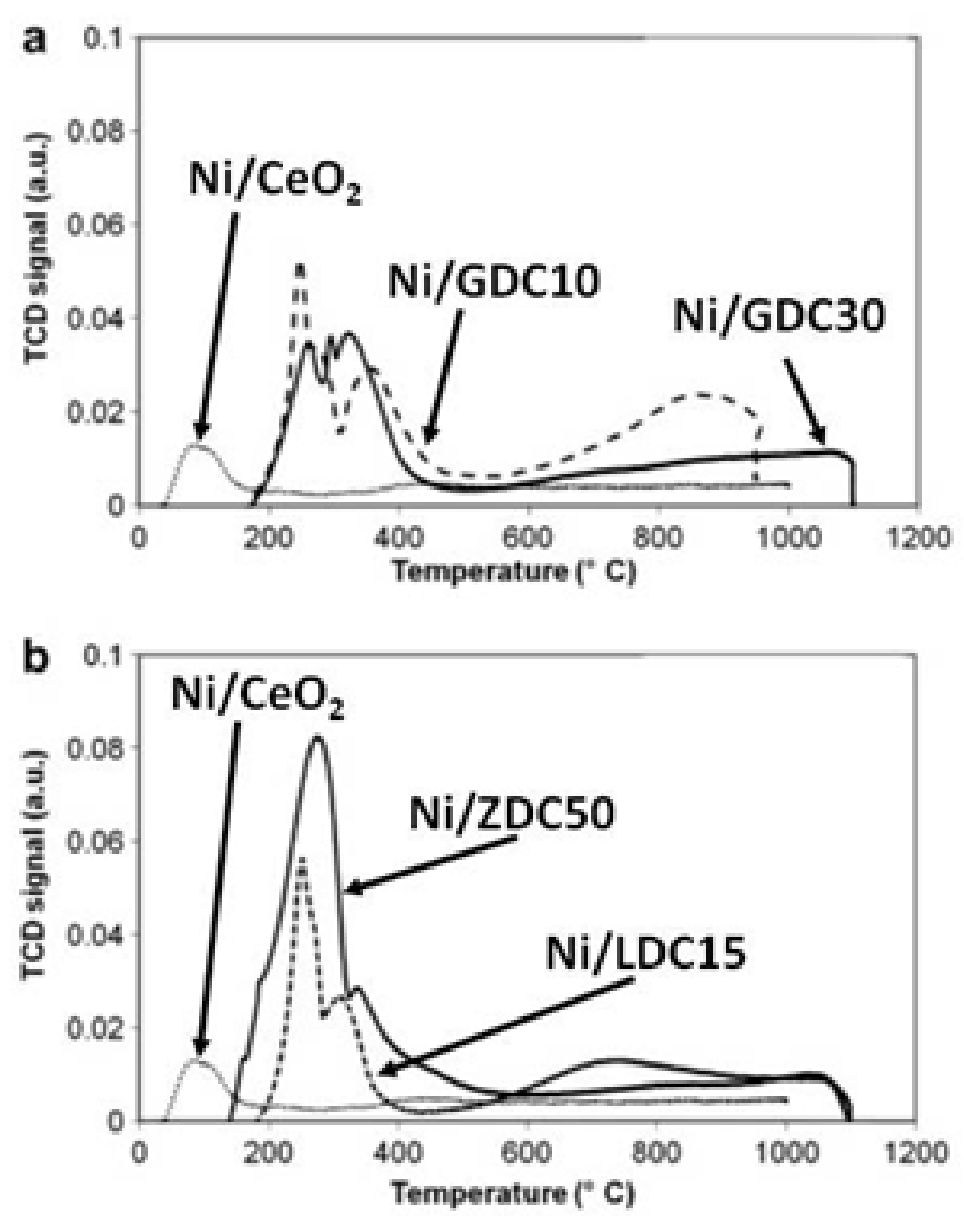

Figure 1-21. TPR profiles for Ni catalysts on several doped-ceria supports [55].

\subsubsection{Noble Metal Catalysts}

Noble metals are attractive for the CPOX of methane because they possess inherently much higher activity and selectivity than base metal catalysts. One major reason for their superior performance is their ability to remain in a reduced state even under highly oxidizing conditions. They are also more resistant to carbon formation and sulfur poisoning. However, they are significantly more expensive than other metal catalysts, making them less favorable for largescale use.

\subsection{Rh and Pt Catalysts}

The majority of research for the CPOX of methane with noble metals has been conducted using Pt and Rh catalysts. Both the direct and indirect mechanisms have been reported for these metals (see

Table 1-3). Under similar conditions, the properties of Pt and Rh are different such that different steps in the mechanism are more favorable for one than the other. For example, studies by Hickmann and Schmidt $[4,10,11,13,56]$ produced the following diagram for comparing the results they observed for these two metals. As shown in Figure 1-22, Pt catalysts promote the formation of surface hydroxides more easily than Rh, which will result in higher yields of steam. 
This is because the activation energy for this step over Pt ( $2.5 \mathrm{kcal} / \mathrm{mol})$ was much lower than for $\mathrm{Rh}(20.0 \mathrm{kcal} / \mathrm{mol})$. This would clearly favor the indirect mechanism, since steam reforming reactions would be faster. In contrast, Rh catalysts are more active for the dissociation of methane to $\mathrm{CH}_{\mathrm{x}}$ species, which can be oxidized to form $\mathrm{CO}$ as the primary product. This supports the reports of Rh catalysts operating under the direct mechanism. Other factors not represented in this diagram are the strength of the bonds of the carbon species formed from methane dissociation with the active metal site. Strongly adsorbed carbon will remain on the catalyst for longer periods of time, which will increase the potential for full oxidation to $\mathrm{CO}_{2}$. Also important is the desorption rate of surface adsorbed $\mathrm{CO}$, which if high enough will result in it being the primary product.

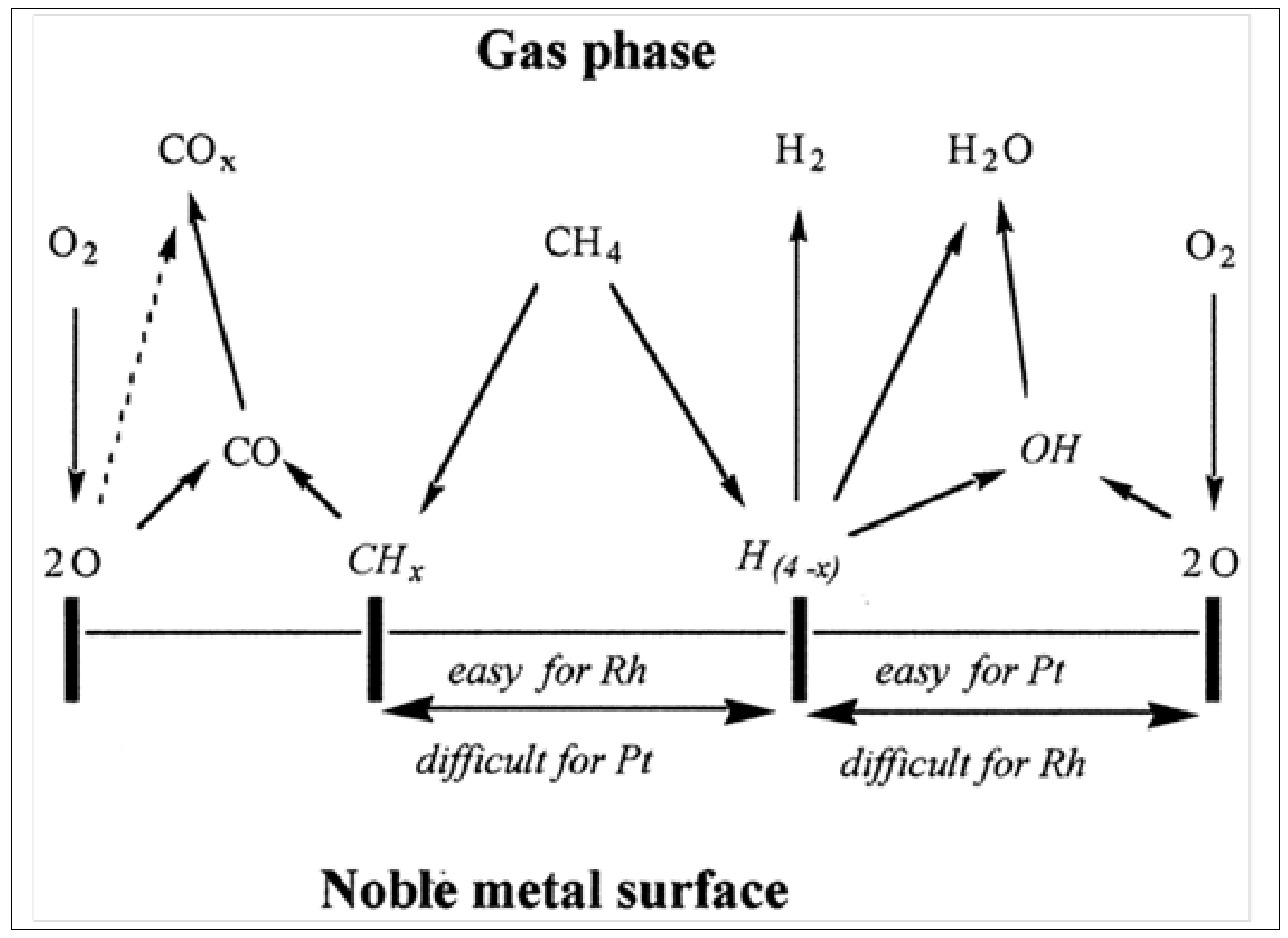

Figure 1-22. Diagram comparing surface reactions on $\mathrm{Pt}$ and $\mathrm{Rh}$ catalysts $[4,10,11,13,56]$.

Another study of these two metals was reported by Hickman and Schmidt [26], which presented potential energy diagrams for Pt and Rh for each step in their proposed mechanism for comparison. This is shown in Figure 1-23 and demonstrates how differently the surface reactions for these metals take place. A major difference is that it takes twice as much energy for Pt (10.3 $\mathrm{kcal} / \mathrm{mol}$ ) for the combined adsorption and dissociation of methane and oxygen gas to the monatomic surface species of each element than for $\mathrm{Rh}(5.0 \mathrm{kcal} / \mathrm{mol})$. This is consistent with the result that $\mathrm{Rh}$ catalyzes the direct mechanism. It would be valuable to conduct the same comparison for the reaction mechanisms for steam reforming, $\mathrm{CO}_{2}$ reforming, and WGS to determine which catalyst is better for promoting secondary reforming reactions for operating 
conditions where that mechanism dominates. The author is not aware of such comparisons for these two metals.

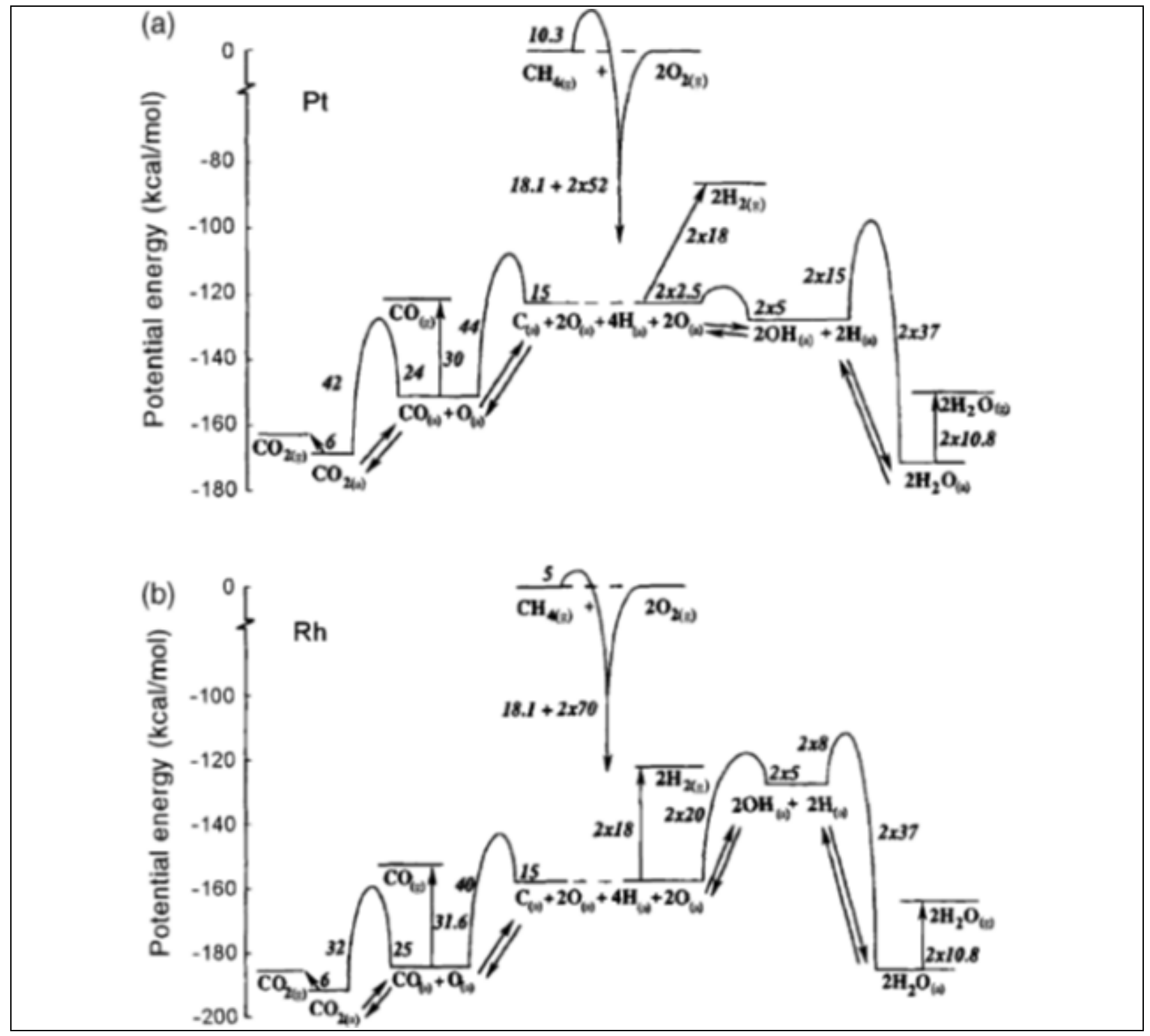

Figure 1-23. Diagram comparing surface reactions on Pt and Rh catalysts [26].

\subsection{Other Support Systems}

$\mathrm{Ru}$ catalysts have been studied over various supports. One study examined the use of $\operatorname{Pr}_{2} \mathrm{Ru}_{2} \mathrm{O}_{7}$ pyrochlore catalyst [57]. It was determined, however, that the active species was reduced $\mathrm{Ru}$ metal on a $\mathrm{PrO}_{2}$ support. The significance of this difference will be discussed in more detail in Section 1.2.4 when higher hydrocarbon CPOX is examined using substituted oxide catalysts where the active species may remain partially in the oxide structure.

Boucouvalas et al. [43] conducted a study with Ru catalyst supported on titanium oxide, $\mathrm{Ru} / \mathrm{TiO}_{2}$. This catalyst was compared to $\mathrm{Ni}, \mathrm{Rh}, \mathrm{Pd}$, Ir, and Ru catalysts supported on alumina. To minimize hot spots and overcome mass and heat transfer limitations, high space velocities, dilute reactants, and dilute catalyst beds were employed. The alumina-supported catalysts 
produced syngas via the indirect mechanism due to the oxidation of the metal surfaces. The ability of $\mathrm{Ru} / \mathrm{TiO}_{2}$ to maintain a reduced surface under oxidizing conditions led to $\mathrm{CH}_{4}$ conversion via the direct mechanism. Isotopic labeling experiments showed the total $\mathrm{CO}$ produced by steam and $\mathrm{CO}_{2}$ reforming (indirect mechanism) was less than $8 \%$ of the total $\mathrm{CO}$ produced. The interaction of the $\mathrm{Ru}$ with the $\mathrm{TiO}_{2}$ support was believed to produce a different type of surface state, which was not fully characterized. Some of the data from this study are presented in Figure 1-24. These results demonstrate a marked improvement in performance for Ru supported on titania over alumina.

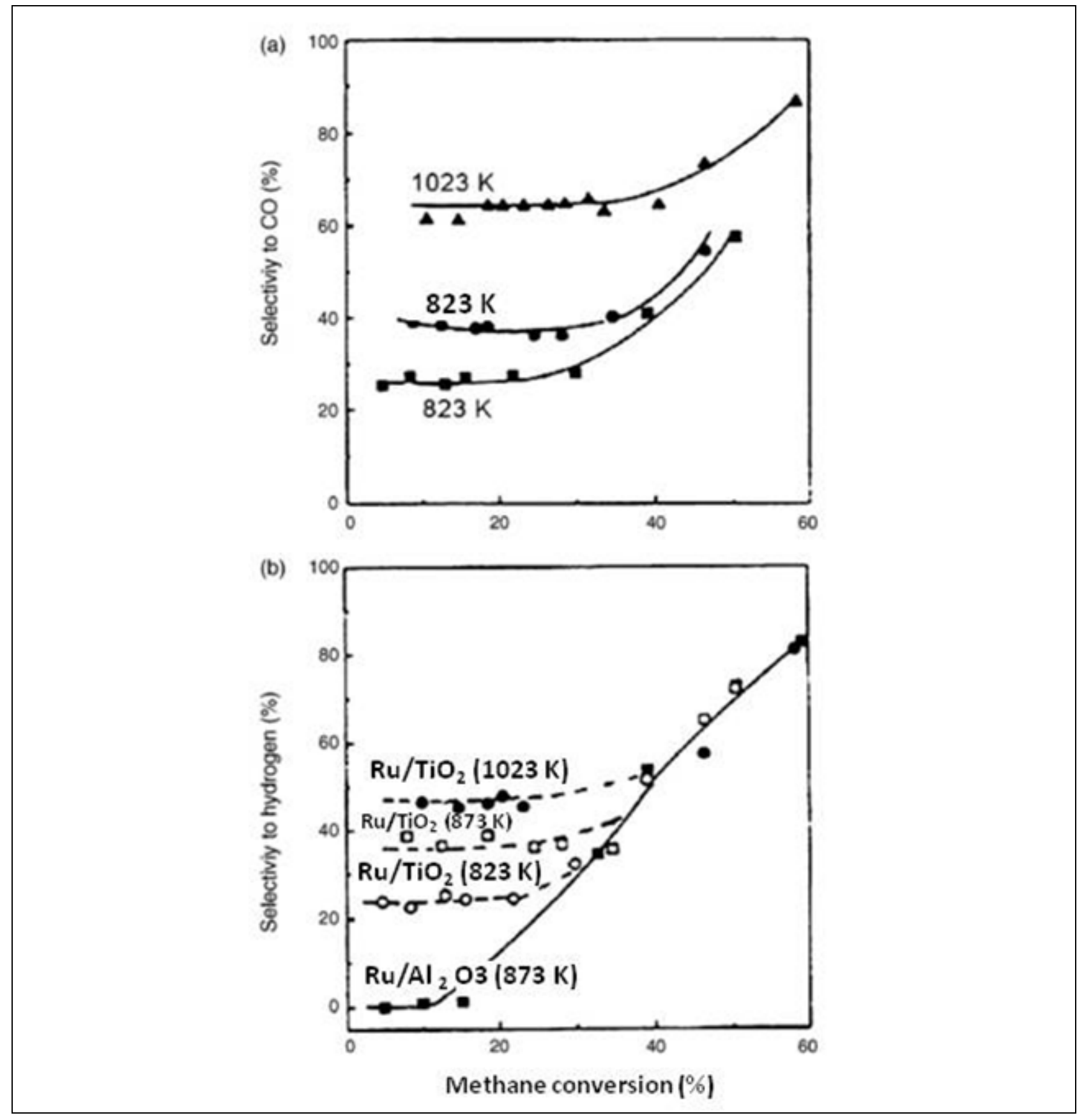

Figure 1-24. CO selectivity (a) and $\mathrm{H}_{2}$ selectivity (b) for CPOX with Ru catalysts on alumina and titania supports as a function methane conversion [43]. 
One final group of supports is mixed oxides with high thermal stability (i.e., perovskites, pyrochlores, hexaaluminates). These supports have been considered for CPOX of methane specifically because of the high operating temperatures, temperature spikes, and potential for hot spots, all of which will eventually cause the support pores to collapse and deactivate the catalysts. A significant amount of work has been done using these supports for methane combustion [58-64], but recent work has been done on methane CPOX as well. Some considerations when using thermally stable oxide supports is that there is a trade-off in surface area compared to traditional alumina supports. While the support may not sinter as rapidly, the catalyst dispersion is limited, which can reduce performance. Further, the Me-O interaction with these supports is much stronger, which may reduce desired lattice oxygen mobility for oxidation steps in the CPOX mechanism. To overcome this the catalyst may require promotion with an oxygen-conducting material.

One example of the use of this type of support is a study by Xiao et al. [65], which examined a $\mathrm{Co} / \mathrm{W}$ carbide catalyst supported by a Mn substituted hexaaluminate combustion catalyst. The hexaaluminate support was shown to stabilize the carbide catalyst and enhance the combustion zone of the reactor. The additional heat from this zone was used to drive reforming reactions. Further, the carbide catalyst showed resistance to deactivation by oxidation.

\subsubsection{Higher Hydrocarbons}

CPOX of liquid hydrocarbon fuels is an attractive option for $\mathrm{H}_{2}$ and $\mathrm{CO}$ production for compact or mobile fuel processing systems. Two major issues that distinguish the CPOX of liquid hydrocarbons and lower hydrocarbons are the propensity to coke the catalyst from unsaturated and/or aromatic compounds found in conventional liquid fuels and the presence of residual organic sulfur compounds, such as dibenzothiophene, that are not easily removed through hydrodesulfurization. The reactions occurring in the CPOX of liquid hydrocarbons are extremely complex. High temperatures from the combustion zone at the front of the catalyst bed result in the fragmentation of the heavier molecular weight hydrocarbons. To avoid excessive fragmentation of the feed, which could result in the formation of unsaturated hydrocarbons and carbon deposits on the catalyst, feed preheat temperatures for liquid fuels range from ambient to just above their boiling point. Reaction temperatures are typically in the range of $700-900^{\circ} \mathrm{C}$. If organic sulfur is present in the feed, then the reactor is typically operated at higher temperatures, where metal sulfides are less stable. The $\mathrm{O}_{2}$ in the feed initially converts organic sulfur compounds in the feed into $\mathrm{SO}_{2}$; however, $\mathrm{SO}_{2}$ may later be converted into $\mathrm{H}_{2} \mathrm{~S}$.

\subsubsection{Base metal catalysts}

Studies on base metal catalysts on a variety of supports for the CPOX of liquid hydrocarbons are presented extensively in the literature. These catalysts are desirable because of their relatively low cost compared with noble metals. However, they are less active and more prone to deactivation from coke and sulfur poisoning.

\subsection{Effect of promoters}

Ni-based catalysts are typically modified with various promoters to limit coke formation, often by neutralizing acid sites thought to be responsible for coking. $n$-Heptane CPOX was studied over NiLiLa/ $\gamma$-alumina by Ran et al. [66]. The catalyst was tested over the temperature range of $700-850^{\circ} \mathrm{C}$ at an $\mathrm{O} / \mathrm{C}=1$ and a GHSV of $38,000 \mathrm{~cm}^{3} / \mathrm{g} / \mathrm{h}$. The LiLa promoter was added to both 
disperse the Ni over the surface of the catalyst and to titrate active Lewis acid sites on the catalyst surface. This catalyst converted $100 \%$ of the $n$-C7 in the feed with $93 \% \mathrm{H}_{2}$ selectivity over a period of $4 \mathrm{~h}$. Similar results were obtained from $n$-C7 CPOX when the catalyst $\mathrm{LiLaNiO} / \gamma-\mathrm{Al}_{2} \mathrm{O}_{3}$ was combined with a dense oxygen permeation membrane $\mathrm{Ba}_{0.5} \mathrm{Sr}_{0.5} \mathrm{Co}_{0.8} \mathrm{Fe}_{0.2} \mathrm{O}_{3}$ that can supply pure $\mathrm{O}_{2}$ for the reaction [67]. The $\mathrm{H}_{2}$ selectivity of $\mathrm{Ni} / \gamma$ alumina, also tested in the study, dropped to $30 \%$ after $4 \mathrm{~h}$ [66].

\subsection{Effect of substituted oxides and oxygen conducting supports}

Another approach to limit catalyst deactivation is to incorporate the active metal into a thermally stable oxide structure. CPOX of $n$-tetradecane, a diesel surrogate fuel, was studied over a series of hexaaluminate catalysts with the general formula $\mathrm{ANi}_{\mathrm{x}} \mathrm{Al}_{12-\mathrm{x}} \mathrm{O}_{19}(\mathrm{~A}=\mathrm{La}, \mathrm{Ba}, \mathrm{Sr})$ by Gardner et al. $[68,69]$. Carbon formation and sulfur poisoning resistance was achieved by substituting the $\mathrm{Ni}$ into the hexaaluminate structure. The temperature programmed reduction profile of $\mathrm{LaNiAl}_{11} \mathrm{O}_{19}$ in $\mathrm{H}_{2}$ exhibited a single broad reduction peak for $\mathrm{Ni}^{2+}$ to $\mathrm{Ni}^{0}$ centered at $996^{\circ} \mathrm{C}$, indicating that the substitution of $\mathrm{Ni}$ into the hexaaluminate structure imparted a high degree of reduction stability. This catalyst was tested isothermally at $850^{\circ} \mathrm{C}, \mathrm{O} / \mathrm{C}=1.2$ and a $\mathrm{GHSV}=$ $10,000 \mathrm{~cm}^{3} / \mathrm{g} / \mathrm{h}$. The average $\mathrm{H}_{2}$ selectivity obtained over $24 \mathrm{~h}$ was $66.2 \%$, and CO was $60 \%$. The $\mathrm{H}_{2} / \mathrm{CO}$ ratio remained unchanged over this time period at 1.18.

Figure 1-25 and Figure 1-26 present results of CPOX activity tests on $n$-tetradecane over Nisubstituted La- and Sr-hexaaluminates, respectively [69]. The La-hexaaluminate catalyst exhibited a continual decline in $\mathrm{H}_{2}$ production, with no recovery once the sulfur species was removed, while the Sr-hexaaluminate suffered an initial decrease in $\mathrm{H}_{2}$ production but remained more stable over the time period it was exposed to sulfur in the feed. The total carbon deposited in the catalyst bed, determined after reaction by temperature programmed oxidation (TPO), was less for the Sr-hexaaluminate than the La-hexaaluminate. These results suggested that the Srhexaaluminate catalyst was more resistant to deactivation from carbon formation in the presence of sulfur, and this was attributed to a reduction in surface acidity since $\mathrm{Sr}$ is more basic than La.

A comparison of three Ni-based catalysts (3wt\%Ni/alumina, 3wt\%Ni/GDC, and bulk 3wt\%Nisubstituted Ba-hexaalumina [BNHA]) for the CPOX of $n$-tetradecane was presented by Smith et al. [70]. The results are shown in Figure 1-27. The 3wt\%Ni/alumina produced the highest $\mathrm{H}_{2}$ and $\mathrm{CO}$ yields. The $3 \mathrm{wt} \% \mathrm{Ni} / \mathrm{GDC}$ demonstrated very low $\mathrm{H}_{2}$ and $\mathrm{CO}$ production, even on pure TD. The poor performance of this material may be explained by the low surface area of the support, which produces fewer and larger metal sites that are more likely to deactivate under these conditions. The lower yields of $\mathrm{H}_{2}$ and $\mathrm{CO}$ may also be an indication that the oxygen-conducting support inhibits the activity of the Ni sites by preventing them from fully reducing to a metallic state.

For the bulk BNHA hexaaluminate, relatively few of the metal sites in the hexaaluminate material are available for participation in the reaction [69]. This may explain the slightly lower initial activity before the dibenzothiophene (DBT) and 1-methylnaphthalene (MN) are introduced into the feed as well as the relatively rapid deactivation in the presence of these contaminants. All three catalysts deactivated completely within $2 \mathrm{~h}$ of exposure to the contaminants, with the $\mathrm{H}_{2}$ and $\mathrm{CO}$ yields reaching those of a reactor filled only with quartz material [71]. A corresponding increase in carbon dioxide and unconverted hydrocarbon (represented as methane) yields occurs after exposure to contaminants, also indicative of catalyst 
site deactivation. None of the materials recovered activity when the feed was switched back to pure TD

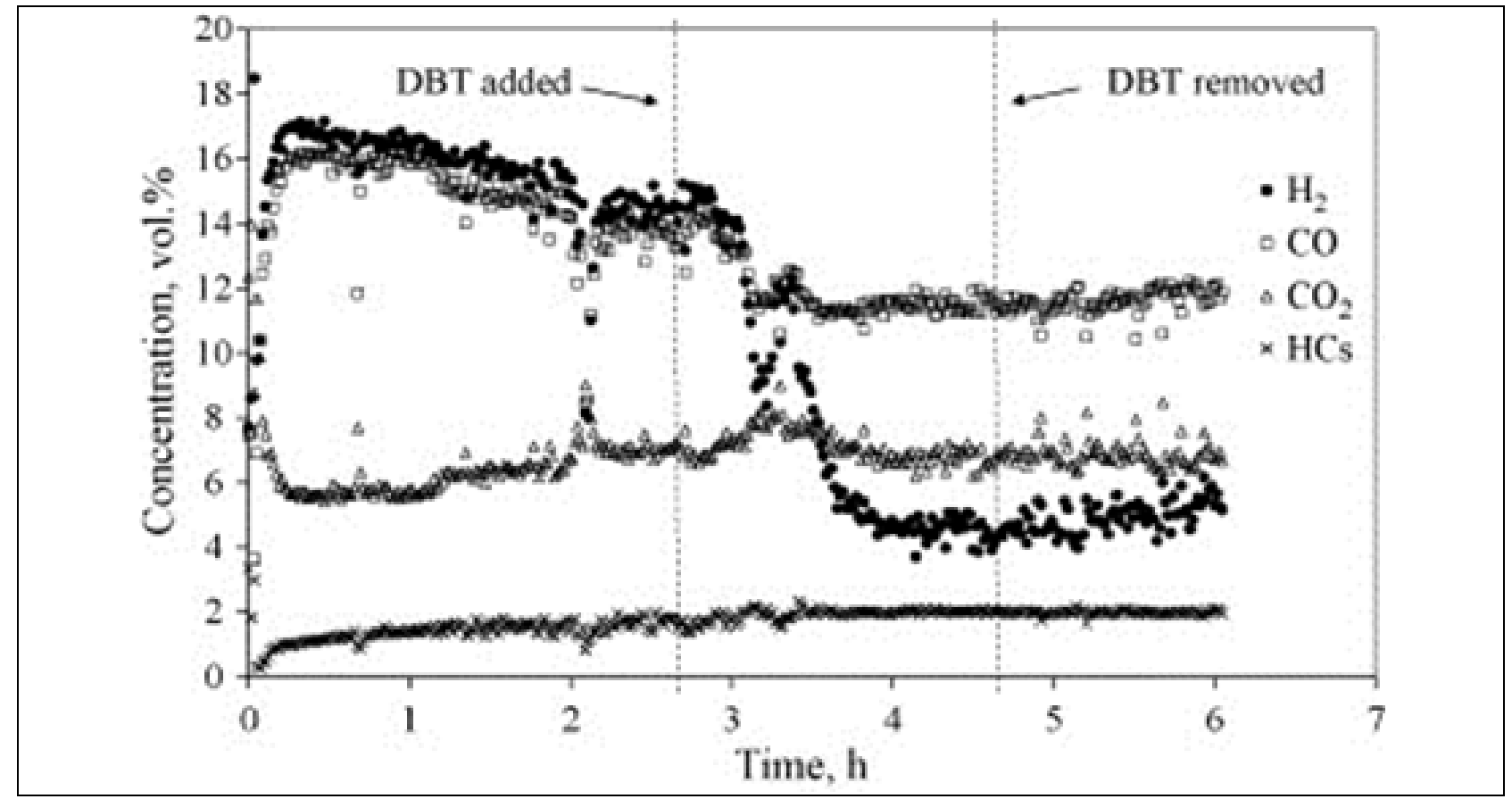

Figure 1-25. Step function response to the introduction of $50 \mathrm{ppmw}$ sulfur as DBT during the partial oxidation of $n$-tetradecane over $\mathrm{LaNi}_{0.4} \mathrm{Al}_{11.6} \mathrm{O}_{19-\delta}$ : $\mathrm{GHSV}=50,000 \mathrm{~cm}^{3} / \mathrm{g} / \mathrm{h}, \mathrm{O} / \mathrm{C}=1.2$, $\mathrm{T}=850^{\circ} \mathrm{C}$ and $\mathrm{P}=197.8 \mathrm{kPa}[69]$.

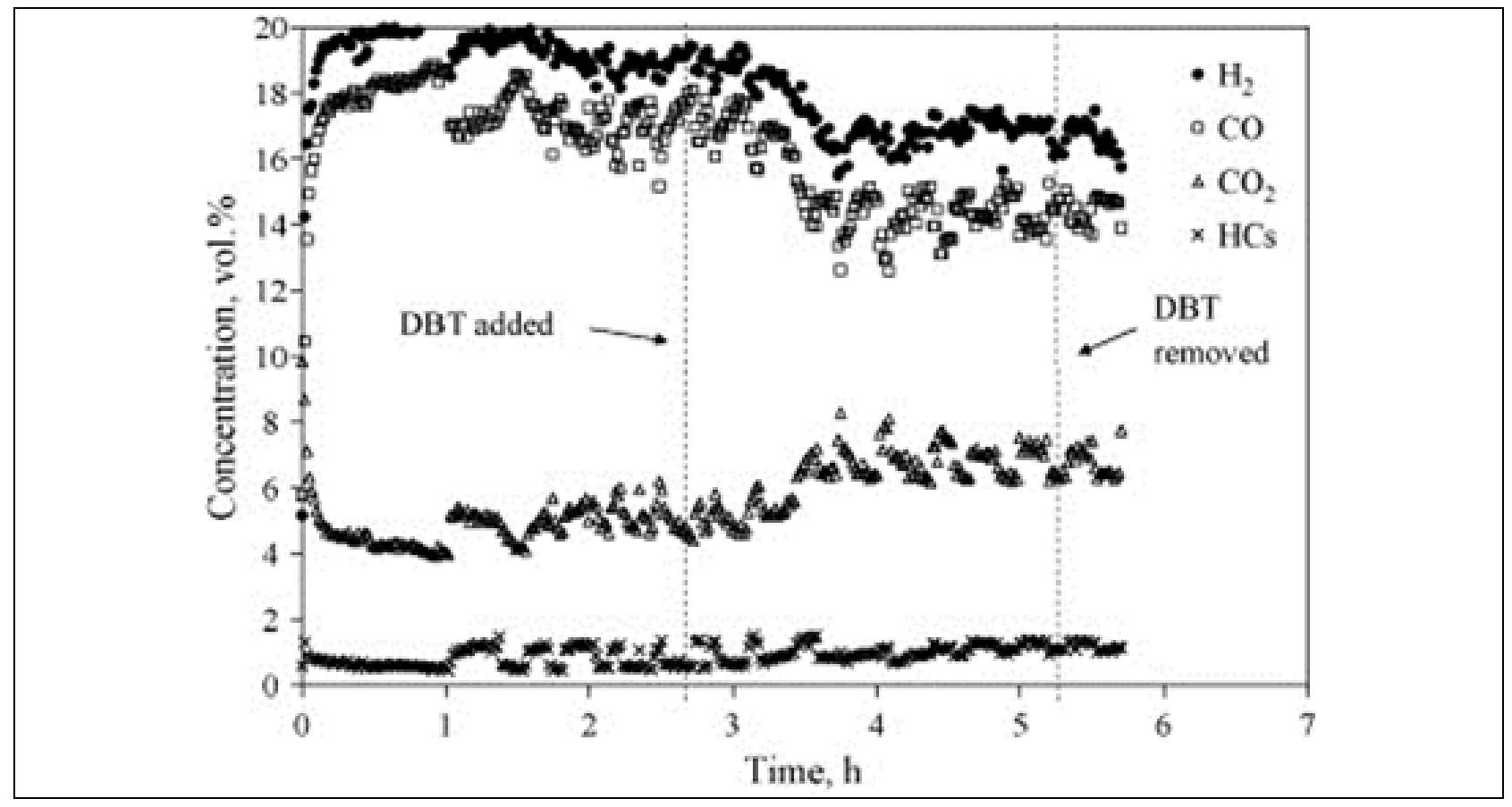

Figure 1-26. Step function response to the introduction of $50 \mathrm{ppmw}$ sulfur as DBT during the partial oxidation of $n$-tetradecane over $\mathrm{SrNi}_{0.4} \mathrm{Al}_{11.6} \mathrm{O}_{19-\delta}$ : GHSV $=50,000 \mathrm{~cm}^{3} / \mathrm{g} / \mathrm{h}, \mathrm{O} / \mathrm{C}=1.2$, $\mathrm{T}=850^{\circ} \mathrm{C}$ and $\mathrm{P}=197.8 \mathrm{kPa}[69]$. 


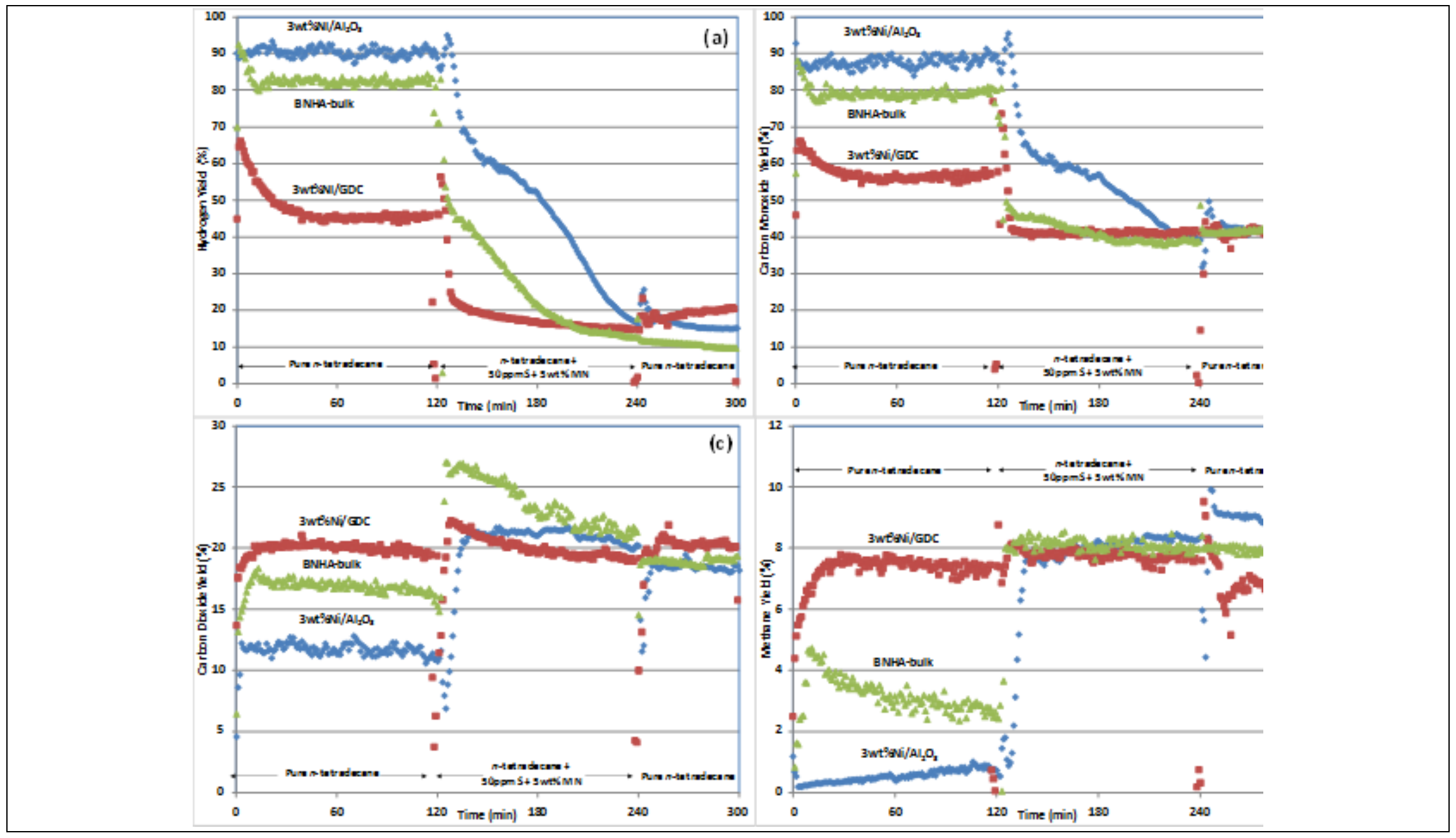

Figure 1-27. Effect of oxygen-conducting supports and metal substitution into an oxide structure on CPOX of $n$-tetradecane: GHSV $=50,000 \mathrm{~cm}^{3} /$ gcat $/ \mathrm{h}, \mathrm{O} / \mathrm{C}=1.2, \mathrm{~T}=900^{\circ} \mathrm{C}, \mathrm{P}=0.23 \mathrm{MPa}[70]$. 
The type of oxide structure into which the active metal is substituted also has an effect on the performance of the CPOX catalyst. This is demonstrated well in a study by Haynes et al. [72], where the Ni-substituted hexaalumina in the previous study is compared to a Ni-substituted pyrochlore with the general formula $\mathrm{La}_{2-\mathrm{x}} \mathrm{Sr}_{\mathrm{x}} \mathrm{Zr}_{2-\mathrm{y}} \mathrm{Ni}_{\mathrm{y}} \mathrm{O}_{7-8}$, where the value of y produces an equivalent $3 \mathrm{wt} \% \mathrm{Ni}$ substitution level. The results of this study are presented in Figure 1-28.

The results show that the presence of MN and DBT produces an immediate drop in synthesis gas yields from the equilibrium values for each catalyst. Active Ni sites in the BNHA are easily deactivated, indicating that reducing the critical ensemble number of $\mathrm{Ni}$ atoms did not prevent deactivation by MN and DBT. The LSZN catalyst is distinguished from the other two by the behavior of its $\mathrm{H}_{2}$ and $\mathrm{CO}$ yields in the presence of the contaminants. Ni substituted into the pyrochlore structure is not continuously deactivated by the MN and DBT, but rather is able to remain active and selective towards $\mathrm{H}_{2}$ and $\mathrm{CO}$, albeit at lower than pre-contaminant levels.

A noticeable difference is also seen in the behavior of the olefins produced by the LSZN catalyst. The olefin formation rate increases sharply after the first hour in the presence of MN and DBT, but only continues to increase slightly after the initial spike. Together, these results coupled with the behavior of the synthesis gas yields show that the sites involved in the eventual formation of $\mathrm{H}_{2}$ and $\mathrm{CO}$ do not become completely deactivated by the contaminants. Instead, the data suggest that the adsorption of MN and DBT only decreases the turnover frequency of the active sites, limiting the approach to equilibrium, rather than continuously accumulating on the surface and leading to eventual deactivation. The $\mathrm{Ni}$ in the pyrochlore structure is believed to retain catalytic properties in the presence of the contaminants through improved oxygen-ion conductivity that occurs as a result of $\mathrm{Sr}$ substitution. Improving this property provides a localized oxygen source from the pyrochlore lattice to react with the strongly adsorbed carbon forming precursors. Deactivation of the Ni is then prevented during the time scale of this study because the accumulation of refractory surface carbon species is limited. Instead, most surface carbon is gasified into $\mathrm{CO} / \mathrm{CO}_{2}$, and active sites become freed for further reactions.

After the contaminants were removed from the feed, activity is not recovered by the BNHA catalysts. Evaluating the gaseous product yields during the recovery period to those produced in the absence of a catalyst showed comparable product selectivity. High selectivity to olefins is observed, and $\mathrm{H}_{2}$ and $\mathrm{CO}$ yields are produced at an $\mathrm{H}_{2} / \mathrm{CO}$ ratio of much less than 1 . This indicates the catalyst has been irreversibly deactivated by the contaminants. Meanwhile, the LSZN is able to recover a portion of its initial activity, showing that most of the effects of the MN and DBT are reversible. $\mathrm{H}_{2}$ and $\mathrm{CO}$ yields both increase, while olefin products return to precontaminant levels, and $\mathrm{CO}_{2}$ and $\mathrm{CH}_{4}$ yields both decrease. The ability to recover activity suggests that the contaminants act, for the most part, as kinetic inhibitors to the $\mathrm{H}_{2}$ and $\mathrm{CO}$ producing sites. However, total initial activity is not recovered, signifying some activity loss was irreversible.

One final aspect in comparing these two catalysts is the amount of carbon measured in the reactor after each test by TPO. For BNHA the total carbon was $2.4 \mathrm{~g} / \mathrm{g}_{\text {cat, }}$ while for LSZN the total carbon was $0.4 \mathrm{~g} / \mathrm{g}_{\text {cat. }}$. This suggests that the carbon formation is related to the catalyst deactivation. 


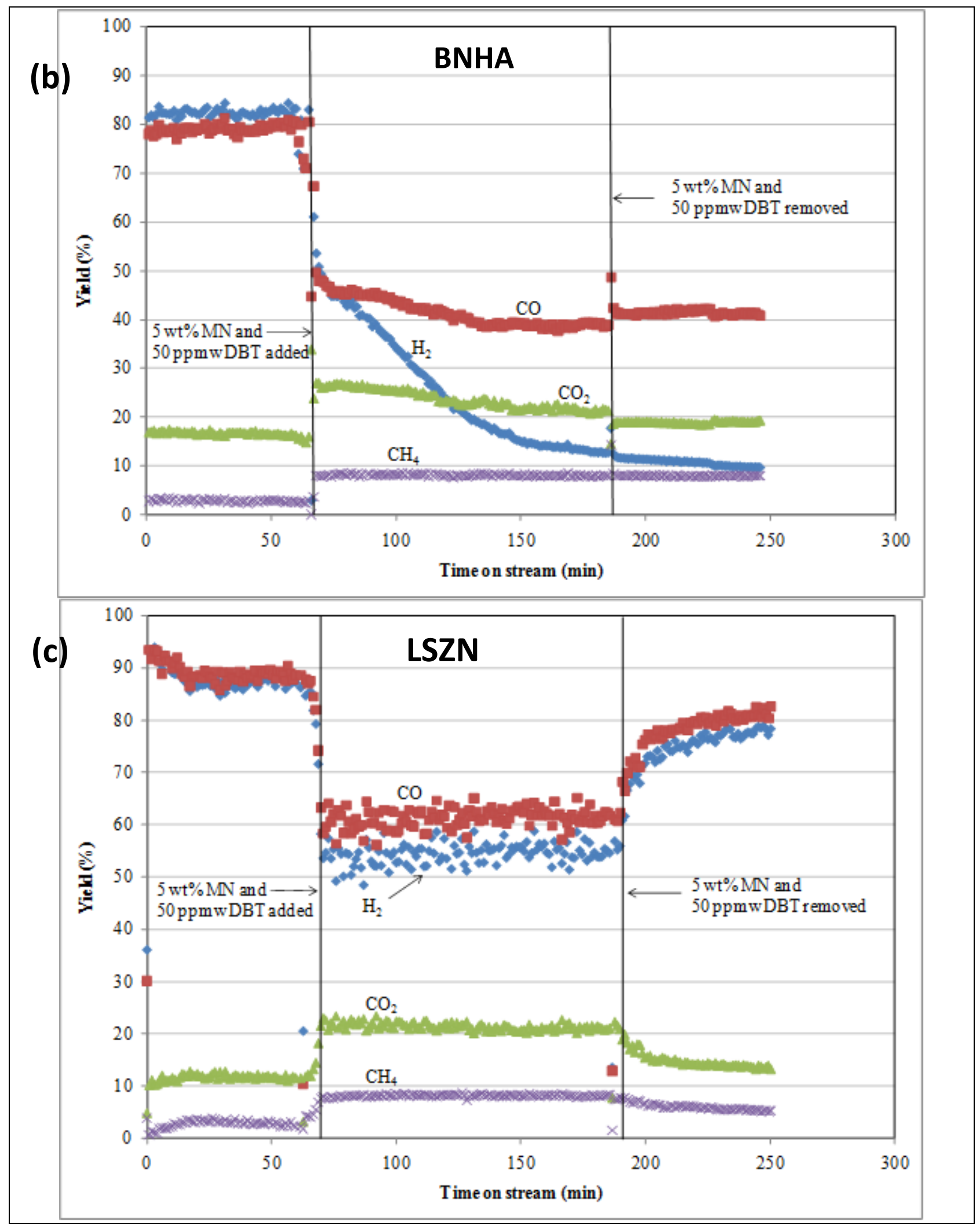

Figure 1-28. Dry gas yields for (b) BNHA, and (c) LSZN catalyst during $4 \mathrm{~h}$ CPOX of $n$-tetradecane with $5 \mathrm{wt} \% \mathrm{MN}$ and $50 \mathrm{ppmw}$ DBT: GHSV $=50,000 \mathrm{~cm}^{3} / \mathrm{g}_{\mathrm{cat}} / \mathrm{h}, \mathrm{O} / \mathrm{C}=1.2, \mathrm{~T}=900^{\circ} \mathrm{C}$, $\mathrm{P}=0.23 \mathrm{MPa}[72]$. 


\subsection{Effect of substituted oxides on oxygen conducting supports}

The use of oxygen-conducting supports to enhance catalyst performance can also be applied to metal-substituted oxide catalysts. Smith et al. [73] examined the combined approach to catalyst design of substituting $\mathrm{Ni}$ into an oxide structure and supporting it onto an oxygen-conducting material. These studies were conducted on $n$-tetradecane with sulfur and aromatic species. The purpose of the study was to compare catalysts with $\mathrm{Ni}$ substituted into a barium-hexaaluminate structure (BNHA) to systems comprised of BNHA layers over gadolinium-doped ceria (GDC), an oxygen-conducting support. The BNHA catalyst layer was supported onto the GDC.

The results of this study are presented in Figure 1-29. It was demonstrated that the stability provided by the oxide phase limited the sintering of $\mathrm{Ni}$ sites seen in pure Ni metal catalysts. Further, the presence of the oxygen-conduction of GDC from the gas phase, through the support to the active sites, promoted the oxidation of deposited coke precursors and reduced carbon formation.

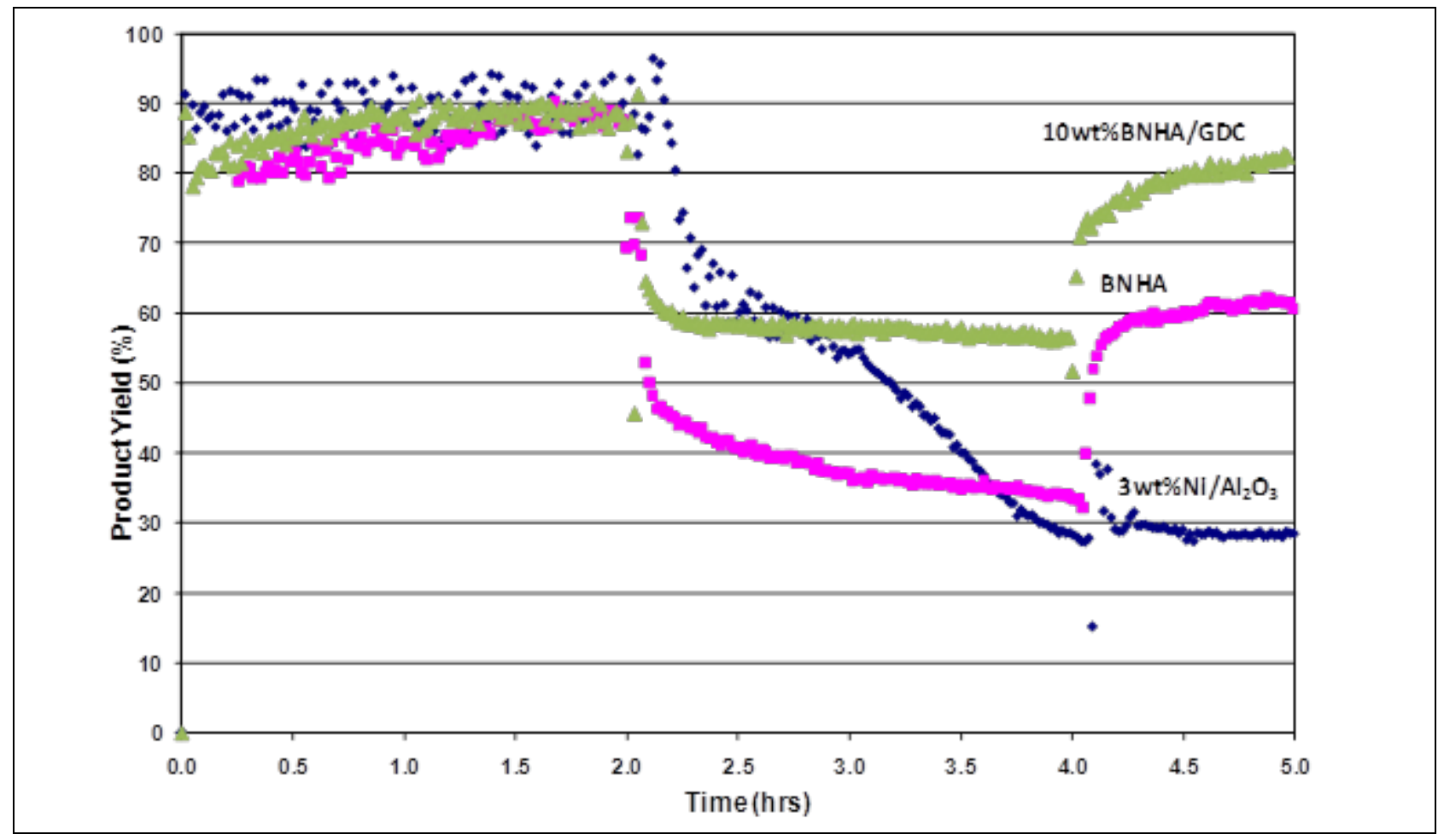

Figure 1-29. Effect of oxygen-conducting support on Ni-substituted hexaaluminate catalysts for the CPOX of $n$-tetradecane in the presence of MN and DBT [73].

\subsubsection{Noble metal catalysts}

The use of noble metal catalysts for CPOX of liquid hydrocarbons has been widely reported in literature. These metals have higher activity and resistance to deactivation than transition metal catalysts, resulting in shorter reaction times, smaller bed sizes, and longer stability. However, these catalysts are much more expensive than other metal catalysts.

Earlier in this section, the issue of sulfur poisoning was identified as a more significant challenge with liquid hydrocarbons than for lighter fuels. Figure 1-30 provides the Gibbs free energy for 
the sulfides of several metals typically used in CPOX [9]. Pt is the least likely to form a sulfide at typical operating conditions, while $\mathrm{Ni}$ is the most likely.

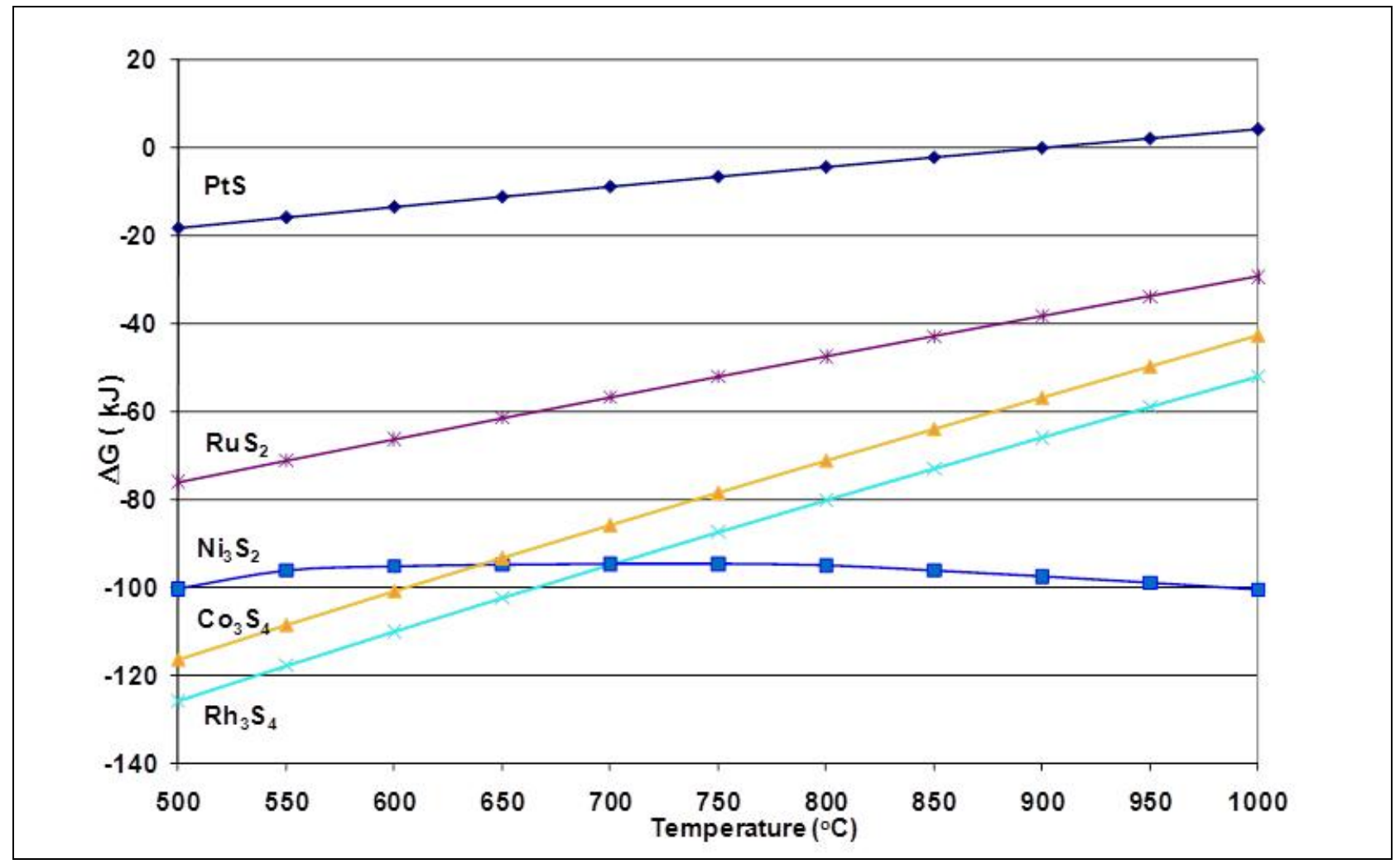

Figure 1-30. Gibbs free energy for sulfides of common metals used in CPOX [9].

\subsection{Effect of Promoters}

Tanaka et al. [74] reported that CPOX of gasoline over Rh, Pt, and Pt-Rh is promoted by alkali ( $\mathrm{Li})$ and alkaline earth metals $(\mathrm{Ba}, \mathrm{Ca}, \mathrm{K})$ supported on magnesium aluminate spinel. The catalysts were tested isothermally at $800^{\circ} \mathrm{C}$ at an air-to-fuel ratio of 5.1 and GHSV $50,000 \mathrm{~h}^{-1}$. $\mathrm{Li}, \mathrm{Mg}$ and $\mathrm{MgLi}$ promoters were added to Pt supported on $\mathrm{MgAl}_{2} \mathrm{O}_{4}$ spinel. All catalysts produced similar $\mathrm{H}_{2}$ and $\mathrm{CO}$ concentrations of 23 and 25 vol\%, respectively. There was a discernable difference in the carbon deposition. The unpromoted Pt catalyst showed carbon levels of $0.02 \mathrm{wt} \%$ carbon, where the alkali and alkaline earth promoted Pt catalysts had carbon levels of $0.01 \mathrm{wt} \%$.

In another study by the same group [74], $\mathrm{K}$, $\mathrm{Ca}$ and $\mathrm{CaK}$ promoters were added to Rh supported on $\mathrm{MgAl}_{2} \mathrm{O}_{4}$ spinel. Both modified and unmodified catalysts produced similar $\mathrm{H}_{2}$ and $\mathrm{CO}$ concentrations of 23 and 25 vol\%, respectively. The different modifiers did affect carbon production on the catalysts. The unpromoted Rh catalyst showed carbon levels of $0.03 \mathrm{wt} \%$ carbon, where the RhK catalyst had $0.02 \mathrm{wt} \%$ carbon, the RhCa $0.015 \mathrm{wt} \%$, and the RhCaK only 0.01 wt\%. Bimetallic PtRh with $\mathrm{Li}, \mathrm{Ba}$ and $\mathrm{LiBa}$ modifiers supported on $\mathrm{MgAl}_{2} \mathrm{O}_{4}$ spinel were also examined for $\mathrm{H}_{2}$ and $\mathrm{CO}$ yields and carbon formation resistance, with similar results to previous work for the yields. The unpromoted PtRh catalyst showed carbon levels of $0.01 \mathrm{wt} \%$ carbon, where the promoted PtRh catalysts all showed reduced coking levels of $0.005 \mathrm{wt} \%$. 


\subsection{Effect of Supports}

The catalyst support is as critical as the active catalyst for the CPOX of higher hydrocarbons. The catalyst may be deposited as a metal onto the support or as a mixed oxide. The support can provide the desired level of metal dispersion and morphology to optimize the catalyst performance by enhancing mass and heat transfer properties. Further, as discussed in the Section 1.2.2, the support often plays a role in the surface reaction mechanism. Therefore, the properties of the support surface are as critical as the catalyst itself.

Shekhawat et al. [75] conducted CPOX studies on $n$-tetradecane (TD) containing sulfur and polynuclear aromatics over supported $\mathrm{Rh}$ and Pt catalysts. The tests were designed to examine the effect of the support on the metal catalyst. The supports used were alumina and zirconiumdoped ceria (ZDC), an oxygen-conducting support. The studies were conducted in three steps: 1) CPOX of pure TD for one hour to establish a baseline, 2) TD + contaminant for two hours, 3) pure TD for two hours to examine recovery of activity. The sulfur contaminant species was dibenzothiophene (DBT) and was added at a level of 1000 ppmw. The aromatic contaminant species was 1-methylnapthalene (MN) and was added to a level of $5 \mathrm{wt} \%$.

The $\mathrm{H}_{2}$ production for each catalyst under the two different conditions is shown in Figure 1-31 and Figure 1-32. The Rh/ZDC catalyst produced the best performance in the presence of both DBT and MN. This was attributed to both the better activity of Rh over Pt, as well as the effect of the oxygen-conductivity of the ZDC. The latter was not verified in this study, since no testing was reported for Rh/alumina. Indeed, the data presented for Pt indicated that the alumina support was better. However, as discussed in Section 1.2.3.1 (see subsection, "Effect of oxygenconducting supports"), the surface area of the support is important since it can affect the dispersion of the catalyst. In this study, the alumina support had a surface area of $198 \mathrm{~m}^{2} / \mathrm{g}$ compared to $70 \mathrm{~m}^{2} / \mathrm{g}$ for the ZDC. Therefore, it is possible that under these conditions that the benefit of the high surface area was greater than the benefit of the oxygen conductivity of the support.

Rh-based catalysts have also been investigated on various support structures, resulting in different $\mathrm{H}_{2}$ and $\mathrm{CO}$ yields. Gasoline and naphtha CPOX over a supported Rh catalyst were reported by Fujitani et al. [76]. For $\gamma$-alumina supported Rh catalyst maximum yields of $96 \%$ of both $\mathrm{H}_{2}$ and $\mathrm{CO}$ were reported with $0.2 \mathrm{wt} \% \mathrm{Rh}$ loading at $700^{\circ} \mathrm{C}$, an air equivalence ratio of 0.41. A 0.05 wt $\%$ Rh supported on zirconia yielded $98 \% \mathrm{H}_{2}$ and $85 \% \mathrm{CO}$ at $725^{\circ} \mathrm{C}$, an equivalence ratio of 0.41 . However, $0.1 \mathrm{wt} \% \mathrm{Rh}$ loaded on a honeycomb structure of $\alpha$-aluminamagnesia gave the highest yield of $\mathrm{H}_{2}$ and $\mathrm{CO}$ (both $98 \%$ ) at $820^{\circ} \mathrm{C}$, air equivalence ratio of 0.41. Furthermore, carbon deposition was not observed with these supported Rh catalysts.

The CPOX reaction has also been studied using reactors with very short contact times. Cyclohexane, $n-C_{6}, n-C_{8}, n-C_{10}, n-C_{16}, i-C_{8}$, toluene, naphthalene, and gasoline CPOX has been studied over Rh-based monolithic catalysts at millisecond contact times [77-80]. Several factors affect the conversion and selectivity of these fuels. The mean cell density, typically defined as pores per inch (ppi) for foam materials (e.g., 40 ppi corresponds to a mean cell diameter of $\sim 0.6$ $\mathrm{mm}$ ), significantly affected the syngas selectivities, but the gas space velocity did not.

Krummenacher et al. [81] reported syngas selectivities greater than $80 \%$ with greater than $99 \%$ conversion of hydrocarbons from the catalytic CPOX of $n-C_{10}$ and $n-C_{16}$ over a Rh-coated monolith at 5 to 25 ms contact times. CPOX of a high grade diesel fuel (10 ppm sulfur, 8\% aromatics, $90 \%$ alkanes) produced syngas at greater than $98 \%$ fuel conversion. Maximum 
selectivities of $\mathrm{H}_{2}$ and $\mathrm{CO}$ observed were $70 \%$ and $80 \%$, respectively, at an $\mathrm{O} / \mathrm{C}$ ratio of 1.4 and 25 ms contact time.

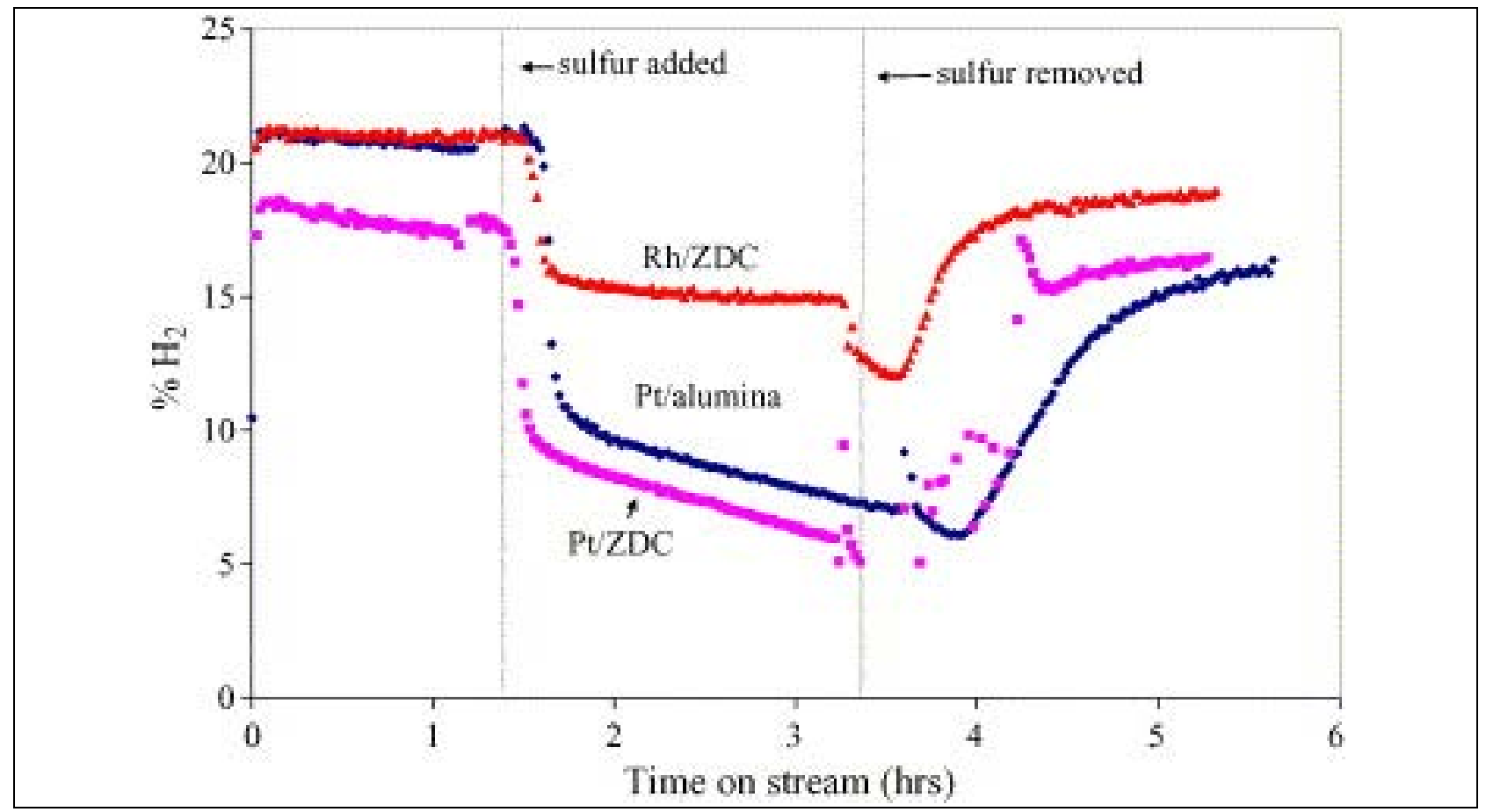

Figure 1-31. CPOX step response plot for $\mathrm{H}_{2}$ production (concentration, dry gas vol\%) from TD with 1000 ppmw sulfur [75].

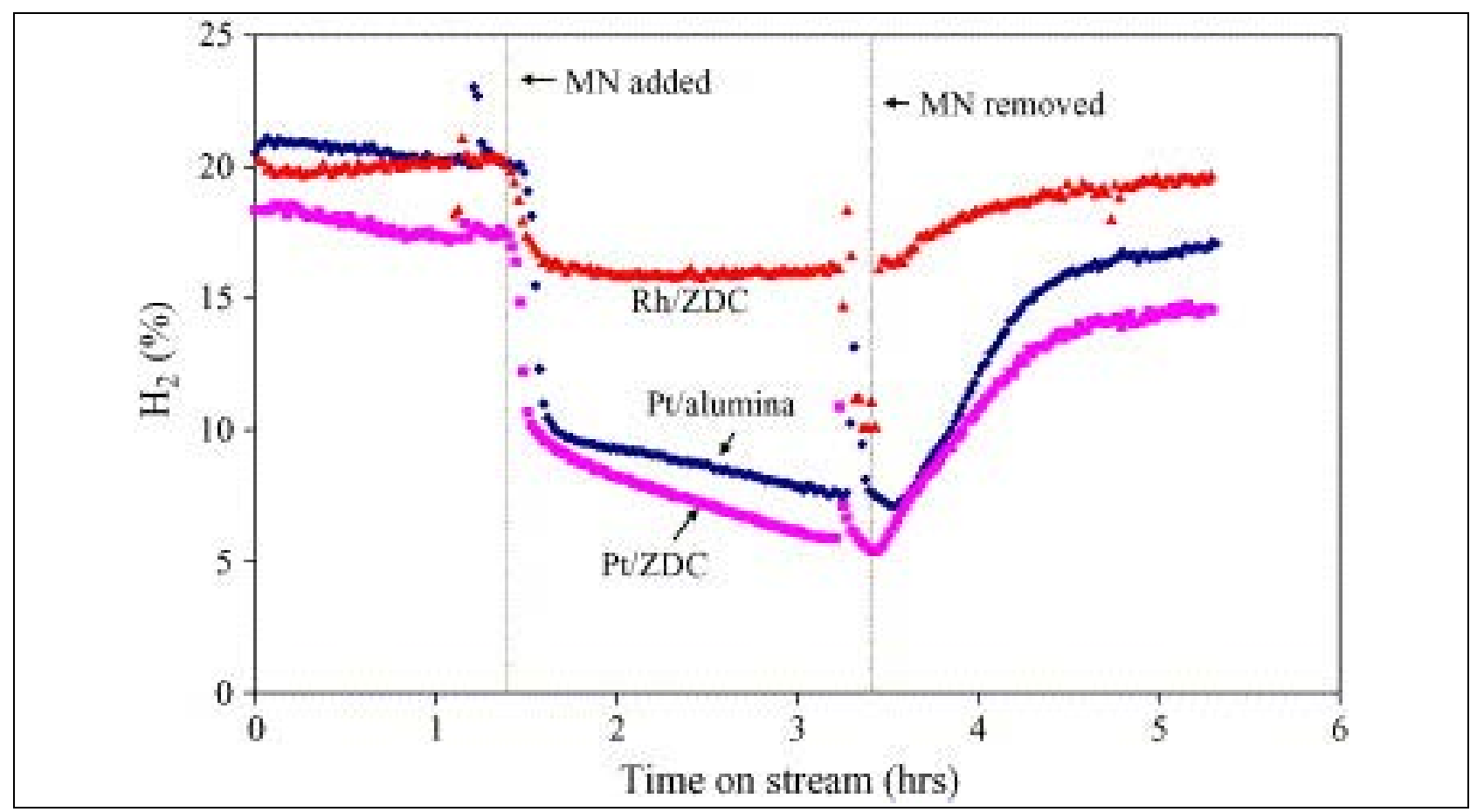

Figure 1-32. CPOX step response plot for $\mathrm{H}_{2}$ production (concentration, dry gas vol\%) from TD with 5 wt\% 1-methylnaphthalene [75]. 


\subsection{Effect of substitution into oxide structures}

One of the challenges for the hexaaluminate structure is the limitation to which metals can be substituted into the lattice. No reports of substituting larger metals like Rh into the hexaaluminate structure were found. However, Rh and Ru have been successfully substituted into oxides such as perovskites and pyrochlores. Haynes et al. [71, 82, 83] reported CPOX testing on $n$-tetradecane for Rh- and Ru-substituted pyrochlores with a great deal of success. These catalysts demonstrated high performance and stability in the presence of sulfur and aromatics.

Figure 1-33 and Figure 1-34 show the performance for the CPOX of $n$-tetradecane of a Ru- and a Rh-substituted pyrochlore, respectively [71, 83]. Both catalysts successfully reform the fuel into $\mathrm{H}_{2}$ and $\mathrm{CO}$, even in the presence of sulfur and aromatic species. Further, the Rh-substituted pyrochlore exhibits stable performance even in the presence of a much higher sulfur concentration of 1000 ppmw, compared to 50 ppmw for Ru.

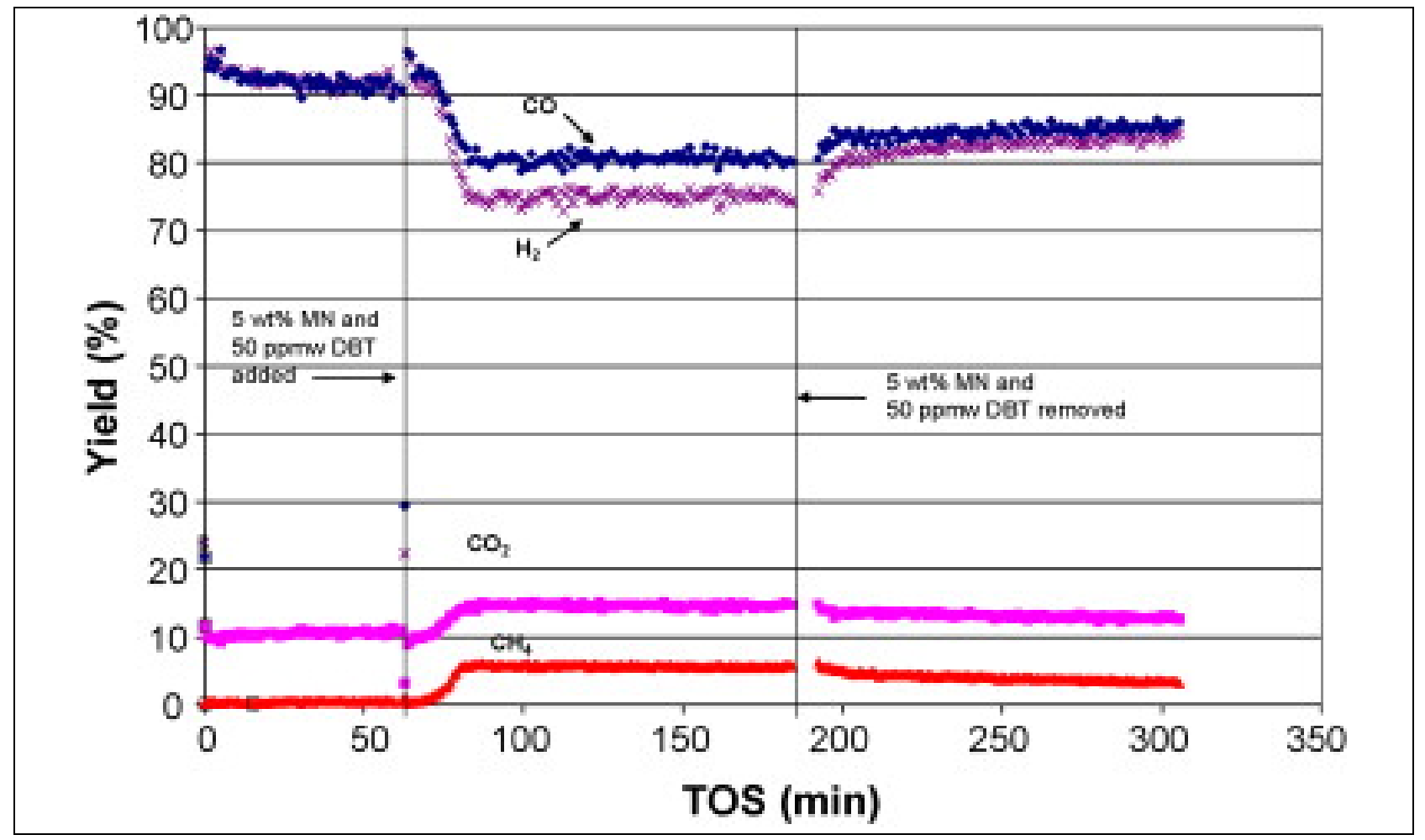

Figure 1-33. Yields for LSRuZ during $5 \mathrm{~h}$ CPOX experiment: GHSV $=50,000 \mathrm{~cm}^{3} / \mathrm{g}_{\mathrm{cat}} / \mathrm{h}, \mathrm{O} / \mathrm{C}=1.2$, $\mathrm{T}=900^{\circ} \mathrm{C}, \mathrm{P}=0.23 \mathrm{MPa}[83]$. 


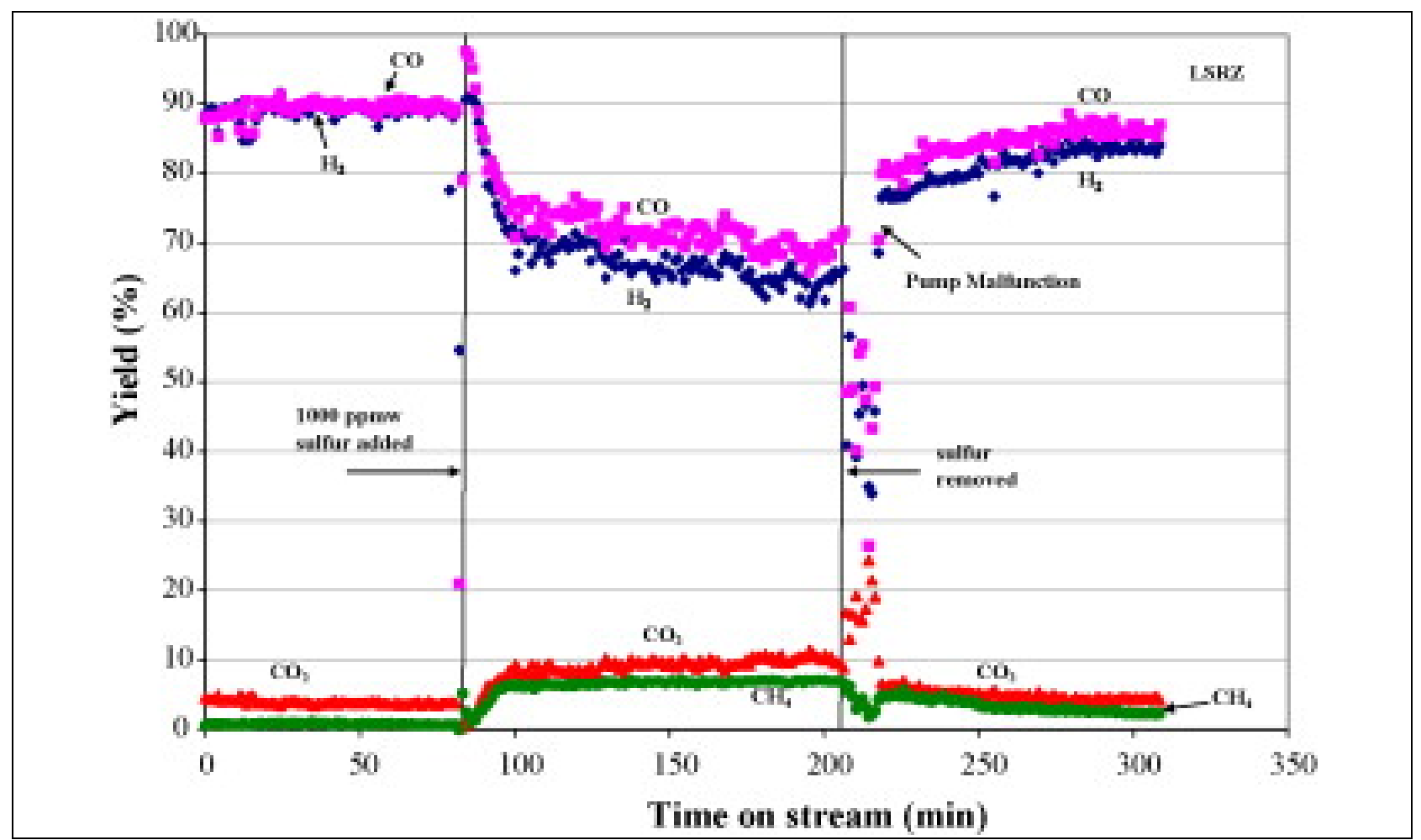

Figure 1-34. Yields for LSRhZ during $5 \mathrm{~h}$ CPOX experiment: GHSV $=50,000 \mathrm{~cm}^{3} / \mathrm{g}_{\text {cat }} / \mathrm{h}, \mathrm{O} / \mathrm{C}=1.2$, $\mathrm{T}=900^{\circ} \mathrm{C}, \mathrm{P}=0.23 \mathrm{MPa}[71]$.

\section{$1.3 \quad$ Research Needs}

\subsubsection{Substituted oxides on oxygen-conducting supports}

The development of hydrocarbon POX catalysts by Shekhawat et al. [53, 68-71, 75, 82-89], discussed in detail in Sections 1.2.3 and 1.2.4, is summarized well by Figure 1-35. Starting with a traditional supported metal catalyst the three major modes of deactivation (thermal sintering, sulfur poisoning, and coke formation) were addressed initially by two separate approaches. The first was substituting the metal into a thermally stable oxide structure, which helped reduce both the thermal sintering and sulfur poisoning. Separately, supporting the active metal onto an oxygen-conducting support helped mitigate carbon formation. Combining these approaches produced the greatest level of success. Ultimately the best catalyst design may consist of substituted oxides containing a certain level of oxygen conductivity (i.e., pyrochlores) deposited onto an oxygen-conducting support.

However, a very important aspect of this catalyst design approach remains to be conducted. While superior performance was attained with this catalyst system $[84,88,89]$ the interaction of the active phase and the support needs to be fully characterized. Specifically, the nature of the active phase and the manner in which it is deposited onto the support can affect its interaction with the support and overall performance. Further, the optimal size of the active phase deposits and their overall ratio to the support will be different for various combinations of materials that can be selected for specific fuels and reaction conditions. Therefore, a method for designing such a catalyst system is needed that can incorporate, at a minimum, the control of the catalytic activity, morphology, and oxygen-conductivity of an active and support phase. 


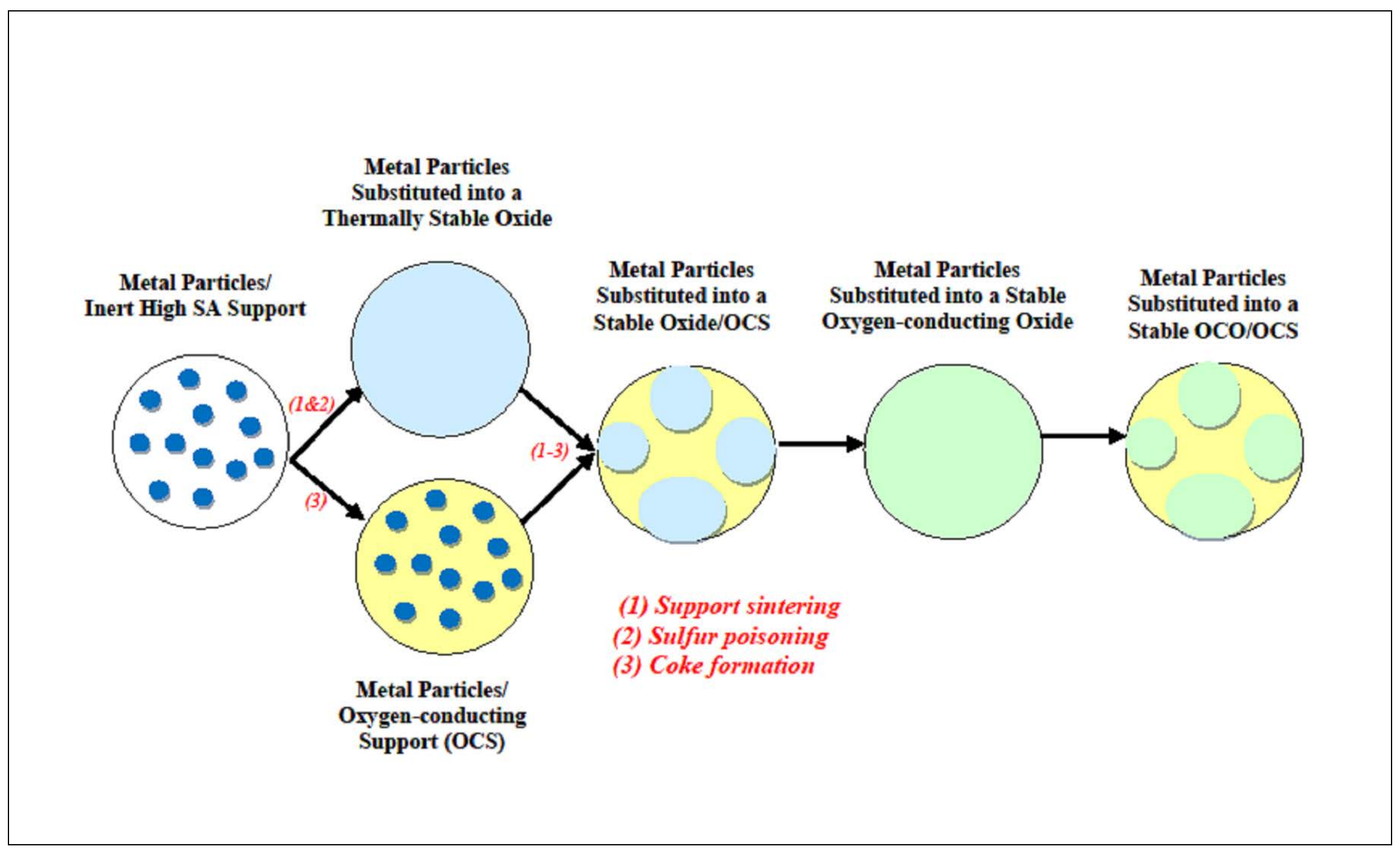

Figure 1-35. Development of POX catalyst for reforming hydrocarbons. 


\subsubsection{Staged or segmented reactor}

The use of a staged reactor system operates on the assumption of an indirect mechanism for the CPOX of hydrocarbons (See Section 9). This approach could take one of two forms to produce a desired product distribution: multiple oxygen feed locations, or multiple catalyst formulations.

\subsubsection{Multiple oxygen feed locations}

The approach of feeding a portion of the oxygen supply to different locations along the length of the reactor could be used to reduce or eliminate the exotherm at the leading edge of the catalyst bed $[90,91]$. This could promote an increase in the extent of reaction from the direct mechanism. It may also allow control of product distribution in the syngas, specifically the $\mathrm{CO} / \mathrm{CO}_{2}$ ratio. Minimizing the temperature spike and the presence of hot spots may also allow the use of less expensive reactor materials, reduction in catalyst loss from vaporization, and support sintering.

\subsubsection{Multiple catalyst formulations}

The approach of using multiple catalyst compositions at different positions in a reactor for the CPOX of methane has been presented in several recent studies [90-94]. Figure 1-36 is a diagram of the justification for such an approach. In considering reactor design it may be advantageous to enhance the reactions occurring in a region where the rate-limiting steps occur. Further, like the staged oxygen feed approach, the temperature spike may be reduced through the use of a less oxidizing catalyst in the front part of the bed. Of greatest interest may be the ability to reduce cost by decreasing the amount of expensive noble metal catalyst needed. This may be accomplished by the use of less expensive catalysts like $\mathrm{Ni}$ or $\mathrm{Ru}$ in the regions of the reactor where conditions are less conducive to deactivation of these metals. The studies previously cited that examined gas composition with respect to reactor position would be most helpful for this design approach.

The segmented catalyst bed approach may prove to be most helpful for the CPOX of higher hydrocarbons because these fuels often contain organic sulfur and aromatic species. Therefore, the form these species take at different positions of the reactor may be more or less likely to deactivate non-noble metal catalyst, again possibly providing an opportunity to reduce cost by their use in these sections. The front section of the catalyst bed may deactivate rapidly due to higher temperatures and contaminant concentrations. Further, the end portion of the catalyst bed may also cause significant deactivation for catalysts susceptible to sulfur poisoning due to the lower temperatures resulting from the endothermic reforming reactions. Therefore, it may be necessary only to use noble metal catalysts in one or both of these sections and a less expensive alternative may be used in the remaining parts of the reactor. 


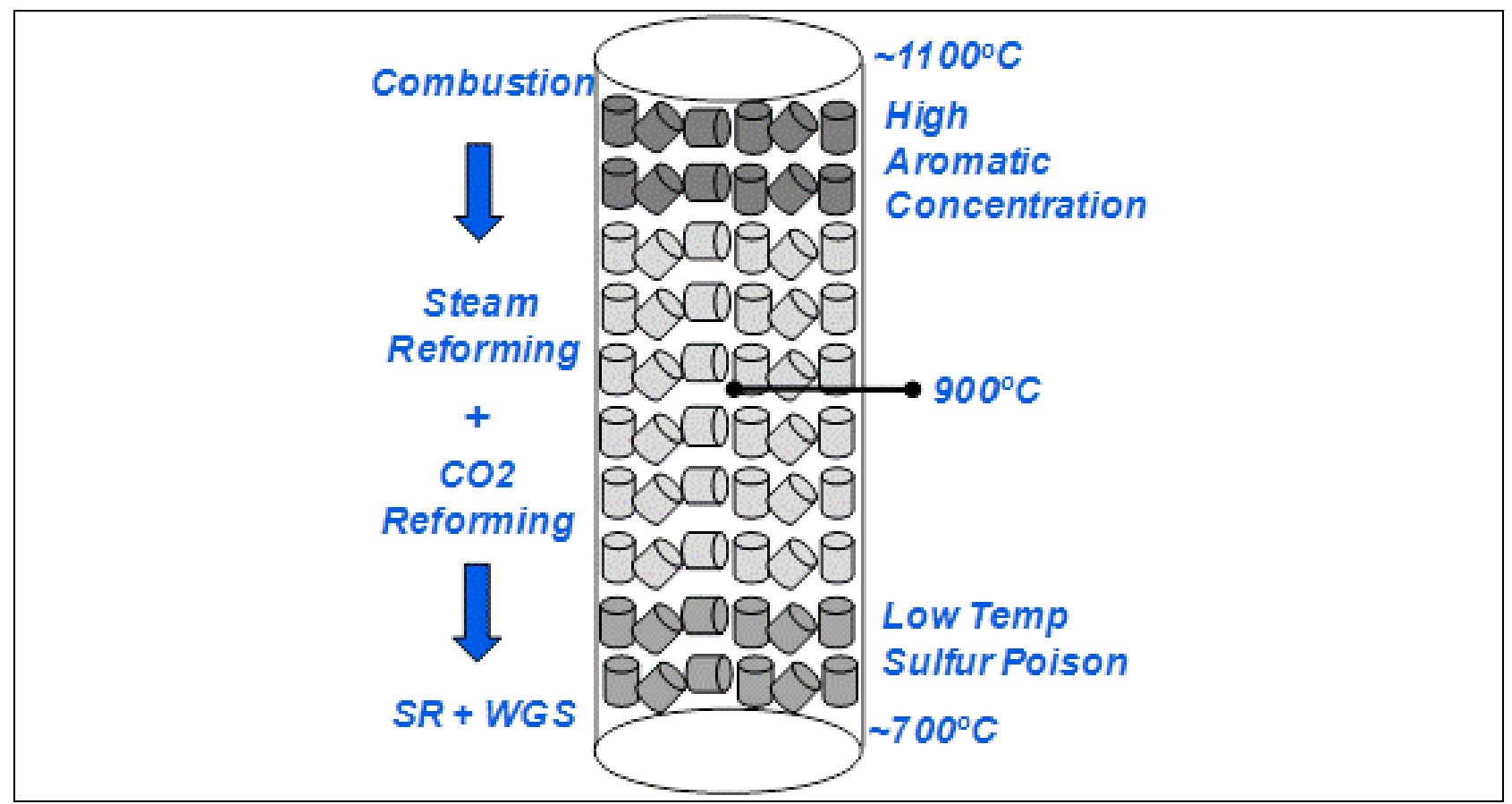

Figure 1-36. Segmented catalyst bed design. 


\section{Substituted Oxides on Oxygen-conducting Supports}

\section{$2.1 \quad$ Effect of Weight Loading and Support Type}

Note: The material in Section 2.1 was presented at the ACS Spring National Meeting 2011 as, "Effect of oxide catalyst surface coverage in the presence of oxygen-conducting supports for CPOX.”

\subsubsection{Introduction}

The use of Ni-based catalysts to reform liquid fuels for solid oxide fuel cell applications is attractive because of their low cost compared to that of noble metal-based catalysts. However, the sulfur and aromatic species in these fuels deactivate Ni sites through sulfur poisoning and carbon (coke) deposition. Approaches to minimize the negative effects of these contaminants on metal-based systems have included using oxygen-conducting supports [75, 95] and substituting the active metal particles into thermally stable oxide structures, such as perovskites and hexaaluminates $[69,96]$. Although these approaches have demonstrated some improvement, deactivation still occurs rapidly, especially when the reforming is carried out by partial oxidation.

The purpose of this study was to combine the two approaches (Figure 2-1) and compare catalysts with Ni substituted into a barium-hexaaluminate oxide structure (BNHA) to systems comprised of different coverage areas of BNHA layers over gadolinium-doped ceria (GDC) or zirconiumdoped ceria (ZDC), both oxygen-conducting supports, for the partial oxidation (CPOX) of $n$ tetradecane (TD).
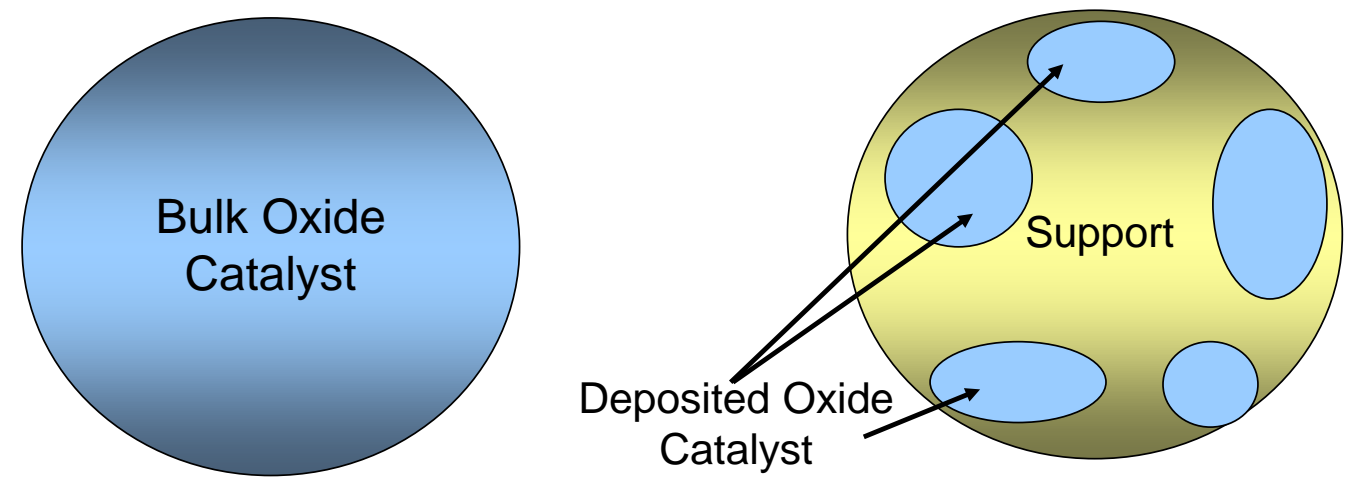

Figure 2-1: Diagram of substituted mixed-metal oxide catalyst over oxygen-conducting support.

\subsubsection{Experimental Methods}

\subsubsection{Catalyst Synthesis}

BNHA catalysts were prepared by co-precipitation of nitrate precursors dissolved in DIW dropped into ammonium carbonate solution. This was followed by calcination to form the appropriate crystal phase. A detailed description of the synthesis method is provided in a previous work [69]. BNHA catalysts supported onto GDC and ZDC were prepared by solid-state mixing (SSM), which consisted of grinding the catalyst and support powders together in appropriate proportions, followed by heat treatment in air for $12 \mathrm{~h}$ at $950^{\circ} \mathrm{C}$. 


\subsubsection{Catalyst Characterization}

The bulk Ni concentration for each catalyst was determined by inductively coupled plasma (ICP) optical emission spectroscopy on a Perkin-Elmer Optima 3000 ICP-OES spectrometer. BET surface area was determined by $\mathrm{N}_{2}$ adsorption using a Quantachrome Surface Area Analyzer 2000. The crystalline phases present in each sample were determined by powder X-ray diffraction (XRD) using a PANalytical X'Pert PRO model XRD, utilizing filtered $\mathrm{Cu} \mathrm{K} \alpha$ radiation.

\subsubsection{Catalyst Performance}

Reaction studies were carried out in a laboratory-scale, fixed-bed reaction system. Partial oxidation step-response experiments were conducted at an O/C $=1.2$, a WHSV $=50,000$ $\mathrm{cm}^{3} / \mathrm{g}_{\mathrm{cat}} \cdot \mathrm{h}$, a pressure of $0.23 \mathrm{MPa}$, and a total inlet gas flow rate of $400 \mathrm{sccm}$. The composition of the feed was $2.17 \% n$-tetradecane (TD), $18.22 \% \mathrm{O}_{2}$, and the balance $\mathrm{N}_{2}$. The catalyst bed temperature was $900^{\circ} \mathrm{C}$. The catalysts were run under partial oxidation for two hours on pure $\mathrm{TD}$, then two hours on TD plus $50 \mathrm{ppm}$ sulfur as dibenzothiophene (DBT) and 5wt\% 1-methyl naphthalene (MN), then again for one hour on pure TD to observe the catalyst recovery.

Total carbon in the catalyst bed was determined by temperature programmed oxidation (TPO) of the catalysts plus bed material. TPO was performed by introducing a gas stream of $10 \mathrm{vol} \%$ $\mathrm{O}_{2} / \mathrm{N}_{2}$ into the reactor and was run from 200 to $900^{\circ} \mathrm{C}$ with a temperature ramp of $1{ }^{\circ} \mathrm{C} / \mathrm{min}$. $\mathrm{CO}_{2}$ evolution was measured continuously by a mass spectrometer and the total carbon that had been deposited in the bed was calculated by integration of the $\mathrm{CO}_{2}$ flow rate exiting the reactor.

\subsubsection{Results and Discussion}

\subsubsection{Catalyst Characterization}

Characterization of the catalyst materials included BET surface area and ICP for composition. A summary of this data is presented in Table 2-1. The surface areas for the layered catalysts indicate that as the amount of BNHA phase increases the surface area of the supported material approaches that of the bulk BNHA.

Table 2-1Summary of Characterization Data.

\begin{tabular}{lcc}
\hline \multicolumn{1}{c}{ Catalyst } & $\begin{array}{c}\text { BET Surface } \\
\text { Area }\left(\mathrm{m}^{2} / \mathrm{g}\right)\end{array}$ & $\begin{array}{c}\text { Ni content } \\
(\mathrm{wt} \%)\end{array}$ \\
\hline GDC & $<1$ & -- \\
BNHA & 13 & 2.60 \\
10\% BNHA /GDC & 2 & 0.24 \\
20\% BNHA/GDC & 3 & 0.53 \\
50\% BNHA /GDC & 6 & 1.40 \\
\hline
\end{tabular}

\subsubsection{Catalyst Performance}

Figure 2-2 presents the results of the CPOX studies conducted with the bulk BNHA and the BNHA catalysts on the GDC at different coverages. The performance was measured by hydrogen production over the 5-h reaction studies. The results indicate that as the coverage of the support increases, the performance approaches that of the bulk BNHA. This is a result of the decreasing ability of the support to improve performance. Further, it suggests that an optimum 
coverage exists for a given catalyst-support system. This is likely related to the ratio of the exposed surface areas of the two phases, as well as the oxygen-conducting properties of the support.

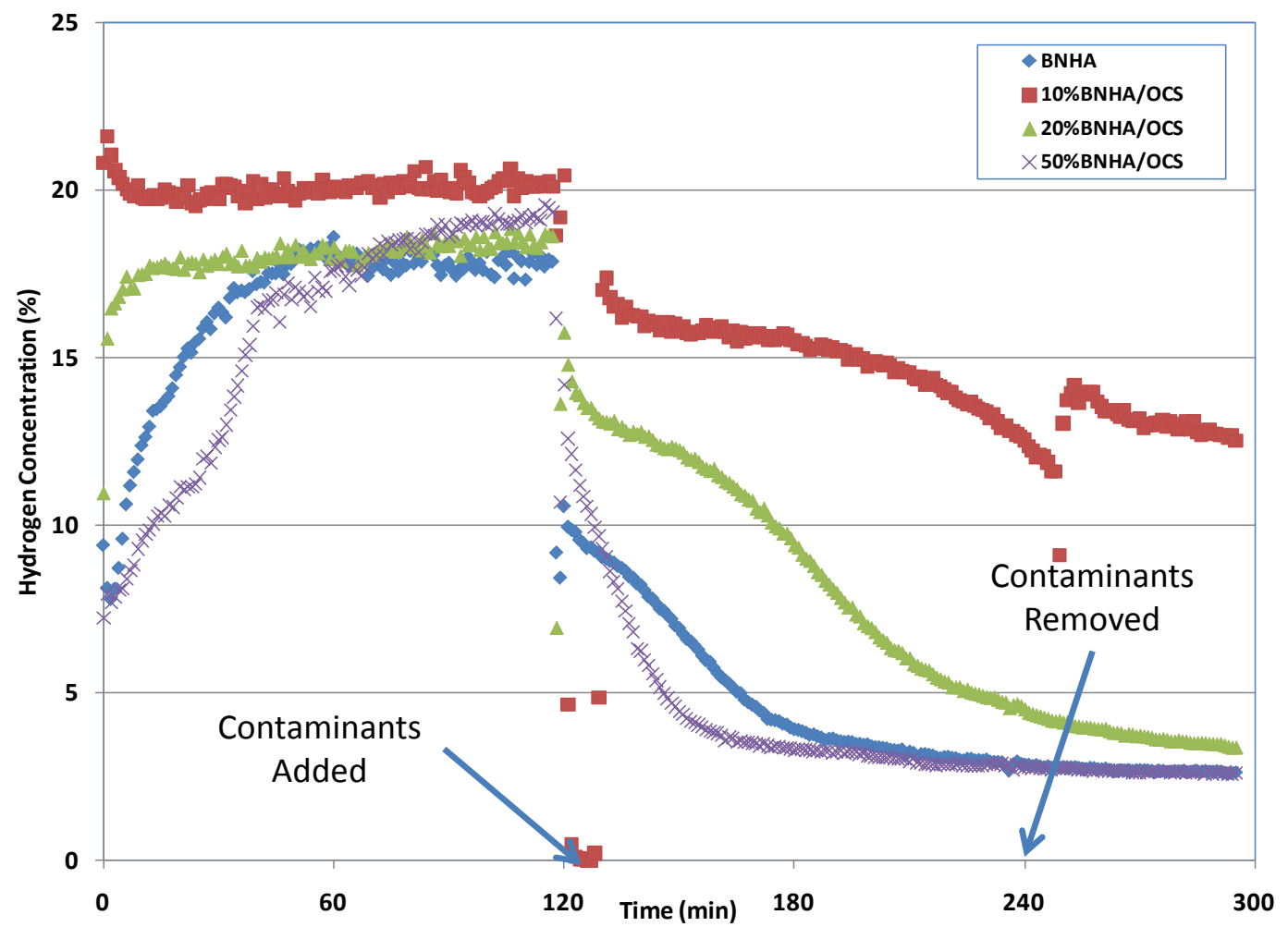

Figure 2-2 Performance of BNHA catalysts over GDC at different surface coverages for the CPOX of TD: WHSV $=50,000 \mathrm{scc} \mathrm{g}_{\mathrm{cat}}{ }^{-1} \mathrm{~h}^{-1}, \mathrm{O} / \mathrm{C}=1.2,900^{\circ} \mathrm{C}$, and $0.23 \mathrm{MPa}$.

Table 2-2 provides the amount of carbon formed in the catalyst bed for the GDC-supported catalysts during reaction. Increasing the coverage area from 10 to $20 \mathrm{wt} \%$ increased the carbon formation in the reactor. The 20wt\%BNHA/GDC catalyst produced nearly the same amount of carbon as the bulk BNHA catalyst.

Table 2-2 Summary of Carbon Formation on GDC Supported Catalysts.

\begin{tabular}{lc}
\hline \multicolumn{1}{c}{ Catalyst } & $\begin{array}{c}\text { Total Bed } \\
\text { Carbon }(\mathrm{g})\end{array}$ \\
\hline GDC & -- \\
BNHA & 0.80 \\
10\% BNHA /GDC & 0.62 \\
20\% BNHA/GDC & 0.84 \\
50\% BNHA /GDC & 0.53 \\
\hline
\end{tabular}

Figure 2-3 presents the results of the BNHA catalyst deposited onto ZDC at 10, 15, and 20 wt\%. All three catalysts had significantly improved performance over unsupported BNHA (Figure 2). Similar to the GDC support, increasing the loading of the active phase on the oxygen-conducting support led to a decline in performance. At $20 \mathrm{wt} \%$ the catalyst deactivates completely with no recovery after removal of fuel contaminants at $240 \mathrm{~min}$. This result indicates that for BNHA, a 
large amount of surface area from the oxygen-conducting support (GDC or ZDC) needs to be available to produce stable performance under CPOX of TD.

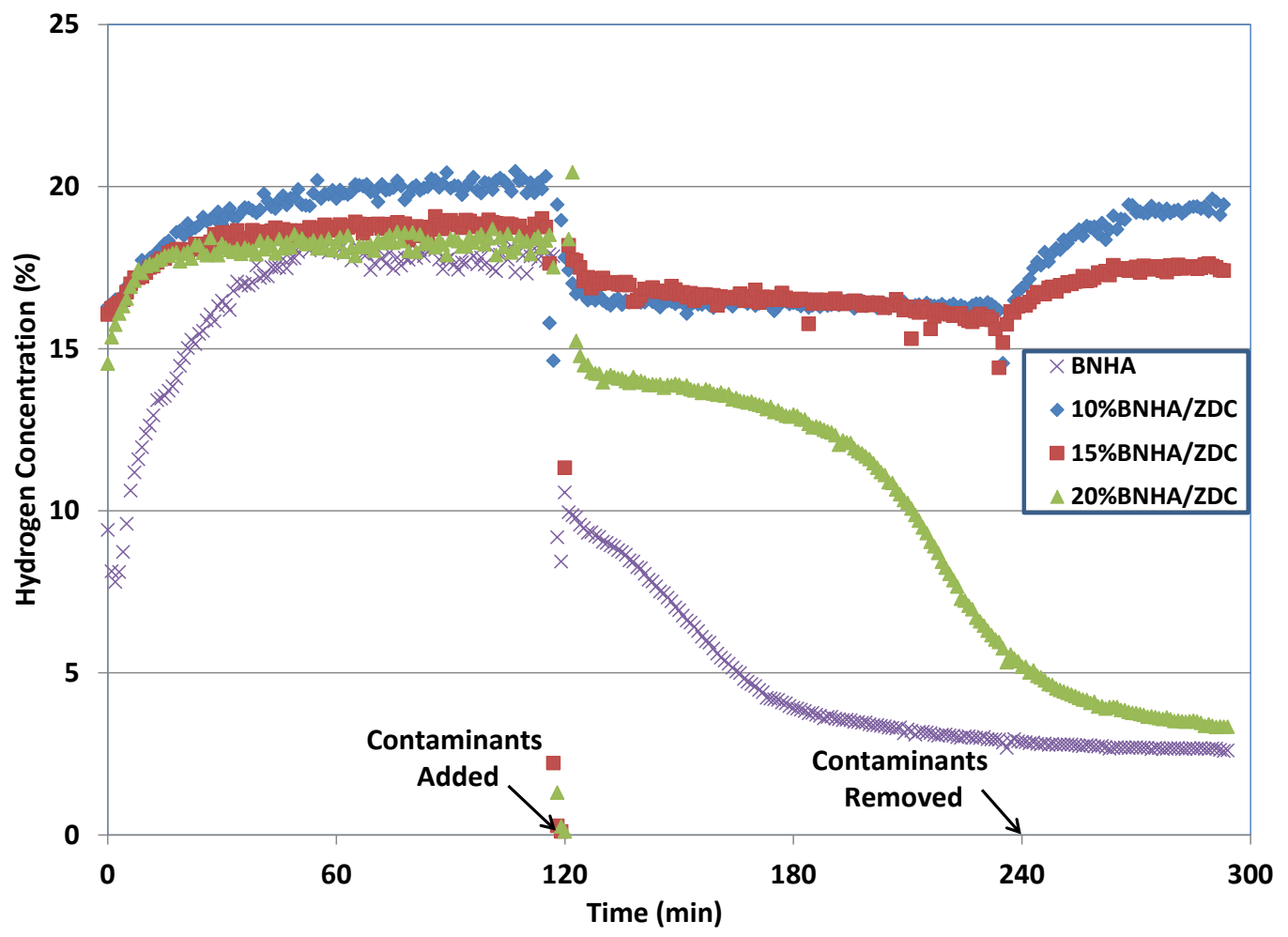

Figure 2-3 Performance of BNHA catalysts over ZDC at different surface coverages for the CPOX of TD: WHSV $=50,000 \mathrm{scc} \mathrm{g}_{\mathrm{cat}}^{-1} \mathrm{~h}^{-1}, \mathrm{O} / \mathrm{C}=1.2,900^{\circ} \mathrm{C}$, and $0.23 \mathrm{MPa}$.

Table 2-3 presents the total carbon, measured by TPO, formed in the catalyst bed during reaction tests with the BNHA deposited on ZDC at different loadings. There is a clear trend between the TBC and performance, where the most stable performance (10wt\%BNHA/ZDC) corresponds to the lowest quantity of carbon. Compared to the GDC support, the carbon produced with the 20wt\%BNHA/ZDC was notably less than the unsupported BNHA. This is likely due to the higher surface area of ZDC, which improves its role of supplying oxygen to the active phase to gasify the carbon deposits as $\mathrm{CO}$ to a greater extent.

Table 2-3 Summary of Carbon Formation on ZDC Supported Catalysts.

\begin{tabular}{lcc}
\hline \multicolumn{1}{c}{ Catalyst } & $\begin{array}{c}\text { BET Surface } \\
\text { Area }\left(\mathrm{m}^{2} / \mathrm{g}\right)\end{array}$ & $\begin{array}{c}\text { Total Bed } \\
\text { Carbon }(\mathrm{g})\end{array}$ \\
\hline ZDC & 21 & -- \\
BNHA & 13 & 0.80 \\
10\% BNHA /ZDC & 15 & 0.29 \\
15\% BNHA/ZDC & 14 & 0.41 \\
20\% BNHA /ZDC & 14 & 0.65 \\
\hline
\end{tabular}

Although Ni-based catalysts offer a potential cost benefit over noble metal-based catalysts, longterm stability was still not observed in these studies for the BNHA catalyst, even when combined with oxygen-conducting supports. Therefore, Rh-substituted pyrochlore catalysts were also tested for the same reaction with different loadings on ZDC. The pyrochlore was a lanthanum 
zirconate $\left(\mathrm{La}_{2} \mathrm{Zr}_{2} \mathrm{O}_{7}\right)$, previously studied as a bulk catalyst by Haynes, et al. [71, 82]. The A-site was doped with $\mathrm{Ca}$ and the active $\mathrm{Rh}$ was substituted into the B-site to give the formula $\mathrm{La}_{1.89} \mathrm{Ca}_{0.11} \mathrm{Zr}_{1.89} \mathrm{Rh}_{0.11} \mathrm{O}_{7-\delta}$ (LCZR). This catalyst was deposited onto ZDC via SSM at 10 and 20 $w t \%$. The results of long-term CPOX tests on these catalysts are presented in Figure 2-4. As the data show, a step-response test was not performed since the deactivation was significantly slower than with the Ni-based catalysts. Further, the performance improved for the 20wt\% loaded catalyst over the $10 \mathrm{wt} \%$, showing no deactivation for $\sim 50 \mathrm{~h}$. This suggests that the LCZR catalyst does not need as much of the oxygen-conducting support to significantly improve catalyst performance. This may be due to the fact that the pyrochlore structure possesses inherent oxygen-conducting properties itself. Finally, these results support the idea that optimum ratio of the active to support phase will not be the same for different combinations of catalysts and supports.

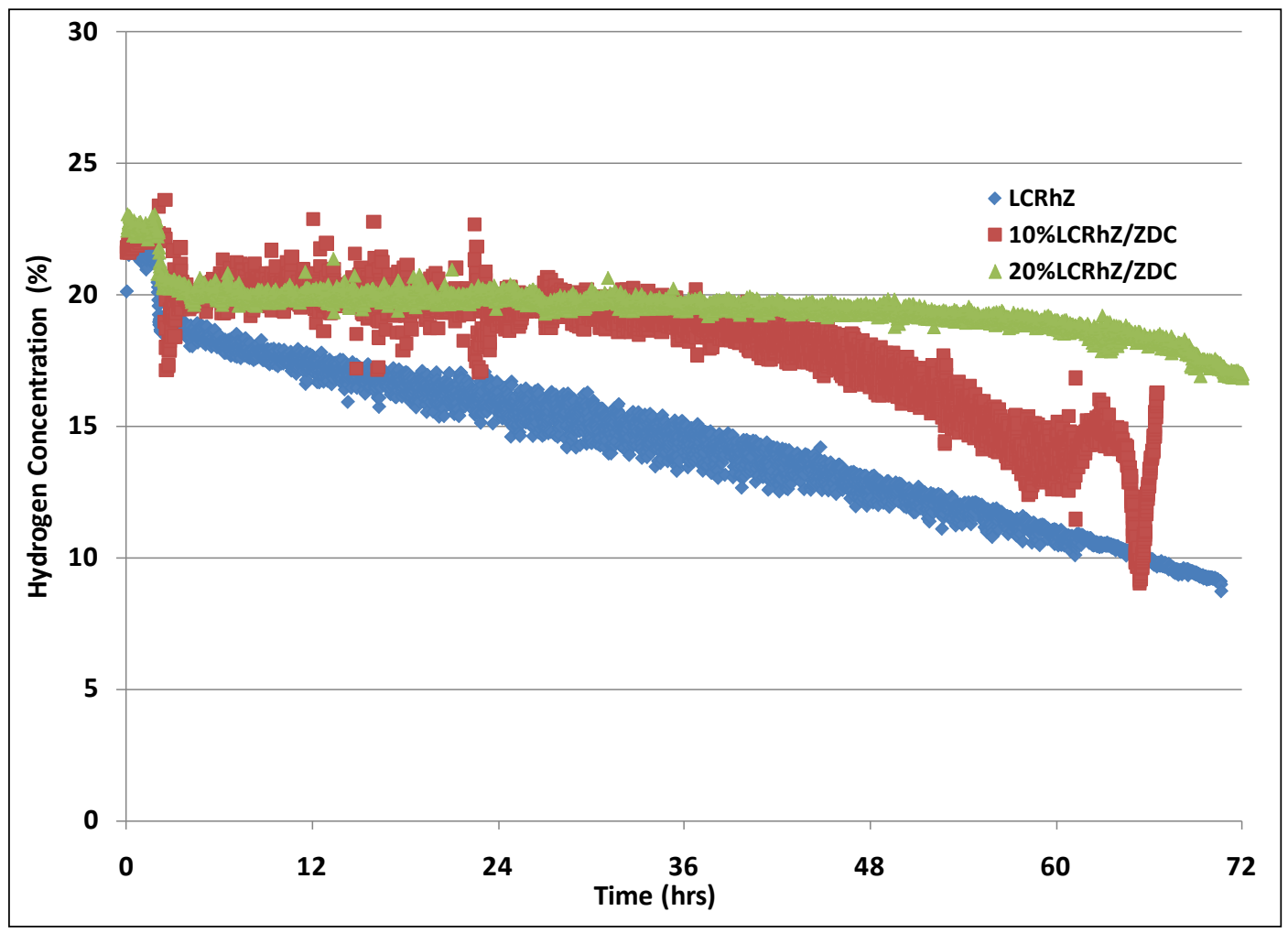

Figure 2-4 Performance of LCZR catalyst over ZDC at different surface coverages for the CPOX of TD: WHSV $=50,000 \mathrm{scc} \mathrm{g}_{\text {cat }}{ }^{-1} \mathrm{~h}^{-1}, \mathrm{O} / \mathrm{C}=1.2,900^{\circ} \mathrm{C}$, and $0.23 \mathrm{MPa}$.

\subsubsection{Conclusions}

Substitution of a catalytically active metal into a mixed-oxide structure for hydrocarbon fuel reforming provides thermal stability and reduced deactivation by preventing the clustering of active sites typically observed in the presence of sulfur contaminants. Depositing the substituted oxide catalyst onto an oxygen-conducting support reduced deactivation from carbon formation in presence of aromatic species. An optimum level of coverage exists for a given combination of active and support phases, beyond which the supported catalyst performs like the unsupported catalyst. 


\subsection{Effect of Synthesis Method}

Note: Section 2.2 was originally published as, "Partial oxidation of liquid hydrocarbons in the presence of oxygen-conducting supports: Effect of catalyst layer deposition,” in Fuel [70].

\subsubsection{Introduction}

For the foreseeable future, fossil-derived liquid hydrocarbons will be the energy source for the majority of transportation needs; however, the relatively low efficiency of internal combustion engines has provided a great deal of incentive for the development of more efficient conversion devices, such as fuel cells, for both transportation and stationary applications. Specifically, solid oxide fuel cells (SOFC) are attractive due to their high operating temperatures $\left(>800^{\circ} \mathrm{C}\right)$ and their ability to convert a hydrogen- and carbon monoxide-rich gas stream to electric power at high efficiencies. Liquid fuels like gasoline, diesel, coal-derived liquids, and Fischer-Tropsch fuels can all be reformed to produce such a gas stream. Diesel fuel is considered to be the best choice for this application since it has the highest energy density and a well-developed distribution infrastructure.

A significant application of interest for SOFCs is auxiliary power units (APUs) for commercial diesel trucks. APUs powered by SOFCs will reduce idling time, and consequently the emissions of combustion products. SOFCs can also be used for distributed and remote power, such as military, industrial, residential, and commercial applications. The greatest challenge to producing a usable feed stream for SOFCs is the development of an effective catalyst system that can reform liquid fuels into hydrogen and carbon monoxide for long periods of time at high temperatures without deactivation. The most desirable reforming mode for these applications is partial oxidation because it is simple and does not require water addition. Supported-metal catalysts typically studied for fuel reforming are deactivated quickly by sulfur and aromatic species through sulfur poisoning and carbon (coke) deposition. Further, high operating temperatures, typically above $900^{\circ} \mathrm{C}$, can produce deactivation via catalyst sintering and vaporization.

Approaches to minimize catalyst deactivation from sulfur and aromatic contaminants during reforming have included 1) using oxygen-conducting supports [53, 75, 95], and 2) substituting active metal particles into thermally stable oxide structures, such as perovskites, $\mathrm{ABO}_{3}$, [96-101], pyrochlores, $\mathrm{A}_{2} \mathrm{~B}_{2} \mathrm{O}_{7},[71,82,102,103]$, and hexaaluminates, $\mathrm{AAl}_{12} \mathrm{O}_{19}$, [69, 94, 96]. Although these approaches have demonstrated some improvement, deactivation still occurs rapidly under partial oxidation conditions. However, combining these approaches by supporting thermally stable oxides on oxygen-conducting supports has led to a synergistic effect in the partial oxidation of $n$-tetradecane (TD) containing sulfur and aromatic species [104].

The study presented here examines a Ni-substituted hexaaluminate catalyst over gadoliniumdoped ceria (GDC) support. The hexaaluminate structure (Figure 2-5) consists of a spinel block of close packed oxide ions that are charge balanced by two large mono-, di-, or trivalent cations. These cations are found in a mirror plane at opposite ends of the spinel block. The catalytically active metals can be substituted into the aluminum sites of the spinel block. 


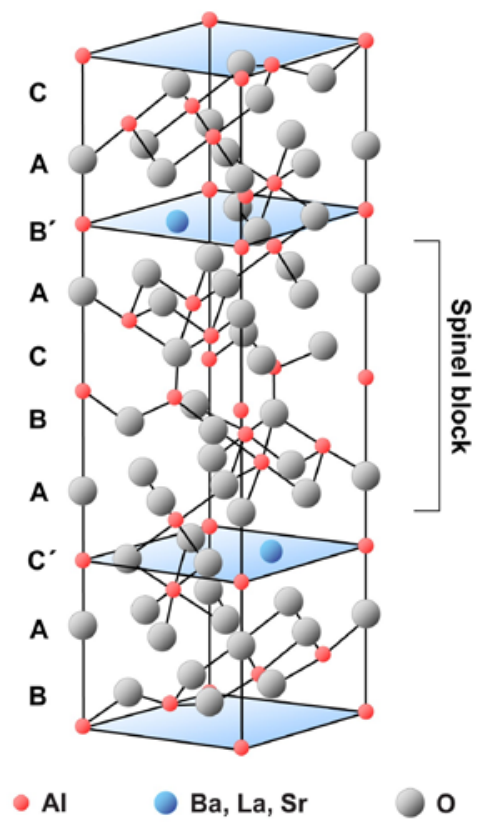

Figure 2-5 Crystal structure of hexaaluminate [62]; Ni particles are substituted into the Al sites.

Hexaaluminates possess qualities that make them attractive as catalysts for the partial oxidation reaction. They exhibit very high thermal stability, as evidenced by their application in combustion catalysis [105-111]. However, unlike doped pyrochlores [112], hexaaluminates are not ion conductive, suggesting that supporting them on an ion conducting support may improve their resistance to deactivation. Gardner, et al. [69] examined the effect of hexaaluminate A-site substitution on resistance to sulfur poisoning in the partial oxidation of a surrogate diesel fuel. The divalent cations Sr and Ba demonstrated better resistance to sulfur poisoning than the trivalent La.

For the present study, the catalytically active phase chosen was Ni-substituted bariumhexaaluminate (BNHA). Here, the hexaaluminate is supported onto Gd-doped ceria (GDC), an oxygen-conducting material. Several investigations have examined the effect of doped ceria materials and their oxygen-conducting properties on hydrocarbon reforming [113-115].

The specific purpose of this study was to compare two methods of supporting a bariumsubstituted nickel hexaaluminate (BNHA): (1) conventional incipient wetness impregnation (IWI) of the GDC support using an aqueous solution of the precursors, followed by drying and calcinations, and 2) solid-state mixing (SSM), which consisted of mechanically grinding solid hexaaluminate particles, produced separately as a bulk powder, together with the GDC powder, followed by thermal treatment of the mixture to improve the interaction of the hexaaluminate and the support. The preparation technique used in catalyst synthesis has been shown to have an effect on catalytic performance [116-118]. The performances of these materials were also compared to base case catalysts: Ni-metal supported on alumina and GDC, and bulk BNHA. 


\subsubsection{Experimental Methods}

\subsubsection{Catalyst Synthesis}

\subsection{Baseline Catalysts}

Ni-Metal Supported on Alumina and GDC

Gadolinium-doped ceria (GDC), $\mathrm{Gd}_{0.1} \mathrm{Ce}_{0.9} \mathrm{O}_{2-\mathrm{x}}$, was prepared by NexTech Materials (Worthington, $\mathrm{OH}$ ) using co-precipitation followed by hydrothermal crystallization. The resulting crystallized powder was calcined at $800^{\circ} \mathrm{C}$ for $4 \mathrm{~h}$ to stabilize its surface area. The material was ground by hand in a mortar and pestle prior to catalyst application. $\gamma$-alumina pellets were obtained commercially from Saint-Gobain NorPro (Stow, OH) and were also ground in a mortar and pestle. The supported Ni metal catalysts were prepared by impregnation using $\mathrm{Ni}\left(\mathrm{NO}_{3}\right)_{2}$ in de-ionized water: (1) 3wt\%Ni/alumina and (2) 3wt\%Ni/GDC. The catalysts were dried at $110^{\circ} \mathrm{C}$ and calcined for $4 \mathrm{~h}$ at $950^{\circ} \mathrm{C}$.

\section{Bulk Hexaaluminate}

The bulk nickel-substituted barium hexaaluminate (BNHA) catalyst, $\mathrm{BaNi}_{0.4} \mathrm{Al}_{11.6} \mathrm{O}_{18.8}$, was prepared by the co-precipitation method described in detail elsewhere [69], and contained a loading of $3 \mathrm{wt} \% \mathrm{Ni}$. Briefly, nitrate precursors of each metal $\left(\mathrm{Ba}\left(\mathrm{NO}_{3}\right)_{2} \bullet \times \mathrm{H}_{2} \mathrm{O}\right.$, $\left.\mathrm{Ni}\left(\mathrm{NO}_{3}\right)_{2} \bullet \mathrm{xH}_{2} \mathrm{O}, \mathrm{Al}\left(\mathrm{NO}_{3}\right)_{3} \bullet \mathrm{xH}_{2} \mathrm{O}\right)$ obtained from Alfa Aesar were dissolved in de-ionized water at $60^{\circ} \mathrm{C}$ in appropriate stoichiometric ratios. This solution was added drop wise to a solution of excess ammonium carbonate; the precipitates formed were aged for $6 \mathrm{~h}$ at $60^{\circ} \mathrm{C}$ with stirring. The aged precipitates were collected by vacuum filtration, rinsed with de-ionized water to remove excess ammonia, and dried overnight at $110^{\circ} \mathrm{C}$. The dried material was heat treated at $425^{\circ} \mathrm{C}$ for one hour to convert the carbonates to an amorphous oxide powder, and then finally calcined at $1300^{\circ} \mathrm{C}$ for $4 \mathrm{~h}$ to form the hexaaluminate phase.

\subsection{Supported Hexaaluminates (10wt\%BNHA/GDC)}

\section{Incipient Wetness Impregnation (IWI) Method}

Nitrate salt precursors in appropriate stoichiometric proportions were dissolved in de-ionized water in a quantity to yield a $10 \mathrm{wt} \%$ layer of BNHA on the support. The solution was applied with a dropper in several applications to the support with drying at $110^{\circ} \mathrm{C}$ between each. After all the solution had been applied, the salt layer on the support was decomposed to an amorphous oxide phase by heat treatment at $425^{\circ} \mathrm{C}$ for one hour with a temperature ramp rate of $5{ }^{\circ} \mathrm{C} / \mathrm{min}$. The material was then calcined in air for $2 \mathrm{~h}$ at $1300^{\circ} \mathrm{C}$ with a temperature ramp rate of $2^{\circ} \mathrm{C} / \mathrm{min}$ to form the hexaaluminate phase.

\section{Solid-State Mixing (SSM) Method}

The SSM method combined the preformed bulk BNHA powder and the GDC powder by grinding in a mortar and pestle to form a well-mixed powder. De-ionized water was added to the mixed powder to form a thick paste which was dried at $110^{\circ} \mathrm{C}$ to produce pellet-like structures. This material was then heat treated at $950^{\circ} \mathrm{C}$ for $12 \mathrm{~h}$ with a ramp rate of $5{ }^{\circ} \mathrm{C} / \mathrm{min}$ to increase contact between the two phases. Figure 2-6 schematically shows the difference between the two preparation methods. 


\section{Incipient Wetness Impregnation}

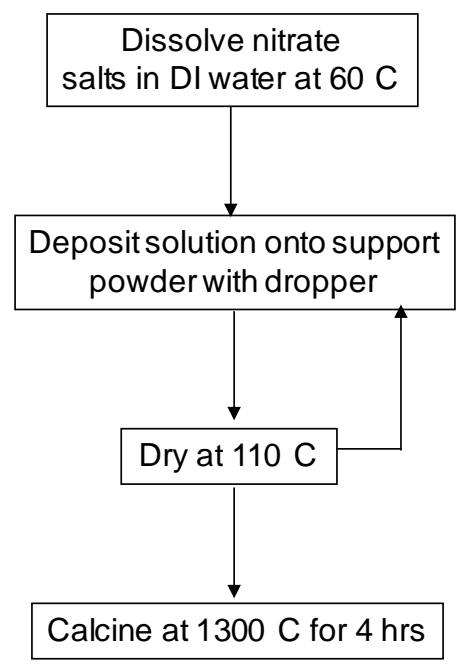

\section{Solid-state Mixing}

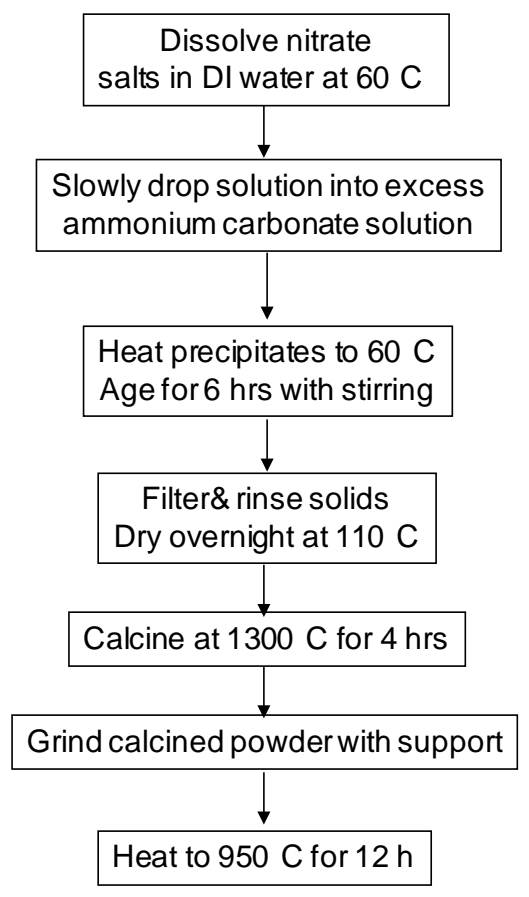

Figure 2-6 Diagram of catalyst deposition methods.

\subsubsection{Material Characterization}

BET surface area was determined by $\mathrm{N}_{2}$ adsorption using a Quantachrome Surface Area Analyzer 2000. The bulk Ni concentration for each catalyst was determined by inductively coupled plasma (ICP) optical emission spectroscopy on a Perkin-Elmer Optima 3000 ICP-OES spectrometer. The crystalline phases present in each sample were determined by powder $\mathrm{X}$-ray diffraction (XRD) using a PANalytical X'Pert PRO model XRD, utilizing filtered $\mathrm{Cu} \mathrm{K} \alpha$ radiation. Scanning electron microscopy (SEM) images were obtained and electron diffraction spectroscopy (EDS) analyses were conducted with a Hitachi S-4700 field emission electron microscope.

\subsubsection{Reaction Studies}

The experimental system used for this study as well as its detailed description is documented elsewhere [75]. Briefly, these runs were carried out in a fixed bed continuous-flow reactor. The catalysts were sized to $-8 /+30$ mesh and diluted with quartz sand (5/1 by weight) to avoid channeling and to minimize temperature gradients. The catalysts were loaded into the reactor as formed with no pretreatment or reduction. The bed was placed in a tubular reactor (8 $\mathrm{mm}$ i.d.) with a coaxially centered thermocouple at the center of the bed. Nitrogen and air flows were delivered by mass flow controllers and the liquid fuel feed was delivered by a high accuracy HPLC dual pump.

n-Tetradecane (TD) was used as a model diesel fuel compound to screen catalysts for activity and selectivity. The sulfur tolerance of the catalysts was assessed through partial oxidation of $n$ - 
tetradecane containing 50 ppmw sulfur as dibenzothiophene (DBT). 1-Methylnaphthalene (MN) (5 wt\% of feed) was used as a model compound for polyaromatics present in diesel fuel.

All catalysts were run under partial oxidation for two hours on pure TD, then two hours on TD plus $50 \mathrm{ppm}$ sulfur as DBT and $5 \mathrm{wt} \% \mathrm{MN}$, then again for one hour on pure TD to observe the catalyst recovery. Additionally, and extended run with fresh samples of the two GDC-supported BNHA catalysts was conducted for two hours on pure TD, and then on the TD plus DBT and MN until the hydrogen level in the product stream was $50 \%$ of the initial concentration, without switching back to pure TD. The reaction conditions are presented in Table 2-4.

Table 2-4 Reaction Conditions for Partial Oxidation Step-response Experiments.

\begin{tabular}{lc}
\hline \multicolumn{1}{l}{ Conditions } \\
\hline Total Flow (sccm) & 300 \\
$n-\mathrm{TD}$, vol\% & 2.17 \\
$\mathrm{O}_{2}$, vol\% & 18.22 \\
$\mathrm{~N}_{2}$, vol\% & 79.61 \\
O/C ratio & 1.2 \\
Catalyst bed $(\mathrm{g})$ & 0.48 \\
GHSV $\left(\mathrm{scc} / \mathrm{g}_{\mathrm{cat}}{ }^{\circ} \mathrm{hr}\right)$ & 50,000 \\
& \\
Pressure $(\mathrm{MPa})$ & 0.23 \\
Feed preheat T $\left({ }^{\circ} \mathrm{C}\right)$ & 375 \\
Center bed T $\left({ }^{\circ} \mathrm{C}\right)$ & 900 \\
\hline
\end{tabular}

\subsubsection{Carbon Deposition}

Total carbon in the catalyst bed was determined by temperature programmed oxidation (TPO) of the catalysts plus bed material after each activity test. TPO was performed by introducing a gas stream of $10 \mathrm{vol} \% \mathrm{O}_{2} / \mathrm{N}_{2}$ into the reactor and was run from 200 to $900^{\circ} \mathrm{C}$ with a temperature ramp of $1{ }^{\circ} \mathrm{C} / \mathrm{min}$. $\mathrm{CO}_{2}$ evolution was measured continuously by a mass spectrometer and the total carbon deposited in the bed, including any carbon deposited on the quartz diluent, was calculated by integration of the $\mathrm{CO}_{2}$ concentration versus temperature curve.

\subsubsection{Product Analysis}

The gases (hydrogen, nitrogen, oxygen, carbon monoxide, carbon dioxide, and methane) were analyzed using a 200 amu scanning magnetic sector mass spectrometer (Thermo ONIX, model no. Prima $\delta b)$. The gaseous hydrocarbon products $\left(C_{1}-C_{6}\right.$ paraffins, $C_{2}-C_{6}$ olefins, and benzene) were analyzed using a HP5890 gas chromatograph equipped with a flame ionization detector (FID). Oxygen conversion was complete during all experiments. Although water was produced in the reaction it was not quantitatively analyzed. Carbon balances were typically within 100 $\pm 5 \%$. 
Yield of product A (hydrogen, carbon monoxide, or carbon dioxide) is defined as:

$$
\text { Yield of } A(\%)=\frac{\text { Moles of A produced } x 100}{\mathrm{~N} x \text { moles of hydrocarbon fed to the reactor }}
$$

where, $\mathrm{N}$ is the number of moles of hydrogen/mole of hydrocarbon for hydrogen yields and the number of carbons in hydrocarbon fuel for carbon oxides.

Yield of hydrocarbons (olefins, paraffins, and benzene) is defined as:

$$
\text { Hydrocarbon Yield }(\%)=\frac{\mathrm{m} \times \text { moles of hydrocarbon produced } \mathrm{x} 100}{\mathrm{~N} \text { x moles of hydrocarbon fed to the reactor }}
$$

where, $\mathrm{m}$ is the number of carbons in the hydrocarbon product.

\subsubsection{Results and Discussion}

\subsubsection{Materials Characterization}

The BET surface area and Ni content of the catalysts are summarized in Table 2-5. Comparison of the surface areas of the two GDC-supported materials indicates that the preparation methods produce very similar morphology. The Ni loading of these two materials were also essentially the same, as determined by ICP analysis. Further, temperature programmed reduction (TPR) experiments (data not shown) demonstrated no significant difference in the reduction temperature of the two supported catalysts before or after reaction studies.

\begin{tabular}{|c|c|c|}
\hline Catalyst/support & $\begin{array}{c}\text { BET SA } \\
\left(\mathrm{m}^{2} / \mathrm{g}\right)\end{array}$ & $\begin{array}{c}\text { Ni content } \\
(w t \%)^{\star}\end{array}$ \\
\hline$\gamma$-alumina & 111 & -- \\
\hline GDC & $<1$ & -- \\
\hline $3 w t \%$ Ni $/ \gamma$-alumina & 74 & 2.6 \\
\hline $3 w t \% \mathrm{Ni} / G D C$ & 2.2 & 2.0 \\
\hline Bulk BNHA & 13 & 2.6 \\
\hline 10wt\%BNHA/GDC - SSM & 1.6 & 0.24 \\
\hline 10wt\%BNHA/GDC - IWI & 1.6 & 0.26 \\
\hline
\end{tabular}

Table 2-5: Comparison of surface area and Ni content of reforming catalysts.

* Determined by ICP-OES

Figure 2-7 shows the XRD spectra for the bulk BNHA, the GDC support, and the two BNHA/support catalysts prepared by IWI and SSM. These spectra indicate that the hexaaluminate phase was present in both GDC-supported materials even though the hexaaluminate peaks had relatively low intensity, possibly because only $10 \mathrm{wt} \%$ of the material was the hexaaluminate phase. The major hexaaluminate peaks in the scans of the GDCsupported materials were observed at $2 \theta=31.7^{\circ}, 33.0^{\circ}, 35.5^{\circ}, 42.0^{\circ}, 44.6^{\circ}, 57.5^{\circ}$, and $66.5^{\circ}$ (JCPDS: 26-0135). 
Figure 2-8 contains SEM images and EDS spectra for the GDC-supported BNHA catalysts prepared by the two different deposition methods. The images provided are representative of images obtained for several particles for each sample at different magnifications. The materials prepared by both methods had similar particle sizes and morphology and produced non-uniform deposits of BNHA on GDC. These images indicate that a greater amount of the smooth, GDC support surface is visible for the catalyst prepared by IWI. This results in greater contact between the oxygen-conducting support surface and the gas phase during reaction. This increased contact area results in an increase in the exchange of oxygen from the gas phase to the support and ultimately more oxygen conducted to the active catalyst to prevent carbon formation.

The circled areas indicate the location on the samples where EDS analysis was performed. The SEM images for both samples contain particles with exposed areas of the GDC support surface around areas of deposited BNHA catalyst. This is supported by the presence of the $\mathrm{Ba}, \mathrm{Al}, \mathrm{Ce}$, and Gd peaks in Figure 2-8(b,d).

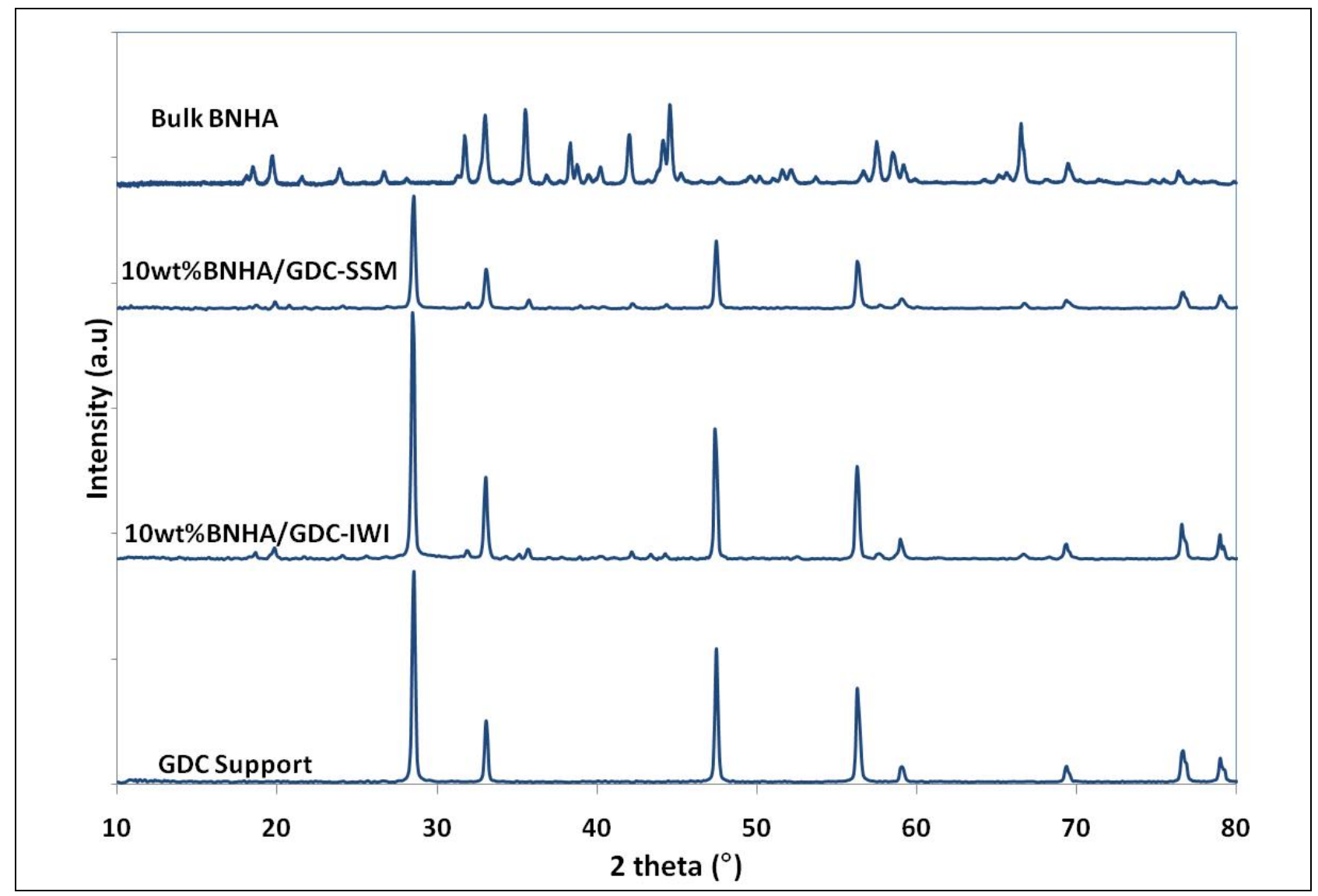

Figure 2-7: XRD spectra for GDC supported BNHA system. 


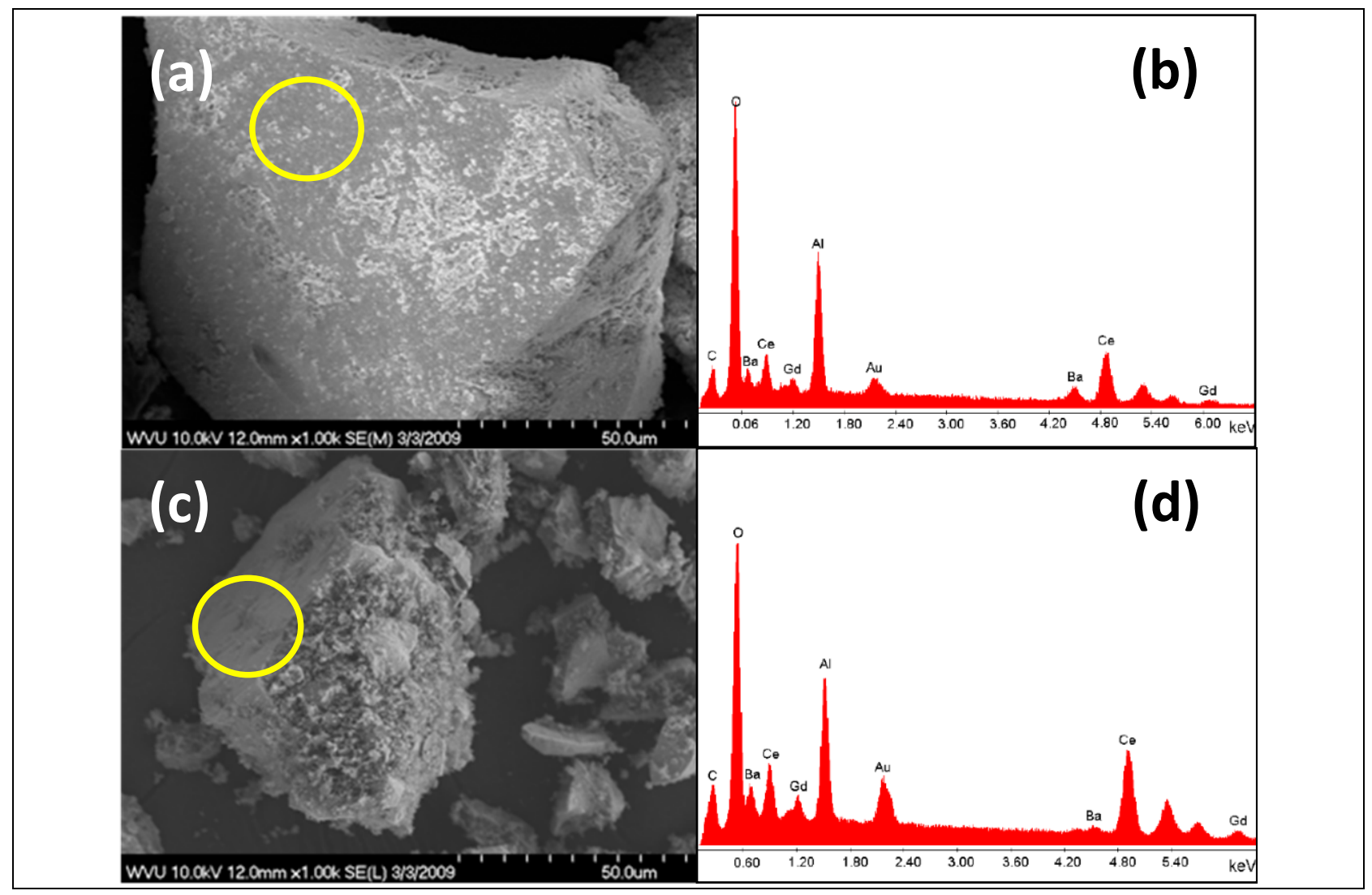

Figure 2-8: SEM images and EDS spectra for catalysts prepared by different methods: $(a, b)$ 10wt\%BNHA/GDC-IWI, (c,d) 10wt\%BNHA/GDC-SSM. The EDS peaks for Au are present since the samples were non-conducting and had to be coated for SEM images.

\subsubsection{Reaction Studies}

Figure 2-9 shows the product yields for three catalysts: $3 w t \% \mathrm{Ni} /$ alumina, 3wt $\% \mathrm{Ni} / \mathrm{GDC}$, and bulk BNHA. The 3wt\%Ni/alumina produced the highest hydrogen and carbon monoxide yields. The 3wt $\% \mathrm{Ni} / \mathrm{GDC}$ demonstrated very low hydrogen and carbon monoxide production, even on pure TD. The poor performance of this material may be explained by the low surface area of the support, which produces fewer and larger metal sites that are more likely to deactivate under these conditions. The lower yields of hydrogen and carbon monoxide may also be an indication that the oxygen-conducting support inhibits the activity of the Ni sites by preventing them from fully reducing to a metallic state.

For the bulk BNHA hexaaluminate, relatively few of the metal sites in the hexaaluminate material are available for participation in the reaction [61]. This may explain the slightly lower initial activity before the DBT and MN are introduced into the feed as well as the relatively rapid deactivation in the presence of these contaminants. All three catalysts deactivated completely within two hours of exposure to the contaminants, with the hydrogen and carbon monoxide yields reaching those of a reactor filled only with quartz material [69]. A corresponding increase in carbon dioxide and unconverted hydrocarbon (represented as methane) yields occurs after exposure to contaminants, also indicative of catalyst site deactivation. None of the materials recovered activity when the feed was switched back to pure TD. 


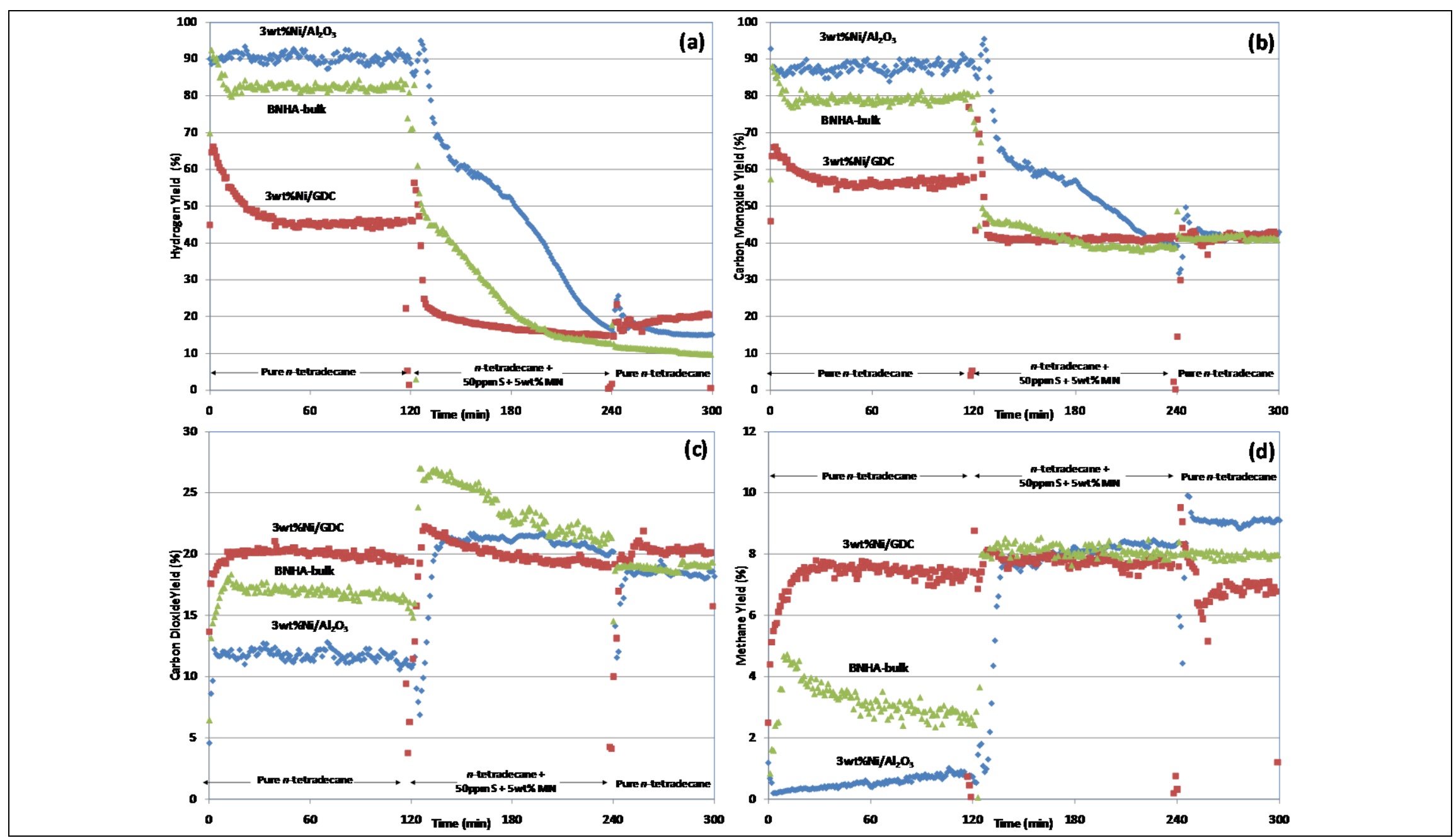

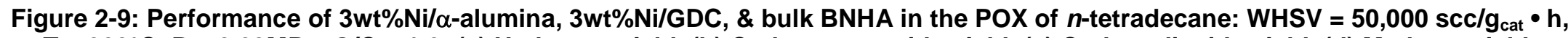
$\mathrm{T}=900^{\circ} \mathrm{C}, \mathrm{P}=0.23 \mathrm{MPa}, \mathrm{O} / \mathrm{C}=1.2:$ (a) Hydrogen yield, (b) Carbon monoxide yield, (c) Carbon dioxide yield, (d) Methane yield. 
Figure 2-10 contains the performance plots for the two GDC-supported BNHA catalysts prepared by the different deposition methods (IWI and SSM). Both catalysts produced near equilibrium conversions [69] for the two hours of testing on pure TD. Both catalysts suffered a rapid decrease in hydrogen and carbon monoxide yields within minutes of switching to the fuel containing sulfur and aromatic contaminants, accompanied by an increase in carbon dioxide and unconverted hydrocarbon (represented as methane) yields. Although the catalyst prepared by IWI had a more significant initial drop in product yields, this catalyst demonstrated more stable production throughout the two hours on in the presence of the contaminants, consistent with kinetic inhibition of the reaction rather than a cumulative effect of sulfur poisoning or carbon deposition. Further, the catalyst prepared by IWI demonstrated nearly complete recovery within one hour of switching the fuel back to pure TD, while the catalyst prepared by SSM remained at the reduced levels.

Figure 2-11 compares the olefin concentrations measured by GC during [the testing of] both of these catalysts. These species are believed to be precursors of carbon formation on active sites. Figure 2-11 certainly suggests that this was the case here. Note the continued olefin formation even after the contaminants are removed for the catalyst prepared by SSM, indicating the surface of the catalyst has been deactivated and reactions are occurring in the gas-phase.

Table 2-6 compares the total carbon formed on un-catalyzed GDC, bulk BNHA, and the two GDC-supported BNHA catalysts. The total carbon formed in a reactor filled only with the quartz material is also provided. The total carbon formed on the quartz and on the GDC was quantitatively similar, indicating that carbon formation occurs on the reactor packing material and/or reactor wall, even in the absence of reaction. This was expected since the TD conversion in the presence of GDC was equal to the conversion in the presence of quartz only.

It is evident that the oxygen-conducting properties of the GDC reduced the overall carbon formation in the supported catalysts compared to the bulk BNHA, which was likely responsible for the decreased rate of deactivation in both supported catalysts. There is no significant difference in the total carbon for these two catalysts, showing that these two ways of applying the BNHA to the GDC have little effect on the total amount of carbon formed.

TPO results in Figure 2-12 show similar profiles for the two GDC-supported catalysts. Further, the TPO peak temperature and shape of the curves for the quartz and the GDC alone show qualitatively similar carbon deposition as the catalysts. Comparing the bulk BNHA with the two GDC-supported BNHA materials shows a clear reduction in the total carbon deposition, consistent with the hypothesis that the oxygen-conducting GDC reduces carbon formation. The GDC support also appears to prevent the formation of the most refractory carbon, as evidenced by the higher TPO temperature required to oxidize the carbon on the bulk BNHA.

Figure 2-13 contains the results of the extended runs for the two GDC-supported BNHA catalysts during which the time needed for the hydrogen yield to drop to the same level was measured. The hydrogen yield for catalyst prepared by IWI decreased from 85\% to 35\%, ( 50\% of the initial hydrogen concentration) in the product stream for more than $4 \mathrm{~h}$ after exposure to DBT and MN, while the hydrogen yield for the material prepared by SSM decreased to the same level in $2 \mathrm{~h}$, consistent with the results presented in Figure 2-10. This significant difference suggests further that the catalyst prepared by incipient wetness resists deactivation for a longer period of time than a nominally identical material prepared by solid state mixing, apparently due to greater interaction of the oxygen-conducting GDC support. 


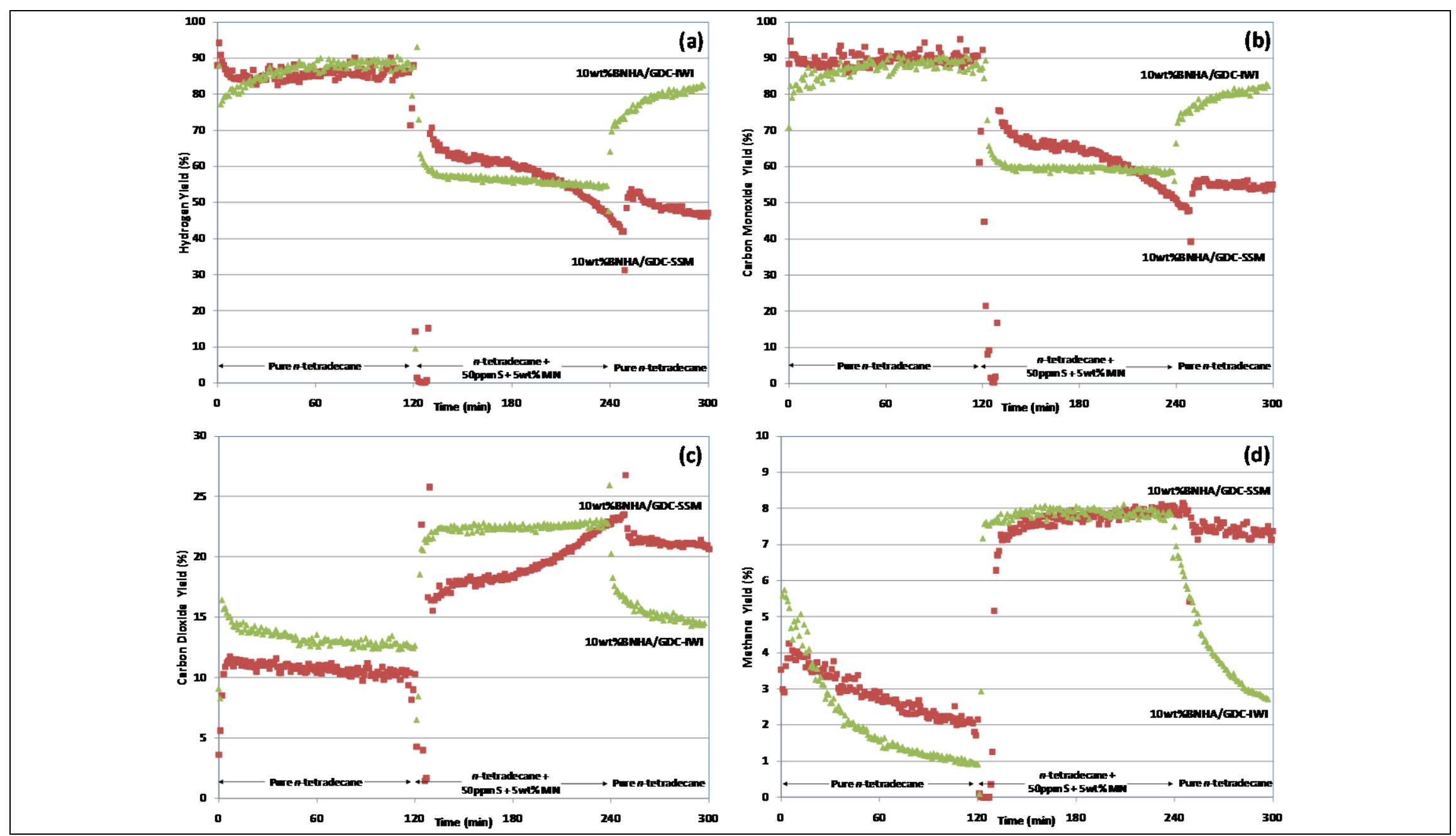

Figure 2-10: Performance of 10wt\%BNHA/GDC-SSM and 10wt\%BNHA/GDC-IWI in the POX of $n$-tetradecane: WHSV $=50,000 \mathrm{scc} / \mathrm{g}_{\mathrm{cat}} \cdot \mathrm{h}$, $\mathrm{T}=900^{\circ} \mathrm{C}, \mathrm{P}=0.23 \mathrm{MPa}, \mathrm{O} / \mathrm{C}=1.2$ : (a) Hydrogen yield, (b) Carbon monoxide yield, (c) Carbon dioxide yield, (d) Methane yield. 


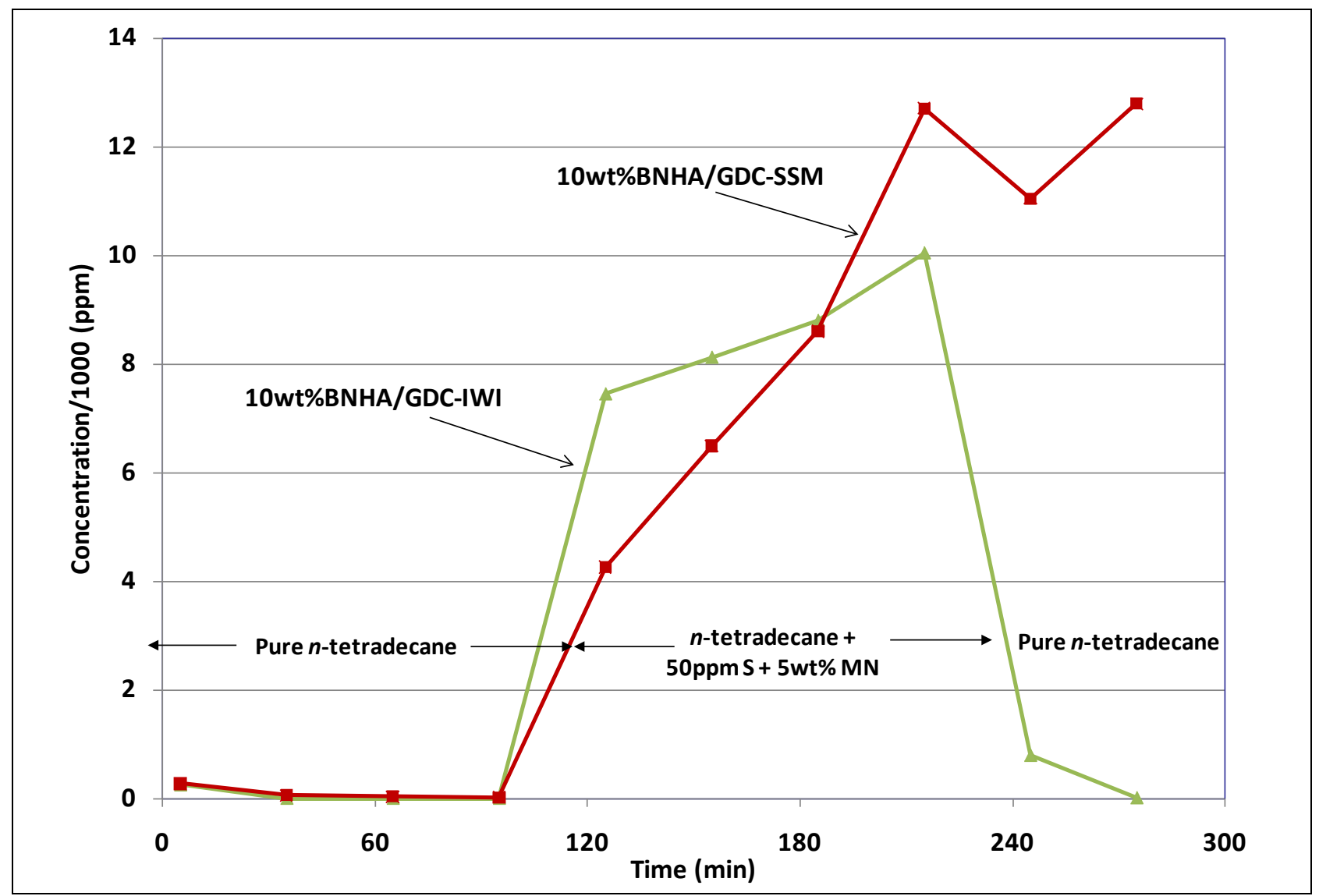

Figure 2-11: Olefin concentrations in product stream determined by GC for 10wt\%BNHA/GDC-SSM and 10wt\%BNHA/GDC-IWI in the partial oxidation of $n$-tetradecane: $W H S V=50,000 \mathrm{scc} / g_{\text {cat }} \bullet h$, $\mathrm{T}=900^{\circ} \mathrm{C}, \mathrm{P}=0.23 \mathrm{MPa}, \mathrm{O} / \mathrm{C}=1.2$.

Table 2-6: Total bed carbon (TBC) formed during CPOX tests.

\begin{tabular}{lc}
\hline Catalyst & TBC (g) \\
\hline Quartz & 0.29 \\
GDC & 0.26 \\
Bulk BNHA & 0.87 \\
10wt\%BNHA/GDC - SSM & 0.62 \\
10wt\%BNHA/GDC - IWI & 0.60 \\
\hline
\end{tabular}

The total carbon formed in the bed for these runs is provided in Table 2-7. The run with the catalyst prepared by IWI produced substantially more carbon in the reactor, yet remained more active longer. The additional carbon is a result of a longer time on stream in the presence of contaminants. It should be noted that the time scales of the two experiments using the catalyst prepared by SSM were roughly similar and the amount of carbon deposited in the bed is consistent with the results presented in Table 2-6. 


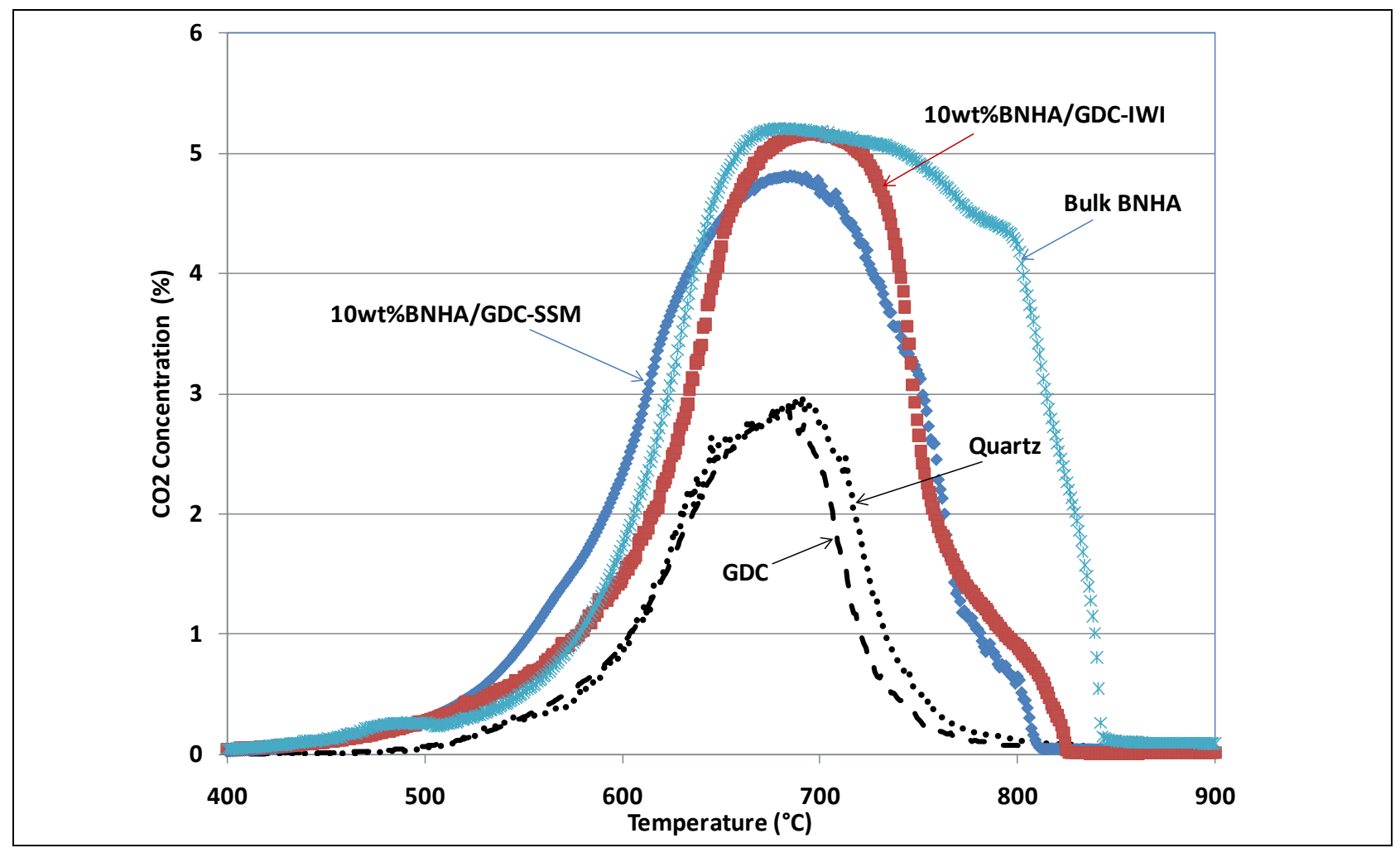

Figure 2-12: TPO plots for reactor beds after partial oxidation tests.

Table 2-7: Total bed carbon (TBC) formed during extended CPOX tests.

\begin{tabular}{lc}
\hline Catalyst & TBC (g) \\
\hline 10wt\%BNHA/GDC - SSM & 0.58 \\
10wt\%BNHA/GDC - IWI & 0.80 \\
\hline
\end{tabular}

\subsubsection{Conclusions}

Two materials containing 10wt\% Ni-substituted barium hexaaluminate (BNHA) deposited onto gadolinium-doped ceria (GDC), an oxygen conductor, were prepared using different methods: incipient wetness impregnation (IWI) and solid-state mixing (SSM). These catalysts were examined for the partial oxidation of $n$-tetradecane containing sulfur and aromatic compounds. Both of the GDC-supported catalysts demonstrated greatly reduced deactivation compared to 3wt\%Ni/alumina and 3wt\%Ni/GDC, and bulk BNHA, with significantly reduced carbon formation. This was attributed to the oxygen-conducting property of the GDC. The material prepared by IWI demonstrated more stable hydrogen and carbon monoxide production than the material prepared by SSM in the presence of sulfur and aromatics, and had significant recovery in product yields when the contaminants were removed. The slower rate of deactivation was attributed to a larger amount of exposed support surface area, which facilitates adsorption and transport of gas phase oxygen to catalytically active sites. Further, it is believed that the material prepared by IWI possessed a greater degree of interaction between the BNHA and GDC phases. 


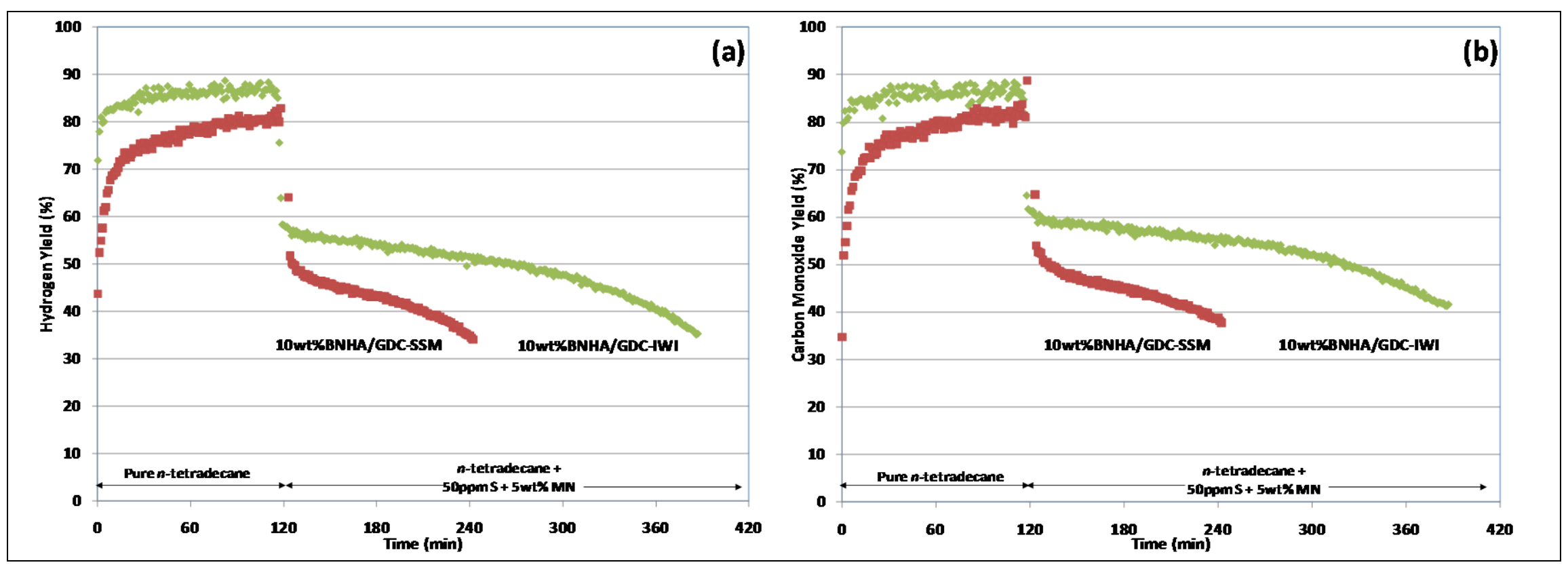

Figure 2-13: Performance of 10wt\%BNHA/GDC-SSM and 10wt\%BNHA/GDC-IWI in the extended POX test with $n$-tetradecane plus DBT and $\mathrm{MN}$ : WHSV $=50,000 \mathrm{scc} / \mathrm{g}_{\mathrm{cat}} \cdot \mathrm{h}, \mathrm{T}=900^{\circ} \mathrm{C}, \mathrm{P}=0.23 \mathrm{MPa}, \mathrm{O} / \mathrm{C}=1.2$ : (a) Hydrogen yield, (b) Carbon monoxide yield. 


\section{$3 \quad$ Segmented Catalyst Bed}

\subsection{Powder Catalyst}

Note: Section 3.1 was originally published as, "Effect of the Catalyst Bed Configuration on the Partial Oxidation of Liquid Hydrocarbons,” in Energy \& Fuels [119].

\subsubsection{Introduction}

Liquid hydrocarbon fuels such as diesel can be reformed into synthesis gas to operate hightemperature solid oxide fuel cells (SOFCs) [120]. This process is especially attractive for transportation and remote energy applications. For these applications, the reforming would most likely be carried out by catalytic partial oxidation (CPOX) or oxidative steam reforming (OSR) since they require little or no water storage. However, traditional reforming catalysts deactivate rapidly under these harsh conditions from thermal sintering, excessive carbon formation, and sulfur poisoning. Deactivation can be reduced by substituting the active metals into thermallystable oxide crystal structures such as perovskites [97-99, 121], pyrochlores [71, 72, 82, 83], and hexaaluminates $[61,62,68-70,72,104,105]$. These materials also show resistance to carbon formation due to enhanced lattice oxygen mobility at high temperatures.

Recent work [71, 72, 82, 83] using pyrochlores, into which active metals have been isomorphically substituted, has shown that these materials retain the thermal stability of the pyrochlore while limiting carbon formation by what is believed to be greater oxygen mobility than the unmodified pyrochlore. The pyrochlore structure, $\mathrm{A}_{2} \mathrm{~B}_{2} \mathrm{O}_{7}$, can (within limits) accommodate substitution in both the A- and B-sites of the lattice, which allows for the addition of both active metals and promoters [122]. Doping the pyrochlore structure with an active and a promoter metal can produce a catalyst that incorporates several unique properties beneficial for hydrocarbon reforming: high catalytic activity, thermal stability, sulfur tolerance, and oxygen conductivity.

A Rh-substituted pyrochlore supported by zirconium-doped ceria (ZDC) successfully converted a commercial diesel fuel to synthesis gas for $1000 \mathrm{~h}$ under OSR conditions [84]. However, since $\mathrm{Rh}$ is an expensive noble metal, it is desirable to find a way to reduce the amount required while maintaining a high level of activity and resistance to deactivation.

It has been widely reported that CPOX and OSR of hydrocarbon fuels proceed via a series of reactions in which oxygen in the feed first reacts to completion with the fuel at the inlet, forming carbon dioxide, water, and with fragments of the fuel produced by heat released in those reactions. In the downstream portion of the bed, the remaining fuel reacts with carbon dioxide and water in a series of endothermic reforming reactions producing primarily carbon monoxide and hydrogen $[6,15,21,25,27,33]$. This sequence is generally referred to as the indirect mechanism, which differs from the direct mechanism that is characterized by the formation of the final syngas products by the reaction of oxygen with the fuel to produce carbon monoxide and hydrogen in one step [6, 10-13, 17, 23]. The indirect mechanism for the CPOX and OSR of diesel reforming is pictured in Figure 3-1[123]. 


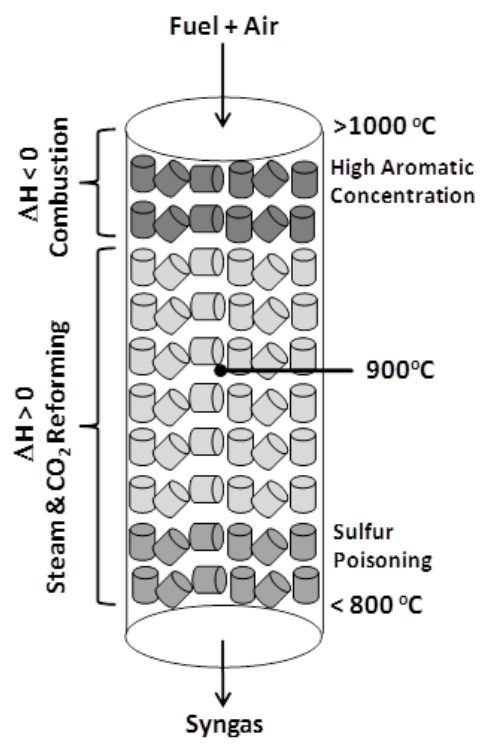

Figure 3-1 Reactor diagram for CPOX of a hydrocarbon via the indirect mechanism.

Considering the conditions shown in Figure 3-1, two approaches for modifying the catalyst bed were examined. In the first approach, the dominant reaction(s) in each section of the reactor was hypothesized, and catalysts were selected that are optimum for the reaction(s) occurring in that particular location. The catalyst formulation that is optimal in one region of the reactor may not be the optimal formulation in another. For example, placing a catalyst specifically designed for combustion in the front of the bed would increase the extent of those reactions, while a catalyst designed for steam and/or carbon dioxide reforming would do the same if placed at the end of the bed.

The second approach focused more on the reaction conditions in the different sections of the reactor to identify regions that would be less likely to deactivate less expensive metal catalysts, like Ni or Ru. Horn et al. [33] examined the indirect mechanism for methane CPOX by measuring the temperature and gas composition profiles down the length of the catalyst bed. The results in this study provide the opportunity to consider the different temperatures and gas compositions at the front, middle, and end of the reactor to determine which region will most likely deactivate by excessive carbon formation or sulfur poisoning. In the study reported here, it was hypothesized that the most rapid deactivation in the front of the catalyst bed is a result of thermal sintering due to highly exothermic oxidation reactions, while rapid deactivation at the end of the catalyst bed is due to sulfur poisoning due to lower temperatures from the endothermic reactions.

A number of studies [90-93] have been reported that utilize similar segmented beds of supported metal catalysts for hydrocarbon reforming. Zhu et al. [92] and Xu et al. [90] reported the use of segmented catalyst beds for the CPOX of methane, while Tong et al. [93] tested OSR of methane. All of these studies utilized the first approach discussed previously of placing a combustion catalyst at the reactor inlet, followed by catalysts suited for endothermic steam and carbon dioxide reforming. All studies reported a benefit to this approach.

Zhu et al. [92] placed yttria-stabilized zirconia (YSZ) in the combustion zone, followed by a Cobased reforming catalyst; however, the two catalysts were placed in separate, sequential reactors. This approach significantly reduced the benefit of the convective heat transfer from the 
combustion zone to the second stage where the endothermic reforming reactions occur. Further, there was a flattening of the temperature profile in the combustion zone, which can minimize catalyst sintering, but will also reduce the amount of heat available in the second stage.

$\mathrm{Xu}$ et al. [90] also used two separate reactor beds; however, the oxygen feed was split and fed separately to the two sections. The combustion catalyst in the first section was a La-based perovskite substituted with $\mathrm{Fe}, \mathrm{Co}$, and $\mathrm{Mn}$. The second section utilized a partial oxidation catalyst, $\mathrm{La}_{2} \mathrm{O}_{3}$ promoted $7 \mathrm{wt} \% \mathrm{Ni} / \mathrm{MgAl}_{2} \mathrm{O}_{4}$. The results were significantly affected by the ratio of the split oxygen feed streams.

Tong et al. [93] conducted studies of the autothermal reforming of methane. In their experiments, a Pt catalyst was used for combustion, and a Ni catalyst was used for the secondary reforming reaction. The catalysts were placed in the same reactor tube. This study looked at varying the space velocity for this configuration, and the performance reported was comparable to the Rhbased catalyst studied until they reached space velocities above 200,000 $\mathrm{h}^{-1}$.

This study examines the possibility of reducing catalyst cost by utilizing two series of segmented beds. Series 1 experiments substituted a Ni-based hexaaluminate catalyst suitable for promoting combustion in place of a Rh-substituted pyrochlore in different reactor configurations. Series 2 experiments examined Ni- and Ru-substituted pyrochlores in different configurations to determine which sections of the reactor deactivate a given catalyst more rapidly.

\subsubsection{Experimental Methods}

\subsubsection{Catalyst Synthesis}

Four catalysts were synthesized for this study and are summarized in Table 3-1. The first was a Ni-substituted barium hexaaluminate (BNHA), which was prepared by co-precipitation. Nitrate precursors of each metal $\left(\mathrm{Ba}\left(\mathrm{NO}_{3}\right)_{2} \bullet \mathrm{xH}_{2} \mathrm{O}, \mathrm{Ni}\left(\mathrm{NO}_{3}\right)_{2} \bullet \mathrm{xH}_{2} \mathrm{O}, \mathrm{Al}\left(\mathrm{NO}_{3}\right)_{3} \bullet \mathrm{xH}_{2} \mathrm{O}\right)$, obtained from Alfa Aesar, were dissolved in de-ionized water at $60^{\circ} \mathrm{C}$ in appropriate stoichiometric ratios. This solution was added drop-wise to a solution of excess ammonium carbonate, forming precipitates, which were aged for $6 \mathrm{~h}$ at $60^{\circ} \mathrm{C}$ with stirring. The aged precipitates were collected by vacuum filtration, rinsed with de-ionized water to remove excess ammonia, and dried overnight at $110^{\circ} \mathrm{C}$. The dried material was heat treated at $425^{\circ} \mathrm{C}$ for one hour to convert the carbonates to an amorphous oxide powder. Finally, the powder was calcined at $1300^{\circ} \mathrm{C}$ for $4 \mathrm{~h}$ to form the hexaaluminate phase.

The remaining three catalysts were Ni-, Ru-, and Rh-substituted pyrochlores prepared by a modified Pechini method [124]. Nitrate salts of each metal were dissolved separately in deionized water and then combined with a citric acid (CA) solution. The solution was heated to $70^{\circ} \mathrm{C}$ while being stirred to ensure complete metal complexation. Once at $70^{\circ} \mathrm{C}$, ethylene glycol (EG) was added to the solution. The solution was stirred continuously at temperature until most of the water had evaporated, leaving a transparent, viscous gel. The stir bar was removed, and the beaker was transferred to a heating mantle preheated to $70^{\circ} \mathrm{C}$. The temperature in the mantle was increased to $140^{\circ} \mathrm{C}$ to promote the polyesterification reaction between EG and CA, which produced an organic polymeric network [125]. This foam-like material was placed in an oven at $130^{\circ} \mathrm{C}$ to dry overnight. Finally, the material was calcined at $1000^{\circ} \mathrm{C}$ for $8 \mathrm{~h}$ to form the pyrochlore crystal phase. 
Table 3-1 Catalysts used in this study.

\begin{tabular}{lcc}
\hline \multicolumn{1}{c}{ Catalyst } & Formula & Symbol \\
\hline $\begin{array}{l}\text { 3 wt \% Ni-substituted barium } \\
\text { hexaaluminate }\end{array}$ & $\mathrm{BaNi}_{0.4} \mathrm{Al}_{11.6} \mathrm{O}_{19-\delta}$ & BNHA \\
3 wt \% Ni-substituted pyrochlore & $\mathrm{La}_{1.89} \mathrm{Ca}_{0.11} \mathrm{Zr}_{1.47} \mathrm{Ni}_{0.28} \mathrm{Y}_{0.25} \mathrm{O}_{7-\delta}$ & Ni3-PC \\
1 wt \% Ru-substituted pyrochlore & $\mathrm{La}_{1.89} \mathrm{Ca}_{0.11} \mathrm{Zr}_{1.69} \mathrm{Ru}_{0.06} \mathrm{Y}_{0.25} \mathrm{O}_{7-\delta}$ & Ru1-PC \\
1 wt \% Rh-substituted pyrochlore & $\mathrm{La}_{1.89} \mathrm{Ca}_{0.11} \mathrm{Zr}_{1.70} \mathrm{Rh}_{0.05} \mathrm{Y}_{0.25} \mathrm{O}_{7-\delta}$ & Rh1-PC \\
\hline
\end{tabular}

\subsubsection{Catalyst Characterization}

Prior to catalytic testing, basic material characterization was performed on each of the catalyst powders. The crystalline phases present in each sample were determined by powder X-ray diffraction (XRD) using a PANalytical X'Pert PRO model XRD utilizing filtered $\mathrm{Cu} \mathrm{K} \alpha$ radiation. BET surface area was determined by nitrogen adsorption using a Quantachrome Surface Area Analyzer 2000.

\subsubsection{Performance/Activity Test}

Reaction studies were carried out in a laboratory-scale fixed-bed continuous-flow reactor system. The catalyst powders were sized to $-10 /+40$ mesh and diluted with quartz sand to a volume of 3 $\mathrm{mL}$ to avoid channeling and to minimize temperature gradients. The catalysts were loaded into the reactor as prepared, with no pretreatment or reduction. The catalyst bed was placed in a tubular reactor (8 $\mathrm{mm}$ i.d.) with a coaxially centered thermocouple at the center of the bed. Nitrogen and air flows were delivered by mass flow controllers, and the liquid fuel feed was delivered by a high accuracy HPLC dual pump (Dionex 680A). Additional details and a reactor schematic are provided elsewhere [75].

Partial oxidation step-response activity experiments were conducted isothermally with a center bed temperature of $900^{\circ} \mathrm{C}$ and a pressure of $0.23 \mathrm{MPa}$. Each experiment was run in three steps: 1) the first hour, the fuel feed was pure $n$-tetradecane (TD) to establish baseline activity; 2 ) the next two hours, the fuel feed was TD with added sulfur specie, dibenzothiophene (DBT), and aromatic specie, 1-methyl naphthalene (MN), to examine the effects of diesel contaminants on catalyst performance; 3 ) the final two hours, the fuel feed was switched back to pure TD to observe catalyst recovery.

Two separate but similar sets of conditions were used. In Series 1, BNHA and Rh1-PC catalysts were studied together. The conditions were selected so that the experiments could be completed in a single day. Preliminary studies showed that at an $\mathrm{O} / \mathrm{C}=1.2$, a high level of $\mathrm{MN}(10 \mathrm{wt} \%)$ was required to produce sufficient deactivation in the base case performances to differentiate between them. Throughout this series, however, the high level of $\mathrm{MN}$ resulted in plugging of reactor exit lines with naphtha. Therefore, in Series 2, the concentration of MN was decreased to $5 \mathrm{wt} \%$ for the experiments using Ni3-PC and Ru1-PC catalysts. Additionally, it was necessary to decrease the $\mathrm{O} / \mathrm{C}$ to 1.1 in Series 2 to produce enough catalyst deactivation. The reaction study conditions are summarized in Table 3-2. 
Table 3-2 Summary of CPOX conditions for reaction studies.

\begin{tabular}{|c|c|c|}
\hline Condition & $\begin{array}{c}\text { Series 1: } \\
\text { BNHA/Rh1-PC } \\
\end{array}$ & $\begin{array}{c}\text { Series 2: } \\
\text { Ni3-PC/Ru1-PC } \\
\end{array}$ \\
\hline O/C ratio & 1.2 & 1.1 \\
\hline Preheat Temperature $\left({ }^{\circ} \mathrm{C}\right)$ & \multicolumn{2}{|c|}{375} \\
\hline Reactor Temperature $\left({ }^{\circ} \mathrm{C}\right)$ & \multicolumn{2}{|c|}{900} \\
\hline Pressure (MPa) & \multicolumn{2}{|c|}{0.23} \\
\hline Flow Rate (sccm) & \multicolumn{2}{|c|}{400} \\
\hline$W H S V\left(s c c / g_{c a t} h\right)$ & \multicolumn{2}{|c|}{25,000} \\
\hline \multicolumn{3}{|l|}{ Gas Composition: } \\
\hline 0-60 min & \multicolumn{2}{|c|}{ Pure TD } \\
\hline $61-180 \min$ & $\begin{array}{c}\text { TD + } 10 \mathrm{wt} \% \mathrm{MN} \\
+50 \mathrm{ppm} \text { DBT }\end{array}$ & $\begin{array}{c}\text { TD + } 5 \text { wt } \% \text { MN } \\
+50 \text { ppm DBT }\end{array}$ \\
\hline 181-300 min & \multicolumn{2}{|c|}{ Pure TD } \\
\hline
\end{tabular}

\subsubsection{Product Analysis}

The gases (hydrogen, nitrogen, oxygen, carbon monoxide, carbon dioxide, and methane) were analyzed using a 200 amu scanning magnetic sector mass spectrometer (Thermo ONIX, model no. Prima $\delta b)$. The gaseous hydrocarbon products $\left(\mathrm{C}_{1}-\mathrm{C}_{2}\right.$ paraffins, $\mathrm{C}_{2}-\mathrm{C}_{4}$ olefins, and benzene) were analyzed using a HP5890 gas chromatograph equipped with a flame ionization detector (FID). Oxygen conversion was complete during all experiments. Although water was produced in the reaction, it was not quantitatively analyzed. Carbon balances were typically within 100 $\pm 5 \%$. Yield and conversion were calculated by the expressions provided in Section 2.2.2.5.

\subsubsection{Carbon Formation Study}

Total carbon in the catalyst bed was determined by temperature programmed oxidation (TPO) of the catalysts plus bed material. TPO was performed by introducing a gas stream of $10 \% \mathrm{O}_{2} / \mathrm{N}_{2}$ into the reactor and was run from 200 to $900^{\circ} \mathrm{C}$ with a temperature ramp of $1^{\circ} \mathrm{C} / \mathrm{min}$. Carbon dioxide evolution was measured continuously by a mass spectrometer, and the total carbon that had been deposited in the bed was calculated by integration of the carbon dioxide flow rate exiting the reactor.

Two values for carbon are provided for each reactor configuration: 1) measured and 2) predicted. The total predicted carbon (TPC) was calculated using the total measured carbon (TMC), determined by the TPO of the two single-composition bed runs by the following equation:

$$
\mathrm{TPC}=\text { Weight }_{{ }_{\text {Cat1 }}} * \mathrm{TMC}_{\text {Cat1 }}+\text { Weight } \%_{\text {Cat2 }} * \mathrm{TMC}_{\text {Cat2 }}
$$

The purpose of these comparisons was to identify any synergistic effects of the segmented bed configurations. 


\subsubsection{Results and Discussion}

\subsubsection{Catalyst Characterization}

The XRD patterns for the fresh pyrochlore catalysts show the desired crystal structure (Figure 3-2). Previous studies provide the XRD spectra to confirm that the BNHA catalyst possesses the hexaaluminate crystal structure [69]. These crystal structures are important because substitution of the catalytically active metals into these refractory materials can provide both thermal stability and resistance to deactivation from sintering, metal site agglomeration, and active metal vaporization.

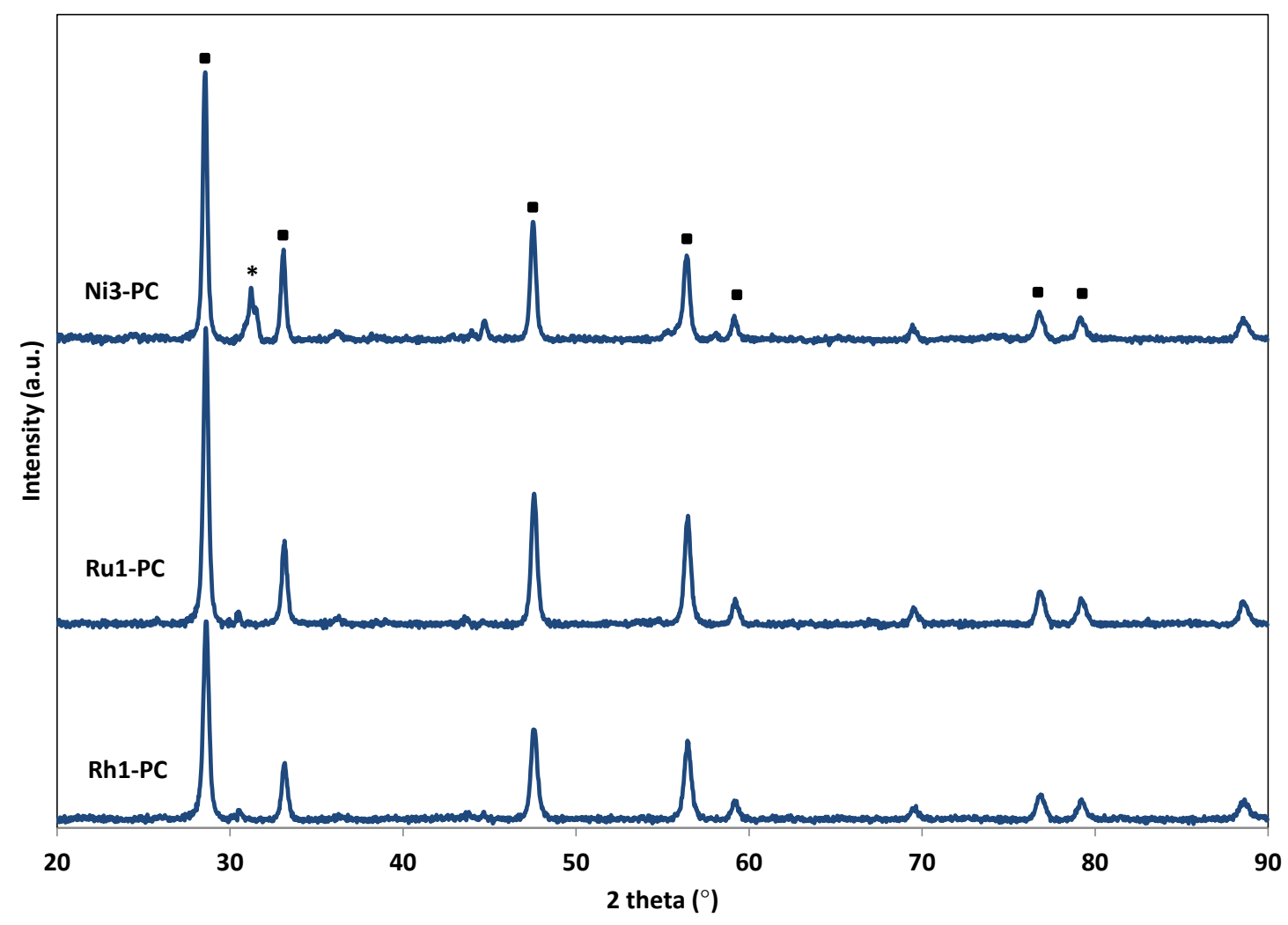

Figure 3-2 XRD spectra of the Rh1-PC, Ru1-PC, and Ni3-PC catalysts; (-) pyrochlore, (*) perovskite.

Table 3-3 summarizes the BET surface areas of all materials in this study. Although these materials exhibit relatively low specific surface areas when compared to traditional supported metal reforming catalysts, they still produce near equilibrium conversions in all activity tests presented in the following sections.

Table 3-3 Surface Area of Reforming Catalysts Used in This Study.

\begin{tabular}{cc}
\hline Catalyst & BET Surface Area $\left(\mathbf{m}^{2} / \mathbf{g}\right)$ \\
\hline BNHA & 13.0 \\
Ni3-PC & 4.6 \\
Ru1-PC & 3.4 \\
Rh1-PC & 3.6 \\
\hline
\end{tabular}




\subsubsection{Series 1: BNHA and Rh1-PC}

\subsection{Single-Composition Beds}

\section{Performance}

The performances for the two single-composition beds used for series 1 are presented in Figure 3-3. The BNHA catalyst was selected from previous studies [68-70, 72, 73] and its performance under similar reaction conditions is known to provide rapid deactivation and minimal recovery. Rh1-PC possesses the same formula as the previously reported $1000 \mathrm{~h}$ reforming study [84] on diesel fuel, except with $1 \mathrm{wt} \% \mathrm{Rh}$ instead of $2 \mathrm{wt} \% \mathrm{Rh}$. The Rh1-PC performed significantly better than BNHA, and both runs are consistent with previous results. The difference in the performances of these two catalysts has been attributed to both the active metal ( $\mathrm{Rh}$ and $\mathrm{Ni}$ ) and the characteristics of the oxide system into which they are substituted (hexaaluminate and pyrochlore). Rh-based catalysts have higher activity than Ni for CPOX of hydrocarbons [13, 126-128] and more resistance to deactivation from carbon formation and sulfur poisoning [75, 128, 129]. Additionally, although both exhibit thermal stability under the reaction conditions, the doped pyrochlore crystal structure possesses properties that provide other benefits over hexaaluminates [72]. Doping the A site with alkaline earth metals has been suggested to improve resistance to excessive carbon formation by increasing surface basicity and lattice oxygen mobility [122], also believed to reduce carbon deposits on the catalyst surface [71, 84]. All catalysts and all configurations produced near equilibrium conversions with carbon balances of $100 \pm 5 \%$. These two compositions (BNHA and Rh1-PC) were selected for segmented bed series 1 for two reasons: (1) significant differences in their performances would likely demonstrate a synergistic effect, if present, more clearly, and (2) BNHA is likely to enhance the indirect reforming mechanism, because oxidized Ni catalysts promote combustion, while Rh-based catalysts have the potential to function as both a direct and an indirect reforming catalyst [10-13, 27, 33].

\section{Carbon Formation}

The total measured carbon (TMC) from the TPOs performed after the reaction tests of the two single-composition runs for series 1 are presented in Table 3-4. As expected, Rh1-PC had significantly less carbon deposition. These measured values are used to calculate the total predicted carbon (TPC) for the segmented beds via Equation 3-1.

Table 3-4 Carbon formation for Series 1 single-composition bed runs.

\begin{tabular}{cc}
\hline Catalyst & TMC (g) \\
\hline Rh1-PC & 0.49 \\
BNHA & 1.88 \\
\hline
\end{tabular}




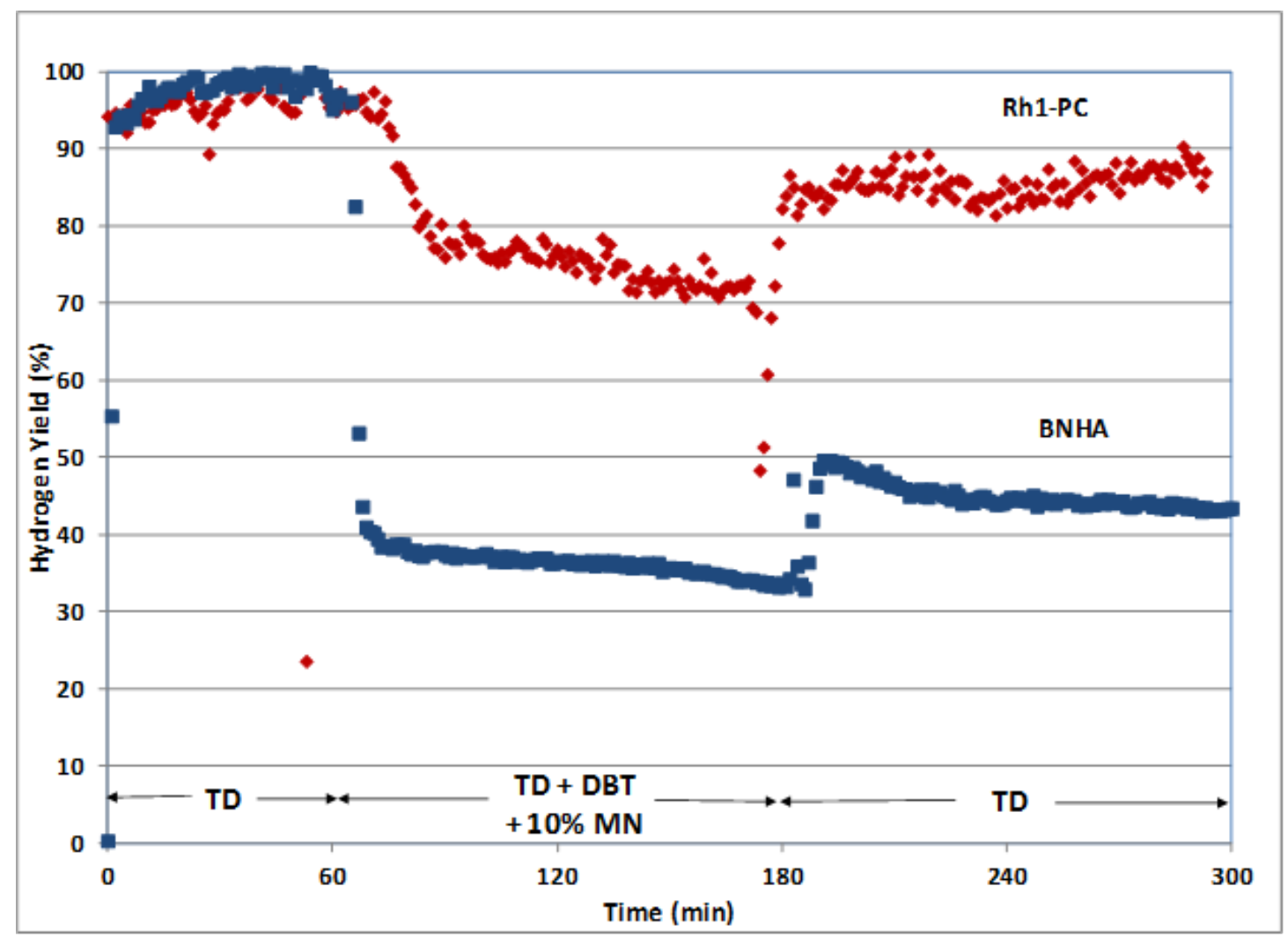

Figure 3-3 Performances of two single-composition bed runs for catalysts used in series 1 under CPOX: WHSV $=25,000 \mathrm{scc} \mathrm{g}_{\mathrm{cat}}{ }^{-1} \mathrm{~h}^{-1}, \mathrm{O} / \mathrm{C}=1.2,900^{\circ} \mathrm{C}$, and $0.23 \mathrm{MPa}$.

\subsection{BNHA and Rh1-PC Segmented Bed Configurations}

\section{Performance}

The performances for the segmented beds in series 1 are presented in Figure 3-4. Although the configuration with BNHA in the inlet of the reactor had a lower hydrogen yield initially, the deactivation for the $2 \mathrm{~h}$ exposed to DBT and MN was less severe and the recovery during the last $2 \mathrm{~h}$ on pure TD was significantly better. The lower hydrogen yield initially may indicate that the BNHA provides sufficient combustion activity at the reactor inlet, but there is not sufficient activity in the remaining part of the bed to complete the secondary reforming reactions. It has been shown that the combustion reactions occur in the very front portion of the catalyst bed [15, 33]. Therefore, a combustion catalyst may provide the most benefit in a smaller region ( $<50 \%)$ of the reactor inlet with a larger section of the reforming catalyst. This conclusion was also stated by Tong et al. [93] for their Pt/Ni catalyst bed. These results may also indicate that the BNHA is deactivated more rapidly in the outlet of the reactor than in the inlet. This would likely be due to sulfur poisoning of $\mathrm{Ni}$ in the lower temperature $\left(<800^{\circ} \mathrm{C}\right)$ conditions in the outlet of the reactor. At these lower temperatures, carbon formation, linked to sulfur poisoning, may be more rapid on Ni catalysts than on Rh. 


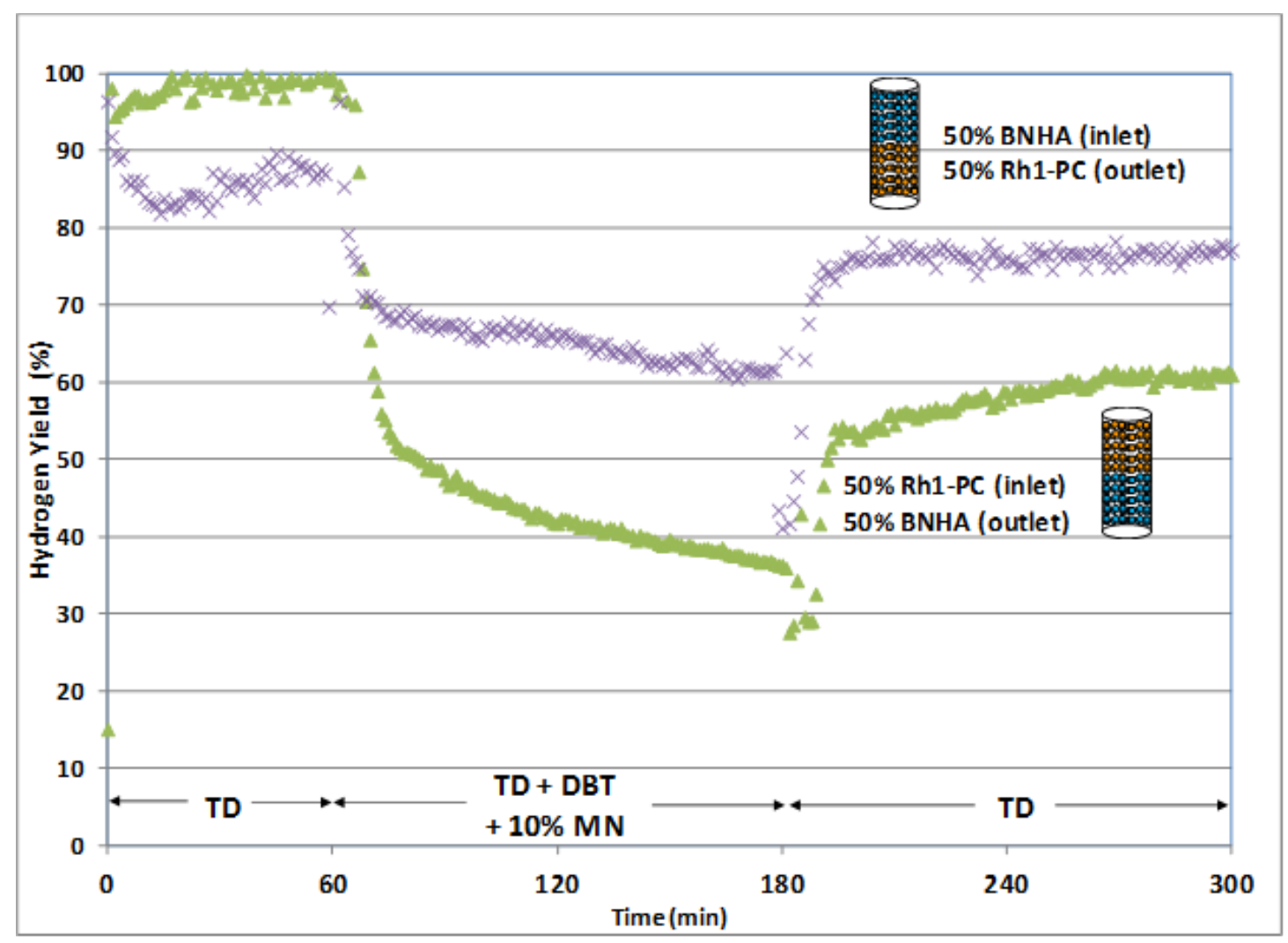

Figure 3-4 Comparison of the performances of different segmented bed configurations using BNHA and Rh1-PC catalysts under CPOX: WHSV $=25,000 \mathrm{scc} \mathrm{g}_{\mathrm{cat}^{-1}} \mathrm{~h}^{-1}, \mathrm{O} / \mathrm{C}=1.2,900^{\circ} \mathrm{C}$, and $0.23 \mathrm{MPa}$.

\section{Carbon Formation}

Table 3-5 summarizes the carbon deposition for the catalyst configurations shown in Figure 3-4. For both configurations, the differences between the measured and predicted carbon values were not significant. However, there was a significant difference between the two segmented bed configurations. The configuration with BNHA at the inlet and Rh1-PC at the outlet of the reactor formed $14 \%$ less carbon than the reverse configuration. This result suggests that more overall carbon is formed with BNHA in the reactor outlet.

Table 3-5 Carbon Formation for Series 1 Segmented Bed Runs.

\begin{tabular}{ccc}
\hline $\begin{array}{c}\text { Inlet (\%) } \\
\text { Outlet (\%) }\end{array}$ & TMC (g) & TPC (g) \\
\hline 50\% Rh1-PC & 1.31 & 1.19 \\
50\% BNHA & & \\
50\% BNHA & \multirow{2}{*}{1.13} & 1.19 \\
$50 \%$ Rh1-PC & & \\
\hline
\end{tabular}




\subsubsection{Series 2: Ni3-PC and Ru1-PC}

\subsection{Single-Composition Beds}

\section{Performance}

Series 2 looked at two different pyrochlore formulations. The first was substituted with $3 \mathrm{wt} \% \mathrm{Ni}$ (Ni3-PC), shown in a previous study [72] to be a better overall Ni-based catalyst than BNHA from series 1 . The second contained $1 \mathrm{wt} \% \mathrm{Ru}$ (Ru1-PC), another reforming catalyst expected to have resistance to sulfur poisoning. Figure 3-5 presents the performance data for these two catalysts in the single-composition bed runs. The performances before and during the addition of DBT and MN are not significantly different; however, the Ni3-PC exhibits better recovery during the last $2 \mathrm{~h}$ of the experiment. This suggests that a larger number of Ni sites were reversibly deactivated while exposed to contaminants. It should also be noted that the total atomic substitution of $\mathrm{Ni}$ in the pyrochlore is nearly 5 times that of $\mathrm{Ru}$.

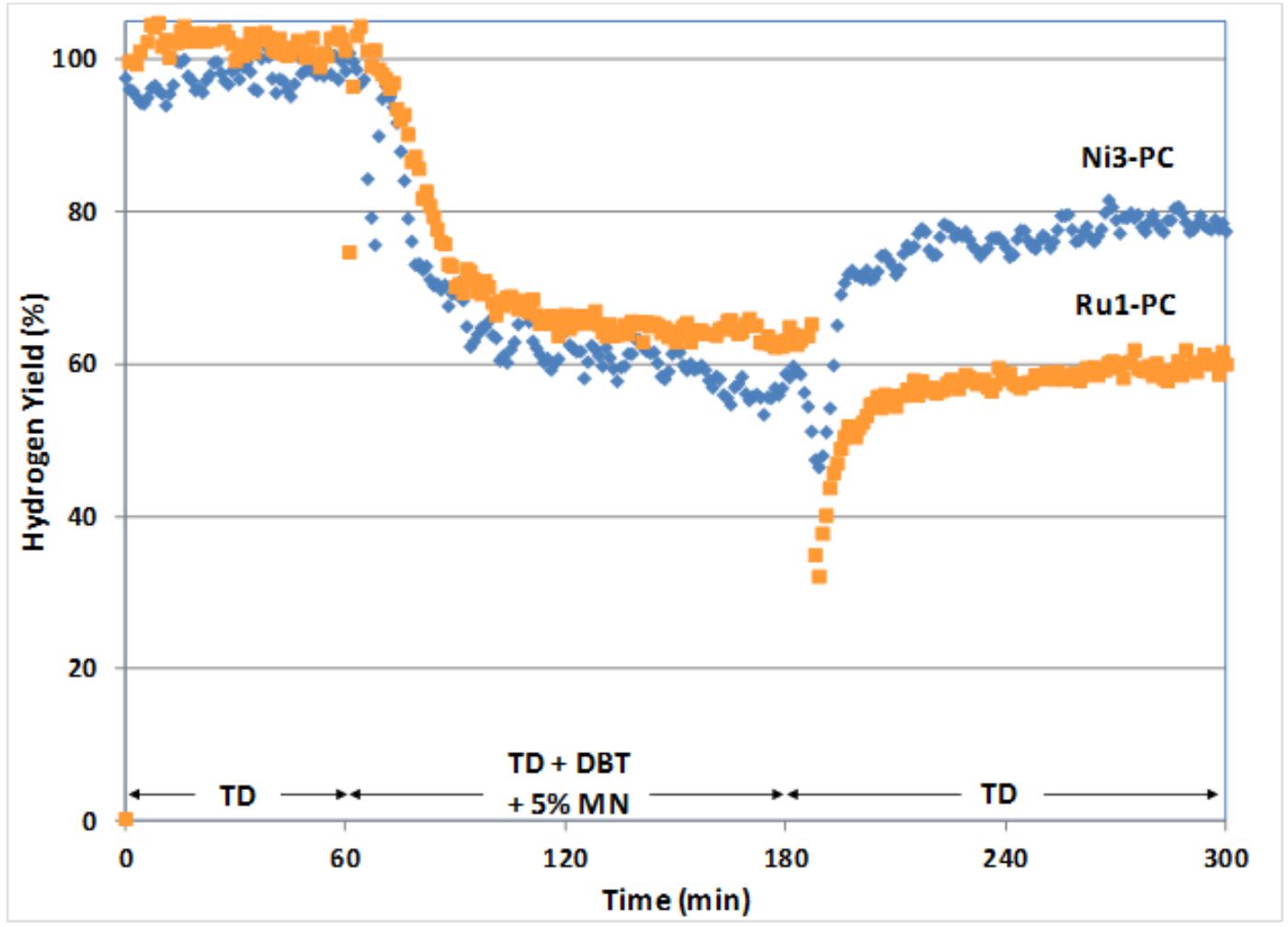

Figure 3-5 Performances of two single-composition bed runs for catalysts used in series 2 under CPOX: WHSV $=25,000 \operatorname{scc~g}_{\text {cat }}{ }^{-1} \mathrm{~h}^{-1}, \mathrm{O} / \mathrm{C}=1.1,900^{\circ} \mathrm{C}$, and $0.23 \mathrm{MPa}$.

\section{Carbon Formation}

The carbon formed during the single-composition bed runs for the catalysts used in series 2 is provided in Table 3-6. The Ni3-PC formed nearly 2 times the carbon as the Ru1-PC, even though it demonstrated a greater amount of recovery during the last $2 \mathrm{~h}$ of the run. The higher atomic substitution level of $\mathrm{Ni}$ in the pyrochlore is one possible explanation for its ability to maintain activity even with higher carbon deposition. Another explanation that must be considered is that carbon formation is not the only deactivation mechanism. It is suspected that sulfur poisoning 
could contribute to deactivation, especially for Ni-based catalysts. Future studies will examine these catalysts without the added sulfur species.

Table 3-6 Carbon Formation for Series 2 Single-composition Bed Runs.

\begin{tabular}{cc}
\hline Catalyst & TMC (g) \\
\hline Ni3-PC & 1.12 \\
Ru1-PC & 0.57 \\
\hline
\end{tabular}

\subsection{Ni3-PC and Ru1-PC Segmented Bed Configurations}

\section{Performance}

Figure 3-6 presents the data for the segmented bed runs for series 2. The configuration with Ni3PC in the reactor outlet produced the lowest hydrogen yield throughout the experiment. This is consistent with the results from series 1 and again suggests that the Ni sites deactivate more rapidly in the endothermic region. In contrast, the two segmented configurations with Ni3-PC in the reactor inlet and Ru1-PC in the outlet experienced less deactivation when exposed to DBT and $\mathrm{MN}$ and recovered to greater than $80 \%$ hydrogen yield in the last $2 \mathrm{~h}$ of the test. While the performances of these two configurations are not significantly different, it is significant that the amount of $\mathrm{Ru}$, a more expensive noble metal, is only needed in a small portion of the reactor outlet to produce the same level of hydrogen yield. This further supports that $\mathrm{Ni}$ is rapidly deactivated in last section of the catalyst bed.

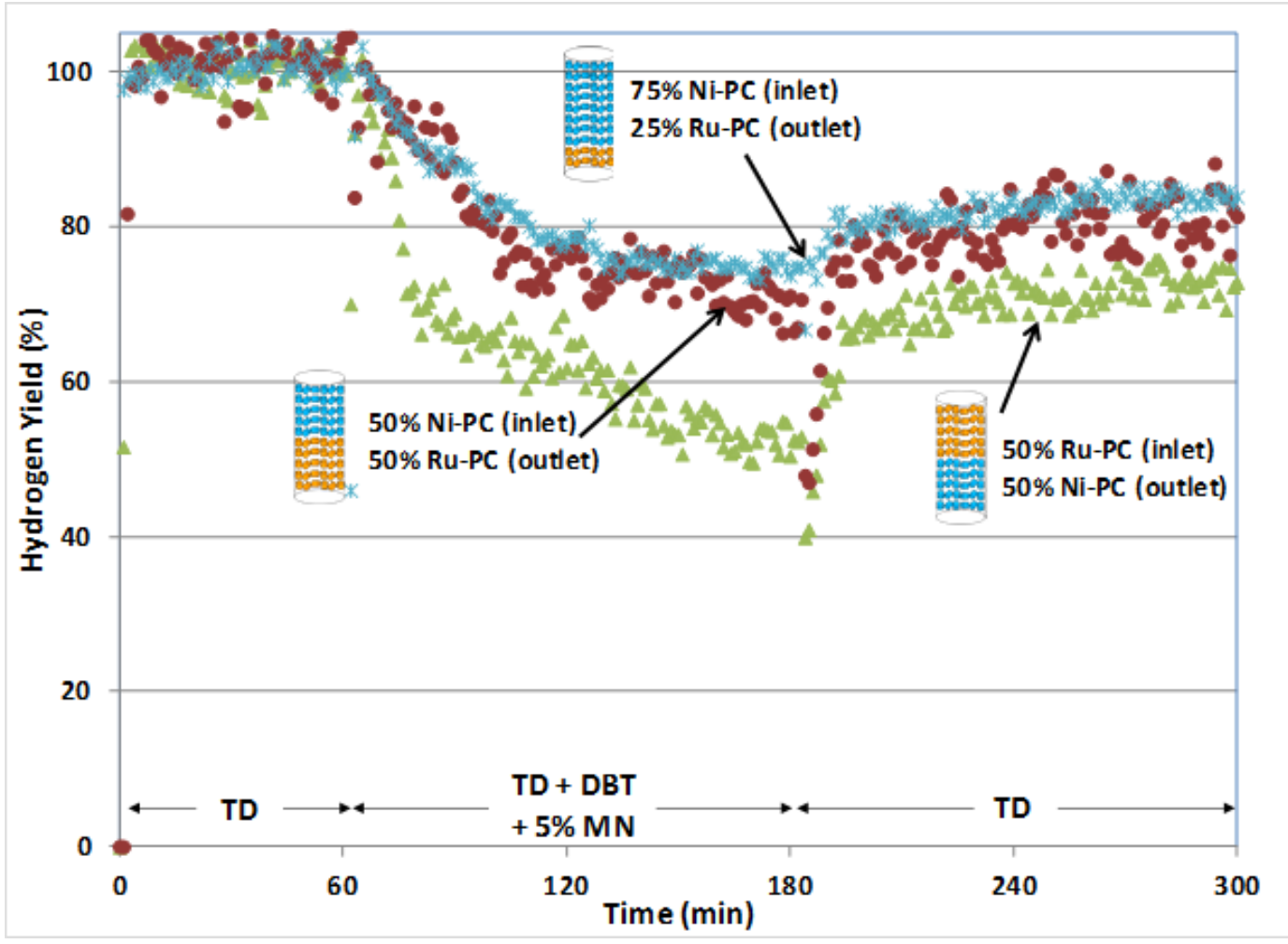

Figure 3-6 Comparison of the performances of different segmented bed configurations using Ni3PC and Ru1-PC catalysts under CPOX: WHSV $=25,000 \mathrm{scc}_{\mathrm{cat}}{ }^{-1} \mathrm{~h}^{-1}, \mathrm{O} / \mathrm{C}=1.1,900^{\circ} \mathrm{C}$, and $0.23 \mathrm{MPa}$. 


\section{Carbon Formation}

Table 3-7 provides the measured and predicted carbon for the Ni- and Ru-based catalysts in the different configurations for the runs presented in Figure 3-6. The greatest difference between the measured and predicted carbon values was seen in the last configuration of 75\% Ni3-PC in the inlet of the reactor and 25\% Ru1-PC in the outlet. This configuration formed nearly $30 \%$ less carbon than predicted, as calculated by linear combination of the carbon formed on the two single-component beds. Again, this result strengthens the conclusion that Ni-based catalysts perform poorly and deactivate most rapidly in the outlet of the reactor, likely because of sulfur poisoning accompanied by excess carbon deposition.

Table 3-7 Carbon Formation for Series 2 Segmented Bed Runs.

\begin{tabular}{ccc}
\hline $\begin{array}{c}\text { Inlet: } \\
\text { Outlet }\end{array}$ & TMC (g) & TPC (g) \\
\hline 50\% Ru1-PC: & 0.75 & 0.85 \\
50\% Ni3PC & & \\
50\% Ni3-PC: & 0.82 & 0.85 \\
50\% Ru1-PC & & \\
75\% Ni3-PC: & 0.72 & 0.98 \\
25\% Ru1-PC & & \\
\hline
\end{tabular}

\subsubsection{Conclusions}

The results of this study indicate that catalyst cost may be reduced using a segmented catalyst bed approach for CPOX or OSR of diesel. Two strategies were examined: (1) promote the indirect reforming mechanism by placing a combustion catalyst in the reactor inlet, followed by a reforming catalyst, and (2) place catalysts in regions of the reactor that have conditions in which they are less likely to deactivate. The first approach demonstrated that a Ni-substituted barium hexaaluminate catalyst can be used in the reactor inlet to promote combustion with a Rhsubstituted pyrochlore in the reactor outlet, but the combustion catalyst should fill less than $50 \%$ of the reactor. The second approach showed a benefit in the use of a sulfur-tolerant noble metal catalyst in the reactor outlet and that a significant portion of the carbon formed on the Nisubstituted pyrochlore is located in the last $25 \%$ of the catalyst bed. 


\subsection{Catalyst Coated Foams}

Note: The material in Section 3.2 was presented at the ACS Spring National Meeting 2012 as, "Carbon Formation in a Graded-Composition Monolithic Catalyst During Partial Oxidation of Hydrocarbons."

\subsubsection{Introduction}

Successful reforming of diesel surrogate fuels has been demonstrated using noble metalsubstituted pyrochlores (PC) [71, 82]. It was proposed that substituting less expensive catalysts in a portion of the catalyst bed may provide acceptable levels of performance and significantly reduce cost. This is driven by the indirect mechanism observed in the catalytic partial oxidation (CPOX) of hydrocarbons reported in literature [123]. This approach has been referred to as the graded catalyst bed (Figure 3-7) and several examples of a similar approach can be found in the literature [90, 91, 93].

In this study the potential benefits of a multi-composition, or "graded," monolith comprised of substituted PC catalysts are studied by placing them in different configurations in a reactor and testing their performance under CPOX conditions. The catalysts used were lanthanum zirconates similar to previously studied powder catalyst [71, 72, 82], with the general formula $\mathrm{La}_{2-\mathrm{x}} \mathrm{Ca}_{\mathrm{x}} \mathrm{Zr}_{2-\mathrm{y} \text { - }}$ ${ }_{z} \mathrm{Me}_{\mathrm{y}} \mathrm{Y}_{\mathrm{z}} \mathrm{O}_{7-\delta}(\mathrm{Me}=\mathrm{Ni}, \mathrm{Rh})$, which were deposited onto alumina foams. Catalytic testing was followed by carbon characterization of the individually coated foams to quantify the amount of carbon formed on each catalyst in the different sections of the reactor during CPOX.

\subsubsection{Experimental Methods}

\subsubsection{Catalyst Preparation}

The catalysts were prepared by coating alumina foam monoliths with a Pechini precursor solution [82]. The samples were dried at $130^{\circ} \mathrm{C}$ between each deposition of precursor solution until the desired weight loading of catalyst was obtained. The coated foams were then calcined in air at $1000^{\circ} \mathrm{C}$ for $8 \mathrm{~h}$ with a ramp rate of $5^{\circ} \mathrm{C} / \mathrm{min}$.
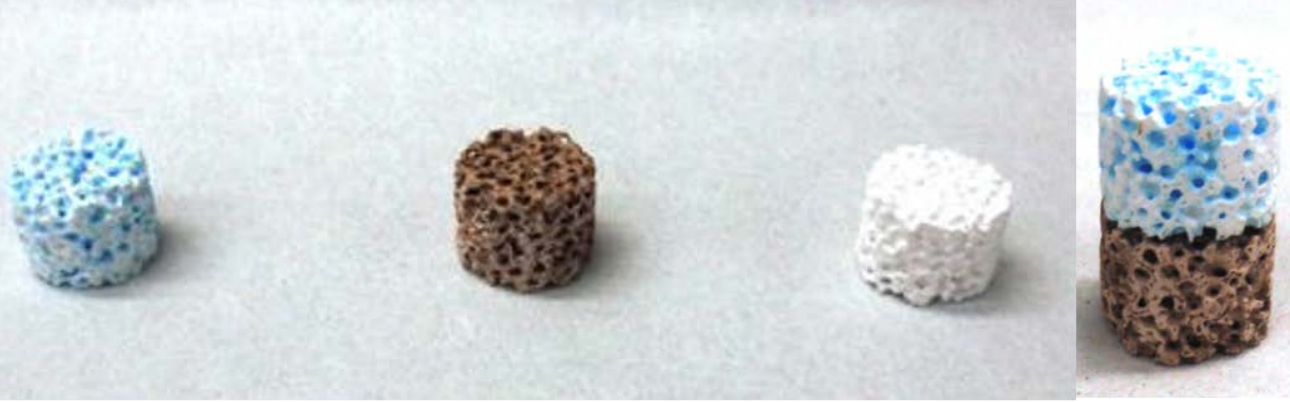

Figure 3-7 Alumina foam materials coated with reforming catalysts.

\subsubsection{Catalyst Performance}

Alumina foams coated with pyrochlore catalysts containing $3 \mathrm{wt} \% \mathrm{Ni}$ (Ni3-PC) or $1 \mathrm{wt} \% \mathrm{Rh}$ (Rh1-PC) substitution were placed in a reactor in different configurations. Reaction studies were carried out in a laboratory-scale, fixed-bed reaction system described elsewhere [75]. CPOX 
step-response experiments were conducted at an $\mathrm{O} / \mathrm{C}=1.1$, a WHSV $=75,000 \mathrm{~cm}^{3} / \mathrm{g}_{\text {cat }} \cdot \mathrm{h}$, a pressure of $0.2 \mathrm{MPa}$, and a total inlet gas flow rate of $400 \mathrm{sccm}$. The catalyst bed temperature was $900^{\circ} \mathrm{C}$. The coated foams were run under CPOX for two hours on pure $n$-tetradecane (TD), a diesel surrogate, then two hours on TD plus 50 ppm sulfur as dibenzothiophene and 5wt\% 1methyl naphthalene, then again for one hour on pure TD to observe the catalyst recovery. These conditions were selected from previous tests to produce a notable rate of deactivation within a single-day test.

Total carbon formed during CPOX was determined by temperature programmed oxidation (TPO) of each foam segment. TPO was performed by introducing a gas stream of $10 \% \mathrm{O}_{2} / \mathrm{N}_{2}$ into the reactor and was run from 200 to $900^{\circ} \mathrm{C}$ with a temperature ramp of $1{ }^{\circ} \mathrm{C} / \mathrm{min} . \mathrm{CO}_{2}$ evolution was measured continuously by a mass spectrometer and the total carbon that had been deposited in the bed was calculated by integration of the $\mathrm{CO}_{2}$ flow rate exiting the reactor, which was measured by online mass spectrometry.

\subsubsection{Results and Discussion}

Figure 3-8 shows the CPOX performance of the base-case configuration of Ni3-PC in both the top and bottom of the reactor. This configuration produced slow, but continuous deactivation for the two hours the catalyst was exposed to the fuel contaminants. Once the contaminants were removed, the catalysts produced very little, but stable recovery for two hours on pure TD fuel.

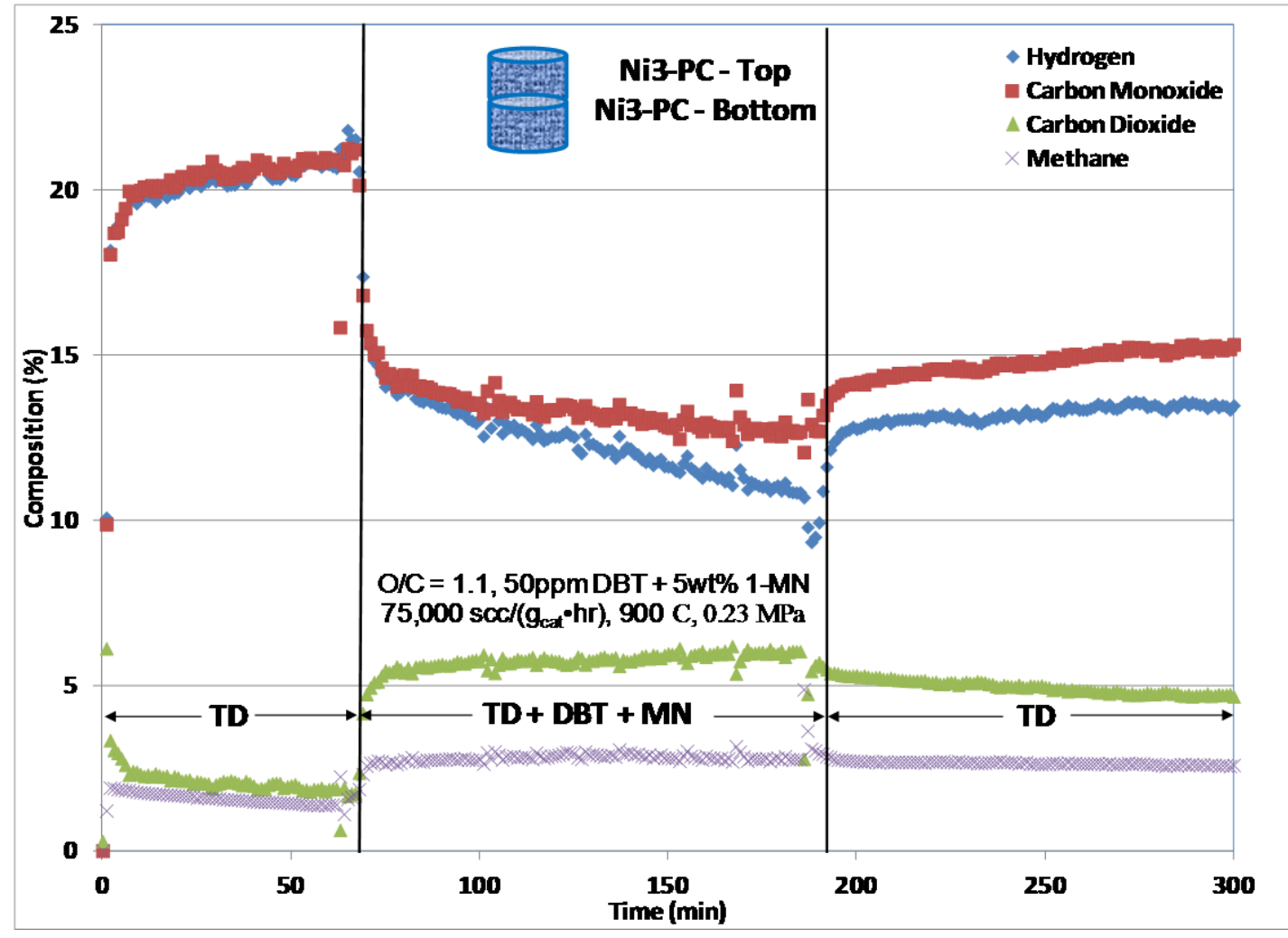

Figure 3-8 Performance of Ni3-PC coated foams in the top and bottom of the reactor under CPOX: WHSV $=75,000 \operatorname{scc~gat~}^{-1} \mathrm{~h}^{-1}, \mathrm{O} / \mathrm{C}=1.1,900^{\circ} \mathrm{C}$, and $0.23 \mathrm{MPa}$. 
The second configuration also had the same catalyst formulation in the top and bottom of the reactor; however, the catalyst was the Rh-substituted pyrochlore, Rh1-PC. The results of the CPOX step-response test for this configuration are presented in Figure 3-9. The deactivation of this catalyst was significantly less than the Ni-substituted pyrochlore, and also displayed nearly complete recovery of activity within two hours of removing the contaminant species.

Figure 3-10 shows the results of the first mixed catalyst configuration with Rh1-PC in the top and Ni3-PC in the bottom of the reactor. This configuration performed similarly poor to the configuration with Ni3-PC in both the top and bottom. These results are consistent with the findings reported in the powder studies in Section 3.1, and indicate that additional benefit cannot be gained by placing an expensive Rh catalyst in the top half of the reactor. This supports the idea that the most rapid deactivation for Ni-based catalysts occurs in the lower part of the CPOX reactor. This is likely due to lower temperatures from endothermic steam reforming, which can lead to formation of stable sulfide species on the catalyst surface. These sulfide species are highly mobile, will agglomerate over time, ultimately leading to an increase in the deposition of deactivating carbon.

Figure 3-11 presents the performance data for the reactor configuration of Ni3-PC in the top of the reactor and Rh1-PC in the bottom. This mixed-catalyst configuration performed much better than the previous; however, the performance is lower than the configuration with Rh1-PC used in the entire catalyst bed. This result supports further that Ni-based catalysts deactivate less rapidly in the top of the reactor. This is likely due to the fact that the top of the reactor is where deep oxidation of the hydrocarbon occurs, producing exothermic conditions that are not favorable for carbon deposition or sulfide formation. This part of the reactor also has the highest partial pressure of oxygen, also making carbon formation unfavorable. Therefore, at least some portion of the front of the reactor can utilize less expensive reforming catalysts (Ni) with the expensive noble metal $(\mathrm{Rh})$ only needed in the more deactivating bottom section of the reactor. An optimal configuration can be determined for a given set of catalysts and reactor conditions.

The carbon formed in each section of the reactor for the four different catalyst configurations is presented in

Table 3-8. The Rh-substituted PC produced the lowest levels of carbon in the top and bottom sections of the reactor. The carbon formed on the Ni-substituted PC reduced slightly when the $\mathrm{Rh}-\mathrm{PC}$ was placed in the top section of the reactor. The difference in carbon formation on the $\mathrm{Rh}-\mathrm{PC}$ in the bottom section was not significant when Ni-PC was placed in the top of the reactor.

\subsubsection{Conclusions}

Utilizing a graded-composition monolith can provide a benefit by reducing catalyst cost in the reforming of hydrocarbons. Specifically, using pyrochlore catalysts substituted with inexpensive, reforming metal catalysts $(\mathrm{Ni})$ in sections of the reactor that are less prone to carbon formation may produce acceptable levels of performance without the need for significant quantities of expensive noble metals like Rh. 


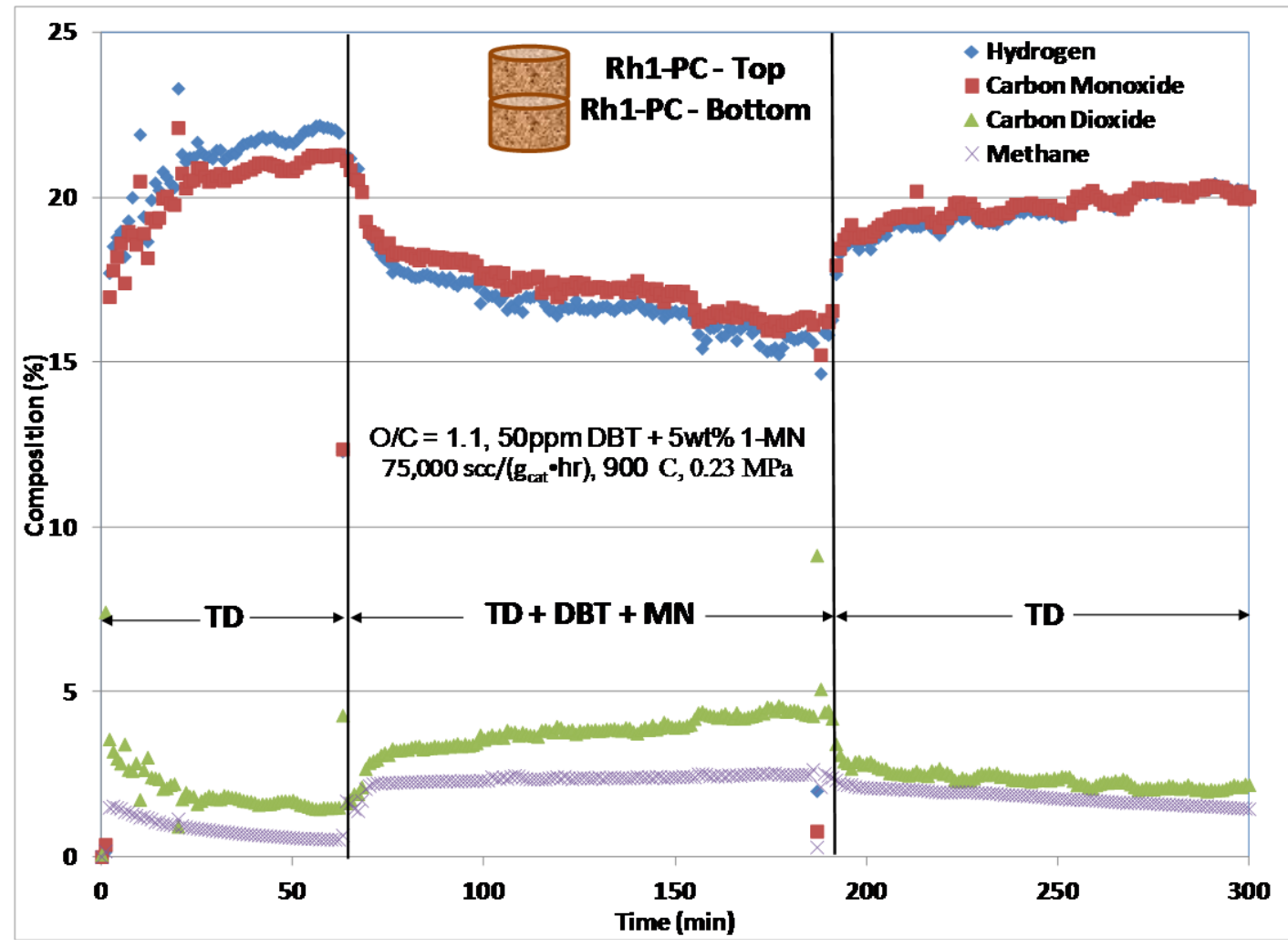

Figure 3-9 Performance of Rh1-PC coated foams in the top and bottom of the reactor under CPOX: WHSV $=75,000 \operatorname{scc~}_{\mathrm{cat}^{-1}} \mathrm{~h}^{-1}, \mathrm{O} / \mathrm{C}=1.1,900^{\circ} \mathrm{C}$, and $0.23 \mathrm{MPa}$.

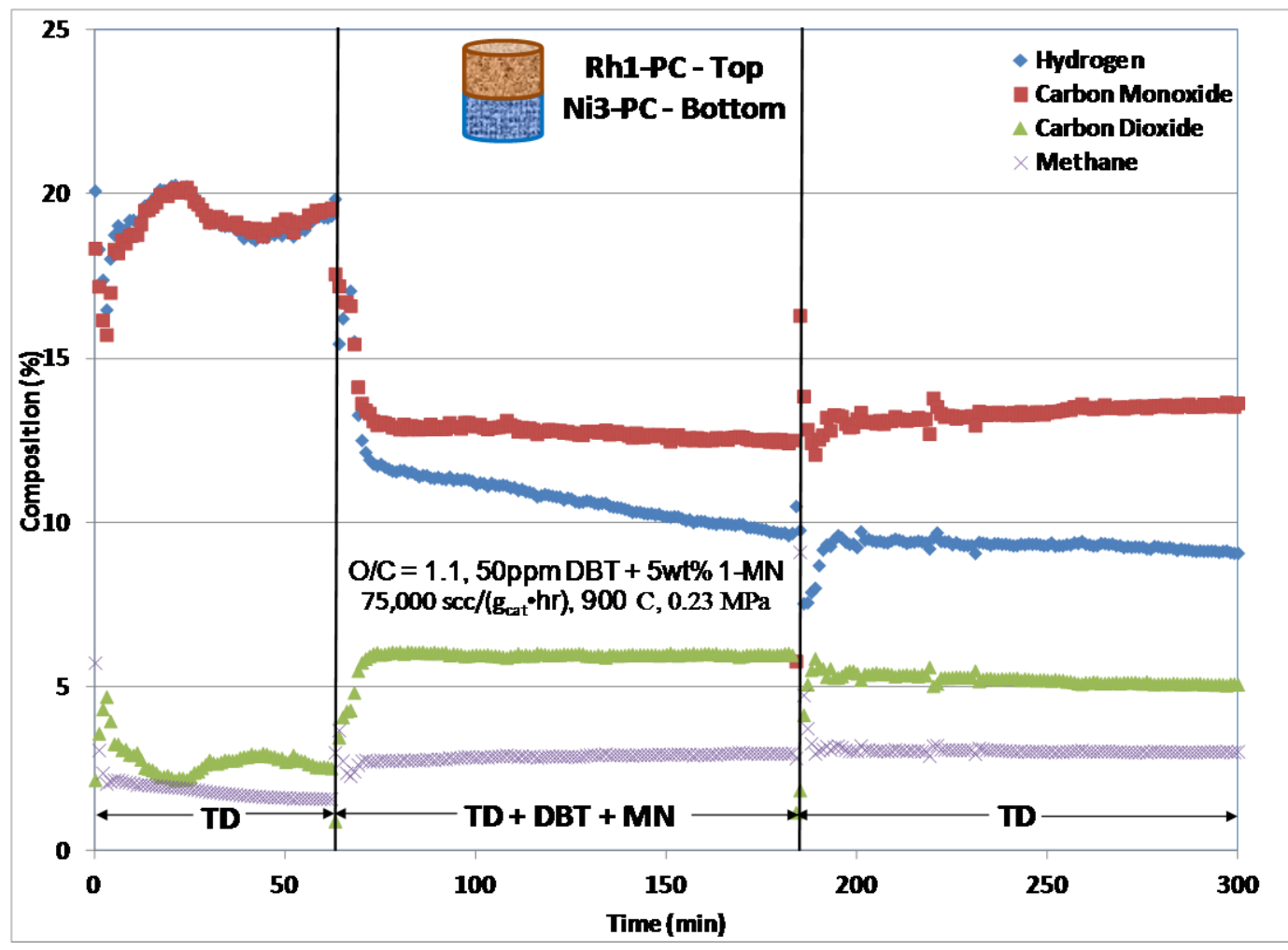

Figure 3-10 Performance of Rh1-PC coated foam in the top and Ni3-PC coated foam in the bottom of the reactor under CPOX: WHSV $=75,000 \mathrm{scc} \mathrm{g}_{\mathrm{cat}}{ }^{-1} \mathrm{~h}^{-1}, \mathrm{O} / \mathrm{C}=1.1,900^{\circ} \mathrm{C}$, and $0.23 \mathrm{MPa}$. 


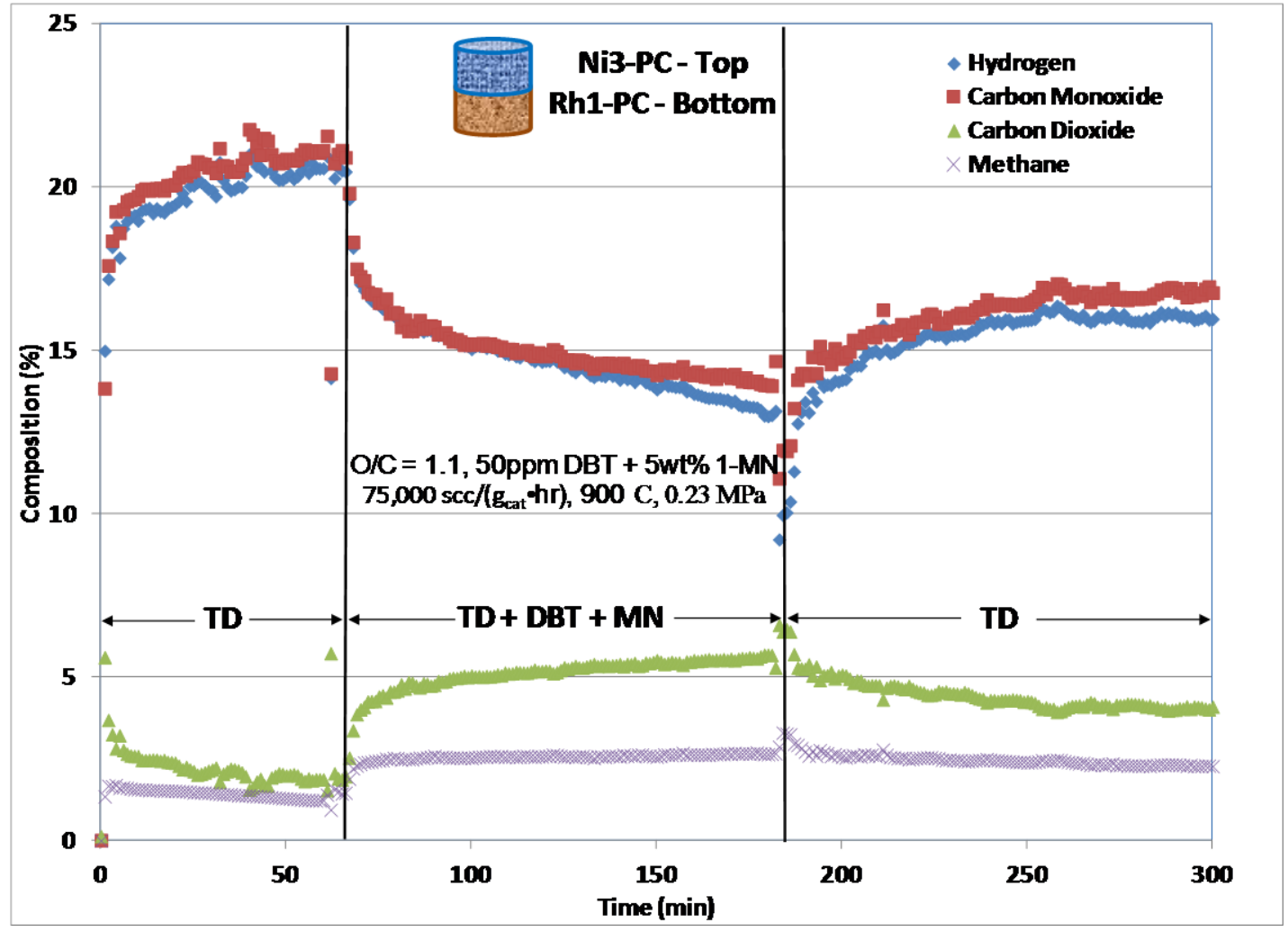

Figure 3-11 Performance of Ni3-PC coated foam in the top and Rh1-PC coated foam in the bottom of the reactor under CPOX: WHSV: $75,000 \mathrm{scc} \mathrm{g}_{\mathrm{cat}}{ }^{-1} \mathrm{~h}^{-1}, \mathrm{O} / \mathrm{C}=1.1,900^{\circ} \mathrm{C}$, and $0.23 \mathrm{MPa}$.

Table 3-8 Carbon Formation in Sections of Segmented Catalyst Bed.

\begin{tabular}{|lcccc|}
\hline & & & & \\
\hline TOP: & Ni3-PC: & Ni3-PC: & Rh1-PC: & Rh1PC: \\
BOTTOM & Ni3-PC & Rh1PC & Ni3-PC & Rh1-PC \\
\hline Carbon (Top), $g$ & 0.42 & 0.38 & 0.08 & 0.05 \\
Carbon (Bottom), $g$ & 0.36 & 0.05 & 0.28 & 0.04 \\
\hline Total, $g$ & 0.78 & 0.43 & 0.36 & 0.09 \\
\hline
\end{tabular}




\section{$4 \quad$ Carbon Formation Study}

\subsection{Low-Temperature Carbon}

Note: Section 4.1 was submitted for publication to Applied Catalysis A as, "Carbon formation on Rh-substituted pyrochlores catalysts under partial oxidation of liquid hydrocarbons.”

\subsubsection{Introduction}

Among several potential applications, reforming liquid hydrocarbons into syngas can be used to operate a solid oxide fuel cell for auxillary power units in long-haul trucks, and for remote, or distributed power generation [120]. For these applications the use of water (i.e. steam reforming, SR, or autothermal reforming, ATR) may not be practical. Instead, partial oxidation (POX) or oxidative steam reforming (OSR), the use of oxygen and steam in ratios different from ATR, may be a more attractive approach to generating syngas. However, these reactions require high temperatures; and, for fuels containing sulfur and aromatic contaminants, like diesel, traditional supported metal reforming catalysts will deactivate rapidly from excessive carbon deposition [53, 130-134], as well as from sintering [135, 136], and sulfur poisoning [137-140].

Catalyst deactivation from excessive carbon deposition is inevitable in hydrocarbon reforming. However, deactivation can be reduced by substituting the active metals into thermally-stable oxide crystal structures such as perovskites [97-99, 121], pyrochlores [71, 72, 82, 83], and hexaaluminates $[61,62,69,70,72,73,105]$. Pyrochlores, into which catalytically active metals have been substituted, have demonstrated high thermal stability while limiting carbon formation, the latter believed to be the result of increased oxygen mobility compared to an unmodified pyrochlore [122, 141, 142]. The pyrochlore structure, $\mathrm{A}_{2} \mathrm{~B}_{2} \mathrm{O}_{7}$, can accommodate substitution into both the A- and B-sites of the lattice, which allows for the addition of both promoter and active catalytic metals [122]. Doping the pyrochlore structure with these metals can produce a catalyst that possesses several unique properties that are beneficial for hydrocarbon reforming: high catalytic activity, thermal stability, sulfur tolerance, and oxygen conductivity [71, 72, 82-84, $122,141,142]$.

A significant reforming study utilized a Rh-substituted pyrochlore, supported by zirconiumdoped ceria (ZDC), to successfully convert commercial diesel fuel to syngas for $1000 \mathrm{~h}$ under OSR conditions [84]. In that study, notable carbon mitigation was achieved by the ZDC support; however, some benefit was also attributed to the doping of the A- and B-site with $\mathrm{Ca}$ and $\mathrm{Y}$, respectively. It is believed that further improvements to the active pyrochlore phase itself can be accomplished through other formula modifications. To guide this effort, additional understanding of how and where carbon forms on the catalyst surface under reaction conditions would be very useful.

The formation of carbon on reforming catalysts has been studied extensively [70, 119, 131, 132, 134, 143]; however, the majority of these studies were conducted on traditional supported metal catalysts. Shamsi, et al. [143] conducted a study on a Pt catalyst deposited on an unmodified alumina support. Unmodified alumina was used to eliminate the effect of promoters on the carbon deposition, which had not previously been reported. The catalyst was tested with several different hydrocarbon fuels, and under three different reforming modes (SR, ATR, and POX). After each test, the carbon deposited on the catalyst and support surfaces was burned off under 
temperature programmed oxidation (TPO) to observe the types and quantity of carbon formed. In all cases, carbon burn-off peaks were observed at several different temperatures. Peaks observed below $200^{\circ} \mathrm{C}$ were attributed to carbon on the deposited metal, while higher temperature peaks were attributed to carbon deposited on the catalyst support.

A few studies using mixed-metal oxide catalysts have been reported for reforming [57, 144], but in these materials, the active metal was a major constituent of the crystal structure. For example, a praseodymium ruthenate $\left(\mathrm{Pr}_{2} \mathrm{Ru}_{2} \mathrm{O}_{7}\right)$ was studied as a reforming catalyst [57], but it was shown that under reaction conditions the $\mathrm{Ru}$ was reduced and the pyrochlore crystal structure broke down, resulting in a $\mathrm{Pr}_{2} \mathrm{O}_{3}$ supported $\mathrm{Ru}$ catalyst. Similarly, $\mathrm{Eu}_{2} \mathrm{Ir}_{2} \mathrm{O}_{7}$ decomposed to Ir metal supported on $\mathrm{Eu}_{2} \mathrm{O}_{3}$ under methane dry reforming [144].

The approach of partial substitution of a catalytically active metal is a relatively new one, which appears to offer additional benefits under high temperature, highly reducing conditions, like those produced during the catalytic POX of liquid hydrocarbons. Thorough characterization of the different surface sites that are present in these types of materials (i.e. complex oxides with multiple partial metal substitutions) is still to be done. The initial purpose of this study is to perform the most useful characterization (e.g. metal reducibility, dispersion, crystal structure) that is relevant to reforming catalyst performance and carbon deposition. The second purpose is to examine how carbon deposits during POX experiments on the different reducible sites of a Rh-substituted $\mathrm{La}_{2} \mathrm{Zr}_{2} \mathrm{O}_{7}$ pyrochlore with different active metal loadings, and for different lengths of time.

\subsubsection{Experimental Methods}

\subsubsection{Catalyst Synthesis}

The Rh-substituted pyrochlores were prepared by a modified Pechini method [124]. The details of the synthesis method are provided in a previous work [Ref]. Generally, nitrate salts of each metal were dissolved separately in de-ionized water and then combined with a citric acid (CA) solution. The solution was heated to $65^{\circ} \mathrm{C}$ while being stirred to ensure complete metal complexation. Once at $65^{\circ} \mathrm{C}$, ethylene glycol (EG) was added to the solution. The solution was stirred continuously at temperature until most of the water had evaporated, leaving a transparent, viscous gel. The stir bar was removed, and the beaker was transferred to a heating mantle preheated to $70^{\circ} \mathrm{C}$. The temperature in the mantle was increased to $140^{\circ} \mathrm{C}$ to promote the polyesterification reaction between EG and CA, which produced an organic polymeric network [125]. This foam-like material was placed in an oven at $130^{\circ} \mathrm{C}$ to dry overnight. Finally, the material was calcined at $1000^{\circ} \mathrm{C}$ for $8 \mathrm{~h}$ to form the pyrochlore crystal phase. Catalysts with four different loading levels of Rh were prepared (Table 4-1).

Table 4-1 Catalysts Prepared for This Study.

\begin{tabular}{|c|c|c|}
\hline Catalyst ID & $\begin{array}{c}\text { Rh Loading } \\
\text { (wt \%) }\end{array}$ & Catalyst Formula* \\
\hline LCZY & 0 & $\mathrm{La}_{1.89} \mathrm{Ca}_{0.11} \mathrm{Zr}_{1.75} \mathrm{Y}_{0.25} \mathrm{O}_{7-\delta}$ \\
\hline LCZR1Y & 1 & $\mathrm{La}_{1.89} \mathrm{Ca}_{0.11} \mathrm{Zr}_{1.70} \mathrm{Y}_{0.25} \mathrm{Rh}_{0.05} \mathrm{O}_{7-\delta}$ \\
\hline LCZR2Y & 2 & $\mathrm{La}_{1.89} \mathrm{Ca}_{0.11} \mathrm{Zr}_{1.64} \mathrm{Y}_{0.25} \mathrm{Rh}_{0.11} \mathrm{O}_{7-\delta}$ \\
\hline LCZR3Y & 3 & $\mathrm{La}_{1.89} \mathrm{Ca}_{0.11} \mathrm{Zr}_{1.59} \mathrm{Y}_{0.25} \mathrm{Rh}_{0.16} \mathrm{O}_{7-\delta}$ \\
\hline
\end{tabular}

* As prepared 


\subsubsection{Catalyst Characterization}

Prior to catalytic testing, material characterization was performed on each of the catalyst powders. Temperature programmed reduction (TPR) and hydrogen pulse chemisorption $\left(\mathrm{H}_{2} \mathrm{PC}\right)$ tests were conducted in a Micromeritics ASAP 2910. Approximately $200 \mathrm{mg}$ of each catalyst were loaded into the sample tube, and were reduced under $5 \mathrm{vol} \% \mathrm{H}_{2} / \mathrm{Ar}$ balance $(25 \mathrm{sccm}$ ) from 30 to $900^{\circ} \mathrm{C}$ with a ramp rate of $10^{\circ} \mathrm{C} / \mathrm{min}$. The $\mathrm{H}_{2} \mathrm{PC}$ measurements were conducted after the $\mathrm{TPR}$ at $50^{\circ} \mathrm{C}$. The same gas mixture was pulsed over the samples every two minutes to determine the $\mathrm{H}_{2}$ uptake on the reduced metal sites. A 1:1 molar ratio of atomic $\mathrm{H}$ to metal was assumed to quantify $\mathrm{H}_{2}$ dissociation. The bulk $\mathrm{Rh}$ concentration for each catalyst was determined by inductively coupled plasma (ICP) optical emission spectroscopy on a Perkin-Elmer Optima 3000 ICP-OES spectrometer. The crystalline phases present in each sample were determined by powder X-ray diffraction (XRD) using a PANalytical X'Pert PRO model XRD utilizing filtered $\mathrm{Cu} \mathrm{K} \alpha$ radiation. Peak identification of the X-ray data was performed using X'pert High Score Plus software, version 2.1.

\subsubsection{Performance/Activity Tests}

Reaction studies were carried out in a laboratory-scale fixed-bed continuous-flow reactor system. The catalyst powders were sized to $-10 /+40$ mesh and diluted with quartz sand to a volume of 3 $\mathrm{mL}$ to avoid channeling and to minimize temperature gradients. The catalysts were loaded into the reactor as prepared, with no pretreatment or reduction. The catalyst bed was placed in a tubular reactor ( $8 \mathrm{~mm}$ i.d.) with a coaxially centered thermocouple at the center of the bed. Nitrogen and air flows were delivered by mass flow controllers, and the liquid fuel feed was delivered by a high accuracy ISCO syring pump. Additional details and a reactor schematic are provided elsewhere. Additional details and a reactor schematic are provided elsewhere [75].

Partial oxidation experiments were conducted isothermally with a center bed temperature of $900^{\circ} \mathrm{C}$ and a pressure of $0.23 \mathrm{MPa}$. Each catalyst was tested for $4 \mathrm{~h}$ under a flow of $n$-tetradecane (TD), a diesel surrogate, with added sulfur specie, dibenzothiophene (DBT), and aromatic specie, 1-methylnaphthalene (MN), representing major contaminants in diesel fuel, and air $(\mathrm{O} / \mathrm{C}=1.25)$. The flows and conditions of the experiments are summarized in Table 4-2. After the three catalysts with different weight loadings were tested, the LCZR2Y catalyst was tested in three additional runs for 2, 4, and $18 \mathrm{~h}$.

Table 4-2 Summary of POX Experimental Conditions.

\begin{tabular}{|l|c|}
\hline \multicolumn{1}{|c|}{ Condition } & Value \\
\hline Feed Preheat T, ${ }^{\circ} \mathrm{C}$ & 325 \\
\hline Reactor $\mathrm{T},{ }^{\circ} \mathrm{C}$ & 900 \\
\hline Pressure, $\mathrm{MPa}$ & 0.23 \\
\hline Feed Flow, sccm & 400 \\
\hline $\mathrm{TD}+\mathrm{DBT}+\mathrm{MN}$, vol\% & 2.1 \\
\hline $\mathrm{O}_{2}, \mathrm{vol} \%$ & 17.9 \\
\hline \multicolumn{1}{|c|}{$\mathrm{N}_{2}$, vol\% } & 80.0 \\
\hline DBT conc., ppm as S & 50 \\
\hline MN conc., wt $\%$ & 5.0 \\
\hline O/C Ratio & 1.25 \\
\hline
\end{tabular}




\subsubsection{Product Analysis}

The gases (hydrogen, nitrogen, oxygen, carbon monoxide, carbon dioxide, and methane) were analyzed using a $200 \mathrm{amu}$ scanning magnetic sector mass spectrometer (Thermo ONIX, Model No. Prima $\delta b)$. Oxygen conversion was complete during all experiments. Although water was produced in the reaction, it was not quantitatively analyzed. Carbon balances were typically within $100 \pm 5 \%$. Yield and conversion were calculated by the expressions provided in Section 2.2.2.5.

\subsubsection{Carbon Formation Study}

\subsection{Temperature programmed oxidation}

The carbon formed during reaction was studied by temperature programmed oxidation (TPO) of the catalyst and bed material (quartz sand) together in the reactor. TPO was performed by introducing a gas stream of $10 \mathrm{vol} \% \mathrm{O}_{2} / \mathrm{N}_{2}$ into the reactor and was ramped from 250 to $750^{\circ} \mathrm{C}$ with a temperature ramp rate of $0.5^{\circ} \mathrm{C} / \mathrm{min}$ for the $4 \mathrm{~h}$ runs on catalysts with different Rh weight loadings. A ramp rate of $0.2^{\circ} \mathrm{C} / \mathrm{min}$ was used for the study of the effect of time on stream using the $2 \mathrm{wt} \%$ Rh catalyst (LCZR2Y). Carbon dioxide evolution was measured continuously by a mass spectrometer, and the total carbon that had been deposited in the bed was calculated by integration of the carbon dioxide flow rate exiting the reactor.

\subsection{Raman spectroscopy}

A Renishaw InVia Raman Microscope with $1.0 \mathrm{~cm}^{-1}$ resolution was used to collect the Raman spectra of the spent samples. The samples were excited using a $532 \mathrm{~nm}$ continuous wave green laser (Crystal 532-100). A 5X magnification microscope objective was used in the experiments. The numerical aperture size of the objective was 0.12 . The experimental laser spot size was measured using a calibration slide and was determined to be $13 \mu \mathrm{m}$.

\subsubsection{Results and Discussion}

\subsubsection{Catalyst Characterization}

\subsection{Temperature Programmed Reduction}

The TPR results for all four catalysts are plotted in Figure 4-1. One high temperature peak, between 460 and $500^{\circ} \mathrm{C}$, was common for all materials, and was the largest peak for each sample. An un-doped lanthanum zirconate (LZ) was reported to produce a similar high temperature reduction peak at $527^{\circ} \mathrm{C}$ [82], and can be attributed to the reduction of the zirconium in the oxide structure. This peak is significantly larger for the Rh-substituted catalysts compared to the LCZY. This suggests that the Rh is associated with the $\mathrm{Zr}$ sites in the pyrochlore structure.

In addition to the high temperature peak a small shoulder was observed at $415^{\circ} \mathrm{C}$ for LCZR1Y. At higher Rh loadings (LCZR2Y/LCZR3Y), in addition to an increase in the high temperature peak, two types of $\mathrm{Rh}$ sites were observed, identified by reduction peaks located at $205 / 225^{\circ} \mathrm{C}$ and $350 / 360^{\circ} \mathrm{C}$. The most reducible Rh site $\left(205 / 225^{\circ} \mathrm{C}\right)$ is not present in LCZR1Y, and is likely from the reduction of rhodium oxide on the pyrochlore surface. There is a theoretical limit to the level of substitution for a given metal in a pyrochlore structure, which is determined by the ratio of the ionic radii of the A- and B-site metals [122]. Excess Rh may form a secondary phase 
and/or deposit as an oxide on the pyrochlore surface. No peaks were observed around $100^{\circ} \mathrm{C}$, which would be associated with a simple supported Rh site [145-147].

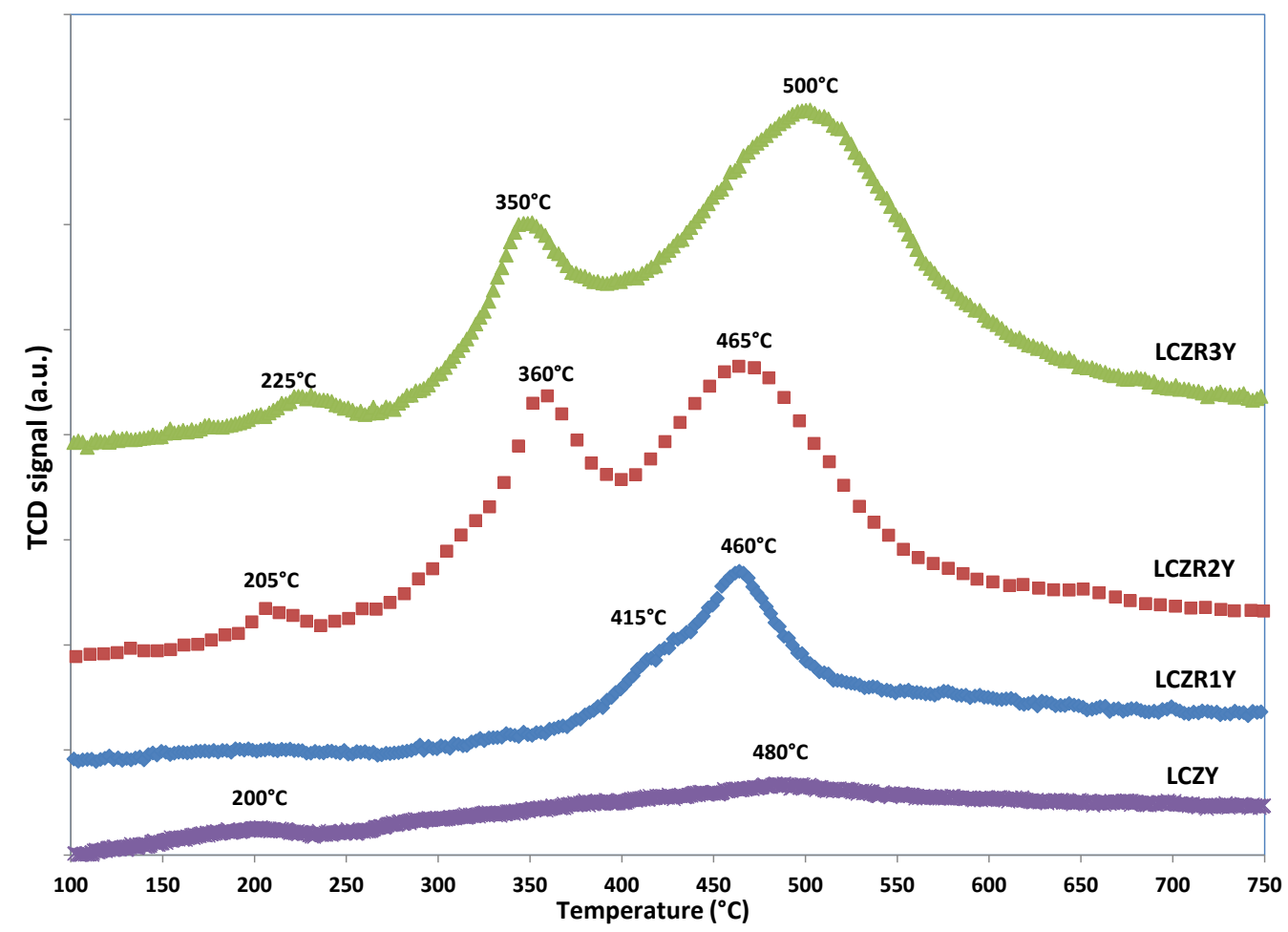

Figure 4-1 TPR of substituted pyrochlore catalysts: LCZY, LCZR1Y, LCZR2Y, and LCZR3Y.

\subsection{Hydrogen Pulse Chemisorption}

After reduction, hydrogen pulse chemisorption was performed on each sample to determine metal dispersion and particle size. Dispersion numbers were consistent with previously reported results for similar substituted pyrochlores [82]. The results of this characterization, as well as ICP results, are presented in Table 4-3. As the Rh loading increased, total dispersion decreased and average particle size increased. It is proposed that as the Rh loading increased, the pyrochlore crystal structure became saturated, and the excess Rh likely formed a secondary oxide phase with larger particles, consistent with the results in Table 4-3.

Table 4-3 Metal Dispersion from $\mathrm{H}_{2}$ PC Experiments.

\begin{tabular}{|c|c|c|c|c|}
\hline Catalyst & $\begin{array}{c}\text { Metal Content } \\
\text { (wt\%) from } \\
\text { ICP }\end{array}$ & $\begin{array}{c}\text { Metal } \\
\text { Dispersion } \\
\mathbf{( \% )}\end{array}$ & $\begin{array}{c}\text { Reducible sites } \\
\left.\mathbf{( 1 0}^{-\mathbf{6}} \mathbf{m o l} / \mathbf{g}\right)\end{array}$ & $\begin{array}{c}\text { Particle } \\
\text { size (nm) }\end{array}$ \\
\hline LCZR1Y & 0.94 & 7.7 & 7.0 & 14 \\
\hline LCZR2Y & 1.96 & 5.5 & 10.5 & 20 \\
\hline LCZR3Y & 3.00 & 3.9 & 11.4 & 28 \\
\hline
\end{tabular}

\subsection{X-ray Powder Diffraction}

The XRD patterns for the four pyrochlore materials show that the desired crystal structure was obtained (Figure 4-2). The most interesting difference in these samples is the emergence and 
increase in the peak at ca. $31.5^{\circ}$ as the $\mathrm{Rh}$ content increased. This peak is associated with a second crystal phase, presumably a $\mathrm{LaRhO}_{3}$ perovskite (JCPDS:10-0305). The Rh associated with this phase is also believed to correspond to the reduction peak observed ca. $350 / 360^{\circ} \mathrm{C}$ in the TPR for LCZR2Y/LCZR3Y (Figure 4-1).

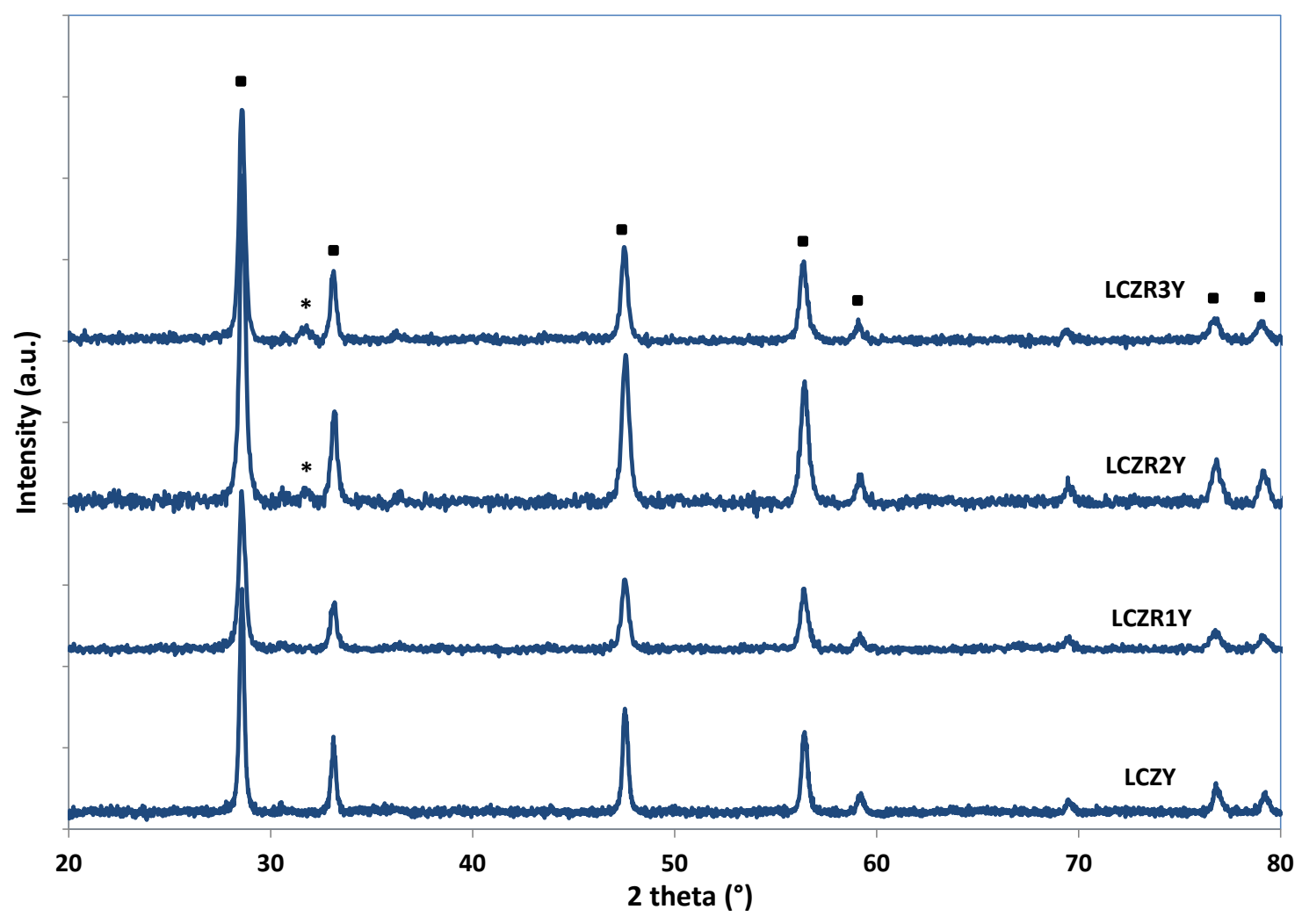

Figure 4-2 XRD of pyrochlore reforming catalysts having different Rh loadings: LCZY, LCZR1Y, LCZR2Y, LCZR3Y; (-) pyrochlore, (*) perovskite.

In order to examine the crystal structure further the LCZR2Y sample was scanned by XRD after being reduced with $\mathrm{H}_{2}$ at 200, 350, and $900^{\circ} \mathrm{C}$, at which Figure 4-1 shows reduction peaks in the TPR experiments. Although the final temperature was much higher than the third reduction peak $\left(460^{\circ} \mathrm{C}\right)$, no peaks were observed beyond this temperature. The results of these scans are presented in Figure 4-3. There was no observable difference in the spectra obtained for the two samples reduced at 200 and $350^{\circ} \mathrm{C}$. However, the sample reduced at $900^{\circ} \mathrm{C}$ showed a significant decrease in the peak located ca. $31.5^{\circ}$, associated with hydrogen reduction of the $\mathrm{LaRhO}_{3}$ perovskite phase. This gives additional evidence for the conclusion that this phase corresponds to the reduction peak observed at $350^{\circ} \mathrm{C}$ in the TPR. Therefore, this indicates that under the reducing atmosphere produced by the reaction conditions the perovskite phase decomposes, presumably allowing more $\mathrm{Rh}$ to participate in the reforming reaction in addition to the $\mathrm{Rh}$ in the pyrochlore phase. 


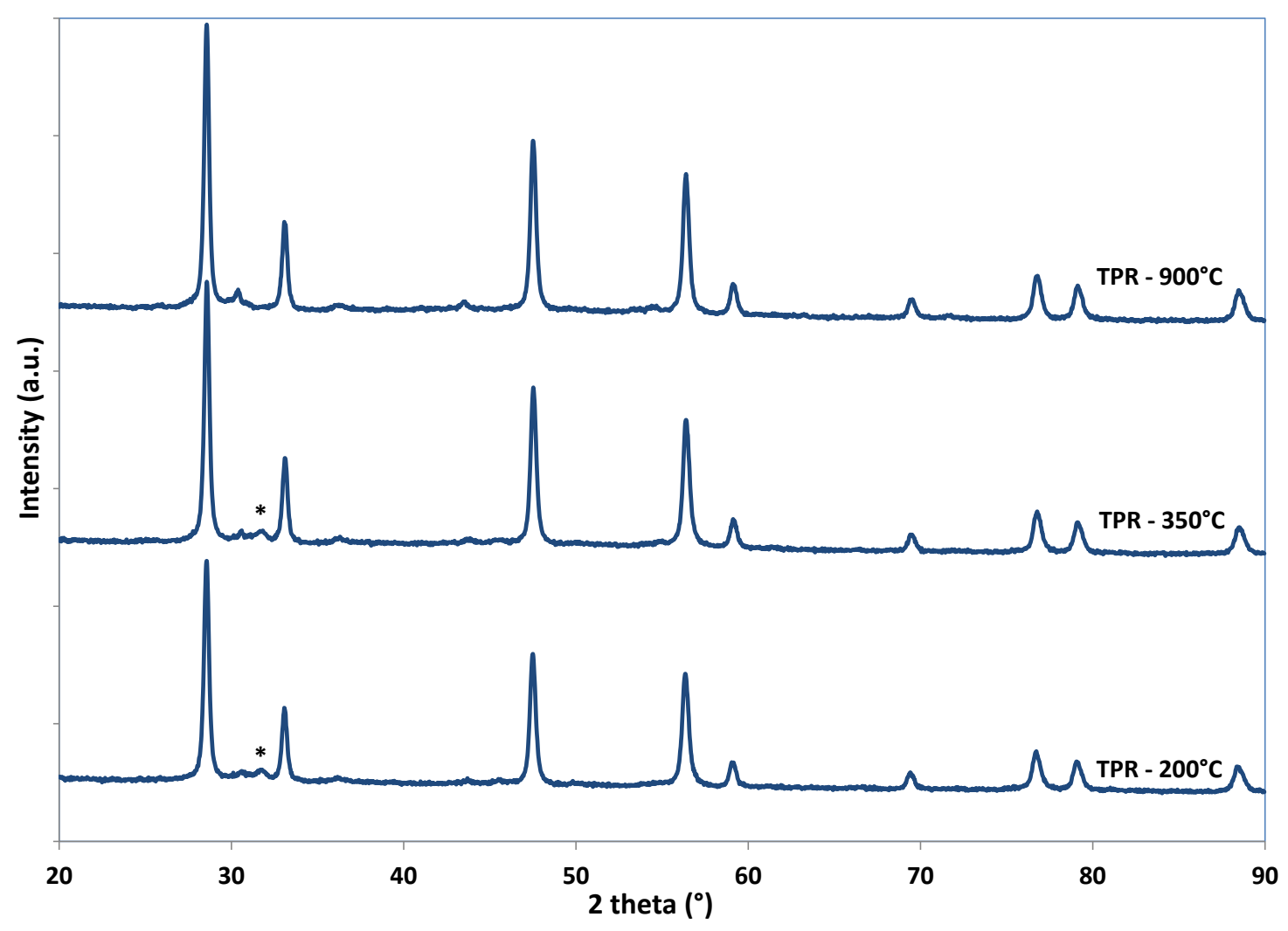

Figure 4-3 XRD spectra of LCZR2Y pyrochlore catalyst after reduction at different temperatures.

\subsubsection{Carbon Formation Study}

\subsection{Partial Oxidation Reaction}

Figure 4-4 shows the product yields during the 18-h POX of TD conducted on the LCZR2Y catalyst. This product distribution is near equilibrium values [9] and the carbon balance was determined to be $100 \pm 5 \%$ throughout the run. The conditions of this experiment were selected to produce a steady state performance with little to no catalyst deactivation. All reaction tests on the $\mathrm{Rh}$ containing catalysts produced the same product distribution throughout the duration of the experiments. The LCZY catalyst had very poor product yields $\left(\mathrm{H}_{2}=20.9 \%, \mathrm{CO}=31.6 \%, \mathrm{CO}_{2}=\right.$ $\left.31.1 \%, \mathrm{CH}_{4}=10.7 \%\right)$, only slightly higher than yields produced in a blank reactor.

\subsection{Effect of Rh loading}

After reaction testing, a temperature programmed oxidation (TPO) was performed on each catalyst to analyze the type and quantity of deposited carbon deposited on the surface. The $\mathrm{CO}_{2}$ formed for each catalyst is plotted in Figure 4-5. Three TPO peaks in the temperature range of $300-550^{\circ} \mathrm{C}$ were observed for the Rh-substituted catalysts. This low-temperature carbon (LTC) is likely deposited on surface sites with a more metallic nature. These peaks are not present with the unsubstituted material (LCZY), which produced one very large peak above $550^{\circ} \mathrm{C}$ that began burning off at ca. $370^{\circ} \mathrm{C}$. More stable, graphitic carbon, which burns off at higher temperatures (HTC), is typically associated with the inert oxide catalyst surfaces, or inert material in the catalyst bed. The formation of this type of carbon will be the focus of a future study. 
The first LTC peak is seen ca. $410-420^{\circ} \mathrm{C}$ for the LCZR2Y and LCZR3Y catalysts, but it is not clear if this peak is present for LCZR1Y due to the contribution of HTC peak (above $550^{\circ} \mathrm{C}$ ). Each Rh-substituted catalyst produced two additional peaks ca. 480 and $550^{\circ} \mathrm{C}$. These carbon species are possibly associated with less metallic Rh sites that are more strongly associated with the oxide crystal structure.

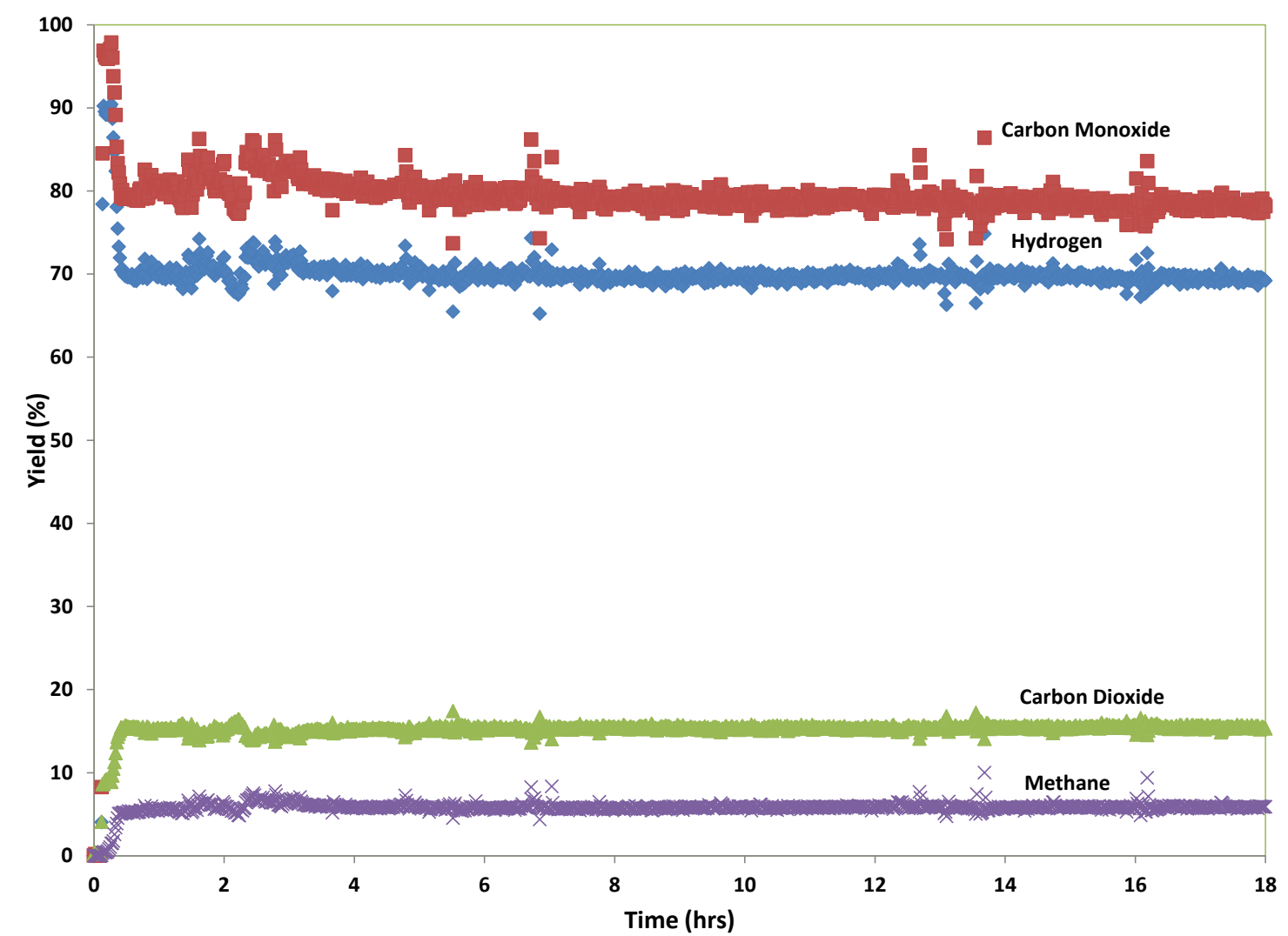

Figure 4-4 POX of TD over LCZR2Y pyrochlore for $18 \mathrm{~h}$ : WHSV $=50,000 \mathrm{scc} \mathrm{g} \mathrm{gat}^{-1} \mathrm{~h}^{-1}, \mathrm{O} / \mathrm{C}=1.1$, $900^{\circ} \mathrm{C}$, and $0.23 \mathrm{MPa}$.

Table 4-4 provides the amount of carbon calculated from the TPO from $250-550^{\circ} \mathrm{C}$ (LTC) for each catalyst calculated by integration of the $\mathrm{CO}_{2}$ plots. The values calculated from straight integration of the curves in Figure 4-5 suggest that the LTC decreases with increasing Rh substitution. However, some of the carbon burning off below $550^{\circ} \mathrm{C}$ is from the simultaneous burn off of carbon that reaches its peak above $600^{\circ} \mathrm{C}$. Therefore, the apparent decrease in LTC is possibly reflective of a decrease in deposition of higher temperature carbon at higher Rhsubstitution.

Origin (OriginLab, Northampton, MA) peak fitting software was used to deconvolute the peaks in each TPO in order to subtract out the contribution of higher temperature burning carbon from the LTC, and these calculated values are provided in the second column of Table 4-4. These values for LTC show a different trend, which would be more expected. As Rh substitution increased, the adjusted amount of LTC deposition increases. Further, when this carbon is normalized with the number of reducible sites reported in Table 4-3, the LTC increases as well with higher substitution. This could be explained by the fact that the particle size (also reported in Table 4-3) increases with substitution, and it is known that larger particles are more susceptible to carbon deposition. 

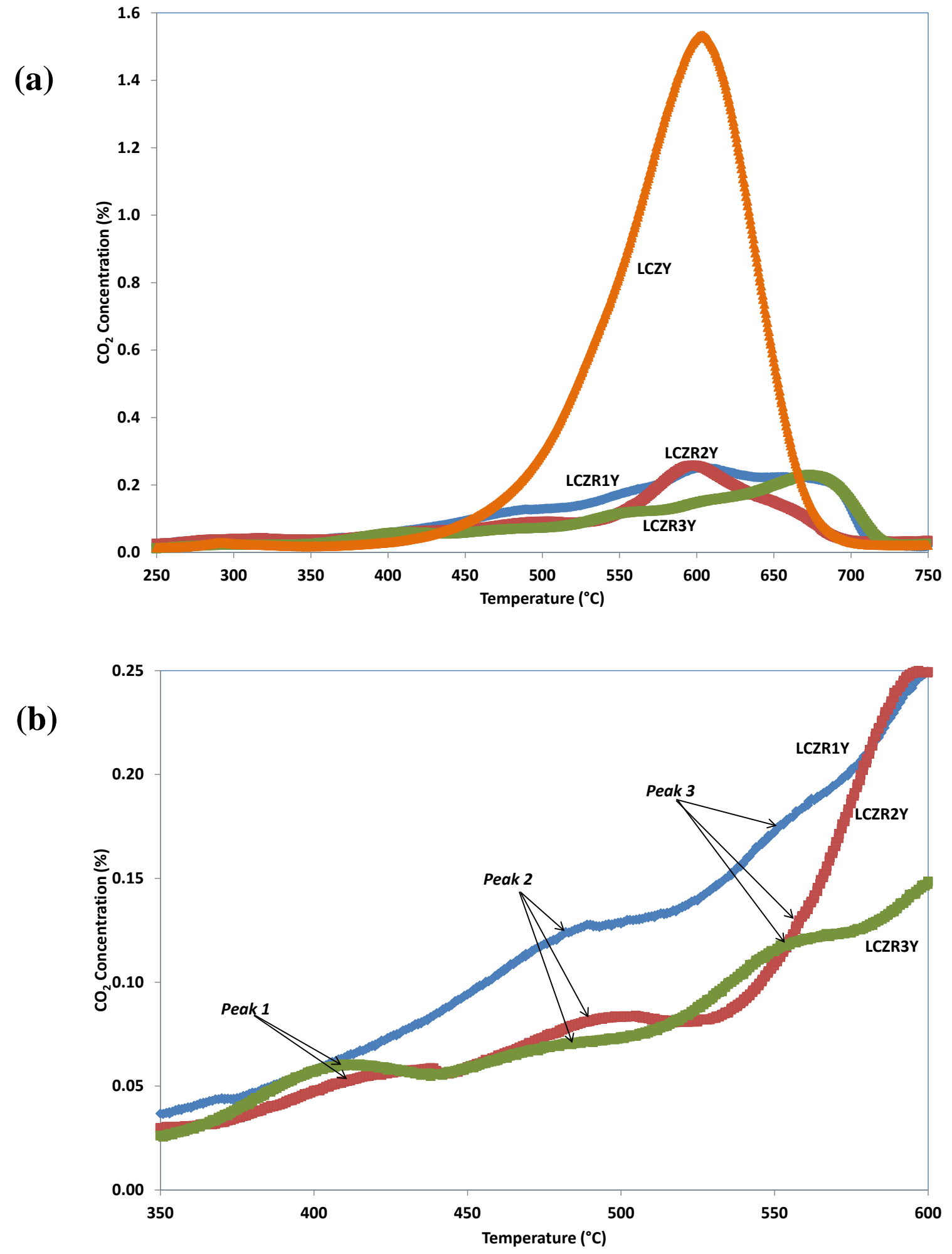

Figure 4-5 TPO of pyrochlore catalysts with different Rh loadings after $4 \mathrm{~h}$ POX of TD: (a) LCZY, LCZR1Y, LCZR3Y, (b) LTC only, LCZY removed. 
Table 4-4 Carbon Formation Determined from TPO of Pyrochlore Catalysts with Different Rh Loadings After $4 \mathrm{~h}$ POX of TD.

\begin{tabular}{|c|c|c|c|}
\hline Catalyst & LTC (mg) & $\begin{array}{c}\text { LTC (mg) After } \\
\text { Deconvolution }\end{array}$ & $\begin{array}{c}\text { LTC/Reducible } \\
\text { Site (mg/10 }\end{array}$ mol) \\
\hline LCZR1Y & 33 & 10 & 3.0 \\
\hline LCZR2Y & 26 & 17 & 3.4 \\
\hline LCZR3Y & 22 & 25 & 4.0 \\
\hline
\end{tabular}

\subsection{Effect of reaction time}

Reaction tests were conducted for different times on stream (TOS) (2, 4, and $18 \mathrm{~h}$ ) with the LCZR2Y catalyst. The TPO plots for these runs are provided in Figure 4-6. Again, three burn-off peaks were observed. The temperature ramp rate was decreased from 0.5 to $0.2^{\circ} \mathrm{C} / \mathrm{min}$ for better peak separation. This also resulted in a shifting of all the peaks to lower temperatures (360, 400, and $440^{\circ} \mathrm{C}$ ) than seen in the previous TPO for LCZR2Y (Figure 4-5). The difference in the amount of carbon calculated from the three peaks for each run time was not significant $(28,25$, and $29 \mathrm{mg}$, respectively). Only the burn-off peak above $500^{\circ} \mathrm{C}$, not examined here, increases over time.

These results, coupled with the fact that there was no observable decrease in the POX reaction over $18 \mathrm{~h}$ TOS (Figure 4-4), suggest that the more reactive carbon accumulates at/near the Rh sites, allowing it to oxidize more readily (i.e. at $\mathrm{T}<460^{\circ} \mathrm{C}$ ). However, this carbon does not apparently irreversibly block the Rh sites, since there is no observed decrease in POX conversion. Less reactive carbon $\left(\mathrm{TPO}>460^{\circ} \mathrm{C}\right)$, likely accumulates near, but not on, the Rh sites, clearly visible in the 18-h runs, but less obvious in the 2- and 4-h TPOs. The progress of carbon deposition appears to start at/near the Rh site, after which less oxidizable carbon, further from the Rh sites, populates the remaining sites. This result is consistent with other results in the literature [132], which showed carbon accumulation only on the catalyst support after a short period of time.

At longer reaction times, the accumulation of higher temperature carbon is expected to continue, ultimately leading to catalyst deactivation. Therefore, to increase resistance to deactivation, approaches to mitigate the formation of this type of carbon could be considered. These approaches may include substitution of different dopants into the pyrochlore structure, addition of surface promoters, or the addition of an oxygen-conducting support.

\subsection{Characterization of carbon type and partial burn-off}

Figure 4-7 shows the Raman spectra for a spent LCZR2Y after $4 \mathrm{~h}$ TOS. After reaction, the catalyst was removed from the reactor without performing a TPO, and separated from the inert bed material (quartz sand). The catalyst was separated into three samples. One of the samples was heat treated in air at $440^{\circ} \mathrm{C}$ to burn off a portion of the LTC. A second sample was heated in air to $700^{\circ} \mathrm{C}$, the temperature at which all carbon was observed to burn off (Figure 4-5). The third sample was not heat treated at all.

For the spent sample and the partially burned off sample, both graphitic ( $\mathrm{G}$ band) and polycrystalline (D band) carbon are seen at 1597 and $1356 \mathrm{~cm}^{-1}$, respectively; however, there is no significant difference in the spectra of these two samples. The LTC may be amorphous 
carbon around $400 \mathrm{~cm}^{-1}$, which has a decrease in intensity after the burnoff at $450^{\circ} \mathrm{C}$. However, the total amount of this carbon is much less compared to the HTC carbon.

\subsubsection{Conclusions}

Mixed-metal oxides substituted with metals that are catalytically active for hydrocarbon reforming demonstrate significantly different surface properties, and catalytic performance over simple supported metal catalysts. In this study, Rh-substituted pyrochlores with three different weight loadings $(1,2$, or $3 \mathrm{wt} \% \mathrm{Rh})$ produced three reduction peaks during a TPR, all of which occurred at much higher temperatures than the single reduction peak of a simple Rh metal deposited on a support. Increasing the level of Rh substitution from 0 to $3 \mathrm{wt} \%$ lead to the formation and growth of the lowest temperature reduction peak. It is proposed that higher substitution levels lead to secondary oxide phases, supported by the XRD spectra. At high enough Rh loading, large clusters of unsubstituted rhodium oxides can form, which would perform more like a simple supported catalyst.

These observations lead to the consideration that carbon deposition on the three reducible sites during reaction could also impact the catalytic performance differently than with a pure metallic site on a support. Therefore, POX of TD followed by TPO of the pyrochlore catalysts were conducted to study the type and quantity of the low temperature carbon $\left(\mathrm{T}<460^{\circ} \mathrm{C}\right)$ deposited on the catalyst surface. Three temperature burn-off peaks were observed in this region for each substituted catalyst, and all were attributed to carbon deposited on Rh sites. Two high temperature burn-off peaks $\left(\mathrm{T}>460^{\circ} \mathrm{C}\right.$ ) were observed for all catalysts, and were attributed to stable, graphitic carbon deposited on the inert surfaces of the catalyst and/or the inert bed material in the reactor.

Ultimately, it was observed that carbon did not accumulate on the catalytically active sites; however, the more stable carbon that burned off at relatively high temperatures did increase with TOS. This result is consistent with previous studies with supported metal catalysts, where carbon accumulated only on the support, and not on the deposited metal sights. However, this similarity does not identify how carbon accumulating on a substituted oxide surface differs from a simple oxide support, and whether or not this accumulation ultimately leads to catalyst deactivation. A follow up study could focus on the accumulating carbon on the same Rh-substituted pyrochlore for extended reaction times, and TPO to higher temperatures. Further recommended studies include studying how different dopants in the A- and B-sites of a pyrochlore impact the deposition of the high-temperature carbon. Finally, the addition of an oxygen-conducting phase to the pyrochlore catalyst should be examined for its impact on carbon deposition as well. 


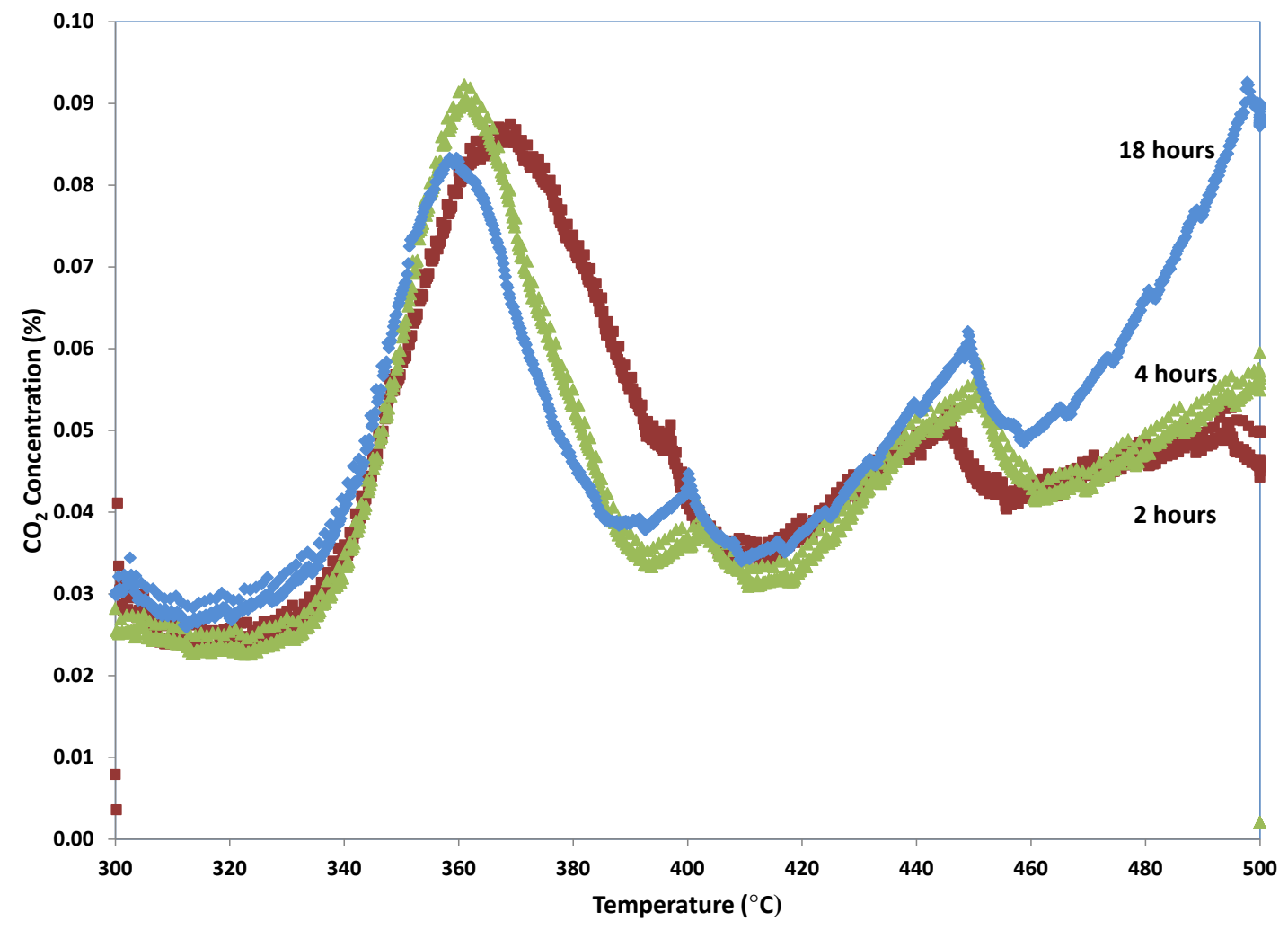

Figure 4-6 TPO of LCZR2Y after POX testing at varying TOS.

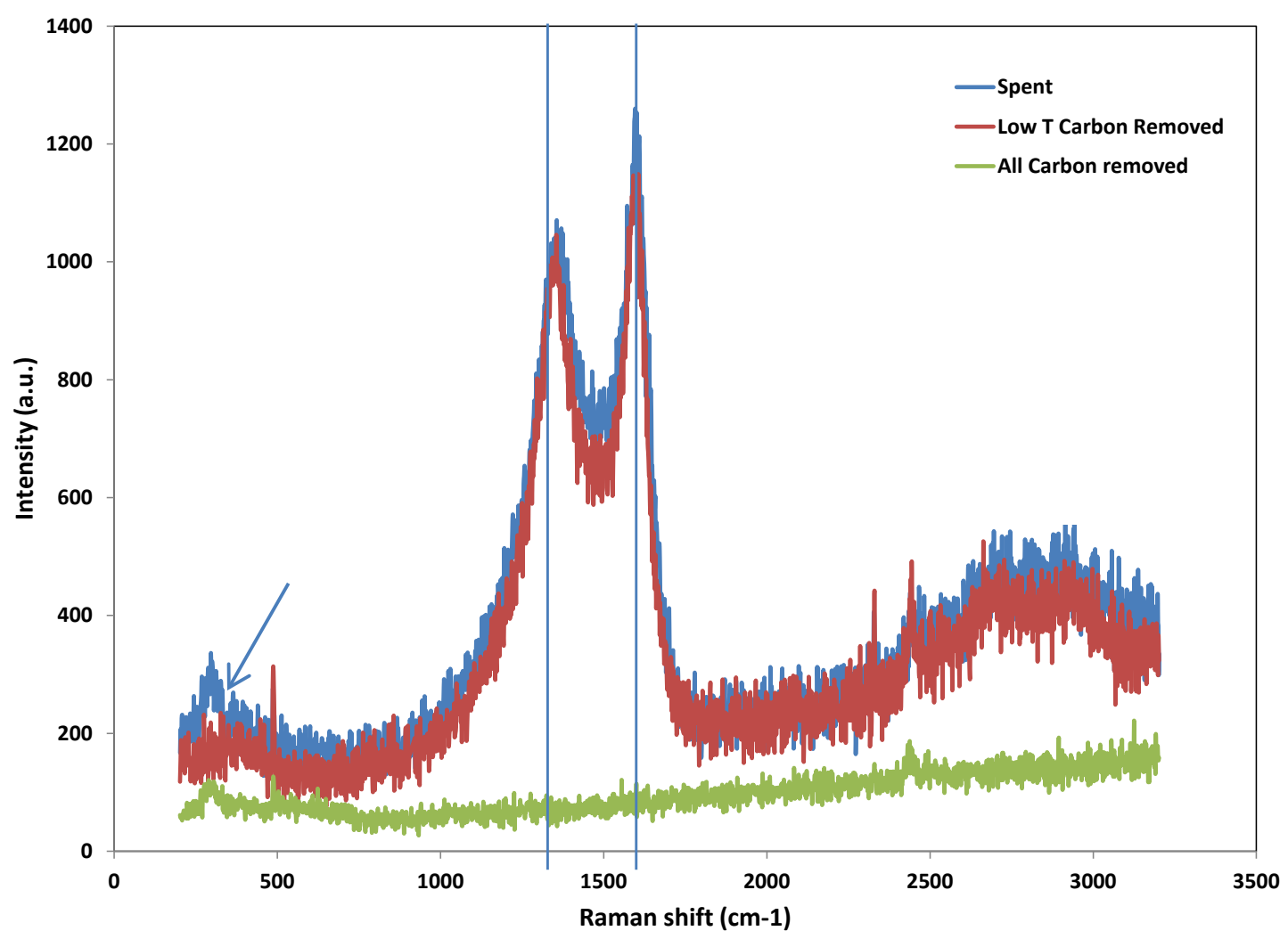

Figure 4-7 Raman spectra of LCZR2Y after POX of TD and partial carbon burn-off. 


\subsection{High-Temperature Carbon}

\subsubsection{Introduction}

Two types of carbon were identified in the study presented in Section 4.1: low-temperature carbon (LTC), and high-temperature carbon (HTC). The results and discussion in 4.1 focused on the LTC, defined as carbon that burns off under TPO conditions (described in 4.1.2.5) at a peak temperature below $550^{\circ} \mathrm{C}$. This carbon was observed to reach a steady state level within two hours of POX of TD at an $\mathrm{O} / \mathrm{C}=1.25$. It was proposed that this type of carbon was associated with the substituted Rh sites in the pyrochlore structure, and was not responsible for catalyst performance degradation.

The HTC burned off under TPO above $550^{\circ} \mathrm{C}$, and was characterized as less reactive carbon deposited on the pyrochlore surface and/or the inert bed material (silica sand) and reactor surfaces. This type of carbon was observed to begin accumulating over time, and is expected to lead to catalyst deactivation. The accumulation of HTC during POX of TD is the focus of this study. The data collected will be used to produce an empirical carbon formation model. This model will be discussed and applied to a second data set with the same catalyst under different reaction conditions.

\subsubsection{Experimental Methods}

The experimental methods for this section are the same as in Section 4.1.2, with the following exceptions:

1. Since the catalysts tested for the HTC formation are the same samples as were used for the LTC study, these samples were not re-characterized (i.e. the characterization presented in Section 4.1.3 applies to this section as well).

2. The oxygen-to-carbon ratio $(\mathrm{O} / \mathrm{C})$ was varied to 1.1 in the second part of this study for testing the model produced from the first data set $(\mathrm{O} / \mathrm{C}=1.25)$.

3. All TPO's in this study were conducted at $0.5^{\circ} \mathrm{C} / \mathrm{min}$.

4. Post-reaction characterization of the deposited carbon on the spent samples by Raman spectroscopy was not part of this study.

\subsubsection{Results and Discussion}

\subsubsection{Experimental Data for Model}

Figure 4-8 displays the TPO plots for the LCZR2Y catalyst after POX of TD $(\mathrm{O} / \mathrm{C}=1.25)$ tests conducted for 2, 4, 18, 46, and $77 \mathrm{~h}$. Under these conditions, no decline in product yields was observed. It is clear that the HTC increases with TOS. Integration of these curves produces the values presented in Table 4-5. The total bed carbon (TBC) is presented first and is the total quantity of all carbon deposited on all surfaces in the reactor. The LTC and HTC were calculated by integrating their respective peaks separately and are presented in the second and third columns. Consistent with the results reported in the previous study (Section 4.1) the LTC reaches a steady state early in the test, with accumulation occurring only for the HTC. 


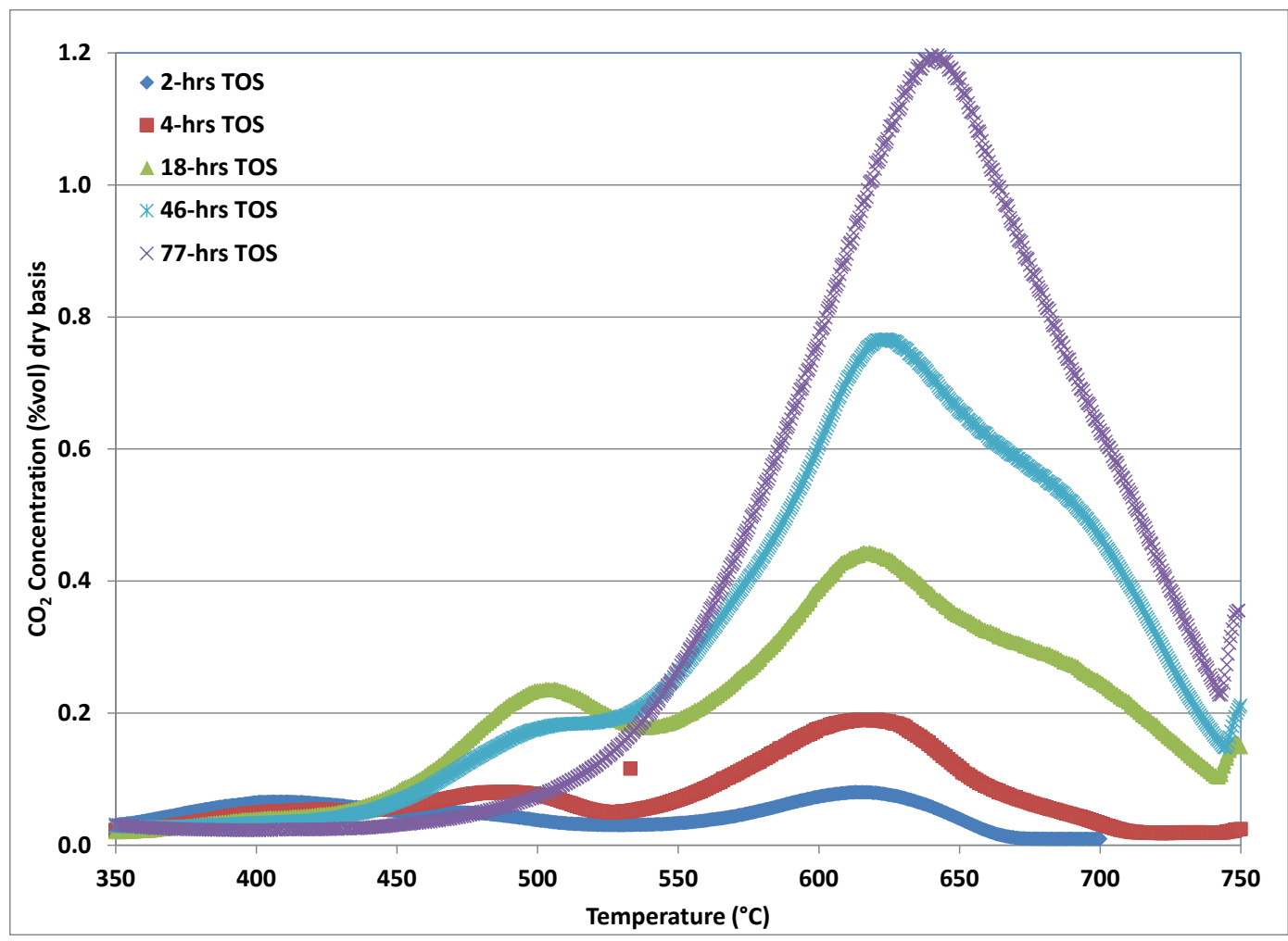

Figure 4-8 TPO profiles of LCZR2Y after POX of TD $(O / C=1.25)$ at various TOS.

Table 4-5 Carbon Calculated from TPO for LCZR2Y After POX of TD at Different TOS: O/C = 1.25.

\begin{tabular}{|c|c|c|c|}
\hline Time (h) & $\begin{array}{c}\text { TBC } \\
\text { (mg/g } \mathbf{c a t})\end{array}$ & $\begin{array}{c}\text { LTC } \\
\text { (mg/g } \mathbf{c a t})\end{array}$ & $\begin{array}{c}\text { HTC } \\
\text { (mg/g } \mathbf{c a t})\end{array}$ \\
\hline 0 & 0 & 0 & 0 \\
\hline 2 & 56 & 31 & 25 \\
\hline 4 & 96 & 31 & 65 \\
\hline 18 & 238 & 41 & 196 \\
\hline 46 & 331 & 31 & 300 \\
\hline 77 & 475 & 23 & 452 \\
\hline
\end{tabular}

\subsubsection{Empirical Carbon Formation Model}

The carbon formation on the pyrochlore catalyst under POX of TD can be expressed by the following:

$$
\frac{d C}{d t}=\frac{\partial C_{L T}}{\partial t}+\frac{\partial C_{H T}}{\partial t}
$$

Since the low temperature carbon formed on the Rh sites rapidly reaches a steady state, the first term can be set to zero and the carbon accumulation is simply the following: 


$$
\frac{d C}{d t}=\frac{\partial C_{H T}}{\partial t}
$$

This term will be determined experimentally from the measured quantity of deposited carbon during TPO of each catalyst after various TOS. The HTC data presented in Table 4-5 was used to generate the plot in Figure 4-9. OriginPro software was used to generate an exponential expression that will be used as the carbon formation model. The expression fitted to the data is the following:

$$
C_{H T}=C_{0}+A_{1} e^{k t}
$$

where $\mathrm{C}_{\mathrm{HT}}$ is the total mass of $\mathrm{HTC}, \mathrm{C}_{\mathrm{o}}$ is the mass of HTC as time approaches infinity, $\mathrm{A}_{1}$ is the pre-exponential factor, $\mathrm{k}$ is the carbon formation rate constant, and $\mathrm{t}$ is the TOS.

The results of the data fitting to the above equation are presented in Table 4-6. The results produce the following expression:

$$
C_{H T}=590.79-577.39 e^{(-0.01739) t}
$$

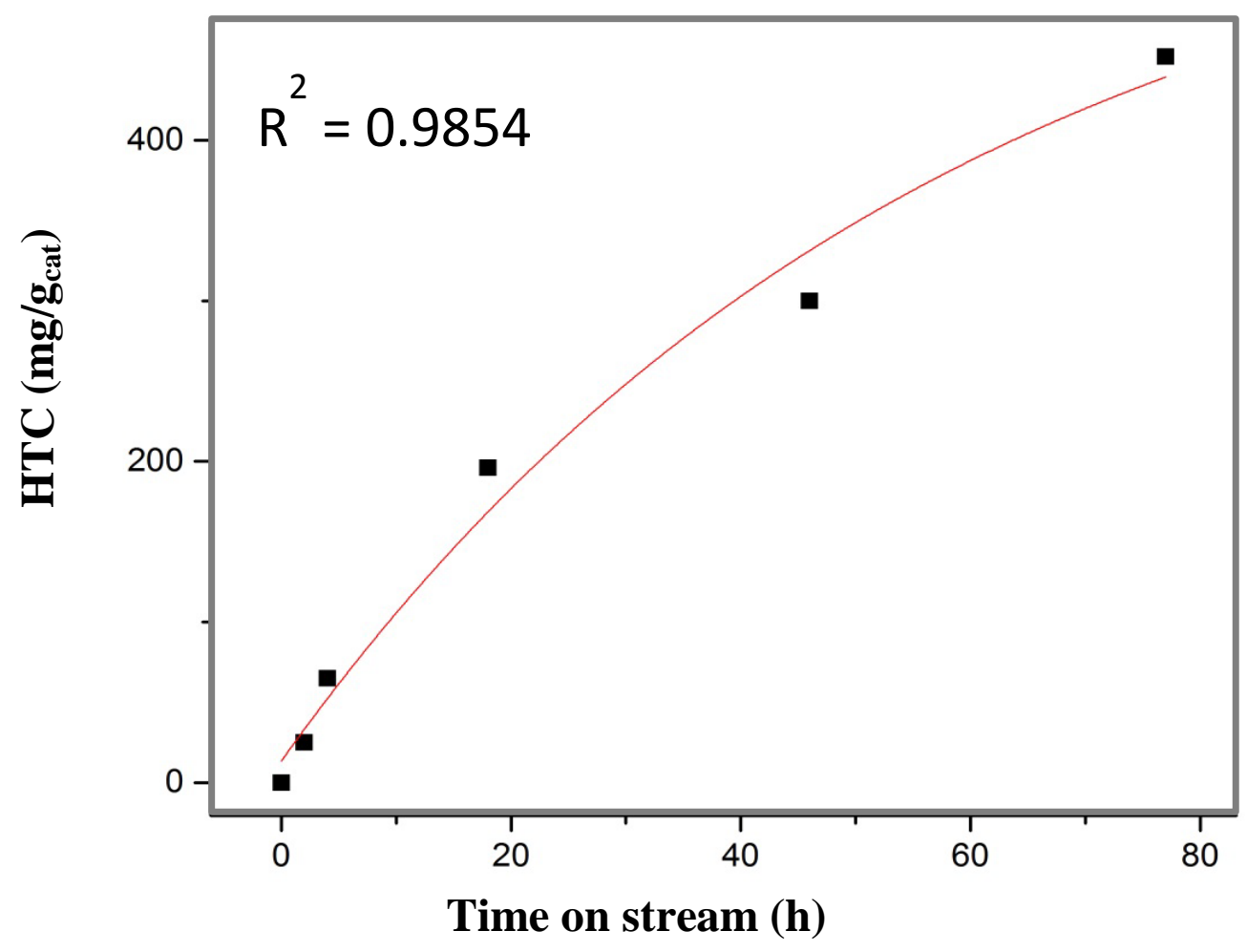

Figure 4-9 Fitting of HTC formation data to produce predictive mathematical expression. 
Table 4-6 Results of data fitting parameters.

\begin{tabular}{|c|c|}
\hline Parameter & Value \\
\hline $\mathrm{C}_{0}, \mathrm{mg}$ & 590.79 \\
\hline $\mathrm{A}_{1}, \mathrm{mg}$ & -577.39 \\
\hline $\mathrm{t}_{1}, \mathrm{~h}$ & -57.51 \\
\hline $\mathrm{k}, \mathrm{h}^{-1}$ & -0.01739 \\
\hline
\end{tabular}

\subsubsection{Model Testing on New Data Set}

The expression developed in the previous section was used to predict carbon formation for a different set of CPOX experiments with one difference in conditions. For these tests the O/C was decreased from 1.25 to 1.1, which should favor a much more rapid formation of carbon deposition. Other than this variable, the CPOX and TPO methods were the same.

The approach of testing the model is to input one experimental result to generate a new expression and compare its prediction to the measured results at various TOS. Figure 4-10 shows the TPO results for four different TOS after CPOX under the new reaction conditions. The calculated carbon deposition is summarized in Table 4-7.

The data measured at $4 \mathrm{~h}$ can be put into Equation 4-3 to calculate a new expression as follows:

$$
242=590.79-577.39 e^{k(4)}
$$

to obtain a new $\mathrm{k}=-1.366499$.

The new expression can be used to predict the HTC formed in another test and compared to real data. For this, a test of $18 \mathrm{~h}$ was selected. According to the model, the quantity of HTC produced should be $590 \mathrm{mg} / \mathrm{g}_{\text {cat }}$. After running the reaction test and TPO, the measured quantity of HTC was $604 \mathrm{mg} / \mathrm{g}_{\text {cat }}$. This result suggests that the model is a good fit to the data, and for predicting data even under different reaction conditions.

\subsubsection{Conclusions}

The HTC deposited on LCZR2Y catalyst during POX of TD $(\mathrm{O} / \mathrm{C}=1.25)$ at different TOS was determined from TPO after each reaction test. This data was used to produce an exponential mathematical expression to compare to experimental data generated in a different set of conditions. POX of TD was repeated over the same catalyst using an $\mathrm{O} / \mathrm{C}=1.1$. The HTC measured from the $4 \mathrm{~h}$ test was used to calculate a new constant in the exponential expression. The new expression was used to predict the formation of HTC under the new reaction conditions for $18 \mathrm{~h}$. The predicted result was within $2.4 \%$ of the measured value, demonstrating the potential value of such a tool. Additional testing for other catalyst formulations and reaction conditions will be need for broader application of the model as a predictive tool for catalyst performance. 


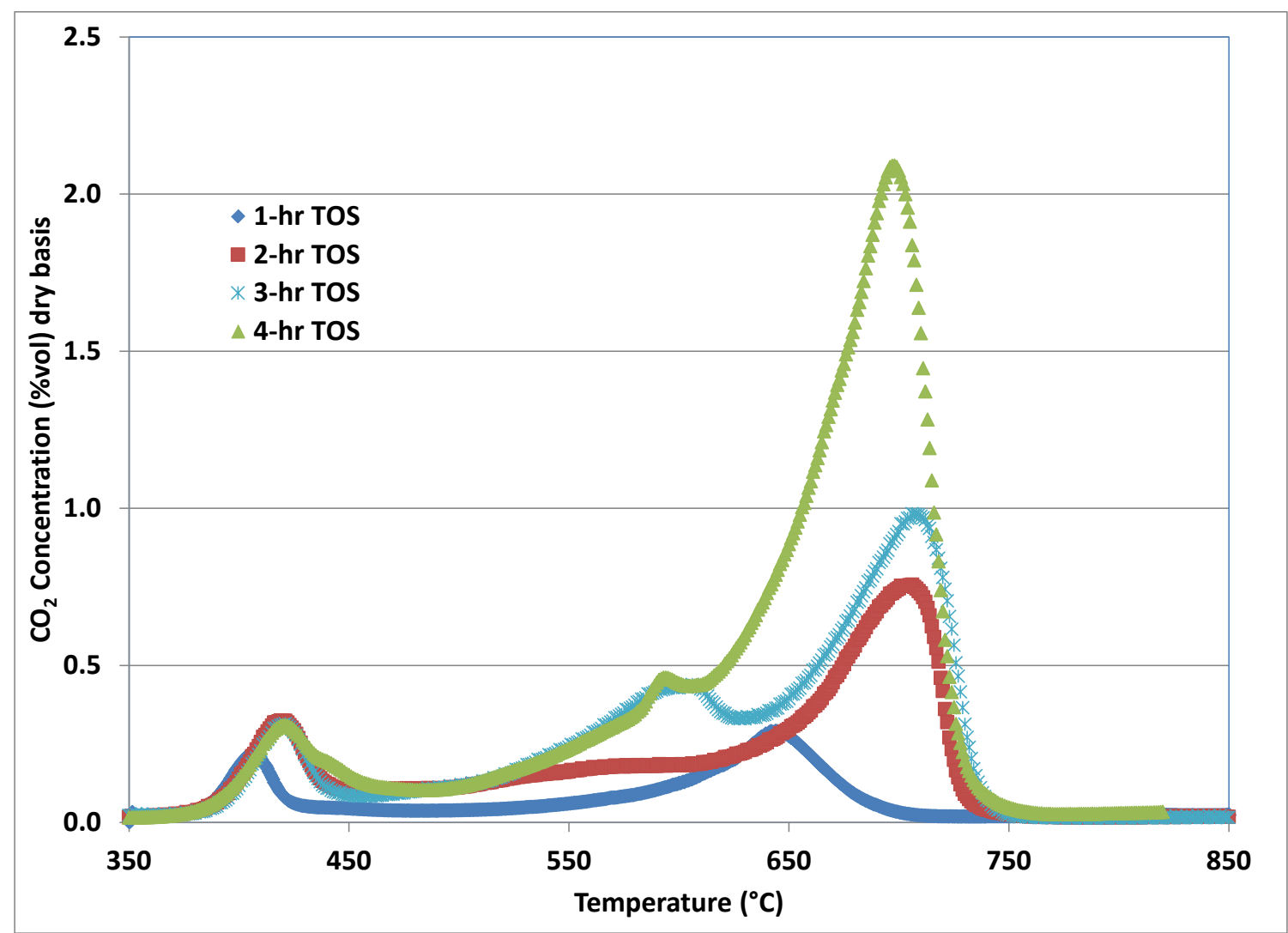

Figure 4-10 TPO profiles for LCZR2Y catalyst after POX of TD $(O / C=1.1)$ at various TOS.

Table 4-7 Carbon calculated from TPO for LCZR2Y After POX of TD at Different TOS: O/C = 1.25

\begin{tabular}{|c|c|c|c|}
\hline Time (h) & $\begin{array}{c}\text { TBC } \\
\text { (mg/gcat) }\end{array}$ & $\begin{array}{c}\text { LTC } \\
\text { (mg/gcat) }\end{array}$ & $\begin{array}{c}\text { HTC } \\
\text { (mg/gcat) }\end{array}$ \\
\hline 0 & 0 & 0 & 0 \\
\hline 1 & 115 & 21 & 94 \\
\hline 2 & 154 & 31 & 123 \\
\hline 3 & 202 & 31 & 171 \\
\hline 4 & 269 & 27 & 242 \\
\hline
\end{tabular}




\section{$5 \quad$ Summary and Conclusions}

The objectives of this dissertation were twofold: (1) study the effect of oxygen-conducting support (OCS) oxides on partially substituted mixed-metal oxide (MMO) catalysts for the partial oxidation (POX) of hydrocarbon fuels, and (2) examine the segmented catalyst bed approach using different configurations of the MMO catalysts for POX of the same fuel. Formation of excess carbon deposits was the primary cause of catalyst deactivation, and was therefore the focus of the experiments for both objectives. Indeed, the approaches taken in both objectives were specifically chosen to mitigate carbon deposition. The final aspect of this work was to examine and characterize the carbon deposition during reaction for one of the selected MMO catalysts. The main goals of the carbon study were to determine the quantity and location of the carbon deposits on the catalyst surface leading to deactivation, and to develop a mathematic expression to predict the rate of deactivating carbon formation.

For Objective 1, two active MMO catalysts were selected: a nickel-substituted barium hexaaluminate (BNHA), with the formula $\mathrm{BaAl}_{11.6} \mathrm{Ni}_{0.4} \mathrm{O}_{18.8}$, and a Rh-substituted lanthanum zirconate pyrochlore (LCZRY) with the formula $\mathrm{La}_{1.89} \mathrm{Ca}_{0.11} \mathrm{Zr}_{1.75-\mathrm{x}} \mathrm{Rh}_{\mathrm{x}} \mathrm{Y}_{0.25}(\mathrm{x}=0.05,0.11$, and 0.16). Substituting the catalytic metals into the hexaaluminate or pyrochlore crystal structure provides thermal stability, resistance to deactivation from sulfur contaminants in the fuel, and in the case of the pyrochlore, reduction in carbon deposition. To improve the carbon resistance these catalysts were combined with doped ceria materials, which contain oxygen storage and conducting properties. These OCS materials were gadolinium-doped ceria (GDC) and zirconium-doped ceria (ZDC). The active catalyst phases were combined with the OCS in different ratios and using different synthesis routes. The catalysts were characterized using several different techniques (ICP, BET, XRD, SEM, TPR, $\mathrm{H}_{2} \mathrm{PC}$ ) and were tested under POX of $n$-tetradecane (TD), a diesel fuel surrogate. The most significant findings were the following:

- The addition of GDC and ZDC to the BNHA catalyst reduced the rate of carbon deposition, but complete deactivation still occurred within 5 hours of exposure to common fuel contaminants.

- The optimum ratio of catalyst to OCS is different for different combinations of active phase and support phase.

- The benefit of the OCS decreased from 10 to $20 \mathrm{wt} \%$ loading of the BNHA; 50wt \% loading BNHA performed slightly worse than the bulk BNHA alone.

- The benefit of the OCS increased up to $20 \mathrm{wt} \%$ loading of the LCZR catalyst; this formulation performed for $50 \mathrm{~h}$ with no significant decline in activity.

- The catalyst prepared by incipient wetness impregnation (IWI) of the BNHA onto GDC produced better, and more stable product yields compared to the catalyst prepared by solid state mixing (SSM).

For Objective 2, several different catalyst formulations (hexaaluminate and pyrochlore) were used in a segmented bed approach. Two strategies were examined: (1) promote the indirect reforming mechanism by placing a combustion catalyst in the reactor inlet, followed by a reforming catalyst, and (2) place catalysts in regions of the reactor that have conditions in which they are less likely to deactivate. The first approach demonstrated that BNHA can be used in the reactor inlet to promote combustion with Rh1-PC in the reactor outlet, but the combustion catalyst should fill less than $50 \%$ of the reactor. The second approach showed a benefit in the use 
of a sulfur-tolerant noble metal catalyst in the reactor outlet and that a significant portion of the carbon formed on the Ni-substituted pyrochlore is located in the last $25 \%$ of the catalyst bed. Similar experiments using alumina foams coated with $\mathrm{Ni}$ - and $\mathrm{Rh}$-substituted pyrochlores confirmed these findings and allowed for the quantification of carbon formation in each segment of the bed independently.

The carbon formation study was conducted on the $2 \mathrm{wt} \%$ Rh-substituted pyrochlore (LCZR2Y). POX of TD for various run times, followed by temperature programmed oxidation revealed two different types of carbon deposition in the catalyst bed. The first type of carbon burned off at relatively low temperature and was labeled low-temperature carbon (LTC); the second type burned off at higher temperatures and was labeled high-temperature carbon (HTC). The LTC was observed to reach a steady state level within two hours of reaction, and was determined to not lead to catalyst deactivation. The HTC continued to accumulate with time on stream. A mathematical expression was developed to predict the rate of formation of the HTC for a given set of reaction conditions $(\mathrm{O} / \mathrm{C}=1.25)$. This expression was modified from data from a run under different reaction conditions $(\mathrm{O} / \mathrm{C}=1.1)$ for one length of time, and was found to predict the carbon formation for a different run time within $3 \%$. 


\section{$6 \quad$ References}

[1] B. Christian Enger, R. Lødeng, and A. Holmen, "A review of catalytic partial oxidation of methane to synthesis gas with emphasis on reaction mechanisms over transition metal catalysts," Applied Catalysis A: General, vol. 346, pp. 1-27, 2008.

[2] S. S. Bharadwaj and L. D. Schmidt, "Catalytic partial oxidation of natural gas to syngas," Fuel Processing Technology, vol. 42, pp. 109-127, 1995.

[3] S. C. Tsang, J. B. Claridge, and M. L. H. Green, "Recent advances in the conversion of methane to synthesis gas," Catalysis Today, vol. 23, pp. 3-15, 1995.

[4] S. Freni, G. Calogero, and S. Cavallaro, "Hydrogen production from methane through catalytic partial oxidation reactions," Journal of Power Sources, vol. 87, pp. 28-38, 2000.

[5] A. P. E. X. York, Tiancun; Green, Malcom L. H., "Brief overview of the partial oxidation of methane to synthesis gas " Topics in Catalysis vol. 22, pp. 345-358, 2003.

[6] A. P. E. York, T. Xiao, M.L.H. Green, J.B. Claridge, "Methane oxyforming for synthesis gas production," Catalysis Reviews, vol. 49, pp. 511-560, 2007.

[7] D. Shekhawat, Berry, David A., Gardner, Todd H., Spivey, James J., "Catalytic reforming of liquid hydrocarbon fuels for fuel cell applications," in Catalysis. vol. 19, J. J. a. D. Spivey, K.M. , Ed. London: The Royal Society of Chemistry, 2006, pp. 184-254.

[8] M. Krumpelt, T. R. Krause, J. D. Carter, J. P. Kopasz, and S. Ahmed, "Fuel processing for fuel cell systems in transportation and portable power applications," Catalysis Today, vol. 77, pp. 3-16, 2002.

[9] A. Roine, "HSC Chemistry Ver. 5.0," 5.0 ed Oy, Finland: Outokumpu Research, 2002.

[10] D. A. Hickmann and L. D. Schmidt, "Synthesis gas formation by direct oxidation of methane over Pt monoliths," Journal of Catalysis, vol. 138, pp. 267-282, 1992.

[11] D. A. a. S. Hickmann, L.D., "Production of syngas by direct catalytic oxidation of methane " Science, vol. 259, p. 343, 1993.

[12] D. A. a. S. Hickmann, L.D., "Synthesis gas formation by direct oxidation of methane over monoliths," in ACS: Washington, D.C., 1993, pp. 416-426.

[13] D. A. a. S. Hickmann, L.D., "Synthesis gas formation by direct oxidation of methane over rhodium monoliths " Catalysis Letters, vol. 17, p. 223, 1993.

[14] K. Peters, Rudolf, M., and Voetter, H., Brennstoff-Chem., vol. 36, p. 257, 1955.

[15] D. Dissanayake, M. P. Rosynek, K. C. C. Kharas, and J. H. Lunsford, "Partial oxidation of methane to carbon monoxide and hydrogen over a Ni/Al2O3 catalyst," Journal of Catalysis, vol. 132, pp. 117-127, 1991.

[16] C. T. Au, Hu, Y. H., and Wan, H. L., " Pulse studies of CH4 interaction with NiO/Al2O3 catalysts " Catalysis Letters, vol. 27, pp. 199-206, 1994.

[17] C. T. Au, H. Y. Wang, and H. L. Wan, "Mechanistic Studies of CH4/O2Conversion over SiO2-Supported Nickel and Copper Catalysts," Journal of Catalysis, vol. 158, pp. 343348, 1996. 
[18] W. J. M. Vermeiren, E. Blomsma, and P. A. Jacobs, "Catalytic and thermodynamic approach of the oxyreforming reaction of methane," Catalysis Today, vol. 13, pp. 427436, 1992.

[19] Y. H. Hu, Ruckenstein, E., "Pulse-MS study of the partial oxidation of methane over Ni/La2O3 catalyst " Catalysis Letters, vol. 34, pp. 41-50, 1995.

[20] Y. H. Hu and E. Ruckenstein, "Transient Kinetic Studies of Partial Oxidation of CH4," Journal of Catalysis, vol. 158, pp. 260-266, 1996.

[21] K. Heitnes, S. Lindberg, O. A. Rokstad, and A. Holmen, "Catalytic partial oxidation of methane to synthesis gas," Catalysis Today, vol. 24, pp. 211-216, 1995.

[22] K. Heitnes, S. Lindberg, O. A. Rokstad, and A. Holmen, "Catalytic partial oxidation of methane to synthesis gas using monolithic reactors," Catalysis Today, vol. 21, pp. 471480, 1994.

[23] E. P. J. Mallens, Hoebink, J. H.B.J., and Marin, G.B., "An investigation on the reaction mechanism for the partial oxidation of methane to synthesis gas over platinum " Catalysis Letters, vol. 33, pp. 291-304, 1995.

[24] F. B. O. Passos, E.R.; Mattos, L.V.; Noronha, F.B., "Effect of the support on the mechanism of partial oxidation of methane on platinum catalysts " Catalysis Letters, vol. 110, pp. 161-167, 2006.

[25] J. K. Hochmuth, "Catalytic partial oxidation of methane over a monolith supported catalyst," Applied Catalysis B: Environmental, vol. 1, pp. 89-100, 1992.

[26] D. A. a. S. Hickmann, L.D., "Steps in methane oxidation on platinum and rhodium surfaces. High-temperature reactor simulations " AIChE Journal, vol. 39, p. 1164, 1993.

[27] S. H. Oh, P. J. Mitchell, and R. M. Siewert, "Methane oxidation over alumina-supported noble metal catalysts with and without cerium additives," Journal of Catalysis, vol. 132, pp. 287-301, 1991.

[28] K. Walter, Buyevskaya, O.V., Wolf, D., and Baerns, M., "Rhodium-catalyzed partial oxidation of methane to CO and H2. In situ DRIFTS studies on surface intermediates " Catalysis Letters, vol. 29, pp. 261-270, 1994.

[29] O. V. Buyevskaya, Walter, K., Wolf, D., and Baerns, M., "Primary reaction steps and active surfaces sites in the rhodium-catalyzed partial oxidation of methane to $\mathrm{CO}$ and $\mathrm{H} 2$ " Catalysis Letters, vol. 38, pp. 81-88, 1996.

[30] O. V. Buyevskaya, Wolf, D., and Baerns, M., "Rhodium-catalyzed partial oxidation of methane to CO and H2. Transient studies on its mechanism " Catalysis Letters, vol. 29, pp. 249-260, 1994.

[31] K. Heitnes, Rokstad, O.A., and Holmen, A., "Partial oxidation of methane over platinum metal gauze " Catalysis Letters, vol. 36, pp. 25-30, 1996.

[32] D. Qin, J. Lapszewicz, and X. Jiang, "Comparison of Partial Oxidation and SteamCO2Mixed Reformingof CH4to Syngas on MgO-Supported Metals," Journal of Catalysis, vol. 159, pp. 140-149, 1996. 
[33] R. Horn, K. A. Williams, N. J. Degenstein, and L. D. Schmidt, "Syngas by catalytic partial oxidation of methane on rhodium: Mechanistic conclusions from spatially resolved measurements and numerical simulations," Journal of Catalysis, vol. 242, pp. 92-102, 2006.

[34] D. Wang, O. Dewaele, A. M. de Groote, and G. F. Froment, "Reaction Mechanism and Role of the Support in the Partial Oxidation of Methane on Rh/Al2O3," Journal of Catalysis, vol. 159, pp. 418-426, 1996.

[35] Y. Boucouvalas, Zhang, Z., and Verykios, X.E., "Heat transport limitations and reaction scheme of partial oxidation of methane to synthesis gas over supported rhodium catalysts " Catalysis Letters, vol. 27, pp. 131-142, 1994.

[36] C. T. Au and H. Y. Wang, "Mechanistic Studies of Methane Partial Oxidation to Syngas over SiO2-Supported Rhodium Catalysts," Journal of Catalysis, vol. 167, pp. 337-345, 1997.

[37] E. Shustorovich, "The Bond-Order Conservation Approach to Chemisorption and Heterogeneous Catalysis: Applications and Implications," in Advances in Catalysis. vol. Volume 37, H. P. D.D. Eley and B. W. Paul, Eds.: Academic Press, 1990, pp. 101-163.

[38] R. Horn, K. A. Williams, N. J. Degenstein, A. Bitsch-Larsen, D. Dalle Nogare, S. A. Tupy, and L. D. Schmidt, "Methane catalytic partial oxidation on autothermal Rh and Pt foam catalysts: Oxidation and reforming zones, transport effects, and approach to thermodynamic equilibrium," Journal of Catalysis, vol. 249, pp. 380-393, 2007.

[39] R. Horn, K. A. Williams, N. J. Degenstein, and L. D. Schmidt, "Mechanism of H2 and $\mathrm{CO}$ formation in the catalytic partial oxidation of $\mathrm{CH} 4$ on Rh probed by steady-state spatial profiles and spatially resolved transients," Chemical Engineering Science, vol. 62, pp. 1298-1307, 2007.

[40] M. Prettre, Eichner, C., and Perrin, M., Trans. Faraday Soc., vol. 43, p. 335, 1946.

[41] B. C. Enger, R. Lødeng, and A. Holmen, "Evaluation of reactor and catalyst performance in methane partial oxidation over modified nickel catalysts," Applied Catalysis A:

General, vol. 364, pp. 15-26, 2009.

[42] P. D. F. Vernon, Green, M.L.H., Cheetham, A.K., and Ashcroft, A.T., "Partial oxidation of methane to synthesis gas," Catalysis Letters, vol. 6, pp. 181-186, 1990.

[43] Y. Boucouvalas, Zhang, Z., and Verykios, X.E., " Partial oxidation of methane to synthesis gas via the direct reaction scheme over $\mathrm{Ru} / \mathrm{TiO} 2$ catalyst " Catalysis Letters, vol. 40, pp. 189-195, 1996.

[44] S. Rabe, Nachtegaal, M., Vogel, F., Physical Chemistry Chemical Physics, vol. 9, p. 1461, 2007.

[45] S. Rabe, F. Vogel, T.-B. Truong, T. Shimazu, T. Wakasugi, H. Aoki, and H. Sobukawa, "Catalytic reforming of gasoline to hydrogen: Kinetic investigation of deactivation processes," International Journal of Hydrogen Energy, vol. 34, pp. 8023-8033, 2009.

[46] V. A. a. V. Tsipouriari, X.E, "Kinetic study of the catalytic partial oxidation of methane to synthesis gas over Ni/La2O3 catalyst," in Studies in Surface Science and Catalysis. 
vol. Volume 119, D. S. A. Parmaliana, F. Frusteri, A. Vaccari, F. Arena, Ed.: Elsevier, 1998, pp. 795-800.

[47] E. L. Gubanova, Y. Schuurman, V. A. Sadykov, C. Mirodatos, and A. C. van Veen, "Evaluation of kinetic models for the partial oxidation of methane to synthesis gas over a $\mathrm{Pt} / \mathrm{PrCeZrOx}$ catalyst coated on a triangular monolith," Chemical Engineering Journal, vol. 154, pp. 174-184, 2009.

[48] C. R. H. de Smet, M. H. J. M. de Croon, R. J. Berger, G. B. Marin, and J. C. Schouten, "An experimental reactor to study the intrinsic kinetics of catalytic partial oxidation of methane in the presence of heat-transport limitations," Applied Catalysis A: General, vol. 187, pp. 33-48, 1999.

[49] A. M. de Groote and G. F. Froment, "Simulation of the catalytic partial oxidation of methane to synthesis gas," Applied Catalysis A: General, vol. 138, pp. 245-264, 1996.

[50] Å. Slagtern, H. M. Swaan, U. Olsbye, I. M. Dahl, and C. Mirodatos, "Catalytic partial oxidation of methane over Ni-, Co- and Fe-based catalysts," Catalysis Today, vol. 46, pp. 107-115, 1998.

[51] S. Tang, Lin, J., Tan, K.L., Catalysis Letters, vol. 51, p. 169, 1998.

[52] D. Ma, D. Mei, X. Li, M. Gong, and Y. Chen, "Partial Oxidation of Methane to Syngas over Monolithic Ni/[gamma]-Al2O3 Catalyst----Effects of Rare Earths and Other Basic Promoters," Journal of Rare Earths, vol. 24, pp. 451-455, 2006.

[53] M. Salazar, D. A. Berry, T. H. Gardner, D. Shekhawat, and D. Floyd, "Catalytic partial oxidation of methane over Pt/ceria-doped catalysts: Effect of ionic conductivity," Applied Catalysis A: General, vol. 310, pp. 54-60, 2006.

[54] M. Dajiang, C. Yaoqiang, Z. Junbo, W. Zhenling, M. Di, and G. Maochu, "Catalytic Partial Oxidation of Methane over Ni/CeO2 -ZrO2 -Al2O3," Journal of Rare Earths, vol. 25, pp. 311-315, 2007.

[55] M. D. Salazar-Villalpando and B. Reyes, "Hydrogen production over Ni/ceria-supported catalysts by partial oxidation of methane," International Journal of Hydrogen Energy, vol. 34, pp. 9723-9729, 2009.

[56] S. S. Bharadwaj and L. D. Schmidt, "Synthesis gas formation by catalytic oxidation of methane in fluidized bed reactors," Journal of Catalysis, vol. 146, pp. 11-21, 1994.

[57] M. G. Poirier, G. Jean, and M. P. Poirier, "Partial Oxidation of Methane over a Praseodymium/Ruthenium Pyrochlore Catalyst," in Studies in Surface Science and Catalysis. vol. Volume 73, J. S. Kevin and C. S. Emerson, Eds.: Elsevier, 1992, pp. 359366.

[58] D. Klvana, J. Vaillancourt, J. Kirchnerova, and J. Chaouki, "Combustion of methane over La0.66Sr0.34Ni0.3Co0.7O3 and La0.4Sr0.6Fe0.4Co0.6O3 prepared by freeze-drying," Applied Catalysis A: General, vol. 109, pp. 181-193, 1994.

[59] B. W. L. Jang, R. M. Nelson, J. J. Spivey, M. Ocal, R. Oukaci, and G. Marcelin, "Catalytic oxidation of methane over hexaaluminates and hexaaluminate-supported Pd catalysts," Catalysis Today, vol. 47, pp. 103-113, 1999. 
[60] J. G. McCarty and H. Wise, "Perovskite catalysts for methane combustion," Catalysis Today, vol. 8, pp. 231-248, 1990.

[61] M. Machida, K. Eguchi, and H. Arai, "Catalytic properties of BaMAl11O19-[alpha] (M = $\mathrm{Cr}, \mathrm{Mn}, \mathrm{Fe}, \mathrm{Co}$, and $\mathrm{Ni}$ ) for high-temperature catalytic combustion," Journal of Catalysis, vol. 120, pp. 377-386, 1989.

[62] M. Machida, K. Eguchi, and H. Arai, "Effect of structural modification on the catalytic property of Mn-substituted hexaaluminates," Journal of Catalysis, vol. 123, pp. 477-485, 1990.

[63] M. Machida, K. Eguchi, and H. Arai, "Effect of additives on the surface area of oxide supports for catalytic combustion," Journal of Catalysis, vol. 103, pp. 385-393, 1987.

[64] H. Arai, T. Yamada, K. Eguchi, and T. Seiyama, "Catalytic combustion of methane over various perovskite-type oxides," Applied Catalysis, vol. 26, pp. 265-276, 1986.

[65] T.-c. Xiao, A. Hanif, A. P. E. York, and M. L. H. Green, "Methane partial oxidation to synthesis gas over bimetallic cobalt/tungsten carbide catalysts and integration with a Mn substituted hexaaluminate combustion catalyst," Catalysis Today, vol. 147, pp. 196-202, 2009.

[66] G. X. R. Ran, S. Sheng, W. Yang, N. Stroh, and H. Brunner, Catalysis Letters, vol. 88, p. 55, 2003.

[67] W. Zhu, G. Xiong, W. Han, and W. Yang, "Catalytic partial oxidation of gasoline to syngas in a dense membrane reactor," Catalysis Today, vol. 93-95, pp. 257-261, 2004.

[68] D. S. T.H. Gardner, and D.A. Berry, in AIChE Fall Meeting Austin, TX, 2004.

[69] T. H. Gardner, D. Shekhawat, D. A. Berry, M. W. Smith, M. Salazar, and E. L. Kugler, "Effect of nickel hexaaluminate mirror cation on structure-sensitive reactions during ntetradecane partial oxidation," Applied Catalysis A: General, vol. 323, pp. 1-8, 2007.

[70] M. W. Smith, D. A. Berry, D. Shekhawat, D. J. Haynes, and J. J. Spivey, "Partial oxidation of liquid hydrocarbons in the presence of oxygen-conducting supports: Effect of catalyst layer deposition," Fuel, vol. 89, pp. 1193-1201, 6// 2010.

[71] D. J. Haynes, D. A. Berry, D. Shekhawat, and J. J. Spivey, "Catalytic partial oxidation of n-tetradecane using Rh and Sr substituted pyrochlores: Effects of sulfur," Catalysis Today, vol. 145, pp. 121-126, 2009.

[72] D. J. Haynes, A. Campos, M. W. Smith, D. A. Berry, D. Shekhawat, and J. J. Spivey, "Reducing the deactivation of Ni-metal during the catalytic partial oxidation of a surrogate diesel fuel mixture," Catalysis Today, vol. 154, pp. 210-216, 2010.

[73] M. W. Smith, Berry, D.A., Shekhawat, D., Haynes, D.J., Spivey, J.J., "Effect of oxide catalysts and oxygen-conducting supports on partial oxidation of liquid hydrocarbons," in American Chemical Society 237th National Meeting and Exposition, Salt Lake City, UT, 2009.

[74] M. T. M. Tanaka, N. Ito, "Catalysts for reforming hydrocarbon fuels." vol. 4088608, U. P. Office, Ed. United States: Nippon Soken, Inc., Japan, 1978. 
[75] D. Shekhawat, T. H. Gardner, D. A. Berry, M. Salazar, D. J. Haynes, and J. J. Spivey, "Catalytic partial oxidation of n-tetradecane in the presence of sulfur or polynuclear aromatics: Effects of support and metal," Applied Catalysis A: General, vol. 311, pp. 816, 2006.

[76] Y. F. a. H. Muraki, "Process for partially oxidizing hydrocarbons ". vol. 4087259, U. P. Office, Ed. United States: Kabushiki Kaisha Toyota Chuo Kenkyusho, Japan

1978.

[77] R. P. O'Connor and L. D. Schmidt, "Catalytic Partial Oxidation of Cyclohexane in a Single-Gauze Reactor," Journal of Catalysis, vol. 191, pp. 245-256, 2000.

[78] R. P. O'Connor, E. J. Klein, D. Henning, and L. D. Schmidt, "Tuning millisecond chemical reactors for the catalytic partial oxidation of cyclohexane," Applied Catalysis A: General, vol. 238, pp. 29-40, 2003.

[79] L. D. Schmidt, E. J. Klein, C. A. Leclerc, J. J. Krummenacher, and K. N. West, "Syngas in millisecond reactors: higher alkanes and fast lightoff," Chemical Engineering Science, vol. 58, pp. 1037-1041, 2003/3//.

[80] R. Subramanian, G. J. Panuccio, J. J. Krummenacher, I. C. Lee, and L. D. Schmidt, "Catalytic partial oxidation of higher hydrocarbons: reactivities and selectivities of mixtures," Chemical Engineering Science, vol. 59, pp. 5501-5507, 2004/12//.

[81] J. J. Krummenacher, K. N. West, and L. D. Schmidt, "Catalytic partial oxidation of higher hydrocarbons at millisecond contact times: decane, hexadecane, and diesel fuel," Journal of Catalysis, vol. 215, pp. 332-343, 2003.

[82] D. J. Haynes, D. A. Berry, D. Shekhawat, and J. J. Spivey, "Catalytic partial oxidation of n-tetradecane using pyrochlores: Effect of Rh and Sr substitution," Catalysis Today, vol. 136, pp. 206-213, 2008.

[83] D. J. Haynes, A. Campos, D. A. Berry, D. Shekhawat, A. Roy, and J. J. Spivey, "Catalytic partial oxidation of a diesel surrogate fuel using an Ru-substituted pyrochlore," Catalysis Today, vol. 155, pp. 84-91, 2010.

[84] D. J. Haynes, Berry, D.A., Shekhawat, D., Smith, M.W., Spivey, J.J. , "Long Term Reforming of Commercial Diesel Fuel Using a Layered Pyrochlore Catalyst," in Spring National Meeting San Francisco, CA: American Chemical Society, 2010.

[85] D. Shekhawat, D. A. Berry, T. H. Gardner, D. J. Haynes, and J. J. Spivey, "Effects of fuel cell anode recycle on catalytic fuel reforming," Journal of Power Sources, vol. 168, pp. 477-483, 2007.

[86] D. Shekhawat, D. A. Berry, D. J. Haynes, and J. J. Spivey, "Fuel constituent effects on fuel reforming properties for fuel cell applications," Fuel, vol. 88, pp. 817-825, 2009.

[87] D. Shekhawat, D. A. Berry, and J. J. Spivey, "Reforming of liquid hydrocarbon fuels for fuel cell applications," Catalysis Today, vol. 136, pp. 189-189, 2008.

[88] M. W. Smith, Berry, D.A., Shekhawat, D., Haynes, D.J., Spivey, J.J. , "Catalytic Material Development for a SOFC Reforming System: Application of an Oxidative Steam Reforming Catalyst to a Monolithic Reactor," in 8th International Fuel Cell Science, 
Engineering and Technology Conference Brooklyn, NY: American Society of Mechanical Engineers, 2010.

[89] M. W. Smith, Berry, D.A., Shekhawat, D., Haynes, D.J., Spivey, J.J. , "Ni-substituted Oxide Catalysts with Oxygen Ion Conductivity for Hydrocarbon Reforming," in 2010 Spring National Meeting San Antonio, TX: American Institute of Chemical Engineers, 2010.

[90] J. Xu, W. Wei, A. Tian, Y. Fan, X. Bao, and C. Yu, "Temperature profile in a two-stage fixed bed reactor for catalytic partial oxidation of methane to syngas," Catalysis Today, vol. 149, pp. 191-195.

[91] S. Shen, Z. Pan, C. Dong, Q. Jiang, Z. Zhang, and C. Yu, "A novel two-stage reactor process for catalytic oxidation of methane to synthesis gas," in Studies in Surface Science and Catalysis. vol. Volume 136, J. J. S. E. Iglesia, T. H. Fleisch, Ed.: Elsevier, 2001, pp. 99-104.

[92] J. Zhu, M. S. M. M. Rahuman, J. G. van Ommen, and L. Lefferts, "Dual catalyst bed concept for catalytic partial oxidation of methane to synthesis gas," Applied Catalysis A: General, vol. 259, pp. 95-100, 2004.

[93] G. C. M. Tong, Flynn, J., Leclerc, C.A., "A dual catalyst bed for the autothermal partial oxidation of methane to synthesis gas," Catalysis Letters, pp. 131-137, 2005.

[94] H. Zhu, R. J. Kee, J. R. Engel, and D. T. Wickham, "Catalytic partial oxidation of methane using RhSr- and Ni-substituted hexaaluminates," Proceedings of the Combustion Institute, vol. 31, pp. 1965-1972, 2007.

[95] H. He and J. M. Hill, "Carbon deposition on Ni/YSZ composites exposed to humidified methane," Applied Catalysis A: General, vol. 317, pp. 284-292, 2007.

[96] T. Utaka, S. A. Al-Drees, J. Ueda, Y. Iwasa, T. Takeguchi, R. Kikuchi, and K. Eguchi, "Partial oxidation of methane over Ni catalysts based on hexaaliminate- or perovskitetype oxides," Applied Catalysis A: General, vol. 247, pp. 125-131, 2003.

[97] V. R. Choudhary and K. C. Mondal, "CO2 reforming of methane combined with steam reforming or partial oxidation of methane to syngas over $\mathrm{NdCoO} 3$ perovskite-type mixed metal-oxide catalyst," Applied Energy, vol. 83, pp. 1024-1032, 2006.

[98] P. Dinka and A. S. Mukasyan, "Perovskite catalysts for the auto-reforming of sulfur containing fuels," Journal of Power Sources, vol. 167, pp. 472-481, 2007.

[99] P. Erri, P. Dinka, and A. Varma, "Novel perovskite-based catalysts for autothermal JP-8 fuel reforming," Chemical Engineering Science, vol. 61, pp. 5328-5333, 2006.

[100] A. Qi, S. Wang, G. Fu, C. Ni, and D. Wu, "La-Ce-Ni-O monolithic perovskite catalysts potential for gasoline autothermal reforming system," Applied Catalysis A: General, vol. 281, pp. 233-246, 2005.

[101] T. Hayakawa, S. Suzuki, J. Nakamura, T. Uchijima, S. Hamakawa, K. Suzuki, T. Shishido, and K. Takehira, "CO2 reforming of CH4 over Ni/perovskite catalysts prepared by solid phase crystallization method," Applied Catalysis A: General, vol. 183, pp. 273285, 1999. 
[102] D. J. Haynes, A. Campos, D. A. Berry, D. Shekhawat, A. Roy, and J. J. Spivey, "Catalytic partial oxidation of a diesel surrogate fuel using an Ru-substituted pyrochlore," Catalysis Today, vol. doi:10.1016/j.cattod.2009.03.025, 2009.

[103] J. Cheng, J. Li, C. Ma, and Z. Hao, "Catalytic combustion of methane over La2TM0.3Zr1.7O7-[delta] (TM = Mn, Fe, and Co) pyrochlore oxides," Catalysis Communications, vol. 10, pp. 1170-1173, 2009.

[104] M. W. Smith, D.A. Berry, D. Shekhawat, D.J. Haynes, J.J Spivey, "Effect of oxide catalysts and oxygen-conducting supports on partial oxidation of liquid hydrocarbons," in 237th National Meeting and Exposition Salt Lake City, UT: American Chemical Society, 2009.

[105] G. Groppi, M. Bellotto, C. Cristiam, P. Forzatti, and P. L. Villa, "Preparation and characterization of hexaaluminate-based materials for catalytic combustion," Applied Catalysis A: General, vol. 104, pp. 101-108, 1993.

[106] H. Arai and H. Fukuzawa, "Research and development on high temperature catalytic combustion," Catalysis Today, vol. 26, pp. 217-221, 1995.

[107] A. Baylet, S. Royer, P. Marécot, J. M. Tatibouët, and D. Duprez, "High catalytic activity and stability of Pd doped hexaaluminate catalysts for the CH4 catalytic combustion," Applied Catalysis B: Environmental, vol. 77, pp. 237-247, 2008.

[108] R. Kikuchi, Y. Tanaka, K. Sasaki, and K. Eguchi, "High temperature catalytic combustion of methane and propane over hexaaluminate catalysts: NOx emission characteristics," Catalysis Today, vol. 83, pp. 223-231, 2003.

[109] C. Meisheng, W. Liangshi, Z. Na, L. Zhiqi, L. Dianqing, and C. Aifan, "LaHexaaluminate Catalyst Preparation and Its Performance for Methane Catalytic Combustion," Journal of Rare Earths, vol. 24, pp. 690-694, 2006.

[110] R. W. Sidwell, H. Zhu, R. J. Kee, and D. T. Wickham, "Catalytic combustion of premixed methane-in-air on a high-temperature hexaaluminate stagnation surface," Combustion and Flame, vol. 134, pp. 55-66, 2003.

[111] E. E. Svensson, M. Boutonnet, and S. G. Järås, "Stability of hexaaluminate-based catalysts for high-temperature catalytic combustion of methane," Applied Catalysis B: Environmental, vol. 84, pp. 241-250, 2008.

[112] K. V. G. Kutty, C. K. Mathews, T. N. Rao, and U. V. Varadaraju, "Oxide ion conductivity in some substituted rare earth pyrozirconates," Solid State Ionics, vol. 80, pp. 99-110, 1995.

[113] P. Biswas and D. Kunzru, "Steam reforming of ethanol for production of hydrogen over $\mathrm{Ni} / \mathrm{CeO} 2-\mathrm{ZrO} 2$ catalyst: Effect of support and metal loading," International Journal of Hydrogen Energy, vol. 32, pp. 969-980, 2007.

[114] N. Laosiripojana, D. Chadwick, and S. Assabumrungrat, "Effect of high surface area $\mathrm{CeO} 2$ and $\mathrm{Ce}-\mathrm{ZrO} 2$ supports over Ni catalyst on $\mathrm{CH} 4$ reforming with $\mathrm{H} 2 \mathrm{O}$ in the presence of O2, H2, and CO2," Chemical Engineering Journal, vol. 138, pp. 264-273, 2008. 
[115] Z. Yuan, C. Ni, C. Zhang, D. Gao, S. Wang, Y. Xie, and A. Okada, "Rh/MgO/Ce0.5Zr0.5O2 supported catalyst for autothermal reforming of methane: The effects of ceria-zirconia doping," Catalysis Today, vol. In Press, Corrected Proof.

[116] S. Wang and G. Q. M. Lu, "CO2 reforming of methane on Ni catalysts: Effects of the support phase and preparation technique," Applied Catalysis B: Environmental, vol. 16, pp. 269-277, 1998.

[117] G. Neri, G. Rizzo, L. De Luca, A. Donato, M. G. Musolino, and R. Pietropaolo, "Supported Pd catalysts for the hydrogenation of campholenic aldehyde: Influence of support and preparation method," Applied Catalysis A: General, vol. 356, pp. 113-120, 2009.

[118] H. Wang, Y. Fan, G. Shi, H. Liu, and X. Bao, "Preparation of hydrotreating catalysts via an oxalic acid-assisted hydrothermal deposition method," Journal of Catalysis, vol. 260, pp. 119-127, 2008.

[119] M. W. Smith, D. Shekhawa, D. A. Berry, D. J. Haynes, D. L. Floyd, J. J. Spivey, and J. W. Zondlo, "Effect of the Catalyst Bed Configuration on the Partial Oxidation of Liquid Hydrocarbons," Energy \& Fuels, vol. 27, pp. 4363-4370, Aug.

[120] D. Shekhawat, Spivey, J.J., and Berry, D.A., "Fuel Cells: Technologies for Fuel Processing," New York: Elsevier, 2011.

[121] D.-J. Liu and M. Krumpelt, International Journal of Applied Ceramic Technology, vol. 2, p. 301, 2005.

[122] M. A. Subramanian, G. Aravamudan, and G. V. Subba Rao, "Oxide pyrochlores -- A review," Progress in Solid State Chemistry, vol. 15, pp. 55-143, 1983.

[123] M. W. Smith, and D. Shekhawat, "Catalytic Partial Oxidation," in Fuel Cells: Technologies for Fuel Processing, D. Shekhawat, J.J. Spivey, and D.A. Berry, Ed. New York: Elsevier, 2011, pp. 73-128.

[124] M. P. Pechini, "Method of preparing lead and alkaline earth titanates and niobates and coating method using the same to form a capacitor.," U. S. P. a. T. Office, Ed. United States, 1963.

[125] M. Popa, J. Frantti, and M. Kakihana, "Characterization of LaMeO3 (Me : Mn, Co, Fe) perovskite powders obtained by polymerizable complex method," Solid State Ionics, vol. 154, pp. 135-141, Dec 2002.

[126] G. J. Panuccio, B. J. Dreyer, and L. D. Schmidt, AICHE Journal, vol. 53, p. 187, 2007.

[127] J. J. Krummenacher and L. D. Schmidt, Journal of Catalysis, vol. 222, p. 429, 2004.

[128] P. M. Torniainen, X. Chu, and L. D. Schmidt, Journal of Catalysis, vol. 146, p. 1, 1994.

[129] R. P. O'Connor, E. J. Klein, and L. D. Schmidt, Catalysis Letters, vol. 70, p. 99, 2000.

[130] J. B. Claridge, M. L. H. Green, and S. C. Tsang, "Methane conversion to synthesis gas by partial oxidation and dry reforming over rhenium catalysts," Catalysis Today, vol. 21, pp. 455-460, 1994.

[131] J. B. Claridge, M. L. H. Green, S. C. Tsang, A. P. E. York, A. T. Ashcroft, and P. D. Battle, "A STUDY OF CARBON DEPOSITION ON CATALYSTS DURING THE 
PARTIAL OXIDATION OF METHANE TO SYNTHESIS GAS," Catalysis Letters, vol. 22, pp. 299-305, 19931993.

[132] J. Barbier, "Deactivation of reforming catalysts by coking - a review," Applied Catalysis, vol. 23, pp. 225-243, 1986.

[133] G. C. Bond, "The role of carbon deposits in metal-catalysed reactions of hydrocarbons," Applied Catalysis a-General, vol. 149, pp. 3-25, Jan 231997.

[134] B. D. Gould, X. Y. Chen, and J. W. Schwank, "n-dodecane reforming over nickel-based monolith catalysts: Deactivation and carbon deposition," Applied Catalysis a-General, vol. 334, pp. 277-290, Jan 2008.

[135] M. Ferrandon and T. Krause, "Role of the oxide support on the performance of Rh catalysts for the autothermal reforming of gasoline and gasoline surrogates to hydrogen," Applied Catalysis a-General, vol. 311, pp. 135-145, Sep 12006.

[136] F. B. Rasmussen, J. Sehested, H. T. Teunissen, A. M. Molenbroek, and B. S. Clausen, "Sintering of Ni/Al2O3 catalysts studied by anomalous small angle X-ray scattering," Applied Catalysis a-General, vol. 267, pp. 165-173, Jul 302004.

[137] C. H. Bartholomew, "Mechanisms of catalyst deactivation," Applied Catalysis a-General, vol. 212, pp. 17-60, Apr 302001.

[138] C. H. Bartholomew, Chemical Engineering, vol. 91, p. 96, 1984.

[139] M. V. T. P.J. Denny, in: B. Delmon, G.F. Froment "Catalyst Deactivation," in Studies in Surf. Sci.Catal. vol. 6: Elsevier, 1980, p. 577.

[140] A. Bitsch-Larsen, N. J. Degenstein, and L. D. Schmidt, "Effect of sulfur in catalytic partial oxidation of methane over Rh-Ce coated foam monoliths," Applied Catalysis B: Environmental, vol. 78, pp. 364-370, 2008.

[141] A. Chroneos, R. V. Vovk, I. L. Goulatis, and L. I. Goulatis, "Oxygen transport in perovskite and related oxides: A brief review," Journal of Alloys and Compounds, vol. 494, pp. 190-195, 2010.

[142] P. J. Gellings and H. J. M. Bouwmeester, "Ion and mixed conducting oxides as catalysts," Catalysis Today, vol. 12, pp. 1-101, 1992.

[143] A. Shamsi, J. P. Baltrus, and J. J. Spivey, "Characterization of coke deposited on Pt/alumina catalyst during reforming of liquid hydrocarbons," Applied Catalysis A: General, vol. 293, pp. 145-152, 2005.

[144] A. T. Ashcroft, A. K. Cheetham, R. H. Jones, S. Natarajan, J. M. Thomas, D. Waller, and S. M. Clark, "AN INSITU, ENERGY-DISPERSIVE X-RAY-DIFFRACTION STUDY OF NATURAL-GAS CONVERSION BY CO2 REFORMING," Journal of Physical Chemistry, vol. 97, pp. 3355-3358, Apr 11993.

[145] C.-P. Hwang, C.-T. Yeh, and Q. Zhu, "Rhodium-oxide species formed on progressive oxidation of rhodium clusters dispersed on alumina," Catalysis Today, vol. 51, pp. 93101, 1999. 
[146] W.-Z. Weng, X.-Q. Pei, J.-M. Li, C.-R. Luo, Y. Liu, H.-Q. Lin, C.-J. Huang, and H.-L. Wan, "Effects of calcination temperatures on the catalytic performance of Rh/Al2O3 for methane partial oxidation to synthesis gas," Catalysis Today, vol. 117, pp. 53-61, 2006.

[147] C. Wong and R. W. McCabe, "Effects of oxidation/reduction treatments on the morphology of silica-supported rhodium catalysts," Journal of Catalysis, vol. 107, pp. 535-547, 1987. 